\author{
UNIVERSIDADE DE SÃO PAULO \\ ESCOLA DE ENGENHARIA DE SÃO CARLOS \\ DEPARTAMENTO DE ENGENHARIA DE ESTRUTURAS
}

EMERSON FELIPE FELIX

Modelagem da Deformação do Concreto Armado Devido à Formação dos Produtos de Corrosão 
EMERSON FELIPE FELIX

\title{
Modelagem da Deformação do Concreto Armado Devido à Formação dos Produtos de Corrosão
}

\author{
VERSÃO CORRIGIDA
}

A versão original encontra-se na Escola de Engenharia de São Carlos

Dissertação apresentada ao Departamento de Engenharia de Estruturas da Escola de Engenharia de São Carlos, Universidade de São Paulo, como parte dos requisitos necessários para a obtenção do título de Mestre em Engenharia Civil (Estruturas).

Orientador: Prof. Dr. Rogério Carrazedo 
AUTORIZO A REPRODUÇÃO TOTAL OU PARCIAL DESTE TRABALHO, POR QUALQUER MEIO CONVENCIONAL OU ELETRÔNICO, PARA FINS DE ESTUDO E PESQUISA, DESDE QUE CITADA A FONTE.

Ficha catalográfica elaborada pela Biblioteca Prof. Dr. Sérgio Rodrigues Fontes da EESC/USP com os dados inseridos pelo(a) autor(a).

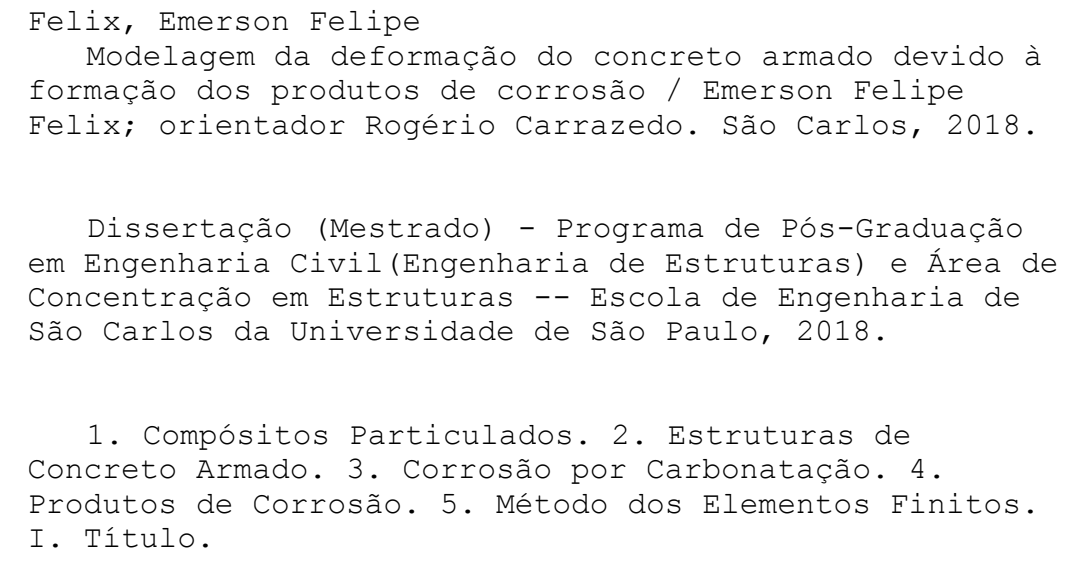




\section{FOLHA DE JULGAMENTO}

Candidato: Bacharel EMERSON FELIPE FéLIX.

Título da dissertação: "Modelagem da deformação do concreto armado devido à formação dos produtos de corrosão".

Data da defesa: 23/02/2018.

Comissão Julgadora:

Prof. Dr. Rogério Carrazedo (Orientador)

(Escola de Engenharia de São Carlos/EESC)

Profa. Dra. Edna Possan

(Universidade Federal da Integração Latino-Americana/UNILA)

Prof. Dr. Ricardo Afonso Angélico

(Escola de Engenharia de São Carlos/EESC)

Coordenador do Programa de Pós-Graduação em Engenharia Civil (Engenharia de Estruturas):

Prof. Titular Humberto Breves Coda

Presidente da Comissão de Pós-Graduação:

Prof. Associado Luis Fernando Cosła Alberto
Resultado:
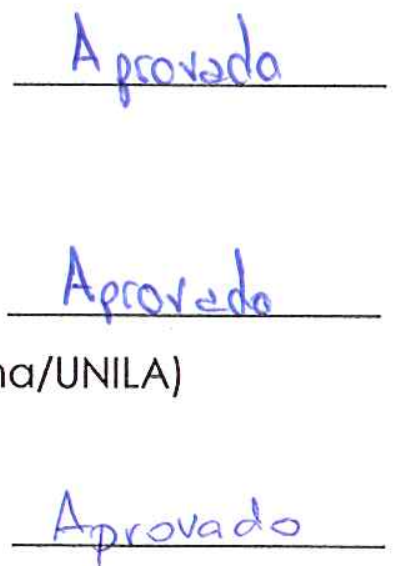
Dedico à minha mãe, Eliane,

e minha avó, Lourdes. 
"Tenho a impressão de ter sido uma criança brincando à beira-mar, divertindo-me em descobrir uma pedrinha mais lisa ou uma concha mais bonita que as outras, enquanto o imenso oceano da verdade continua misterioso diante de meus olhos."

(Isaac Newton) 
Inicialmente agradeço à Deus, que me guia, me protege, me da força e sabedoria para vencer todos os desafios desta vida.

À minha mãe, Eliane, e minha avó, Lourdes, por todo amor e por sempre fazerem de tudo para que eu pudesse realizar meus sonhos.

Ao meu orientador, professor Dr. Rogério Carrazedo, por ter acreditado em meu potencial desde o início. Agradeço pela sua dedicação, atenção, experiência e contínua presença em todas as etapas de desenvolvimento deste trabalho.

Agradeço à professora Dra. Edna Possan por ter me iniciado nos caminhos da investigação científica, e por ter me incentivado a sempre ir atrás dos meus sonhos. Agradeço pela sua dedicação, amizade e comprometimento.

Agradeço à professora Dra. Gláucia Dalfré por sempre ter me incentivado, pelo seu constante suporte, amizade e por ter me encorajado a vir desenvolver o mestrado no Departamento de Estruturas, da Escola de Engenharia de São Carlos-EESC/USP.

Aos professores Dr. Rodrigo Paccola e Dr. Humberto Breves Coda pelo auxílio no desenvolvimento dos códigos desenvolvidos neste trabalho e por sempre estarem dispostos a transmitir conhecimento, e ao professor Dr. Edson Leonel pelas contribuições fornecidas no exame de qualificação.

Aos demais professores do Departamento de Estruturas e aos funcionários por todo o suporte.

À UNILA, e aos professores Cesar Winter, Helenice Sacht, Rodrigo Lameiras, Aref Kzam, Herlander Mata-Lima, Jian Frigo, Ricardo Pedro Konzen e Rodrigo Bloot pela importante contribuição no início da minha formação acadêmica.

A todos os amigos que fiz em São Carlos, especialmente, no Departamento de Estruturas da EESC/USP (Felipi, Vanessa, Rafaella, Giovane, Yagho, Alex), os quais ajudaram a diminuir as saudades de Foz do Iguaçu. À ME-05 (Fabiana, Francielle, Mariana e Tito) pelos bons papos e companheirismo, ao longo destes dois anos.

Aos amigos de Foz e do mundo, que apesar de estarem longe, sempre se fizeram presentes, em especial, Rosemary, Luis, Daniely, Alexia, Bianca, Thays, Gabriela, Amanda, Rubia, Verediana, Camila, Carlos e Barbará Ribas.

Por fim agradeço à Coordenação de Aperfeiçoamento de Pessoal de Nível Superior (CAPES), pela bolsa de mestrado concedida. 


\section{RESUMO}

\section{FELIX, E. F. Modelagem da Deformação do Concreto Armado Devido à}

Formação dos Produtos de Corrosão. 2018. 162 p. Dissertação (Mestrado em Engenharia de Estruturas) - Departamento de Engenharia de Estruturas, Escola de Engenharia de São Carlos, Universidade de São Paulo, São Carlos, 2018.

A fim de prever mecanismos para o controle dos danos impostos pela corrosão faz-se necessário deter ferramentas e conhecimento suficientes para entender os efeitos desta manifestação patológica sobre o comportamento mecânico do concreto armado. Nos últimos anos tornou-se crescente a utilização da modelagem numérica na simulação da degradação causados pela corrosão, graças ao baixo custo necessário à sua fomentação. Sabendo disso, nesta pesquisa foi desenvolvido um modelo numérico para a simulação em nível mesoscópico da expansão do concreto armado devido à formação de produtos de corrosão. O modelo desenvolvido é baseado no Método dos Elementos Finitos Posicional (MEFP) sob formulação Lagrangiana total, considerando material elástico isotrópico, com lei constitutiva de Saint-Venant-Kirchhoff e comportamento não linear geométrico. Para a representação das armaduras e dos produtos de corrosão, os quais estão inseridos na matriz de concreto, empregam-se elementos finitos lineares (fibras) ou planos (partículas) acoplados à malha de concreto por meio da técnica de embutimento. O comportamento dos produtos de corrosão é descrito por meio de formulações existentes na literatura, utilizando modelos analíticos relacionados a parâmetros intrínsecos ao fenômeno da corrosão e ao tempo de propagação. Os resultados encontrados neste trabalho apontam a eficiência do modelo desenvolvido e a sua aplicabilidade frente à simulação do comportamento mecânico de estruturas de concreto armado sujeitas à corrosão uniforme.

Palavras-chave: Compósitos Particulados. Estruturas de Concreto Armado. Corrosão por Carbonatação. Produtos de Corrosão. Método dos Elementos Finitos. 


\section{ABSTRACT}

\section{FELIX, E. F. Modeling of Reinforced Concrete Expansion Due to Rust}

Formation. 2018. 162 p. Dissertation (M. Sc. In Structural Engineering) - Department of Structural Engineering, School of Engineering of São Carlos, University of São Paulo, São Carlos, 2018.

In order to provide the mechanisms for corrosion damage control, it is necessary to own sufficient software tools and knowledge for understanding the effects of this pathologic manifestation on the mechanic behavior of the reinforced concrete. In recent years it has become expanding the utilization of numeric modeling in the simulation of degradation arising from corrosion, thanks to low-cost of its fomentation. Knowing that in this research was designed a numeric model for a simulation at the mesoscopic level of the reinforced concrete because of the corrosion products. The designed model is based on the Finite Element Method (FEM) using the total Lagrange formulation, considering an elastic isotropic material, with a constitutive law of Saint-Venant-Kirchhoff and a behavior nongeometric linear. For a representation of the reinforcements and of the corrosion products (rust), which are inserted in the concrete matrix, it is used finite linear elements (fibers) or planes (particles) attached to the matrix of concrete through the technic embodiment. The products corrosion behavior is described by the formulations found in the literature, using analytical models related to parameters intrinsic to the corrosion phenomenon and to propagation time. The observed results in this work point out to the efficiency of this developed model and its applicability in view of the mechanical behavior of reinforced concrete structures liable to uniform corrosion.

Key-words: Particulate Composites. Reinforced Concrete Structures. Corrosion Due to Carbonation. Corrosion Products. Finite Element Method. 


\section{LISTA DE ILUSTRAÇÕES}

Figura 1.1 - Formação dos produtos de corrosão por carbonatação. . . . . . . . . . . . 21

Figura 1.2 - Mapa de incidência e dos custos advindos da corrosão alguns países. . . 22

Figura 1.3 - Desabamento de arquibancada no Estádio Octávio Mangabeira em 2007. 23

Figura 1.4 - Desabamento de Marquise no Rio de Janeiro em 2006. . . . . . . . . . 23

Figura 1.5 - Número de trabalhos publicados nos últimos 10 anos. . . . . . . . . . . 25

Figura 2.1 - Representação esquemática do processo de corrosão eletroquímica. . . . 32

Figura 2.2 - Desenvolvimento da corrosão em função do agente agressivo. . . . . . . . 33

Figura 2.3 - Esquematização da estrutura interna do concreto. . . . . . . . . . . . . 37

Figura 2.4 - Fatores que influenciam na corrosão por carbonatação. . . . . . . . . . 38

Figura 2.5 - Carbonatação em função da umidade e da exposição à chuvas. . . . . . 39

Figura 2.6 - Carbonatação em função da concentração de $\mathrm{CO}_{2}$. . . . . . . . . . . . 40

Figura 2.7 - Profundidade de carbonatação em função da temperatura. . . . . . . . . 41

Figura 2.8 - Profundidade de carbonatação em função do tipo de cimento. . . . . . . 42

Figura 2.9 - Representação da microestrutura dos concretos simulados. . . . . . . . 43

Figura 2.10-Frente de carbonatação do concreto. . . . . . . . . . . . . . . . . . 44

Figura 2.11-Coeficiente de difusão de $\mathrm{CO}_{2}$ versus fator a/c. . . . . . . . . . . . . 45

Figura 2.12-Diagrama de equilíbrio termodinâmico para o sistema ferro $-\mathrm{H}_{2} \mathrm{O}$ a $25^{\circ} \mathrm{C} .46$

Figura 2.13-Redução da capacidade mecânica de vigas de concreto sob corrosão. . 48

Figura 2.14-Carga máxima de vigas de concreto em função do nível de corrosão. . 48

Figura 2.15-Força vs. deslocamento em função do nível de corrosão. . . . . . . . . . 49

Figura 2.16-Influência da corrosão na aderência entre o aço e o concreto. . . . . . . . 50

Figura 2.17-Efeitos da corrosão em estruturas de concreto armado. . . . . . . . . . 50

Figura 3.1 - Mudança de configuração de um sólido deformável. . . . . . . . . . . . 64

Figura 4.1 - Discretização de um sólido por meio do MEF. . . . . . . . . . . . . . . 72

Figura 4.2 - Elemento finito bidimensional do tipo chapa com aproximação cúbica. . 75

Figura 4.3 - Elemento finito linear (barra de treliça) . . . . . . . . . . . . . . . . . . 78

Figura 4.4 - Arranjo das fibras no domínio bidimensional (matriz). . . . . . . . . . 80

Figura 4.5 - Matriz com elementos finitos de partículas dispersos. . . . . . . . . . . 83

Figura 4.6 - Algoritmo do MEFP para compósitos com partículas. . . . . . . . . . . 86

Figura 5.1 - Geometria e condições de contorno da viga. . . . . . . . . . . . . . 87

Figura 5.2 - Configurações deformadas da viga para distintos níveis de carregamento. 88

Figura 5.3 - Comparação dos resultados - Exemplo 1. . . . . . . . . . . . . . . . . 89

Figura 5.4 - Geometria e condições de contorno da chapa. . . . . . . . . . . . . . . 90 
Figura 5.5 - Configurações do reforço nas chapas de argamassa. . . . . . . . . . . . 90

Figura 5.6 - Deslocamento horizontal da chapa sem fibras. . . . . . . . . . . . . . . 91

Figura 5.7 - Deslocamento vertical da chapa sem fibras. . . . . . . . . . . . . . . 91

Figura 5.8 - Deslocamento horizontal da chapa com fibras longas ordenadas verticalmente. . . . . . . . . . . . . . . . . . . . 92

Figura 5.9- Deslocamento vertical da chapa com fibras longas ordenadas verticalmente. 92

Figura 5.10-Deslocamento horizontal da chapa com fibras nas duas direções. . . . . 93

Figura 5.11-Deslocamento vertical da chapa com fibras nas duas direções. . . . . . 93

Figura 5.12-Chapa com fibras curtas dispersas aleatoriamente. . . . . . . . . . . . 94

Figura 5.13-Chapa com fibras curtas dispersas aleatoriamente. . . . . . . . . . . . . 94

Figura 5.14-Deslocamentos horizontais máximos da chapa. . . . . . . . . . . . . . . 94

Figura 5.15-Geometria, malha e condições de contorno da chapa de argamassa. . . 96

Figura 5.16-Deslocamento vertical da chapa para o primeiro e último passo de carga. 96

Figura 5.17-Configurações das chapas compósitas (matriz cimentícia + agregados). 97

Figura 5.18-Configuração deformada da chapa com 4 partículas. . . . . . . . . . . . 97

Figura 5.19-Configuração deformada da chapa com 16 partículas. . . . . . . . . . . 98

Figura 5.20-Configuração deformada da chapa com 64 partículas. . . . . . . . . . . 98

Figura 5.21-Carregamento versus deformação (chapa de concreto). . . . . . . . . . 99

Figura 5.22-Modelos reológicos para a representação de compósitos. . . . . . . . . . 99

Figura 5.23-Módulos de elasticidade do compósito obtido nas modelagens e modelos. 100

Figura 5.24-Geometria e condições de contorno da viga de concreto. . . . . . . . . . 101

Figura 5.25-Deslocamento vertical (análise linear geométrica). . . . . . . . . . . . . 102

Figura 5.26-Tensão de compressão máxima. . . . . . . . . . . . . . . . . . . . . . 102

Figura 5.27-Deslocamento vertical (análise não linear geométrica). . . . . . . . . . 103

Figura 5.28-Deslocamento vertical da viga para cada análise. . . . . . . . . . . . . 104

Figura 5.29-Geometria e condições de contorno da barragem maciça. . . . . . . . . 105

Figura 5.30-Geometria e condições de contorno da barragem. . . . . . . . . . . . . 105

Figura 5.31-Deslocamentos da barragem para o primeiro passo de carga. . . . . . . 106

Figura 5.32-Deslocamentos da barragem para o último passo de carga. . . . . . . . 106

Figura 5.33-Deslocamento horizontal da barragem com malha vazada e com partículas.107

Figura 5.34-Deslocamento vertical. . . . . . . . . . . . . . . . . . 108

Figura 5.35-Deslocamento horizontal. . . . . . . . . . . . . . . . . . . . . 108

Figura 5.36-Geometria, condições de contorno e malha utilizadas para a matriz. . . 109

Figura 5.37-Malha das chapas considerando a configuração das descontinuidades. . 109

Figura 5.38-Deslocamento vertical da chapa com descontinuidade (CASO I) . . . . . 110

Figura 5.39-Deslocamento vertical da chapa com descontinuidade (CASO II). . . . 110

Figura 5.40-Deslocamentos vertical da chapa com descontinuidade (CASO III). . . 110

Figura 5.41-Distribuição das tensões longitudinais na chapa com descontinuidade. . 111

Figura 5.42-Tensão longitudinal em diferentes regiões da chapa. . . . . . . . . . . . 112 
Figura 6.1 - Desenvolvimento dos produtos de corrosão na matriz de concreto. . . . 115

Figura 6.2 - Formação dos produtos de corrosão. . . . . . . . . . . . . . . . . . . 116

Figura 6.3 - Representação do modelo de Kiani e Shodja (2011) . . . . . . . . . . . 117

Figura 6.4 - Elemento de concreto armado e a expansão das armaduras. . . . . . . . 119

Figura 6.5 - Algoritmo baseado no MEFP para a modelagem de elementos de concreto armado sujeitos à corrosão. . . . . . . . . . . . . . . . . . . . 121

Figura 7.1 - Dimensões e condições de ensaio da placa de concreto armado. . . . . . 123

Figura 7.2 - Representação da região da placa modelada e da sua discretização. . . 124

Figura 7.3 - Comparação entre os resultados numéricos e experimental. . . . . . . . 125

Figura 7.4 - Formação das fissuras ao longo do tempo. . . . . . . . . . . . . . . . . 125

Figura 7.5 - Deslocamento horizontal $(\mathrm{em} \mathrm{cm}) . \ldots \ldots$. . . . . . . . 126

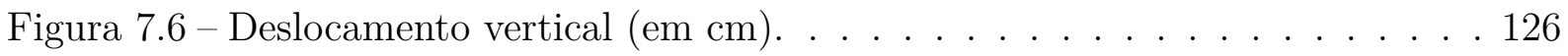

Figura 7.7 - Tensão horizontal $(\mathrm{em} \mathrm{MPa}) . \ldots \ldots$. . . . . . . . . 127

Figura 7.8 - Tensão vertical (em MPa) . . . . . . . . . . . . . . . . 127

Figura 7.9 - Geometria e malha do corpo de prova modelado. . . . . . . . . . . . . 128

Figura 7.10-Deslocamento vertical do corpo de prova. . . . . . . . . . . . . . . . . 129

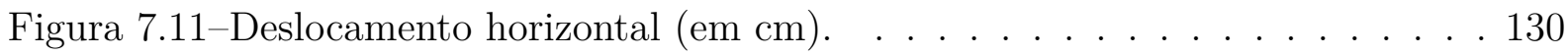

Figura $7.12-$ Deslocamento vertical $(\mathrm{em} \mathrm{cm}) \ldots \ldots$. . . . . . . . . . 130

Figura 7.13-Geometria, configuração de carregamento e malha do corpo de prova. . 131

Figura 7.14-Tensão horizontal na região de interface aço/concreto. . . . . . . . . . . 131

Figura 7.15-Tensão vertical na região de interface aço/concreto. . . . . . . . . . . . 132

Figura 7.16-Desenvolvimento teórico das fissuras. . . . . . . . . . . . . . . . . 132

Figura $7.17-$ Tensão horizontal $\left(\mathrm{kN} / \mathrm{cm}^{2}\right)$. . . . . . . . . . . . . . . . 133

Figura $7.18-$ Tensão vertical $\left(\mathrm{kN} / \mathrm{cm}^{2}\right)$. . . . . . . . . . . . . . . . 133

Figura 7.19-Geometria e dimensões da viga de concreto. . . . . . . . . . . . . . 134

Figura 7.20-Deslocamento vertical da viga de concreto sob corrosão acelerada. . . . 135

Figura 7.21-Configuração deformada da viga de concreto sob corrosão acelerada. . . 135

Figura $7.22-$ Deslocamento vertical da viga no ponto "S" . . . . . . . . . . . . . 136

Figura $7.23-$ Deslocamento vertical da viga no ponto "M" . . . . . . . . . . . . . . . 136

Figura $7.24-$ Deslocamento vertical da viga no ponto "I". . . . . . . . . . . . . . 137

Figura 7.25-Configuração deformada da viga de concreto. . . . . . . . . . . . . 137

Figura 7.26-Tensão longitudinal em diferentes regiões da viga. . . . . . . . . . . . . 138

Figura 7.27-Deslocamento vertical da viga de concreto sob corrosão natural. . . . . 139

Figura 7.28-Detalhamento da viga de concreto armado. . . . . . . . . . . . . . . . 140

Figura 7.29-Comparação entre as taxas de aumento dos deslocamentos. . . . . . . . 141

Figura 7.30-Detalhamento da viga. . . . . . . . . . . . . . . . . . . . . . . 142

Figura 7.31-Variáveis do modelo de predição e topologia da RNA. . . . . . . . . . . 143

Figura 7.32-Processos de cálculos para a obtenção da vida útil. . . . . . . . . . . . . 144

Figura 7.33-Frente de carbonatação do concreto das vigas modeladas. . . . . . . . . 144 
Figura 7.34-Avanço da degradação das armaduras ao longo do tempo. . . . . . . . . 145

Figura 7.35-Abertura de fissuras ao longo da vida útil. . . . . . . . . . . . . . . . 145

Figura 7.36-Tensão e deslocamento da viga com cobrimento de $20 \mathrm{~mm}$. . . . . . . . 146

Figura 7.37-Tensão e deslocamento da viga com cobrimento de $25 \mathrm{~mm}$. . . . . . . . 146

Figura 7.38-Tensão e deslocamento da viga com cobrimento de $30 \mathrm{~mm}$. . . . . . . . 146

Figura 7.39-Deslocamento vertical das vigas ao longo da vida útil. . . . . . . . . . . 147 


\section{LISTA DE TABELAS}

Tabela 5.1 - Comparação entre os resultados - Exemplo 1. . . . . . . . . . . . . . . 89

Tabela 5.2 - Deslocamentos máximos da chapa. . . . . . . . . . . . . . . . . . . 95

Tabela 5.3 - Comparação entre os deslocamento máximos $(\mathrm{cm})$. . . . . . . . . . . . 103

Tabela 5.4 - Comparação entre as tensões $\left(k N / m^{2}\right)$ na ponta da fissura. . . . . . . 112

Tabela 7.1 - Parâmetros de entrada dos modelos. . . . . . . . . . . . . . . . . . 125

Tabela 7.2 - Propriedades dos materiais. . . . . . . . . . . . . . . . . . . . . 142

Tabela 7.3 - Dados referentes ao concreto e ambiente de exposição. . . . . . . . . . 142 
INTRODUÇÃO . . . . . . . . . . . . . . . . 19

1.1 Considerações iniciais . . . . . . . . . . . . . . . 19

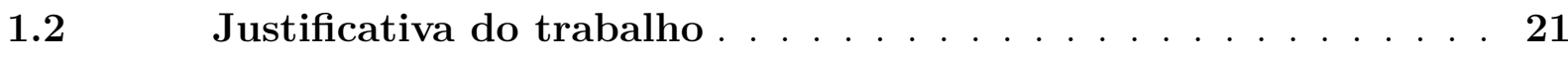

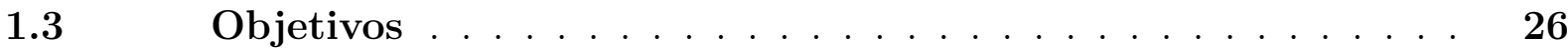

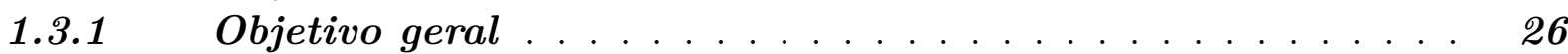

1.3.2 Objetivos específicos .................. 26

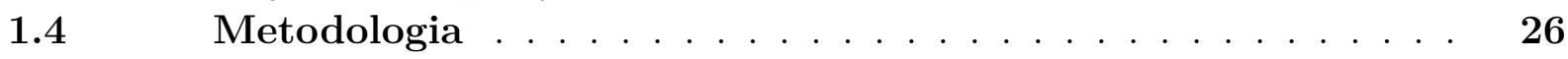

1.5 Organização da dissertação . . . . . . . . . . . . . . . 28

2 CORROSÃO DO AÇO NO CONCRETO . . . . . . . . . 29

2.1 Considerações iniciais . . . . . . . . . . . . . . . 29

$2.2 \quad$ Princípios da corrosão . . . . . . . . . . . . . . . 30

2.2.1 Reações eletroquímicas . . . . . . . . . . . . . . 30

2.2.2 Mecanismos de transporte no concreto . . . . . . . . . . . 33

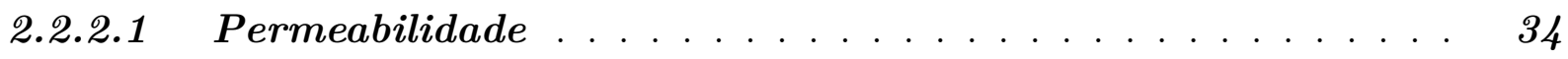

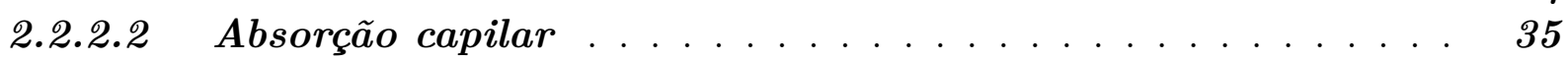

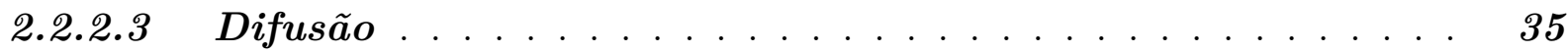

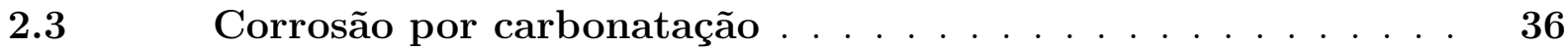

2.3.1 Fatores que influenciam na corrosão por carbonatação . . . 37

2.3.1.1 Umidade e incidência de chuvas . . . . . . . . . . . . . . 38

2.3.1.2 Concentração de $\mathrm{CO}_{2} \ldots \ldots \ldots \ldots \ldots \ldots$

2.3.1.3 Temperatura ....................... 40

2.3.1.4 Composição do concreto . . . . . . . . . . . . . 41

2.3.1.5 Relação água/cimento e resistência à compressão. . . . . . 44

$2.4 \quad$ Produtos de corrosão . . . . . . . . . . . . . . . . . 45

$2.5 \quad$ Efeitos da corrosão no concreto armado . . . . . . . . . . . . 47

$2.6 \quad$ Avanços nos estudos da corrosão . . . . . . . . . . . . . 51

3 FUNDAMENTOS DA MECÂNICA NÃO-LINEAR . . . . . 61

3.1 Não linearidade geométrica dos sólidos . . . . . . . . . . 61

$3.2 \quad$ Cinemática dos sólidos deformáveis . . . . . . . . . . . . . 62

3.2.1 Configuração de um corpo . . . . . . . . . . . . . . . 63

3.2.2 Mudança de configuraçẫo dos sólidos deformáveis . . . . . 63

3.2.3 Gradiente de deformação. . . . . . . . . . . . . 64

3.2.4 Tensor de estiramento à direita de Cauchy-Green. . . . . . . 65

3.2.5 Tensor de deformação Green-Lagrange . . . . . . . . . . 65

3.2.6 Lei constitutiva de Saint-Venant-Kirchhoff . . . . . . . . . 66

3.2.7 Tensor tensão de Piola-Kirchhoff de segunda espécie. . . . . 66

3.3 Princípios fundamentais da mecânica dos sólidos . . . . . . . . 67

3.3.1 Conservação da energia mecânica . . . . . . . . . . . . . . 67

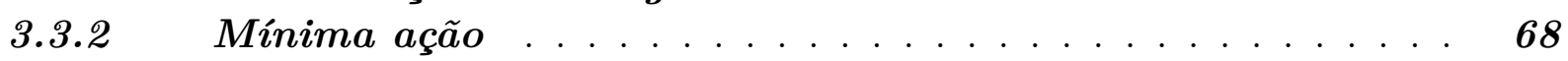


4 MODELAGEM DE SÓLIDOS COMPÓSITOS VIA MEFP . . 71

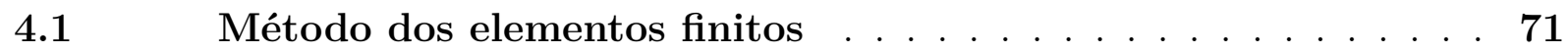

$4.2 \quad$ Formulação do MEFP . . . . . . . . . . . . . . . . 72

4.2.1 Método de solução do sistema não linear . . . . . . . . . 74

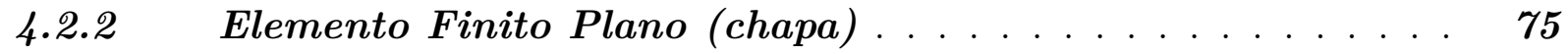

4.2.2.1 Energia de deformação . . . . . . . . . . . . . 76

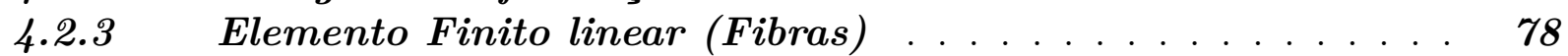

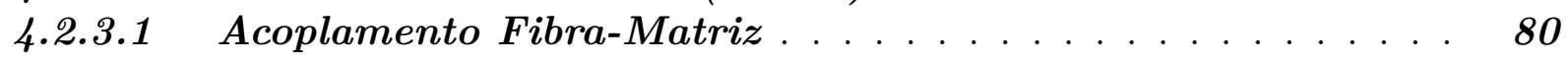

4.2.4 Elemento Finito Bidimensional (Partículas) . . . . . . 83

4.2.4.1 Acoplamento Partícula-Matriz ............. 83

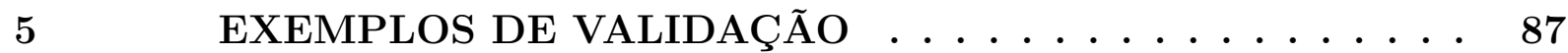

$5.1 \quad$ Exemplo 1: Viga sob grandes deslocamentos . . . . . . . 87

5.2 Exemplo 2: Chapa reforçada com fibras . . . . . . . . . 90

$5.3 \quad$ Exemplo 3: Avaliação do módulo de elasticidade . . . . . . 95

$5.4 \quad$ Exemplo 4: Viga de concreto armado . . . . . . . . . . 101

5.5 Exemplo 5: Representação de vazios em sólidos . . . . . . . . 105

5.6 Exemplo 6: Descontinuidades em sólidos . . . . . . . . . . 109

6 MODELAGEM DA FORMAÇÃO DOS PRODUTOS DE CORROSÃO . . . . . . . . . . . . . . . . . 115

$6.1 \quad$ Considerações iniciais . . . . . . . . . . . . . . . 115

6.2 Modelos da perda de seção de aço e formação dos produtos de corrosão . . . . . . . . . . . . . . . . . . . . . 117

6.2.1 Modelo I - Kiani e Shodja (2011) . . . . . . . . . . . 117

6.2.2 Modelo II - Rodriguez e Andrade (1990) . . . . . . . . . . 118

$6.3 \quad$ Modelo numérico baseado no MEFP . . . . . . . . . . . . . 119

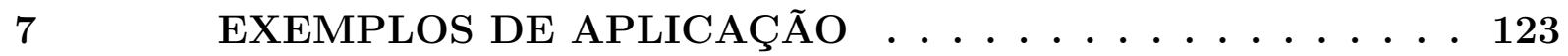

$7.1 \quad$ Placa de concreto armado sujeita à corrosão . . . . . . . . . 123

7.2 Corpo de prova sob corrosão sujeito a diferentes níveis de tensão aplicada . . . . . . . . . . . . . . . . . . . . 128

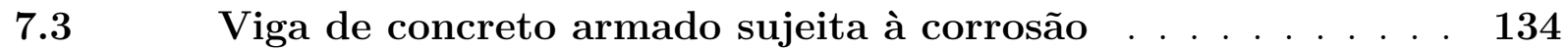

7.4 Análise da vida útil de vigas de concreto armado sob corrosão 139

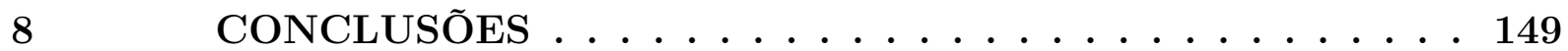

$8.1 \quad$ Sugestões para trabalhos futuros $\ldots \ldots \ldots \ldots$

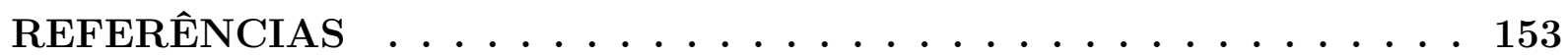


CAPÍTULO
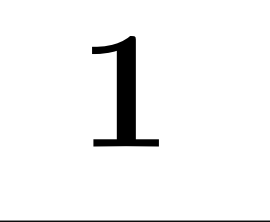

\section{INTRODUÇÃO}

Neste primeiro capítulo, a corrosão em estruturas de concreto armado é abordada de forma a contextualizar e justificar o desenvolvimento da pesquisa. Também são apresentados os objetivos e a metodologia empregada no trabalho. Por fim, apresentam-se os conteúdos explorados nos demais capítulos.

\subsection{Considerações iniciais}

O concreto armado tem sido utilizado como o principal material construtivo na produção de estruturas em todo o mundo, superando os demais materiais, por exemplo, o aço, a madeira e o bloco cerâmico (RIBEIRO; CUNHA; HELENE, 2015). Uma justificativa para a sua preferência deve-se a maior durabilidade dos seus componentes, uma vez que o aço está protegido pelo concreto da agressividade do ambiente de exposição.

Com o desenvolvimento acelerado das cidades, tornou-se necessário evoluir o setor da construção civil. Assim os métodos de cálculos foram atualizados, permitindo a otimização de materiais, o aumento da esbelteza das estruturas (menores cobrimentos) e da sua capacidade portante, garantindo maior produtividade e menores custos. Entretanto, de acordo com Mehta (1991), esses avanços colocaram em xeque a ideia de que o concreto armado era eterno, e que o mesmo apresenta manifestações patológicas relacionadas desde a qualidade dos materiais à forma de execução das estruturas, reduzindo sua durabilidade.

Assim, apesar de apresentar uma associação inteligente entre diferentes materiais (aglomerantes, agregados, aço e água), o concreto armado está sujeito à deterioração, consequência da ação de diferentes mecanismos de degradação, por exemplo, a corrosão, a reação álcali-agregado e o ataque de sulfatos.

A corrosão de armaduras é definida como uma manifestação patológica que gera prejuízos estéticos, financeiros e, em casos de severa agressividade ambiental, a perda da capacidade mecânica do elemento estrutural. 
A corrosão pode ser entendida como a interação destrutiva do material com o meio ao qual está inserido, apresentando-se como um mecanismo de deterioração da fase metálica existente, na qual se desenvolve a perda de massa do aço e a formação de produtos de corrosão, mais conhecido como ferrugem (MEHTA; MONTEIRO, 2014; RIBEIRO; CUNHA; HELENE, 2015).

Em geral o concreto apresenta condições suficientes para a proteção das armaduras frente à corrosão, graças a alta alcalinidade da pasta (pH situado entre 12 e 13). Entretanto, esta proteção é perdida ao longo do tempo, à medida em que o concreto é atacado pelos diferentes agentes agressivos presentes no meio no qual está inserido, por exemplo, íons de cloreto $\left(\mathrm{Cl}^{-}\right)$e dióxido de carbono $\left(\mathrm{CO}_{2}\right)$ (GENTIL, 2011).

A depender da concentração do agente agressivo, o processo corrosivo pode ser classificado como uniforme ou localizado. A corrosão localizada (ou por pite) ocorre quando íons cloretos causam um aumento da condutividade elétrica do concreto e atacam a camada passivadora que protege as armaduras. Neste tipo de corrosão, apenas algumas regiões da armadura perdem massa de aço, justificando o termo "localizada", utilizado em sua classificação (RIBEIRO; CUNHA; HELENE, 2015). Outras formas de corrosão podem ser vistas em Gentil (2011), por exemplo, corrosão por empolamento do hidrogênio, intergranular e transgranular.

O processo corrosivo é dito uniforme (ou por carbonatação) quando o teor de $\mathrm{CO}_{2}$ presente na atmosfera é preponderante ao de íons cloretos. Neste caso, a difusão do $\mathrm{CO}_{2}$ no concreto causa a diminuição do pH da matriz cimentícia (de aproximadamente 13 ou 12 até 9), o que leva a destruição da camada passivadora que envolve as armaduras, tornando o aço susceptível à corrosão (MEHTA; MONTEIRO, 2014).

De acordo com Tuutti (1982), Stanish, Hooton e Thomas (2000), Santos (2006) e Graeff (2007), o processo de corrosão pode ser dividido em dois estágios, denominados de iniciação e propagação. O estágio de iniciação refere-se ao período que compreende desde a produção do elemento de concreto até o instante em que ocorre a despassivação da armadura. A fase de propagação refere-se ao período após início da despassivação das armaduras e se estende com a vida útil do elemento de concreto.

A corrosão geralmente ocorre em estruturas com concreto de baixa qualidade, em locais onde o cobrimento da armadura é insuficiente para garantir a proteção do aço ou em ambientes de severa agressividade (RIBEIRO; CUNHA; HELENE, 2015). Helene (1986) verificou que nestes casos, a corrosão leva à formação de produtos de corrosão na interface entre o aço e o concreto e que estes podem ocupar espaços de 3 a 10 vezes maiores que os inicialmente ocupados.

Com a formação dos produtos de corrosão, campos internos de tensão são gerados na interface entre o aço e concreto (Figura 1.1a). A medida em que as tensões geradas pelos produtos de corrosão se tornam superiores às resistidas pelo concreto, microfissuras surgem na matriz de concreto que, com o avanço da corrosão, aumentam de tamanho e 
espessura, espalhando-se por todo o elemento estrutural até causar o destacamento do concreto de cobrimento, afetando a sua durabilidade (Figura 1.1b).

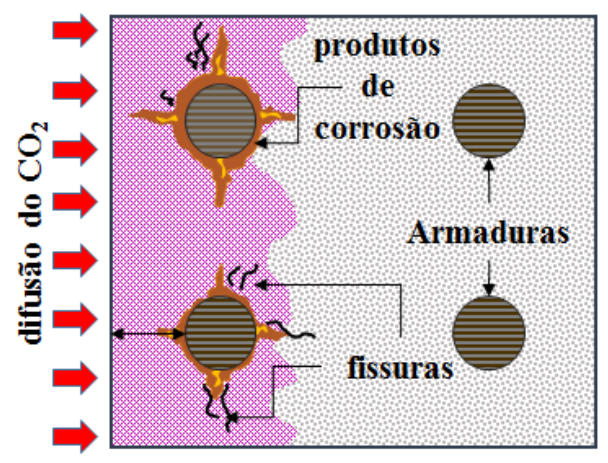

(a) Surgimento dos produtos de corrosão.

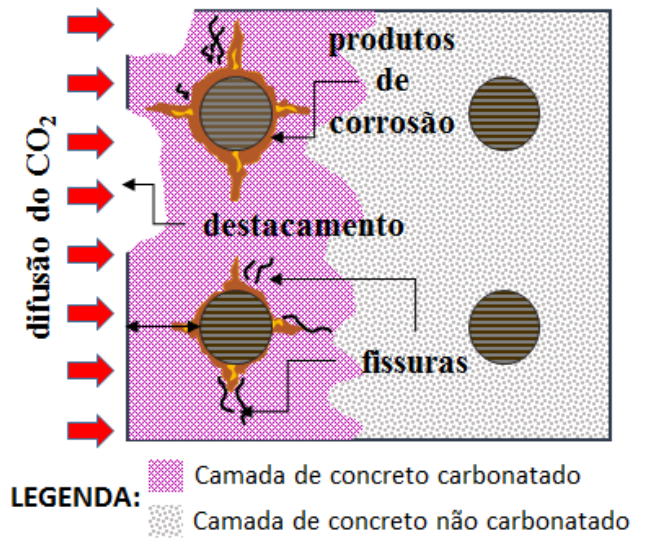

(b) Fissuração e destacamento do concreto.

Figura 1.1 - Formação dos produtos de corrosão por carbonatação.

Assim, percebe-se que o estudo e a modelagem estrutural precisa e eficiente da deterioração causada pela corrosão torna-se essencial, de modo a reduzir os custos advindos de manutenções e reparos, corroborando com o estudo da durabilidade de estruturas de concreto armado (VU; STEWART, 2000; RAO et al., 2017).

\subsection{Justificativa do trabalho}

Considerando que o concreto armado é o material mais empregado para construção de estruturas no mundo, a corrosão apresenta-se como um tema de grande relevância no cenário científico internacional, com vasto campo para pesquisas, em especial, abordagens numéricas para avaliação da segurança, vida útil e confiabilidade das estruturas de concreto armado.

De acordo com o World Corrosion Organization, os custos envolvidos com a corrosão alcançam valores superiores a 3\% do Produto Interno Bruto (PIB), em diversos países, e que a ocorrência desta manifestação patológica em estruturas de concreto armado se destaca dentre as demais, sendo observados índices de até $48 \%$ na África do Sul. Na Figura 1.2 é possível ver o índice de ocorrência da corrosão e os custos gerados na economia de alguns países (os dados utilizados para a montagem da figura foram extraídos do World Corrosion Organization $\left.{ }^{1}\right)$.

Carmona e Marega (1988), Dal Molin (1988), Andrade (1992) e Aranha (1994) relatam que no Brasil o índice de ocorrência da corrosão de armaduras em estruturas de

1 Disponível em: <https://www.nace.org/Corrosion-Central/Industries/Highways-and-Bridges >. Acesso em out. 2017. 
concreto armado varia entre 14 e $64 \%$, a depender do ambiente de exposição do concreto, e que a corrosão se classifica como a deterioração mais frequente nestes tipos de estruturas.

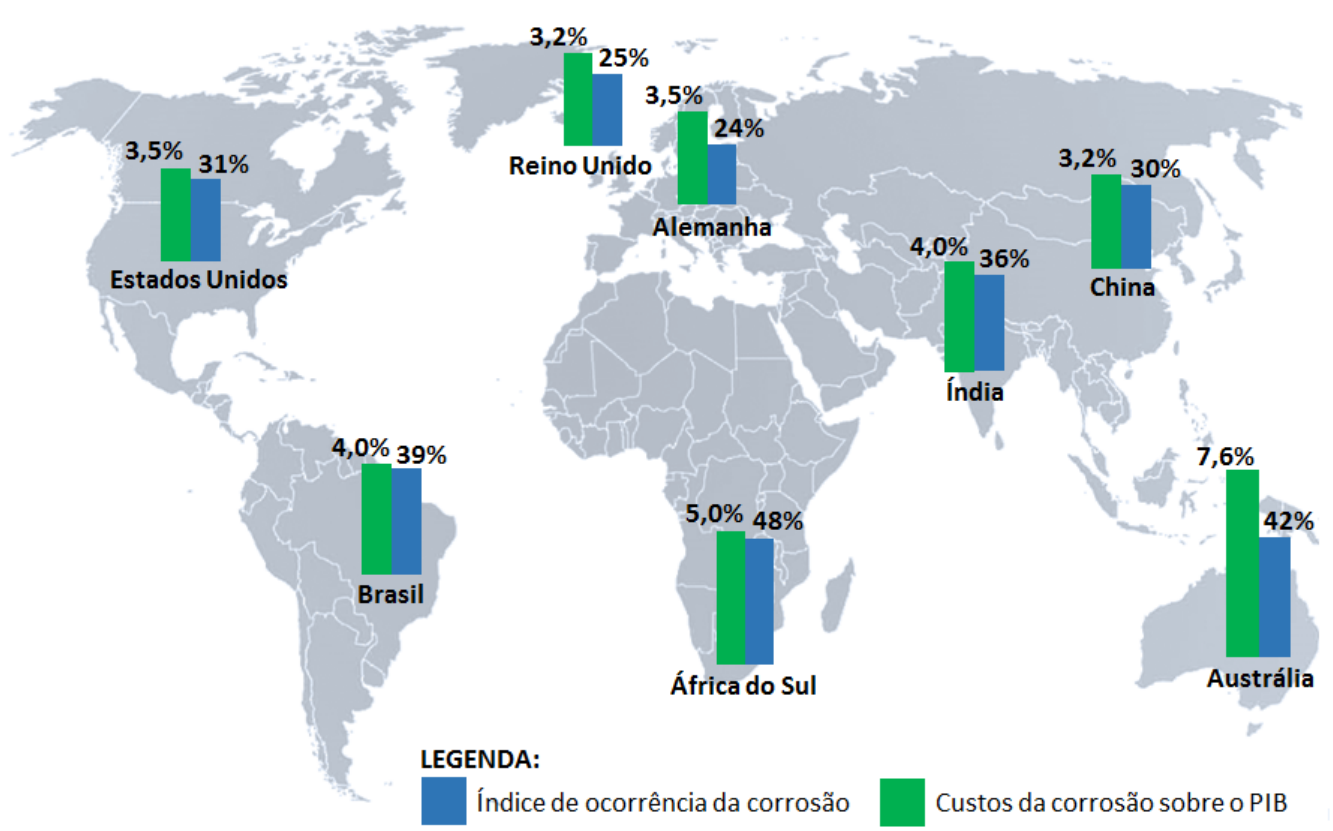

Figura 1.2 - Mapa de incidência e dos custos advindos da corrosão alguns países.

Fonte: Dados da World Corrosion Organization ${ }^{2}$.

Durante a segunda Conferência Internacional sobre a Durabilidade do Concreto, sediada no Canadá, Mehta (1991) abordou fatores relevantes às diferentes manifestações patológicas em estruturas de concreto (i.e., corrosão de armaduras, reações álcali-agregados, reações com sulfatos, etc.), relacionadas com a perda de durabilidade, dando enfase à corrosão de armaduras.

Em seu trabalho, Mehta (1991) quantificou os danos decorrentes da corrosão de armaduras na segunda metade do século $X X$, sendo os principais:

- 253.000 tabuleiros de pontes rodoviárias e ferroviárias, nos Estados Unidos, tiveram problemas de durabilidade, referentes à corrosão, acarretando em gastos com reparos que alcançaram 90 bilhões de dólares americanos;

- Vários túneis em diferentes localidades do mundo apresentavam problemas associados à corrosão;

- 27 edifícios ruíram na Inglaterra devido à corrosão, sendo que 8 destes vieram ao colapso entre 8 e 40 anos de vida útil;

- Milhares de estruturas residenciais e comerciais destinadas a garagens e estacionamentos no Canadá apresentaram danos devidos à corrosão, as quais totalizaram um custo de aproximadamente 3 bilhões de dólares americanos.

2 Disponível em: <https://www.nace.org/Corrosion-Central/Industries/Highways-and-Bridges>. Acesso em out. 2017. 
No Brasil, existem diversos casos em que a corrosão acarretou no colapso de estruturas de concreto armado, causando prejuízos financeiros e risco à integridade dos seus usuários, por exemplo, a queda da adutora principal da Companhia de Saneamento Básico do Estado de São Paulo - Sabesp ${ }^{3}$ sobre o Rio Pinheiros (São Paulo - SP), que deixou mais de 3 milhões de habitantes sem água potável durante 15 dias (RIBEIRO; CUNHA; HELENE, 2015), o desabamento de arquibancadas de concreto armado do Estádio Octávio Mangabeira em Salvador, em 2007, que acarretou na morte de 7 pessoas (Figura 1.3) e o desabamento de uma marquise no centro da cidade do Rio de Janeiro em 2006 (Figura 1.4).

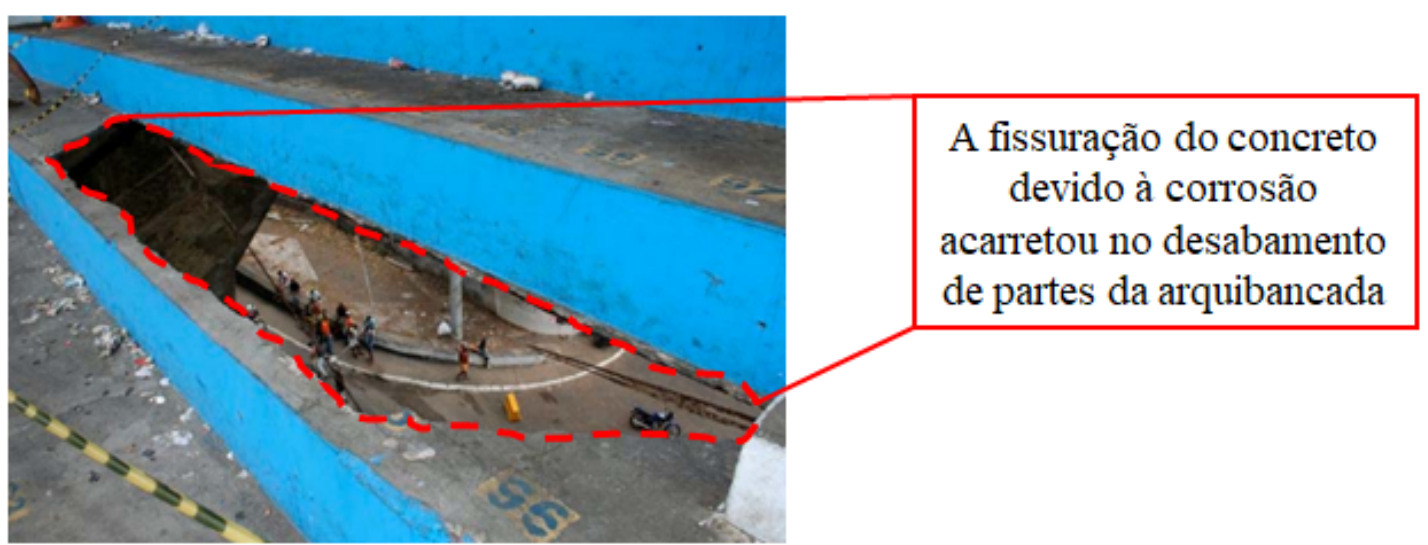

Figura 1.3 - Desabamento de arquibancada no Estádio Octávio Mangabeira em 2007. Fonte: CREA-BH ${ }^{4}$.

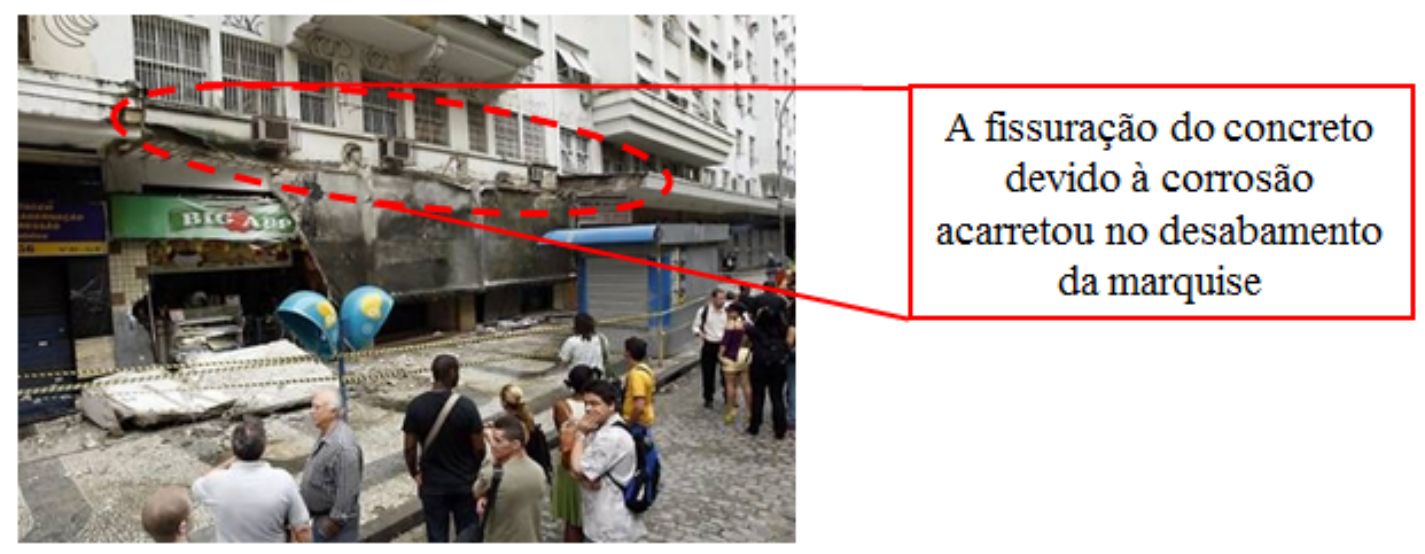

Figura 1.4 - Desabamento de Marquise no Rio de Janeiro em 2006.

Fonte: Masset (2006).

3 Publicado em manchete de primeira página no Jornal da Tarde de 22 de junho de 1988.

4 Disponível em: <http://www.creaba.org.br/Imagens/FCKimagens/12-2009>. Acesso em set. 2016. 
Ainda no Brasil, Magalhães, Folloni e Furman (1989) realizaram vistorias em 145 viadutos e pontes da capital do estado de São Paulo, classificando 22 de alto risco, com a probabilidade de ocasionar sérios danos aos seus usuários. Ao todo, $58 \%$ das estruturas apresentavam problemas devido à corrosão.

A fim de minimizar os efeitos da corrosão é necessário conhecimento técnico atualizado e abrangente do fenômeno, detendo informações detalhadas sobre o seu estado de desenvolvimento e dos mecanismos de iniciação e propagação, possibilitando a redução de sua incidência e, em casos avançados, a repararão e/ou restauração de estruturas de concreto, aumentando a vida útil destas estruturas e, reduzindo riscos aos seus usuários.

No que condiz a modelagem da corrosão e os danos que esta causa às estruturas de concreto armado, boa parte das pesquisas se concentram no estudo do estágio de iniciação, com o desenvolvimento de modelos para a estimativa da frente de carbonatação. Os primeiros modelos para a previsão da profundidade de carbonatação foram obtidos por meio de regressões lineares e não lineares, considerando diferentes fatores, por exemplo, a relação água/cimento (a/c), o tipo do aglomerante e as condições de exposição, como é visto nos trabalhos de Hamada (1968), Smolczyk (1968) e Helene (1986).

Nos anos seguintes, nos modelos desenvolvidos por Papadakis, Vayenas e Fardis (1991), Andrade (1992), Jepsen (2002) e Hyvert (2009), formulações físico-químicas referentes às reações de hidratação da pasta de cimento e da dissolução do $\mathrm{CO}_{2}$ na matriz porosa do concreto foram inseridas. No entanto estes modelos possuem grande complexidade quanto à resolução das equações que regem a difusão do $\mathrm{CO}_{2}$ no concreto, além de possuírem parâmetros de difícil mensuração, por exemplo, o coeficiente de difusão do dióxido de carbono no concreto.

Com o avanço da computação e o surgimento de técnicas de aprendizado de máquinas, novas formulações foram desenvolvidas, reduzindo as incertezas dos modelos produzidos por meio de regressões lineares e não lineares (UKRAINEZYK; MATUSINOVIÉ, 2005; MARTINS, 2011; LUO; NIU; DONG, 2014; FELIX, 2015).

Quanto à modelagem do período de propagação da corrosão, pouca atenção era dada até meados da década de 80 em virtude das dificuldades em representar o avanço do fenômeno neste estágio e da reduzida quantidade de dados disponíveis na literatura. Porém com o surgimento e aprimoramento de técnicas numéricas, novas formulações foram desenvolvidas. De forma geral, os modelos que consideram o período de propagação, propostos ao longo dos últimos anos, são classificados em empíricos, analíticos e numéricos.

Cabrera (1996), Almusallam et al. (1996), Rodriguez, Ortega e Casal (1997), Du, Clark e Chan (2005), Šavija et al. (2013) e Muthulingam e Rao (2014) propuseram modelos empíricos por intermédio de relações entre a taxa de corrosão e de parâmetros referentes aos materiais. Hansen e Saouma (1999), Maruya et al. (2003) e Bhargava et al. (2005) utilizaram métodos numéricos para a resolução de forma automatizada de equações matemáticas referentes aos mecanismos da corrosão, o que possibilitou analisar e estimar 
os efeitos da corrosão e sua progressão ao longo do tempo. O mesmo procedimento foi adotado por Coronelli e Gambarova (2004), Isgor e Razaqpur (2006), Xu, Jiang e Wang (2009), Du e Jin (2014), Ožbolt, Oršanić e Balabanić (2014), Paul e Zijl (2016) e Zhao et al. (2016), porém, sob formulações baseadas no Método dos Elementos Finitos. Já Wang e Liu (2006), Yuan e Ji (2009), Shodja, Kiani e Hashemian (2010), Pengwei et al. (2011) e Pluciński (2015) desenvolveram modelos analíticos capazes de representar os efeitos da corrosão sobre o concreto armado.

O interesse e o desenvolvimento de pesquisas na área continuam crescentes. Observase na Figura 1.5 o número de artigos publicados em periódicos indexados nos últimos dez anos contendo como tema a corrosão em estruturas de concreto ${ }^{5}$.

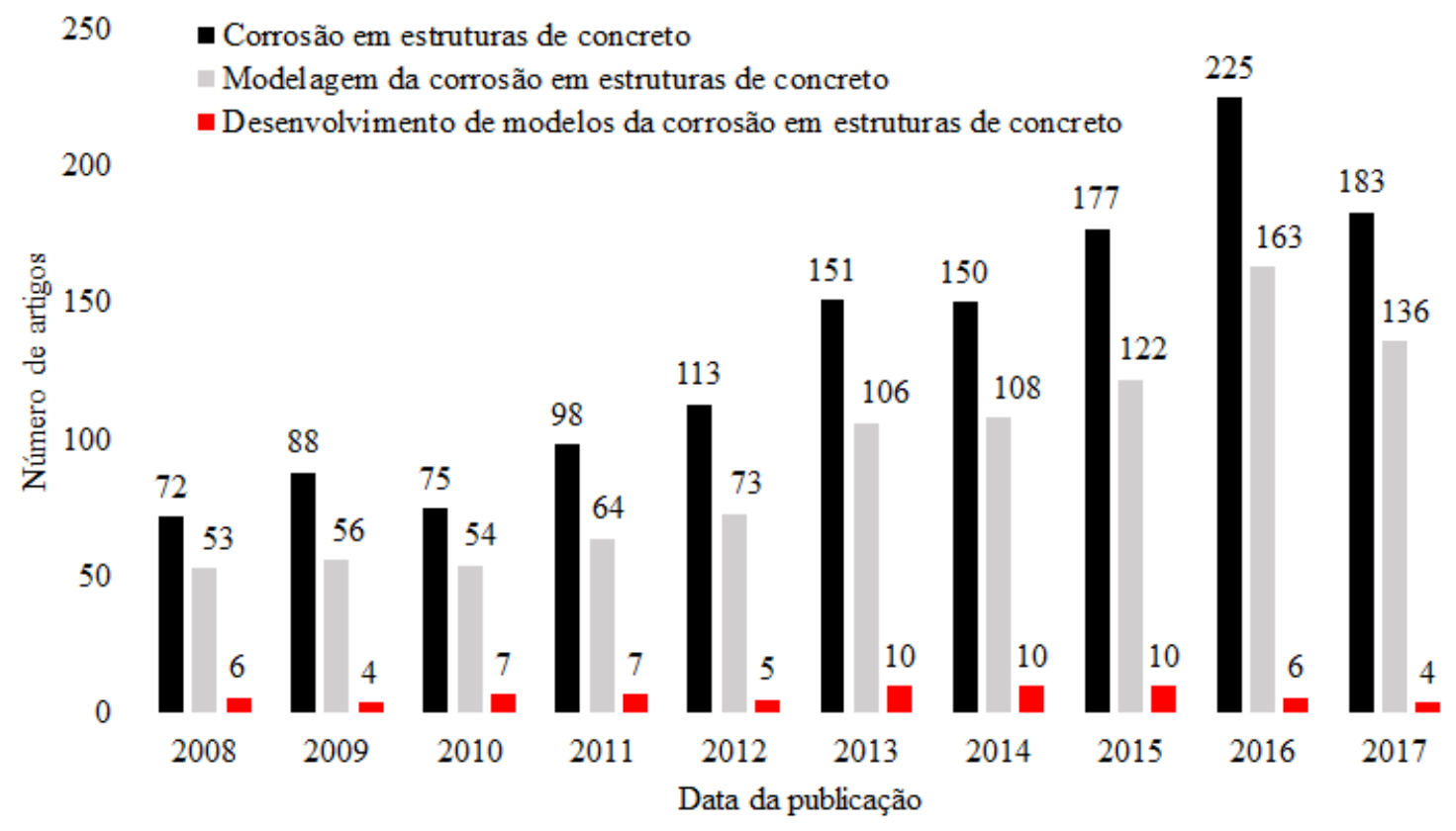

Figura 1.5 - Número de trabalhos publicados nos últimos 10 anos.

É possível observar na Figura 1.5 a quantidade de trabalhos desenvolvidos a cada ano, considerando diferentes temáticas relacionadas à corrosão (estudos gerais, modelagem e desenvolvimento de modelos) e, que a maior parte dos trabalhos desenvolvidos se referem à modelagem de estruturas submetidas à corrosão (69,9\% dos trabalhos). Nota-se ainda que uma pequena quantia destes trabalhos, $5,8 \%$, possuem como escopo o desenvolvimento de modelos para a representação da corrosão em estruturas de concreto, demonstrando assim, a carência de estudos na área e, consequentemente, a relevância da presente dissertação.

$\overline{5}$ Análise feita por meio do banco de dados do ScienceDirect e do portal de periódicos da CAPES, acesso em novembro de 2017. 


\subsection{Objetivos}

\subsubsection{Objetivo geral}

O presente trabalho tem como principal objetivo o desenvolvimento de um código computacional baseado no método dos elementos finitos posicional (MEFP) para modelar a deformação do concreto armado decorrente da formação dos produtos de corrosão devido à corrosão uniforme.

\subsubsection{Objetivos específicos}

- Desenvolver um código baseado no (MEFP), com elementos finitos do tipo chapa, para a análise não-linear geométrica de sólidos elásticos bidimensionais;

- Implementar elementos finitos do tipo barra simples (fibras) e chapa (partículas) e acoplá-los ao código anterior, de forma que o mesmo possibilite a análise não-linear geométrica de sólidos compósitos, em especial, elementos de concreto armado;

- Implementar e acoplar ao código anterior um modelo representativo do processo de corrosão uniforme de armaduras (fase de propagação), considerando tanto a formação dos produtos de corrosão quanto a perda de massa do aço;

- Simular e analisar a deformação de elementos de concreto armado quando submetidos ao processo de corrosão uniforme.

\subsection{Metodologia}

Para o desenvolvimento do presente trabalho, a metodologia foi dividida em seis partes, sendo: (i) levantamento bibliográfico; (ii) desenvolvimento de um código computacional baseado no método dos elementos finitos posicional; (iii) implementação e acoplamento de elementos finitos de fibras e partículas; (iv) implementação de um modelo representativo da formação dos produtos de corrosão; (v) seleção de exemplos para a validação dos modelos gerados; (vi) desenvolvimento de artigos.

A seguir, apresenta-se de forma detalhada a metodologia seguida no trabalho:

i Levantamento bibliográfico: esta etapa estendeu-se por todo o período de desenvolvimento do trabalho, uma vez que serve de base para todas as outras etapas da pesquisa. É no levantamento que foram colhidos dados relacionados ao tema da pesquisa, possibilitando alcançar os objetivos almejados;

ii Desenvolvimento de um código computacional baseado no método dos elementos finitos posicional: nesta etapa foi implementado em linguagem Fortran um programa para a simulação de elementos bidimensionais do tipo chapa. O programa 
foi desenvolvido com base no método dos elementos finitos posicional (MEFP), usando a relação constitutiva de Saint-Venant-Kirchhoff para materiais elásticos não lineares. O desenvolvimento do código computacional ocorreu concomitantemente à disciplina: SET5884 Introdução à Dinâmica Não Linear de Estruturas Reticuladas Bidimensionais - Uma abordagem Energética Baseada no Método dos Elementos Finitos, oferecida pelo departamento de Engenharia de Estruturas (SET/EESC USP) e ministrada pelo professor Titular Humberto Breves Coda;

iii Implementação e acoplamento de elementos finitos de fibras e partículas: nesta fase foram implementados os elementos finitos para a representação de fibras e partículas. As fibras são representadas por elementos de barra simples, também denominados barras de treliça $2 D$. As partículas são representadas por elementos finitos triangulares com ordem cúbica de aproximação para as suas posições nodais. Em seguida realizou-se o acoplamento dos elementos finitos do tipo fibra e partícula no programa de chapa (elemento finito para a representação da matriz). Para o correto acoplamento utilizou-se a técnica de embutimento adotada por Vanalli (2004), Sampaio, Coda e Paccola (2011), Sampaio (2014), Nogueira et al. (2014), Moura (2015) e Paccola e Coda (2016), o qual consiste na inserção das posições nodais das fibras/partículas sobre as dos elementos finitos de chapa (matriz), onde estão inseridas;

iv Implementação de um modelo representativo da formação dos produtos de corrosão: para a análise dos efeitos da corrosão das armaduras imersas no concreto, foram desenvolvidas e implementadas diferentes técnicas numéricas para a representação da formação dos produtos de corrosão, assim como da perda de massa do aço;

v Seleção de exemplos para a validação dos modelos gerados: durante a revisão bibliográfica foram selecionados exemplos da literatura para validar e analisar o desempenho dos códigos desenvolvidos nas fases ii, iii e iv. Atenção especial é dada às validações finais, referentes à simulação da corrosão (fase iv). Após a validação dos códigos desenvolvidos (com resultados conhecidos pela literatura ou por meio de modelos analíticos), elementos de concreto armado sob corrosão foram modelados, de forma a analisar os efeitos da corrosão uniforme na deformação do concreto;

vi Desenvolvimento de artigos: ao longo do desenvolvimento da dissertação artigos foram desenvolvidos e submetidos para apresentação em congressos e publicação em revistas, a fim de trocar informações com outros pesquisadores da área e disseminar os resultados aqui encontrados. 


\subsection{Organização da dissertação}

Esta dissertação está organizada em oito capítulos, abordando temas referentes à mecânica do contínuo, método dos elementos finitos posicional e corrosão das armaduras do concreto armado.

Ao longo do capítulo dois, a definição da corrosão e suas generalidades são apresentadas, descrevendo como ocorre o processo de corrosão de armaduras e quais os mecanismos que a iniciam e permitem a sua progressão. Ao final do capítulo são descritos os principais modelos para a obtenção da taxa de avanço da corrosão e os modelos representativos da formação dos produtos de corrosão.

No capítulo três são apresentados conceitos referentes à mecânica não linear do contínuo, introduzindo os elementos necessários para o entendimento da formulação utilizada no trabalho.

Conceitos e formulações que subsidiam a modelagem do comportamento estrutural de elementos compósitos, especialmente o concreto armado, são apresentados no capítulo quatro. Inicialmente é apresentada e definida a formulação referente o método dos elementos finitos posicional (MEFP). Em seguida, descrevem-se os elementos finitos implementados no trabalho, a saber, o linear (do tipo barra simples) e o plano (do tipo chapa). No final do capítulo são apresentadas as estratégias utilizadas para o acoplamento das fibras e/ou partículas na matriz.

No capítulo cinco são apresentados exemplos numéricos a fim de validar as formulações implementadas e demonstrar as suas potencialidades.

No capítulo seis são descritas as formulações e técnicas numéricas utilizadas e implementadas para representar a formação dos produtos de corrosão.

No sétimo capítulo são apresentados exemplos com o propósito de demonstrar a eficiência do código desenvolvido para a modelagem da corrosão uniforme em estruturas de concreto amardo.

Compondo a parte final da dissertação, o capítulo oito apresenta as conclusões obtidas durante o desenvolvimento do trabalho e sugere tópicos para futuras pesquisas. 
CAPÍTULO

\section{CORROSÃO DO AÇO NO CONCRETO}

Neste capítulo o processo de corrosão do aço imerso em estruturas de concreto é explorado, descrevendo os principais mecanismos que levam ao surgimento e desenvolvimento desta manifestação patológica, descrevendo ainda, os efeitos da corrosão sobre o comportamento mecânico do concreto armado.

\subsection{Considerações iniciais}

Com o surgimento do concreto armado em meados do século XIX, houve um significativo acréscimo da utilização do concreto como material construtivo e estrutural. A alta capacidade à tração e a ductilidade do aço transformaram o concreto em um material que até aquele momento só poderia receber grandes cargas de compressão, noutro com a capacidade de receber grandes cargas quando submetido à flexão e, em algumas aplicações, sob tensão direta (RIBEIRO; CUNHA; HELENE, 2015).

Mesmo o concreto armado apresentando-se como um material compósito de grande aplicabilidade e capacidade portante, o mesmo possui desvantagens sob ambientes agressivos, já que estes propiciam o surgimento de diversos mecanismos de deterioração, sejam eles: físicos (retração, fissuras térmicas, gelo-degelo, abrasão e erosão) ou químicos (ataque de sulfatos, reação álcali-agregado, ataque de ácidos e corrosão) (MEHTA; MONTEIRO, 2014). Assim, uma das desvantagens da utilização do aço como material estrutural, é a sua susceptibilidade ao fenômeno da corrosão (RIBEIRO; CUNHA; HELENE, 2015).

A corrosão é caracterizada pela perda de material da superfície de um metal e apresenta-se como um mecanismo de deterioração do reforço quando imerso no concreto. A perda de material tem como consequência direta a redução da capacidade portante do concreto armado (TAFFESE; SISTONEN, 2013; KARI; PUTTONEN; SKANTZ, 2014; RIBEIRO; CUNHA; HELENE, 2015). 
Como a degradação do aço devido à corrosão está relacionada à vida útil de estruturas de concreto armado, a durabilidade do material compósito torna-se função de vários parâmetros, como, por exemplo, de características do projeto, dos materiais, da agressividade do ambiente em que está inserido, das condições de uso, entre outros.

\subsection{Princípios da corrosão}

A corrosão pode ser entendida como uma transformação não intencional de um material metálico a partir das suas superfícies em contato com a atmosfera, em compostos não aderentes, solúveis no mesmo ambiente (BAUER, 2005).

Em geral, a corrosão é um fenômeno natural que se desenvolve ao longo do tempo, onde o material tende a regressar a sua forma original (forma disponível na natureza), e espontâneo, correspondendo a uma redução do estado de energia, buscando a estabilidade do material. Essa redução é conhecida como redução da energia de Gibbs (RIBEIRO; CUNHA; HELENE, 2015).

De acordo Helene (1986) e Cascudo (1997) a deterioração das armaduras presentes em estruturas de concreto armado ocorre de duas formas, por oxidação (conhecida por corrosão química) e/ou por corrosão (conhecida por corrosão eletroquímica).

A corrosão sofrida pelas armaduras devido ao processo de oxidação é provocada pela reação gás-metal que dá origem a uma película de óxido que envolve o elemento metálico (RIBEIRO; CUNHA; HELENE, 2015). Este tipo de corrosão possui um processo de evolução lento, quando em ambiente de exposição à temperatura ambiente $\left( \pm 25^{\circ} \mathrm{C}\right)$, salvo em condições de exposição de agressividade severa, ou na presença de gases extremamente agressivos presentes na atmosfera (HELENE, 1986).

A corrosão que ocorre nas armaduras de aço caracteriza-se pela transferência de elétrons e íons entre duas regiões distintas do metal, sendo esta denominada de corrosão eletroquímica (STREHBLOW; MARCUS, 1995). Segundo Ribeiro, Cunha e Helene (2015) a corrosão eletroquímica ocorre devido à formação de uma película de eletrólito envolvendo os metais, desenvolvendo-se preferencialmente em meio aquoso.

\subsubsection{Reações eletroquímicas}

Os materiais metálicos e cerâmicos estão suscetíveis em toda sua vida ao processo de degradação por corrosão, o qual é definido pela dissolução do material, consequência de reações químicas de redução e oxidação.

De acordo com Ribeiro, Cunha e Helene (2015), a corrosão eletroquímica fundamentase na interação entre um agente oxidante (i.e., o oxigênio e/ou hidrogênio) e o aço. Ao entrar em contato com a superfície de um metal, elétrons são doados ao material metálico de forma a ocorrer reações de redução. 
Os elétrons que são consumidos pela ação de redução (na região catódica) são transportados e doados pela reação de oxidação (na região anódica), tornando o meio metálico um agente de transferência de elétrons (STREHBLOW; MARCUS, 1995).

Assim, quando o metal sofre oxidação, dá-se inicio o processo de desprendimento de compostos da estrutura metálica, resultando na dissolução do metal e, consequentemente, na perda de massa (GENTIL, 2011).

As Equações 2.1 - 2.6 descrevem as reações básicas que são desencadeadas em um processo de corrosão eletroquímica (RIBEIRO; CUNHA; HELENE, 2015).

$$
\begin{aligned}
& M \rightarrow M^{n+}+n e \\
& \frac{n}{4 \mathrm{O}_{2}}+\frac{n}{2 \mathrm{H}_{2} \mathrm{O}}+n e \rightarrow n \mathrm{OH}^{-} \\
& \frac{n}{4 \mathrm{O}_{2}}+n H^{+}+n e \rightarrow \frac{n}{2 \mathrm{H}_{2} \mathrm{O}} \\
& n \mathrm{H}^{+}+n e \rightarrow \frac{n}{2 \mathrm{H}_{2}} \\
& n \mathrm{H}_{2} \mathrm{O}+n e \rightarrow \frac{n}{2 \mathrm{H}_{2}}+\mathrm{OH}^{-} \\
& \mathrm{Cl}_{2}+2 e \rightarrow 2 \mathrm{Cl}^{-}
\end{aligned}
$$

em que $n$ representa o termo de balanceamento das reações.

A Equação 2.1 representa uma reação anódica de um metal $(M)$. Já as Equações 2.2 - 2.6, representam reações catódicas, sendo: Equação 2.2, uma redução de oxigênio em um meio neutro alcalino; Equação 2.3, uma redução do oxigênio em meio ácido; Equação 2.4, uma redução do íon $H^{+}$meio ácido não aerado; Equação 2.5, uma redução do $H^{+}$em meio neutro não aerado; e Equação 2.6, uma redução do $C l_{2}$.

Em armaduras de estruturas de concreto a reação anódica se caracteriza pela oxidação do ferro (geração de elementos de ferrugem), já a catódica pela redução de oxigênio no concreto (GENTIL, 2011).

De acordo com Ribeiro, Cunha e Helene (2015) em uma superfície metálica se encontram muitas microrregiões anódicas e catódicas, que levam à geração de uma grande quantidade de pilhas eletroquímicas, sendo estas responsáveis por transportar elétrons e acelerar o processo de corrosão. A Figura 2.1 representa esquematicamente a formação de pilhas eletroquímicas na superfície metálica de uma armadura imersa no concreto.

Ribeiro, Cunha e Helene (2015) relatam para que ocorra a corrosão é necessário a existência de três elementos básicos: o eletrólito (meio contendo íons livres), a pilha eletroquímica (diferença de potencial) e o oxigênio.

Para Helene (1986), além dos três elementos citados (eletrólito, pilha e oxigênio), 
deve-se verificar a existência de agentes agressivos (íons de sulfetos $\left(S^{2-}\right)$, nitritos $\left(\mathrm{NO}^{3-}\right)$, íons de cloreto $\left(\mathrm{Cl}^{-}\right)$, dióxido de carbono $\left(\mathrm{CO}_{2}\right)$, gás sulfídrico $\left(\mathrm{H}_{2} \mathrm{~S}\right)$, fuligem, etc), que podem acelerar o processo corrosivo devido a um aumento significativo da condutividade elétrica do eletrólito.

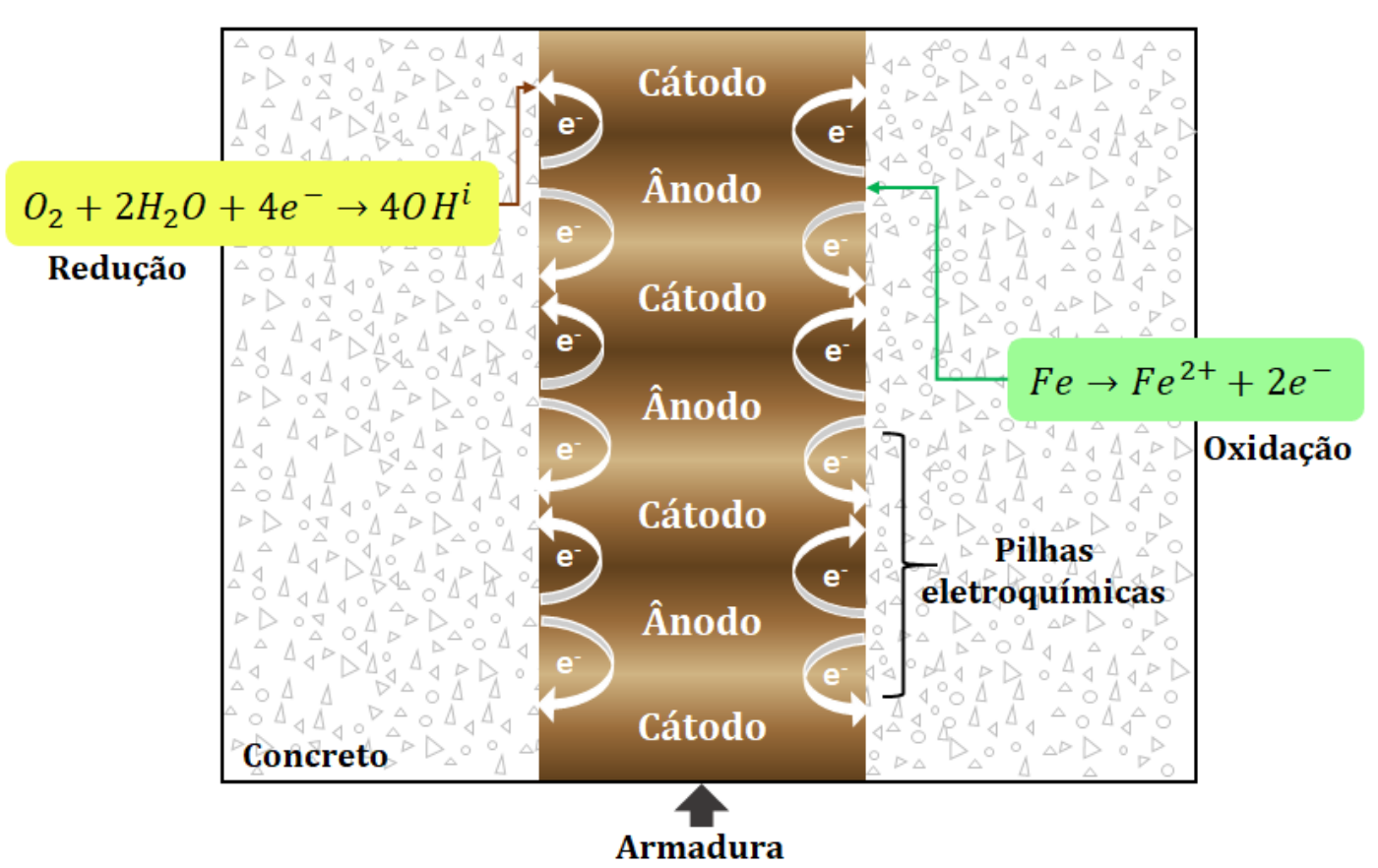

Figura 2.1 - Representação esquemática do processo de corrosão eletroquímica.

Em ambiente marítimo, a quantidade de íons de cloretos o torna o principal responsável pelo processo de corrosão em armaduras. Já no meio urbano, o agente agressivo que mais contribuí para a corrosão é o dióxido de carbono, sendo intensificada a sua presença em locais com maior movimentação de veículos, i.e., garagens, túneis e ambientes próximos às vias de transporte (MARTINS, 2011).

Deste modo, a corrosão de armaduras presentes em estruturas de concreto pode ser classificada em função do agente agressivo que difunde no concreto e ataca o metal. De acordo com Ribeiro, Cunha e Helene (2015) quando a corrosão é iniciada devido à difusão de íons de cloretos, a mesma é classificada de corrosão por pites. Já a corrosão iniciada pela penetração de $\mathrm{CO}_{2}$ é classificada como corrosão uniforme.

A corrosão uniforme, como o nome sugere, ocorre de forma uniforme em toda a armadura (Figura 2.2b). Já a corrosão por pites ocorre de forma não linear e o seu desenvolvimento se dá em regiões localizadas da armadura (Figura 2.2a). Por isso também é denominada de corrosão localizada.

Existem alguns casos em que a corrosão pode ocorrer tanto por carbonatação quanto pela difusão de cloretos. No entanto o progresso da corrosão é definido em função da proporção de cada um dos agentes agressivos presente no ambiente. 


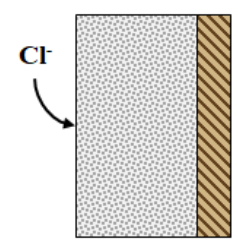

Difusão de $\mathrm{Cl}$

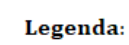

Concreto

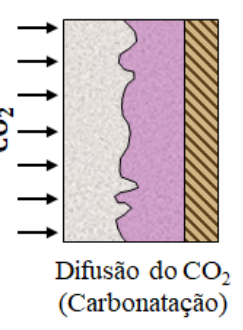

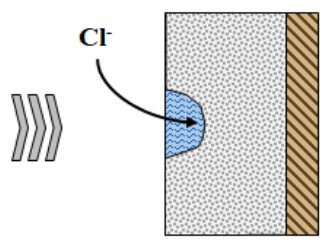

Avanço da difusão dos cloretos

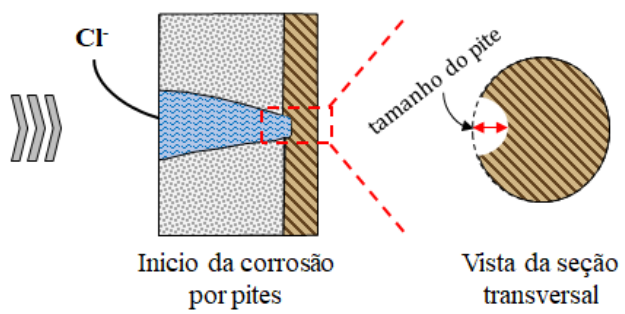

MArmadura Fi

(a) Corrosão localizada (por pites).

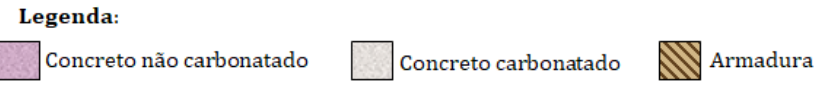

(b) Corrosão uniforme (por carbonatação).

Figura 2.2 - Desenvolvimento da corrosão em função do agente agressivo.

De acordo com Meira et al. (2003) e Mehta e Monteiro (2014) a ocorrência da corrosão devido à ação combinada de íons de cloretos e dióxido de carbono se dá, sobretudo, em regiões marítimas e, que a corrosão por carbonatação torna-se preponderante à medida em que a estrutura se distancia do mar.

Diante do exposto, faz-se necessário conhecer os mecanismos de transporte no concreto, referentes aos agentes agressivos presentes na atmosfera. A seguir são descritos os principais mecanismos, dando ênfase à penetração do $\mathrm{CO}_{2}$ e do $\mathrm{Cl}^{-}$.

\subsubsection{Mecanismos de transporte no concreto}

O concreto armado quando bem executado passa a ser a principal proteção das armaduras quanto à corrosão. A espessura de cobrimento da armadura é um fator importante de controle quanto a movimentação dos íons agressivos presentes na atmosfera, uma vez que ao se aumentar a camada de cobrimento da armadura, aumenta-se o intervalo de tempo em que os agentes agressivos externos atinjam internamente o aço, aumentando sua resistividade à corrosão.

Ribeiro, Cunha e Helene (2015) relatam que o correto cobrimento das armaduras com um concreto de alta compacidade, de composição homogênea e adequada, garante por impermeabilidade a proteção do aço ao ataque de diferentes agentes agressivos externos.

Mehta e Monteiro (2014) descrevem que um cobrimento adequado deve ser dado às armaduras do concreto armado, evitando a formação de células eletroquímicas, graças 
a proteção física e química, e principalmente devido à alta alcalinidade ( $\mathrm{pH}$ entre $12 \mathrm{e}$ 13,5) da matriz pasta-agregados.

Assim, percebe-se que existe uma relação entre a corrosão e o concreto de cobrimento das armaduras. A impermeabilidade do concreto é a principal característica de análise na determinação do grau de proteção das armaduras de um elemento armado. O desempenho do concreto armado frente à corrosão passa a ser função da distribuição e do tamanho dos poros (a impermeabilidade é correlacionada à porosidade da matriz pasta-agregados) (MEHTA; MONTEIRO, 2014) .

Mehta e Monteiro (2014) relatam que ao ultrapassar a quantidade de água necessária para a hidratação do cimento, vazios são produzidos, e em conjunto com um mau adensamento, uma conectividade dos vazios é produzida, gerando caminhos microscópicos dentro do concreto, que facilitam a penetração de diferentes agentes agressivos presentes no ambiente.

A existência de caminhos internos na matriz pasta-agregados conduz à necessidade em se conhecer os diferentes mecanismos de transportes de líquidos e gases no concreto, destacando-se neste texto os influentes no fenômeno da corrosão por carbonatação, por exemplo, a permeabilidade, a absorção capilar e a difusão de $\mathrm{CO}_{2}$.

\subsubsection{Permeabilidade}

De acordo com Ribeiro, Cunha e Helene (2015), a permeabilidade pode ser definida como o fluxo de um líquido devido a um gradiente de pressão, caracterizando-se pela facilidade em que o mesmo tem em fluir em um sólido poroso sob um diferencial de pressão.

A permeabilidade do concreto (não estando fissurado) é geralmente determinada em função da permeabilidade da pasta de cimento, a qual é dependente da relação água/cimento e do grau de hidratação (HELENE, 1986).

Os gases apresentam diferentes velocidades de penetração em um mesmo meio sólido (i.e., concreto), por exemplo, o oxigênio penetra mais rápido que o $\mathrm{CO}_{2}$. O dióxido de carbono aparenta não penetrar no concreto além da profundidade carbonatada, sendo lento o avanço desta camada ao longo do tempo, uma vez que sua permeabilidade diminui com a carbonatação do concreto, que tende a preencher os poros capilares.

Já a difusão dos cloretos no concreto ocorre de forma indireta, diferente do gás carbono. A penetração dos cloretos se dá através da penetração de água, na qual esses encontram-se dissolvidos (SANTOS, 2006).

A permeabilidade do concreto aos gases é altamente dependente do ambiente de exposição, uma vez que a mesma é função da umidade relativa do ar. Helene (1986) descreve que em ambientes secos $(U R<80 \%)$, ou submetidos a ciclos de secagem e umedecimento, a profundidade de carbonatação é maior que em ambientes úmidos $(U R>80 \%)$. 


\subsubsection{Absorção capilar}

O transporte de fluídos devido à tensão superficial atuante nos poros capilares do concreto recebe o nome de absorção capilar. O mesmo pode ainda ser definido como o fluxo de líquidos devido ao gradiente de umidade (MARTYS; FERRARIS, 1997).

No concreto a absorção de água é um dos fatores mais difíceis de se controlar. Em geral, quanto menor o diâmetro dos capilares, maiores serão as pressões capilares, tornando mais rápida e maior a absorção.

Helene (1986) relata que a redução na relação a/c contribui na redução da absorção de água do concreto. Porém para Ribeiro, Cunha e Helene (2015) a medida em que o concreto se torna mais denso e compacto (menor a/c), diminuindo o diâmetro dos capilares, a intercomunicação dos poros pode se tornar maior, e consequentemente aumentar a absorção de água. E em concretos porosos a absorção é baixa, tendo problemas insuperáveis de permeabilidade e carbonatação.

A saturação do elemento de concreto também deve ser analisada, uma vez que em concretos saturados a absorção de água passa a ser nula, e assim, caso não existam pressões externas, será nulo também o ingresso de agentes agressivos por meio da absorção.

\subsubsection{Difusão}

Os dois principais agentes agressivos que comprometem as armaduras, o cloreto e o dióxido de carbono, possuem sua penetração controlada pela difusão. A penetração de oxigênio, substância básica para o progresso do processo catódico, também é governada pela difusão (SANTOS, 2006). Em alguns casos é o único responsável pela corrosão.

Este mecanismo ocorre devido a uma diferença de potencial químico, muitas vezes da concentração de uma substância em um meio, assim a mesma é transportada para outro local com menor concentração.

A difusão se dá por dois diferentes estágios de fluxo, o estacionário e o não estacionário. O estágio estacionário corresponde ao fluxo constante de substâncias em difusão, já o não estacionário é caracterizado por um fluxo dependente do tempo e da profundidade de penetração (RIBEIRO; CUNHA; HELENE, 2015). Os dois estágios são representados pela primeira e segunda lei de Fick, sendo o estacionário representado pela primeira lei (Equação 2.7) e a segunda lei para o não estacionário (Equações 2.8 e 2.9), também denominado coeficiente de difusão aparente. Comenta-se que as Equações 2.7, 2.8 e 2.9 são válidas como solução para um sólido semi-infinito.

$$
\begin{aligned}
& q=-D \nabla C \\
& \frac{\partial C}{\partial t}=-D \frac{\partial^{2} C}{\partial^{2} x}
\end{aligned}
$$




$$
C(x, t)=C_{s}\left(1-\operatorname{erf} \frac{x}{2 \sqrt{D t}}\right)
$$

em que $q_{m}$ representa o fluxo de massa, $x$ é a profundidade onde deseja-se conhecer a quantidade da substância que penetrou, $C$ é a concentração, $D$ é o coeficiente de difusão, $C(x, t)$ é a concentração de uma sustância a uma dada profundidade $(x)$ e em um determinado tempo $(t)$ e $C_{s}$ é a concentração superficial em difusão.

Helene (1993) declara as variáveis que influenciam no coeficiente de difusão, sendo elas: a porosidade, a relação água/cimento, o teor de cimento, a composição química do cimento, a umidade relativa do ambiente de exposição do concreto e a temperatura.

Quanto a difusão de $\mathrm{CO}_{2}$, Santos (2006) verificou que este gás se dissolve na solução aquosa dos poros reagindo com o hidróxido de cálcio (devido a hidratação do cimento), abaixando o pH do concreto (inicialmente entre 13 e 12,5), tornando a armadura despassivada (sem o filme passivo) e suscetível à corrosão.

Com o crescente desenvolvimento das cidades e a tendência mundial de aumento das emissões de $\mathrm{CO}_{2}$ na atmosfera, a corrosão por carbonatação tem sua incidência alavancada em estruturas de concreto armado (POSSAN, 2010). Isso porque a velocidade de carbonatação aumenta com a elevação do teor de $\mathrm{CO}_{2}$ no meio ambiente, afetando o ciclo de vida das estruturas e a durabilidade das mesmas, sendo necessário conhecer e entender o mecanismo de corrosão por carbonatação, o qual é escopo do presente trabalho.

\subsection{Corrosão por carbonatação}

A carbonatação é um fenômeno físico-químico que provoca alterações no concreto, por exemplo, redução da permeabilidade e da alcalinidade e, no concreto armado propicia a corrosão das armaduras (NEVILLE, 1997).

A carbonatação é descrita pela reação entre os produtos de hidratação de cimento no concreto $\left(\mathrm{Ca}(\mathrm{OH})_{2}\right)$ e o $\mathrm{CO}_{2}$, resultando na formação do carbonato de cálcio $(\mathrm{CaCO} 3)$, conforme mostra a Figura 2.3. Ribeiro, Cunha e Helene (2015) relatam que o processo de carbonatação pode ser dividido em dois estágios: a dissolução do dióxido de carbono em água (capilar) e a reação dos produtos de dissolução com produtos de hidratação.

Um dos resultados desta reação é a redução do pH do meio, que despassiva o aço imerso no concreto, deixando a armadura suscetível à corrosão. Segundo Bakker (1988) o concreto à temperatura ambiente apresenta $\mathrm{pH}$ de aproximadamente 12,5, em virtude da presença de $\mathrm{Ca}(\mathrm{OH})_{2}$. Com a redução do teor de hidróxido de cálcio do interior dos poros da pasta de cimento hidratado e posterior transformação em carbonato de cálcio $\left(\mathrm{CaCO}_{3}\right)$ devido às reações de carbonatação, o pH é reduzido para aproximadamente 9 , o que pode ser prejudicial para a armadura imersa no concreto.

De acordo com Vesikari (1988) e Hamada (1968) a profundidade de carbonatação do concreto aumenta gradativamente com o tempo (Figura 2.3), em função da quantidade 
de $\mathrm{CO}_{2}$ ao qual está exposto, da porosidade e da proporção de hidróxido de cálcio livres para reagirem com o gás carbono. Assim, a frente de carbonatação está relacionada a vários parâmetros intrínsecos ao concreto e ao meio ambiente.

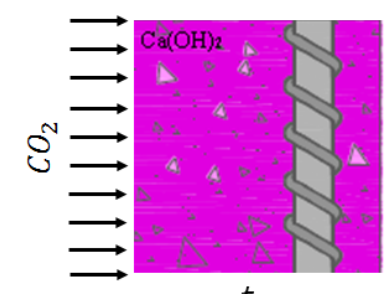

$t_{0}$

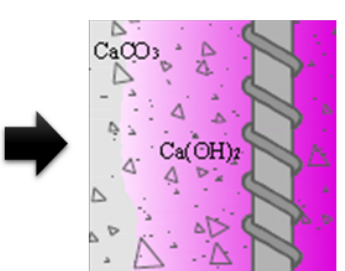

$t_{1}$

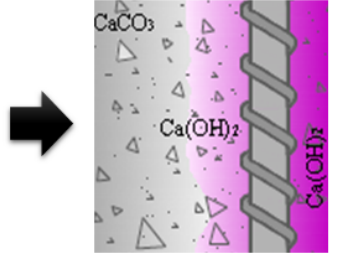

$t_{2}$

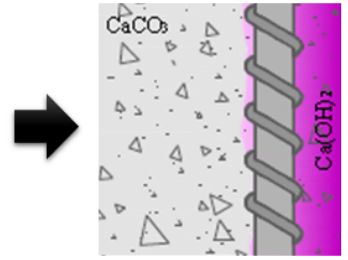

$t_{3}$

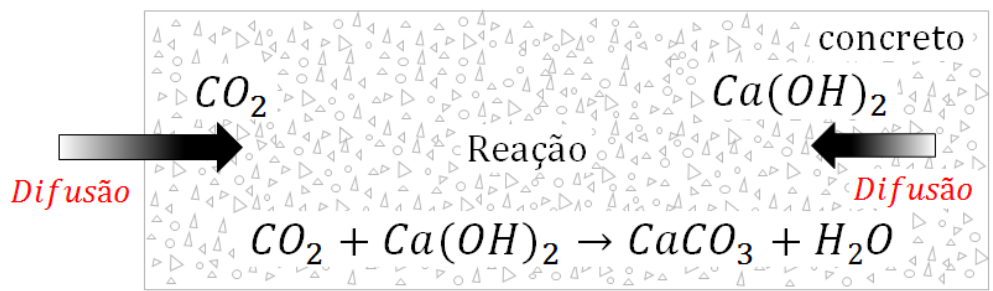

Legenda:

Zona não carbonatada

Zona parcialmente carbonatada

Zona carbonatada

Figura 2.3 - Esquematização da estrutura interna do concreto.

Fonte: Adaptado de Felix, Carrazedo e Possan (2017).

Estes fatores devem ser levados em consideração tanto no estudo do fenômeno da carbonatação quanto na corrosão iniciada por ela, considerando assim, a contribuição de todos os parâmetros correlacionados ao fenômeno.

\subsubsection{Fatores que influenciam na corrosão por carbonatação}

A corrosão por carbonatação se desenvolve uniformemente na seção transversal da armadura. O processo corrosivo ocorre a uma velocidade controlada pela taxa de corrosão, $i_{\text {corr }}$, sendo dependente de diversos fatores, sejam eles ambientais ou relativos a parâmetros relacionados às propriedades do concreto (BAKKER, 1988).

Parrott (1987) e Houst e Wittmann (2002) dividem os fatores que influenciam na carbonatação do concreto em duas categorias, internos e externos, sendo alguns deles representados esquematicamente na Figura 2.4.

Os principais fatores externos são a concentração de $\mathrm{CO}_{2}$ presente na atmosfera, a incidência de chuvas, a umidade relativa do ar e a temperatura. Quanto aos fatores internos, citam-se a relação água/cimento para a produção do concreto, a resistência à compressão do concreto, a espessura do concreto de cobrimento e a composição do concreto. 


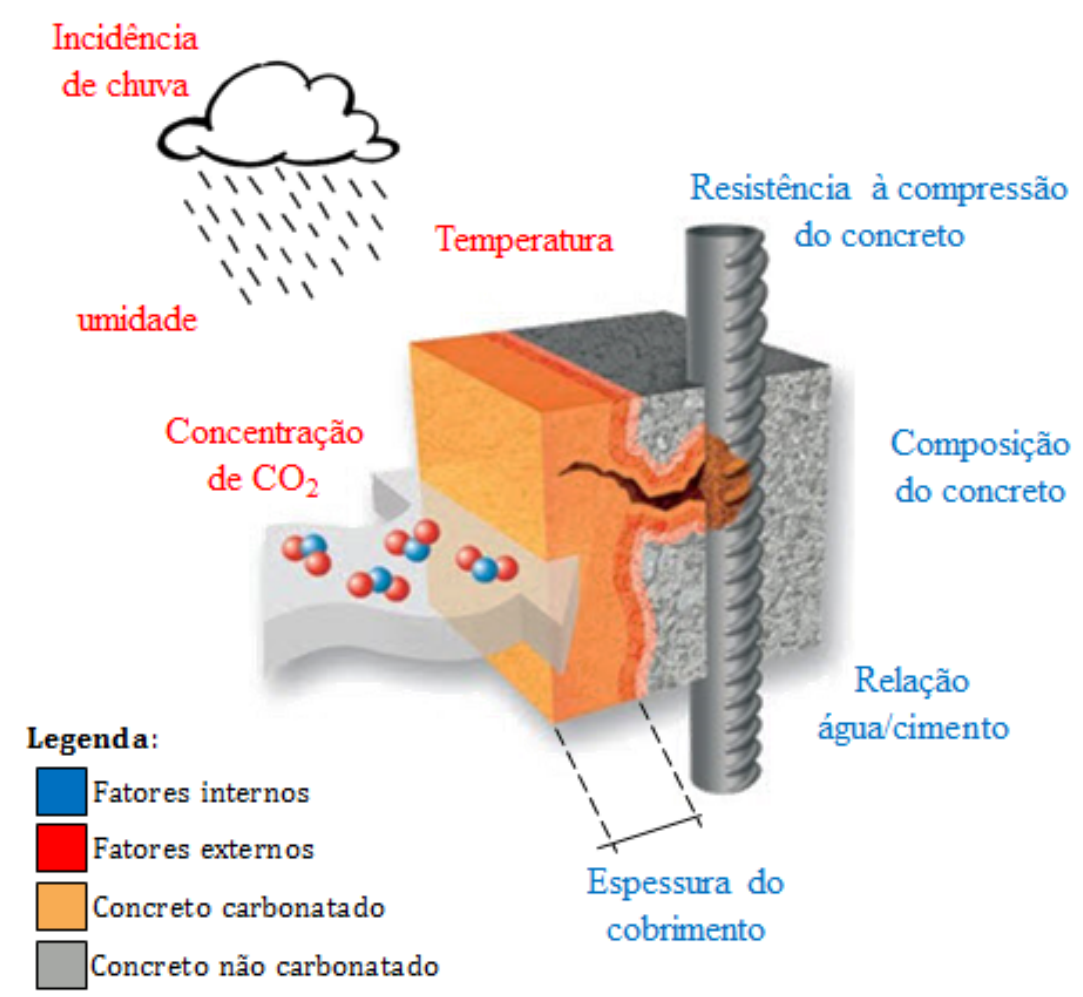

Figura 2.4 - Fatores que influenciam na corrosão por carbonatação.

\subsubsection{Umidade e incidência de chuvas}

A carbonatação possui relação direta com a umidade relativa do ar, uma vez que o ingresso de $\mathrm{CO}_{2}$ no interior da matriz cimentante ocorre principalmente pela difusão deste gás. Na difusão, a quantidade de água capilar funciona como veículo para o transporte de $\mathrm{CO}_{2}$ através da porosidade do concreto. Portanto, quando na presença de poros saturados ou secos, o processo de difusão encontra-se impedido, não havendo ingresso do dióxido de carbono.

Verbeck (1958) relata que a carbonatação está diretamente relacionada com a umidade, de modo que a camada de concreto carbonatado alcança valores máximos quando a umidade relativa do ambiente se situa dentro do intervalo de 50 a $70 \%$.

Felix, Carrazedo e Possan (2017) modelaram a carbonatação do concreto em função da umidade do ambiente. Os autores observaram que a carbonatação tem seu pico quando a umidade do ambiente encontra-se próxima a $60 \%$ (ver Figura 2.5), valor situado dentro do intervalo relatado por Verbeck (1958).

De acordo com Steffens, Dinkler e Ahrens (2002) a incidência de chuvas faz com que parte da água livre seja absorvida pela atmosfera e o restante penetre no concreto por capilaridade. Assim, durante os períodos de chuvas, concretos situadas em ambiente externo e em contato com a chuva, têm os seus poros totalmente saturados, dificultando a difusão de $\mathrm{CO}_{2}$. Porém, com a estiagem, parte da água livre é evaporada, facilitando a 
penetração do dióxido de carbono e potencializando a carbonatação.

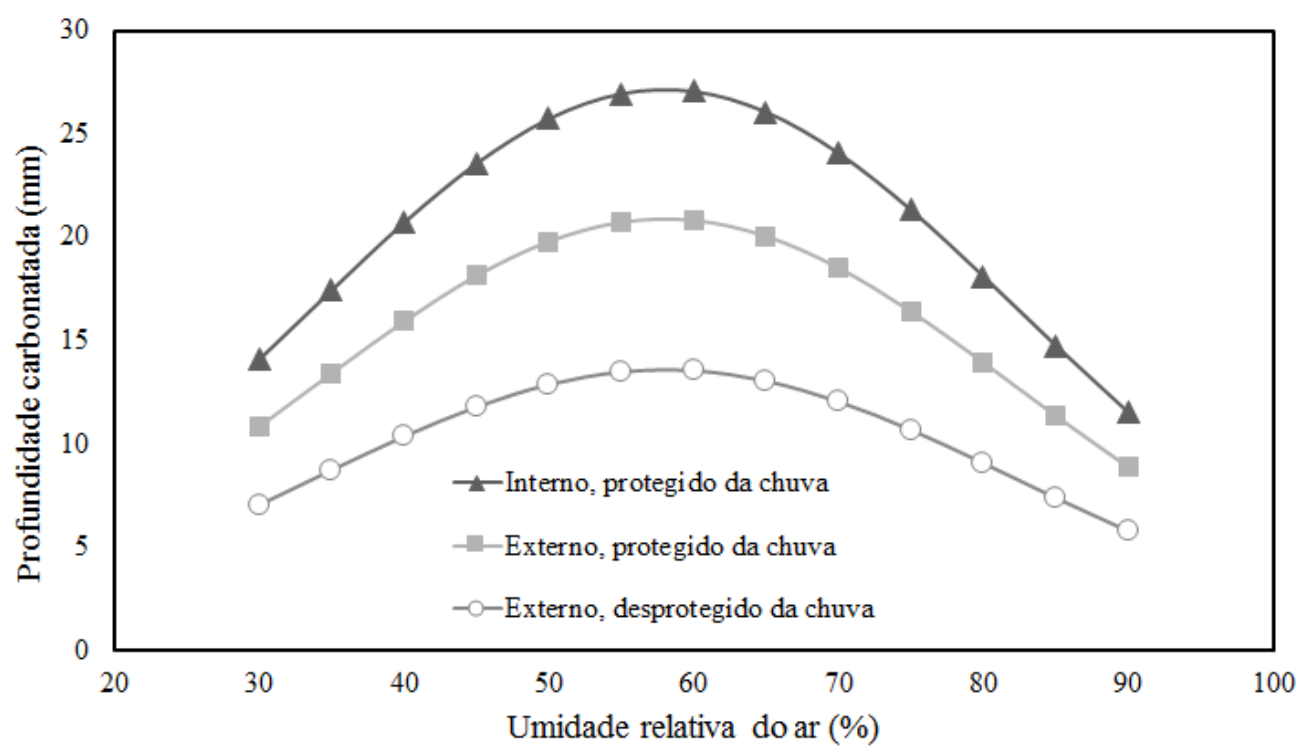

Figura 2.5 - Carbonatação em função da umidade e da exposição à chuvas.

Fonte: Felix, Carrazedo e Possan (2017).

Assim, pode-se dizer que a carbonatação tem seu desenvolvimento influenciado pelos níveis de saturação dos poros, e que quanto maior o contato direto entre o concreto e as precipitações, menor é a carbonatação do concreto Possan et al. (2017), conforme vê-se na Figura 2.5.

\subsubsection{Concentração de $\mathrm{CO}_{2}$}

A difusão de dióxido de carbono no concreto é governada pelos mecanismos de transporte de gases em meios sólidos, mecanismos estes já descritos neste capítulo. Graças a primeira lei de Fick (Equação 2.7), onde a penetração do $\mathrm{CO}_{2}$ é proporcional à diferença de concentração entre a atmosfera e o interior do concreto, ou entre a porção carbonatada e a não carbonatada, sabe-se que quanto maior é a diferença de concentração entre os dois meios analisados, maior é o potencial de carbonatação.

De acordo com Papadakis, Vayenas e Fardis (1991) e Helene (1993) o processo de corrosão por carbonatação é mais lento que o de corrosão por pites. Porém, em locais onde a concentração de $\mathrm{CO}_{2}$ é maior, i.e., regiões urbanas e zonas industriais, o processo de corrosão por carbonatação ocorre com maior intensidade (VERBECK, 1958).

Saetta e Vitaliani (2004) classificam os ambientes em ordem crescente em função da taxa de carbonatação: (i) ambientes costeiros; (ii) rurais; (iii) suburbanos; (iv) urbanos.

Na Figura 2.6 é apresentada a análise feita por Felix, Carrazedo e Possan (2017) da influência da concentração de $\mathrm{CO}_{2}$ no avanço da difusão do gás ao longo de 50 anos. As análises foram feitas para cinco diferentes ambientes de exposição. 


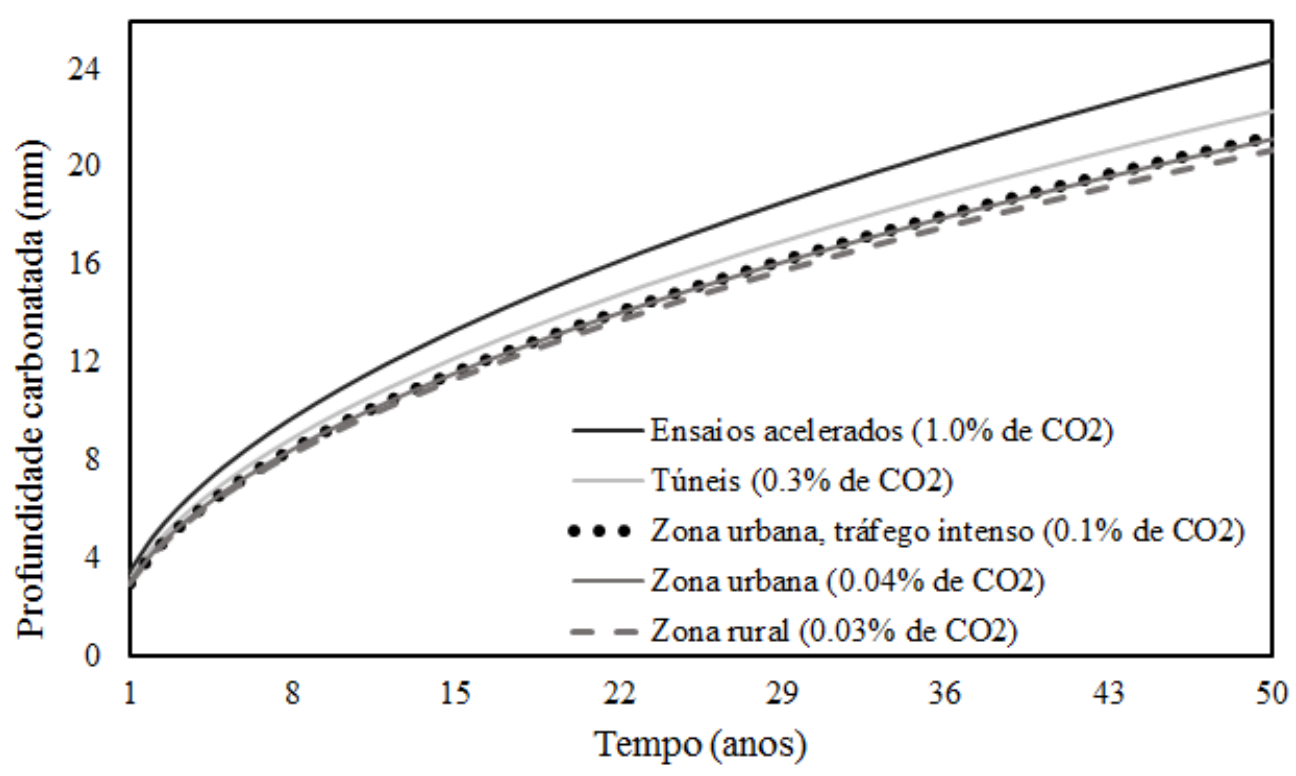

Figura 2.6 - Carbonatação em função da concentração de $\mathrm{CO}_{2}$.

Fonte: Felix, Carrazedo e Possan (2017).

Felix, Carrazedo e Possan (2017) comprovaram por meio de modelagens que quanto maior o grau de exposição ao $\mathrm{CO}_{2}$ maior é o avanço da carbonatação do concreto ao longo do tempo, e que o aumento de $0,1 \%$ na concentração de $\mathrm{CO}_{2}$ no ambiente, provoca um avanço de $2,15 \%$ na profundidade carbonatada.

\subsubsection{Temperatura}

Como mencionado anteriormente, a carbonatação é controlada pela difusão dos gases em um meio sólido, e o coeficiente de difusão é dependente da temperatura, sendo esta dependência descrita por meio da equação de Arrhenius (Equação 2.10).

$$
k=A e^{-E_{a} / R T}
$$

em que $k$ representa a taxa de transporte do $\mathrm{CO}_{2}$ dentro dos poros do concreto, $A$ é uma constante, $E_{a}$ é a energia de ativação para a difusão $(\mathrm{J} / \mathrm{mol}), R$ é a constante dos gases ( $J / K$ mol) e $T$ é a temperatura $(K)$.

Dessa forma, à medida em que a temperatura aumenta, pode-se esperar que a taxa de transporte do dióxido de carbono também aumente (DYER, 2015). Entretanto, com o aumento da temperatura, a solubilidade do hidróxido de cálcio diminui, reduzindo a taxa de reação da carbonatação. Liu et al. (2001) relatam que a redução da solubilidade, e consequentemente da reação de carbonatação, ocorre para temperaturas acima dos $60^{\circ} \mathrm{C}$.

De acordo com Papadakis, Vayenas e Fardis (1991) a influência da temperatura na difusão de $\mathrm{CO}_{2}$ é relativamente baixa, como mostra a Figura 2.7. A Figura 2.7 apresenta a profundidade de carbonatação de um concreto exposto por 5 dias a uma atmosfera com 
$50 \%$ de $\mathrm{CO}_{2}$, com uma umidade relativa de $65 \%$ em função da temperatura.

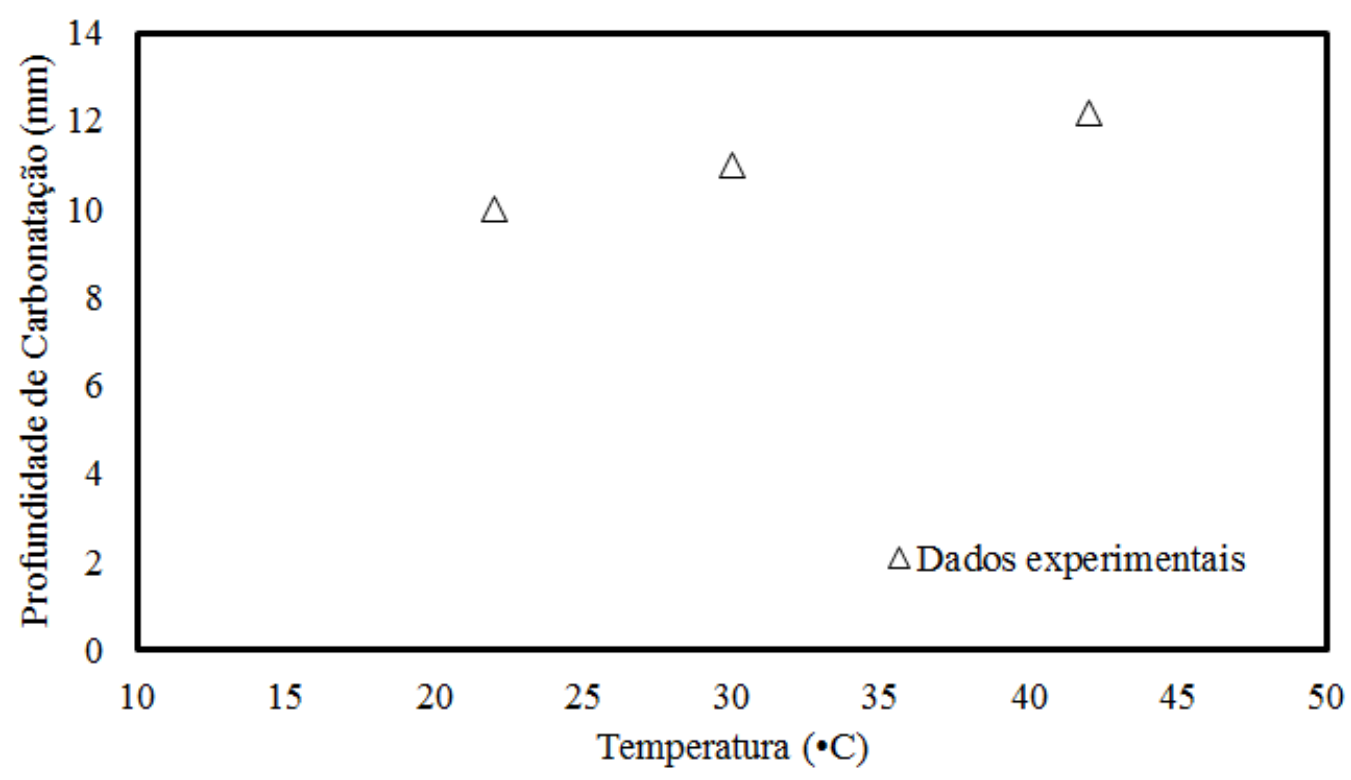

Figura 2.7 - Profundidade de carbonatação em função da temperatura.

Fonte: Adaptado de Papadakis, Vayenas e Fardis (1991).

Kazmierczak (1995) relata que a frente de carbonatação está diretamente relacionada à temperatura, uma vez que esta influencia na existência de vapor d'água ou na saturação dos poros capilares, item fundamental para que haja o transporte do $\mathrm{CO}_{2}$ na matriz de concreto.

\subsubsection{Composição do concreto}

A utilização de elevados teores de adições pozolânicas densifica a matriz de concreto, reduzindo a porosidade capilar do mesmo. Porém as adições podem vir a consumir o hidróxido de cálcio $\mathrm{Ca}(\mathrm{OH})_{2}$, reduzindo o pH da solução dos poros e propiciando a difusão do dióxido de carbono no concreto de forma acelerada.

Para concretos com resistências à compressão inferiores a $40 \mathrm{MPa}$, as adições possuem efeitos negativos na carbonatação já que aumenta a frente de propagação da mesma, pois, o efeito da reserva alcalina se prepondera sobre a densificação da porosidade (POSSAN, 2010).

Jiang, Lin e Cai (2000) verificaram a existência de uma influência negativa de adições no avanço da frente de carbonatação, devido à redução da reserva alcalina do concreto quando produzidos com cimentos Portland do tipo $\mathrm{CP} \mathrm{III}^{1} \mathrm{e} \mathrm{CP}^{\mathrm{IV}}{ }^{2}$, os quais possuem elevados teores de escória (de 35 a 70\%) e pozolana (de 15 a 50\%) em suas composições, respectivamente. Felix, Carrazedo e Possan (2017) modelaram a carbonatação de concretos produzidos com diferentes tipos de cimentos Portland comercializados no 
Brasil (Ver Figura 2.8), comprovando a influência negativa das adições presentes nos cimentos CP III e CP IV quanto ao avanço da carbonatação.

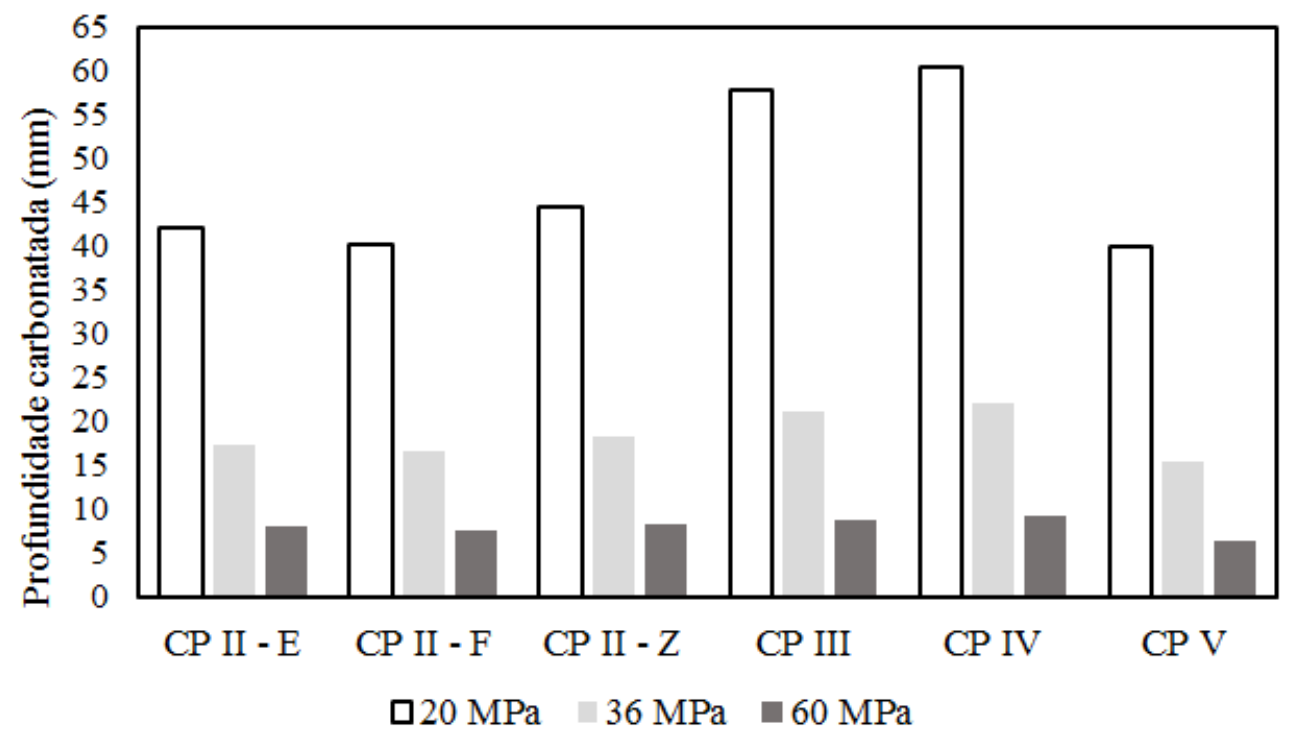

Figura 2.8 - Profundidade de carbonatação em função do tipo de cimento.

Fonte: Adaptado de Felix, Carrazedo e Possan (2017).

Isaia (1999), Ho e Lewis (1988) e Possan (2010) também comprovaram a influência negativa das adições no avanço da carbonatação. Em especial, Possan (2010) observou por meio de modelagens que, para concretos de baixa resistência à compressão (20 MPa), quanto maior o teor de adições, maior será a profundidade carbonatada. Já para concretos com resistência elevada (50 MPa) não foi observada uma influência significativa do teor de adições no avanço da carbonatação.

Sobre a influência dos agregados graúdos, Larrard et al. (2013) investigaram por meio de simulações numéricas, via Método dos Elementos Finitos, o efeito do formato dos agregados. Para as análises, os autores consideraram quatro diferentes formatos (circular, cúbico, partículas de Voronoi e poligonal), conforme mostra Figura 2.9. Os autores verificaram que existe uma pequena variação na profundidade de carbonatação ao comparar a frente de carbonatação dos concretos contendo em sua composição os diferentes formatos de agregados.

Quanto à facilidade de difusão do $\mathrm{CO}_{2}$ no meio, Larrard et al. (2013) verificaram que a utilização de agregados circulares propiciam uma maior difusão do gás, ao contrário dos agregados do tipo partículas de Voronoi, que geraram concretos com as menores taxas de carbonatação. Os autores justificaram os resultados em função do índice de vazios que os diferentes formatos conferem ao concreto.

2 Cimento CP III: cimento Portland de alto forno, regulamentado pela NBR 5735 (ABNT, 1991a).

2 Cimento CP IV: cimento Portland pozolânico, regulamentado pela NBR 5736 (ABNT, 1991b). 


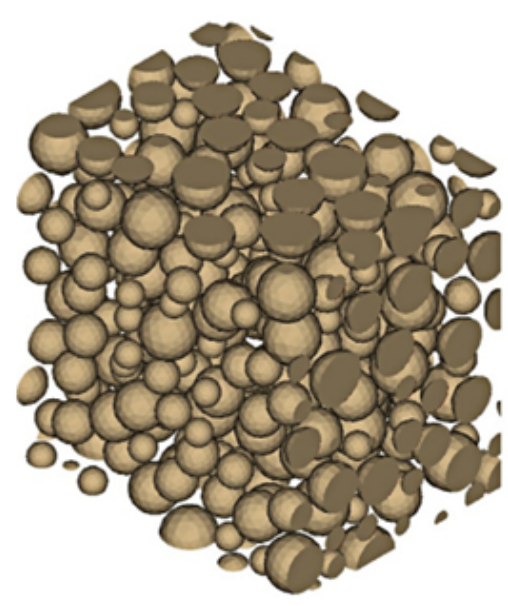

(a) Agregado circular.

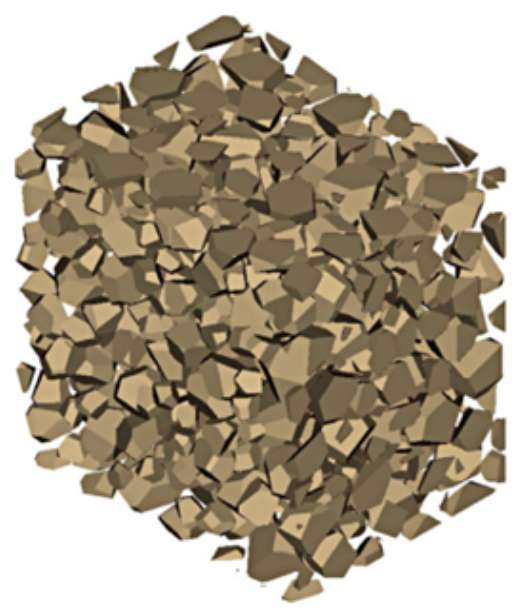

(c) Agregado com partículas Voronoi.

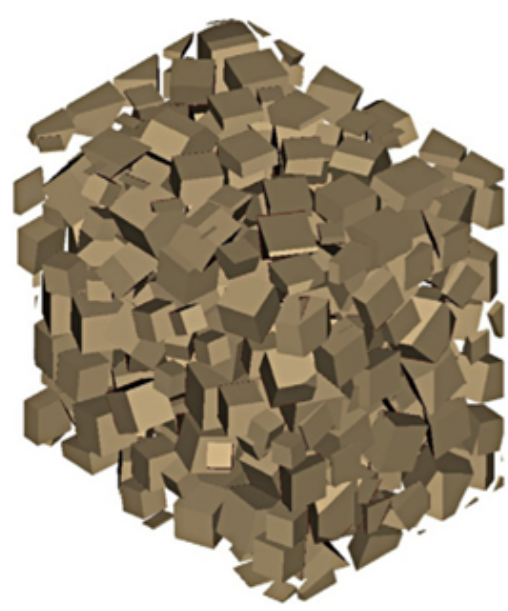

(b) Agregado cúbico.

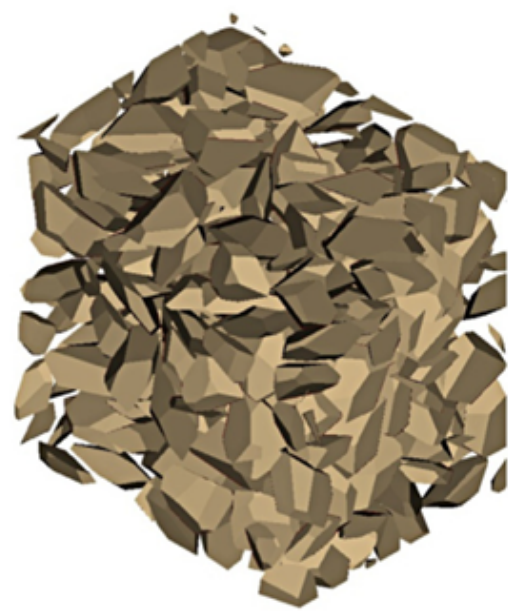

(d) Agregado poligonal.

Figura 2.9 - Representação da microestrutura dos concretos simulados.

Fonte: Larrard et al. (2013).

A fim de analisar a relação entre a proporção em volume de agregados no concreto e a sua dimensão máxima, Han et al. (2016) simularam numericamente concretos compostos com $0 \%, 30 \%, 37 \%$ e $45 \%$ de agregados graúdos em seu volume, assim como, concretos contendo agregados com diferentes dimensões máximas (10, 14 e 18 mm). Nas Figuras 2.10a e 2.10b são apresentados os perfis de carbonatação dos concretos em função da dimensão máxima dos agregados e da proporção em volume, respectivamente. As análises foram realizadas para um período de 10 anos.

Han et al. (2016) observaram que a dimensão dos agregados não influencia na frente de carbonatação do concreto, conforme vê-se na Figura 2.10a. Entretanto, ao analisar a carbonatação de concretos com distintas proporções de agregados (Figura 2.10b), os autores verificaram que quanto maior for a proporção de agregados menores são as taxas de carbonatação. 


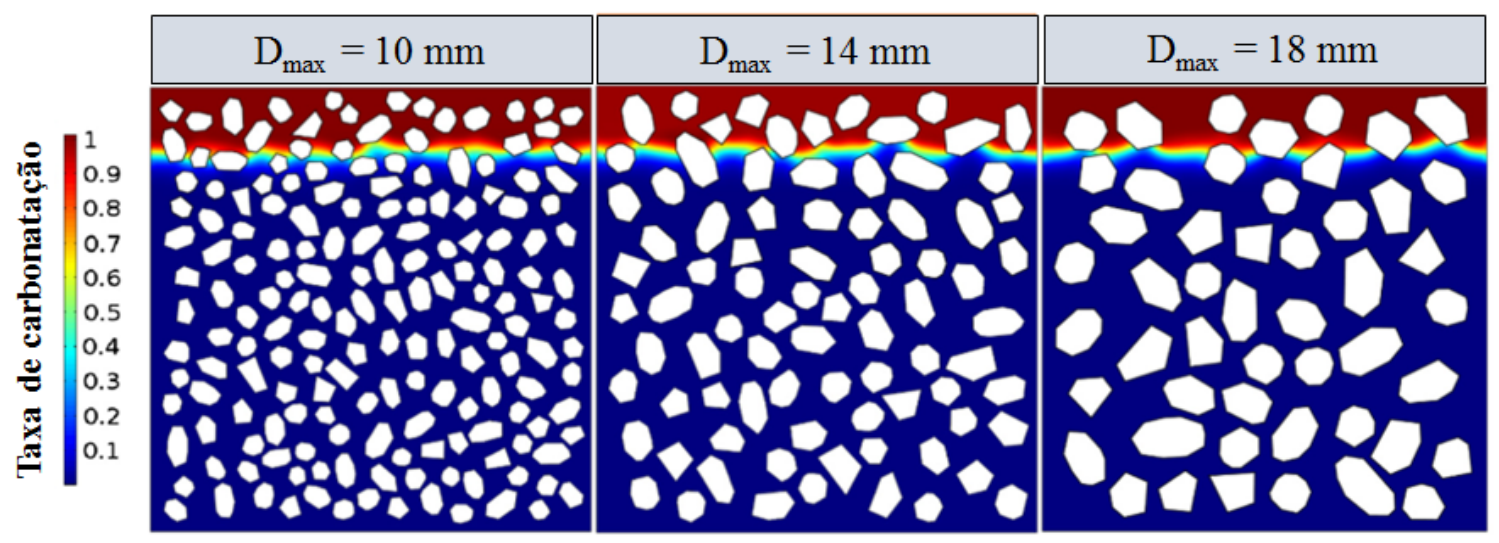

(a) Carbonatação em função da dimensão máxima dos agregados.

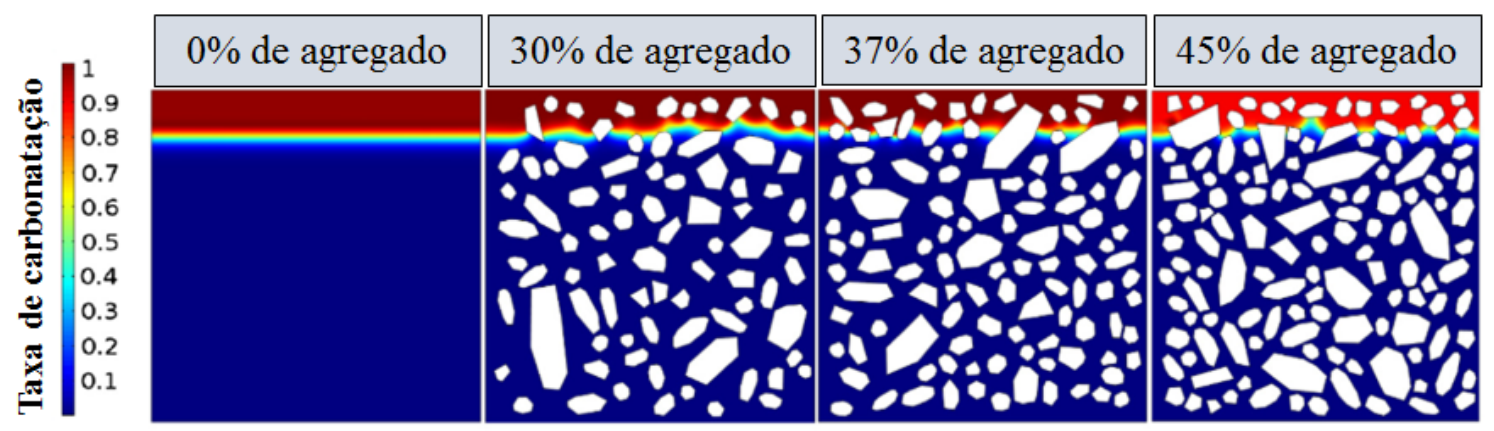

(b) Carbonatação em função da proporção de agregados.

Figura 2.10 - Frente de carbonatação do concreto.

Fonte: Han et al. (2016).

Han et al. (2016) descrevem que à medida em que é aumentada a fração de agregados graúdos, a proporção de pasta de cimento é reduzida, diminuindo a quantidade de hidróxido de cálcio, componente químico necessário para a reação de carbonatação. Também foi constatado que os agregados graúdos dificultam o transporte de $\mathrm{CO}_{2}$ dentro da matriz porosa do concreto.

\subsubsection{Relação água/cimento e resistência à compressão}

Considerando a importância dos mecanismos de difusão no processo de carbonatação, a natureza da porosidade desempenha um importante papel frente à taxa de difusão do dióxido de carbono no concreto.

De acordo com Ribeiro, Cunha e Helene (2015) a influência do índice de vazios está diretamente relacionado à fração de água utilizada na produção do concreto. Deste modo, pode-se relacionar a porosidade por meio do fator água/cimento $(a / c)$.

Houst e Wittmann (1994) definiram por meio de experimentos a relação existente entre o fator $a / c$ e a taxa de difusão do $\mathrm{CO}_{2}$ no concreto. Os autores relatam que existe uma relação direta entre as duas variáveis de análise, sendo que a taxa de carbonatação 
cresce exponencialmente com o aumento do fator $a / c$, conforme mostra a Figura 2.11.

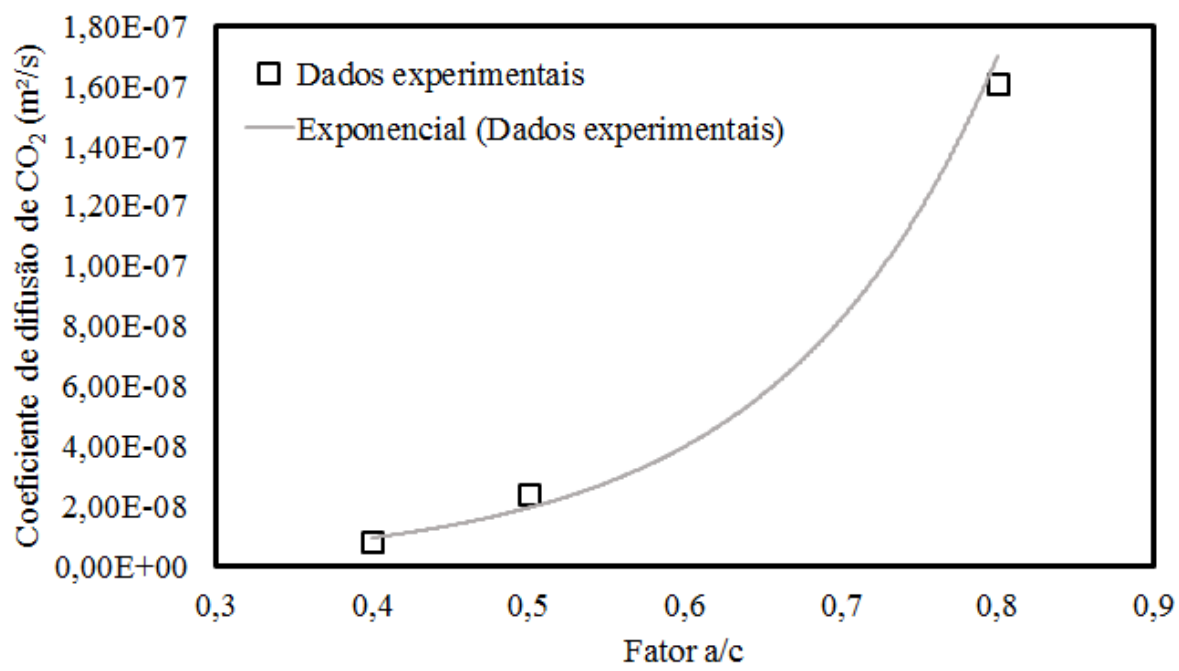

Figura 2.11 - Coeficiente de difusão de $\mathrm{CO}_{2}$ versus fator a/c. Fonte: Houst e Wittmann (1994).

Para Aïtcin (2000) a produção de concretos com reduzidos valores de a/c permite que as partículas de cimento fiquem mais próximas umas das outras na pasta fresca, reduzindo a porosidade do concreto na fase endurecida. Venquiaruto, Isaia e Gastaldini (2001) descrevem a relação $a / c$ como um dos principais fatores para a determinação do comportamento e do grau de carbonatação, sendo ainda o parâmetro mais importante para a definição da resistência à compressão do concreto.

Assim, o fator $a / c$ e a resistência à compressão do concreto possuem o mesmo grau de influência na determinação do comportamento da carbonatação, uma vez que menores (ou maiores) valores de a/c, produzem concretos mais (ou menos) resistentes e, consequentemente, menores (ou maiores) taxas de carbonatação, devido à mútua relação entre porosidade, resistência à compressão e o fator $a / c$.

\subsection{Produtos de corrosão}

A depender da composição e do meio corrosivo, o cátion metálico resultante do processo de corrosão pode sofrer dissolução ou então reagir com os elementos presentes no meio (i.e., oxigênio, hidroxila, enxofre e outros), resultando em um filme superficial, localizado na interface aço/concreto (RIBEIRO; CUNHA; HELENE, 2015).

O filme superficial gerado como resultado das reações impostas pelo processo corrosivo pode se apresentar de duas formas, sendo elas:

i Filme retardador: é característico de produtos corrosivos que se concentram sob as superfícies metálicas de forma porosa, não compacta e com baixa aderência. Este 
tipo de filme aumenta a resistência à corrosão, porém dependendo da porosidade o aumento chega a ser insignificante;

ii Filme inibidor: é gerado quando o produto de corrosão, depositado sob as superfícies da armadura, encontram-se na forma compacta e com grande aderência. Neste caso a corrosão pode ser retardada.

De acordo com Gentil (2011), através do diagrama de equilíbrio termodinâmico, diagrama de Pourbaix, é possível identificar os produtos de corrosão que estão presentes nos elementos metálicos. O diagrama de Pourbaix (ver Figura 2.12) é definido em função do potencial elétrico e do pH da solução aquosa em temperatura ambiente.

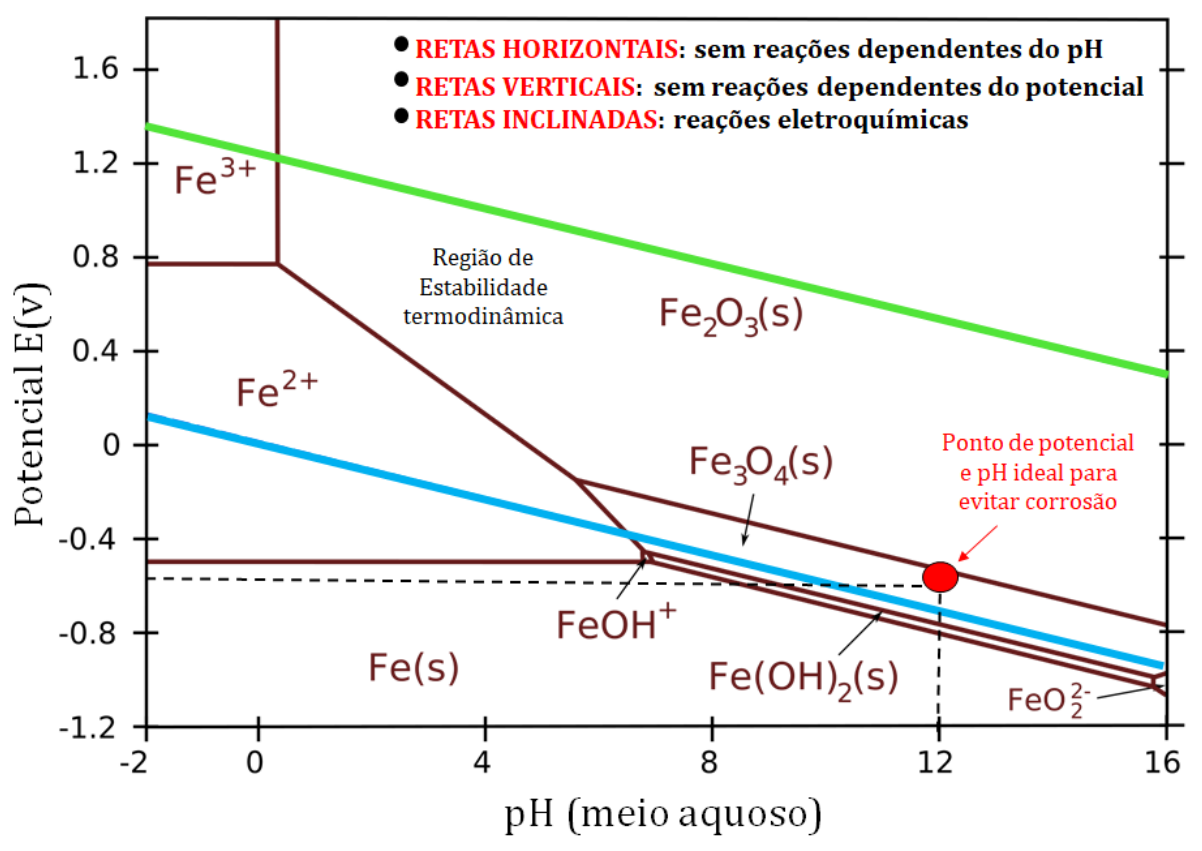

Figura 2.12 - Diagrama de equilíbrio termodinâmico para o sistema ferro - $\mathrm{H}_{2} \mathrm{O}$ a $25^{\circ} \mathrm{C}$. Fonte: Adaptado de Gentil (2011).

Segundo Ribeiro, Cunha e Helene (2015), quando o aço se encontra em um potencial de $-550 m V(-0.55 V)$, e com $p H$ de 12 (ver Figura 2.12), na superfície da armadura estará presente um filme de $\mathrm{Fe}_{3} \mathrm{O}_{4}$, compacto e com grande aderência (filme inibidor), o qual age de forma a proteger a armadura, servindo como uma barreira contra os agentes desencadeadores da corrosão, reduzindo significativamente a taxa de dissolução do metal.

No entanto, com a diminuição do $p H$, o filme passivo $\left(\mathrm{Fe}_{3} \mathrm{O}_{4}\right)$ deixa de ser estável e passa a ser formado um filme não protetor $\left(\mathrm{Fe}_{2} \mathrm{O}_{3} \cdot 3 \mathrm{H}_{2} \mathrm{O}\right)$, vulgarmente denominado ferrugem ou produtos de corrosão. Este filme torna a armadura suscetível a degradação por corrosão, levando a perda de massa e ao surgimento do produto corrosivo em maior proporção (RIBEIRO; CUNHA; HELENE, 2015). 
De acordo com Mehta e Monteiro (2014) a presença dos filmes não protetores, resultados da corrosão, causam a expansão do volume do metal original, surgindo na interface aço/concreto pressões que se acentuam com o avanço da corrosão. Essa expansão causa a formação de fissuras localizadas, e a progressão destas fissuras promovem o destacamento do concreto.

\subsection{Efeitos da corrosão no concreto armado}

Andrade (1992) descreve três formas de manifestação dos efeitos da corrosão sobre o material compósito: a redução da capacidade mecânica, a perda de aderência entre aço e concreto, e a fissuração do concreto de cobrimento.

No que se refere à capacidade mecânica, é notório que a mesma é reduzida à medida em que a corrosão progride com o tempo. A redução se dá tanto pela perda das propriedades mecânicas dos materiais quanto pela perda de seção do aço.

De acordo com Du, Clark e Chan (2005), o efeito combinado da corrosão, que geram esforços de origem química, com os esforços advindos do carregamento da estrutura, faz com que a redução da resistência residual da armadura seja desproporcional à perda de seção da mesma.

Com o objetivo de quantificar e relacionar a perda da capacidade mecânica do aço em função do nível de corrosão ao qual está submetida, Du, Clark e Chan (2005) analisaram experimentalmente diversos elementos de concreto sob corrosão e, com os resultados, geraram a Equação 2.11, a qual possibilita estimar a resistência residual do aço em função do seu nível de corrosão.

$$
f=\left(1-0,005 Q_{\text {corr }}\right) f_{0}
$$

em que $f$ corresponde à resistência residual da armadura, $f_{0}$ refere-se à resistência antes do início do processo corrosivo e $Q_{c o r r}$ representa o nível de corrosão da armadura (\%), dada pela Equação 2.12.

$$
Q_{c o r r}=0,46 \frac{i_{c o r r}}{d} t_{p}=1-\left(\frac{d_{s}}{d}\right)^{2}
$$

em que $t_{p}$ representa o tempo decorrido após a despassivação da armadura (anos), $d_{s}$ é o diâmetro da armadura corroída $(\mathrm{mm})$, $d$ é o diâmetro da armadura não corroída $(\mathrm{mm})$ e $i_{c o r r}$ é a taxa de corrosão real $\left(\mu A / \mathrm{cm}^{2}\right)$, definida por Vu e Stewart (2000) por meio da Equação 2.13.

$$
i_{\text {corr }}\left(t_{p}\right)=\left[\frac{37,8\left(1-\frac{a}{c}\right)^{-1,64}}{c o b}\right] 0,85 t_{p}^{-0,29}
$$


em que $i_{\text {corr }}$ representa a taxa de corrosão $\left(\mu A / \mathrm{cm}^{2}\right), t_{p}$ refere-se o tempo de progressão da corrosão (anos), $\frac{a}{c}$ é a relação água/cimento e cob é o cobrimento do concreto $(\mathrm{cm})$.

Tapan e Aboutaha (2011) analisaram a resistência residual de armaduras de vigas de concreto armado sob condições naturais de corrosão, validando as Equações 2.11 e 2.12 propostas por Du, Clark e Chan (2005).

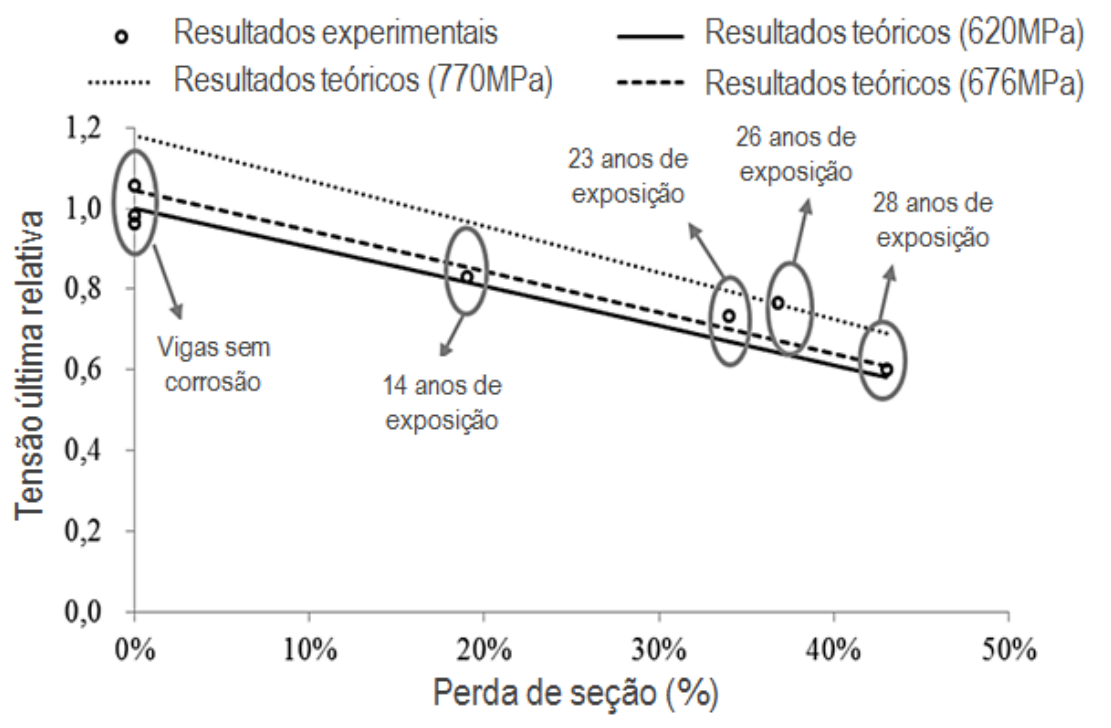

Figura 2.13 - Redução da capacidade mecânica de vigas de concreto sob corrosão.

Fonte: Khan, François e Castel (2011).

Khan, François e Castel (2011) analisaram a capacidade mecânica de vigas de concreto armado submetidas à corrosão natural, observando que a capacidade mecânica das vigas reduz à medida em que a corrosão se propaga, e que a relação entre a perda de resistência e a taxa de corrosão é não linear, conforme mostra a Figura 2.14.

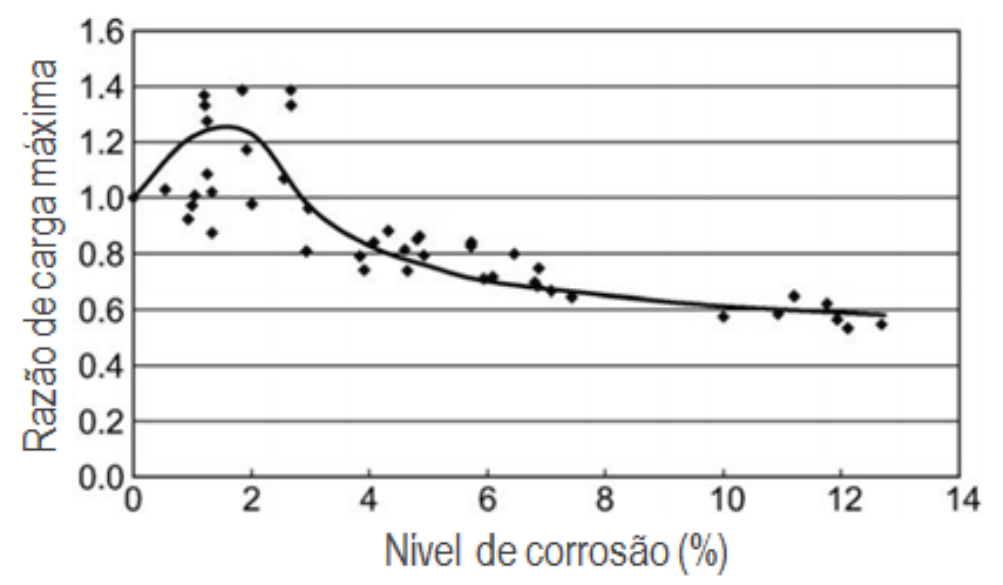

Figura 2.14 - Carga máxima de vigas de concreto em função do nível de corrosão.

Fonte: Chung et al. (2004). 
Chung et al. (2004) observaram em seus experimentos que a corrosão do aço só começa a produzir uma perda na capacidade mecânica de estruturas de concreto armado quando a degradação das armaduras alcança níveis entre 2 e $4 \%$ (ver Figura 2.14). Uma das razões para que isto ocorra deve-se ao fato de que a formação inicial dos produtos de corrosão na interface aço/concreto melhora a ligação entre os dois materiais, já que parte destes produtos preenchem os vazios da matriz porosa do concreto dessa região. Porém, com o avanço da degradação e da formação dos produtos de corrosão, esse ganho deixa de ser significativo, já que não há mais espaço na matriz para a alocação do material ferruginoso, o que leva ao surgimento de microfissuras na região e, consequentemente, à perda de rigidez do elemento estrutural.

Por meio de experimentos, Almusallam (2001) verificou que a deformabilidade de vigas de concreto armado é reduzida quando submetida à corrosão, e que a medida em que a corrosão progride o elemento estrutural tem a sua capacidade portante diminuída.

Na Figura 2.15 observa-se que a ductilidade das armaduras sofre uma redução significativa mesmo sob baixos níveis de corrosão, sendo uma perda de ductilidade em maior proporção quando a degradação das armaduras superam os 12\%. Almusallam (2001) relata que nestes casos o patamar de escoamento do aço é reduzido ou até mesmo extinguido, alterando o modo de ruptura do elemento estrutural.

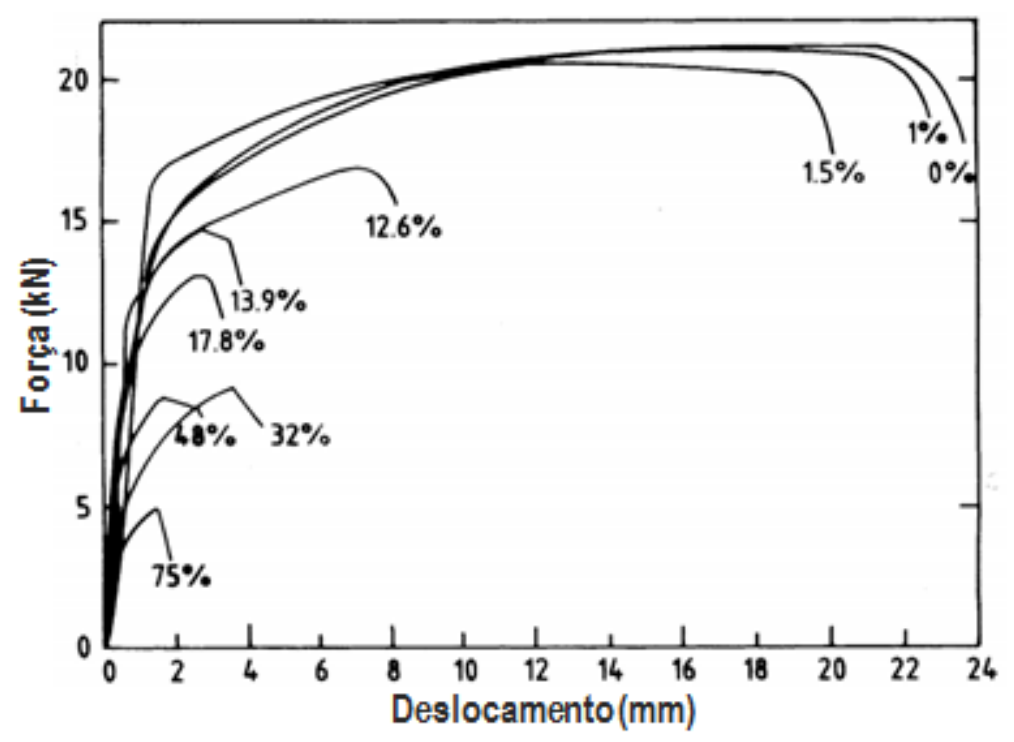

Figura 2.15 - Força vs. deslocamento em função do nível de corrosão.

Fonte: Almusallam (2001).

Quanto à aderência entre o aço e o concreto, Helene (1986) e Cascudo (1997) relatam que a propriedade possui ganhos significativos à medida em que a corrosão avança. Helene (1986) relaciona o ganho de aderência à maior superfície de contato gerada pela armadura corroída, uma vez que os produtos de corrosão causam um aumento de volume da armadura de 3 a 10 vezes. 
Em seus estudos, Chung et al. (2004) observaram que, em seu primeiro estágio, a corrosão proporciona um aumento da aderência entre o aço e o concreto (Figura 2.16). No entanto, com o avanço da formação dos produtos de corrosão, a aderência entre os dois materiais é reduzida de forma acelerada, mesmo sob baixo nível de corrosão.

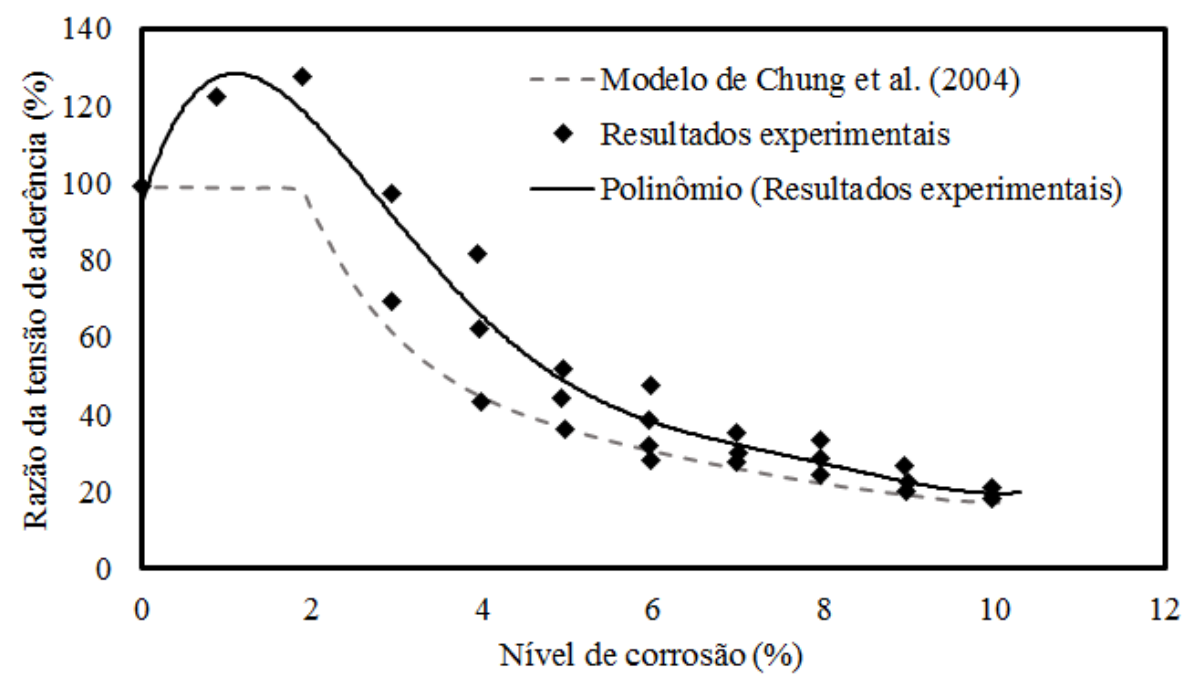

Figura 2.16 - Influência da corrosão na aderência entre o aço e o concreto.

Fonte: Chung et al. (2004).

Entretanto, Almusallam et al. (1996) descrevem que a deterioração progressiva causada pela corrosão degrada a aderência entre o aço e o concreto, e que a mesma causa uma redução na capacidade de carga do elemento estrutural.

No que se refere à fissuração do concreto decorrente da corrosão, Gentil (2011) relata que fissuras são criadas no concreto à medida em que são formados os produtos de corrosão, tendo a sua progressão controlada pela intensidade do campo de tensão interno que surge na região de acúmulo do material ferruginoso. Para Cánovas (1988) as tensões de tração causadas pelos produtos de corrosão podem chegar até $40 \mathrm{MPa}$, valor superior ao resistido pelo concreto.

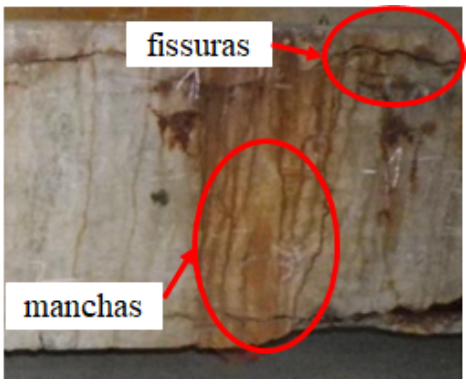

(a) Fissuração do concreto.

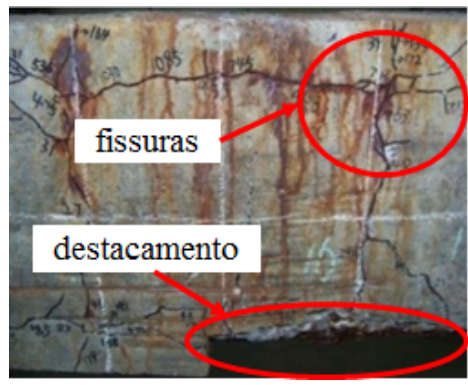

(b) Destamento do concreto.

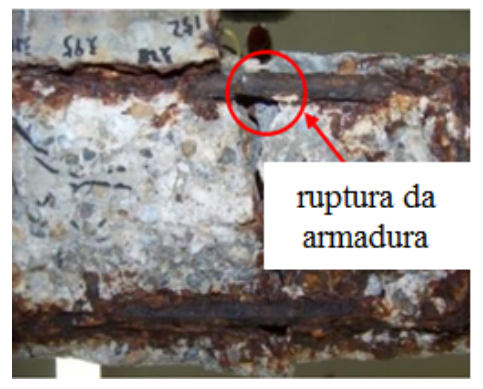

(c) Ruptura das armaduras.

Figura 2.17 - Efeitos da corrosão em estruturas de concreto armado.

Fonte: Adaptado de Zhu (2014). 
As fissuras criadas pelas forças expansivas são denominadas por Cascudo (1997) por fissuras ativas progressivas, e se estabelecem segundo direção paralela as barras corroídas (ver Figura 2.17a). Cascudo relata ainda que as fissuras se desenvolvem concomitantemente à corrosão, sendo esta a explicação para a sua denominação progressiva.

A medida em que as fissuras progridem estas aumentam a área de entrada dos agentes agressivos presentes na atmosfera, o que leva a um aumento da taxa de corrosão e, por consequência, na progressão das fissuras no concreto. As fissuras podem alcançar dimensões elevadas, causando o destacamento do concreto de cobrimento, deixando a armadura totalmente exposta à atmosfera (Figuras 2.17b e 2.17c).

No entanto, Cascudo (1997) relata que a corrosão pode não causar fissuração. Em casos onde a umidade do concreto é alta, os óxidos serão gerados a uma taxa constante, sendo expelidos pelos poros da matriz de concreto aparecendo sob a superfície na forma de manchas (Figura 2.17a). Neste caso serão apenas dois os efeitos sentidos pela estrutura, a perda de seção e a redução da aderência entre o aço e o concreto.

Diante do exposto, a corrosão quando não evitada ou controlada desencadeia diversos danos às estruturas de concreto armado, gerando prejuízos e riscos aos seus usuários. Pensando nisso, faz-se necessário estudar e modelar os efeitos da corrosão sobre o comportamento mecânico do concreto armado.

\subsection{Avanços nos estudos da corrosão}

A seguir são listados alguns trabalhos desenvolvidos nas últimas duas décadas, período em que ocorre um avanço considerável nos estudos referentes à corrosão de armaduras e à vida útil de estruturas de concreto armado. Os trabalhos são apresentados em ordem cronológica, descrevendo os principais resultados e as limitações encontradas.

Cabrera (1996), por exemplo, investigou por meio de dados experimentais os efeitos da taxa de corrosão na fissuração do concreto de cobrimento e na aderência da região de contato aço/concreto. As análises realizadas pelo pesquisador possibilitaram o desenvolvimento de modelos numéricos para a predição da taxa de corrosão em concretos sob intenso estado de fissuração, além da taxa de perda de aderência entre o aço e o concreto e da perda de vida útil de elementos de concreto, desde que fosse conhecido o nível de corrosão ao qual estão submetidas as estruturas. Cabrera (1996) também observou que existe uma relação inversa entre a dimensão do cobrimento das armaduras e o grau de corrosão à qual ficam submetidas. Ademais, o autor verificou que ao aumentar o nível da corrosão em vigas de concreto armado sob flexão, aumentam-se os deslocamentos do centro do vão. Por exemplo, quando a corrosão alcança a taxa de $9 \%$, a deflexão cresce de 1 a 5 vezes.

Almusallam et al. (1996) avaliaram os efeitos da corrosão quanto a aderência entre o concreto e o aço em vigas e lajes de concreto armado. Neste estudo verificou-se que, 
além da existência de uma relação entre a taxa de corrosão e a perda de aderência entre os diferentes materiais, o avanço da degradação reduz significativamente a resistência à flexão de lajes. Os autores observaram ainda que taxas de corrosão entre 5 e $7 \%$ levam ao desenvolvimento de fissuras no concreto de cobrimento e que, ao serem desenvolvidas tais fissuras, é necessário um pequeno acréscimo da taxa de corrosão para reduzir a aderência e levar as estruturas a níveis inaceitáveis de tensão.

Rodriguez, Ortega e Casal (1997) realizaram um estudo experimental com 31 vigas de concreto armado submetidas à deterioração por corrosão, sendo aplicada uma solução aquosa contendo cloretos criando uma corrente de densidade constante de $100 \mu \mathrm{A} / \mathrm{cm}^{2}$. Nos ensaios foram alteradas algumas das variáveis envolvidas, como a taxa de corrosão, os níveis de carregamento e as configurações das armaduras, possibilitando realizar uma análise paramétrica. A partir dos resultados obtidos foi possível analisar o comportamento das vigas sob corrosão e quantificar os efeitos causados nas tensões de cisalhamento e de compressão. Os autores verificaram que a corrosão afeta significativamente a deflexão e a espessura das fissuras em vigas de concreto armado sob flexão e que a vida útil destas pode ser drasticamente reduzida. Quanto à configuração das armaduras, verificou-se que o modo de ruptura varia de acordo com a seção de armadura utilizada, sendo observada em mais de $60 \%$ dos casos a ruptura por cisalhamento.

Enright e Frangopol (1998) estudaram probabilisticamente a resistência à deterioração de vigas de pontes de concreto armado sujeitas a ação da corrosão, considerando a perda da resistência à flexão. Os autores verificaram que o tempo para levar ao desencadeamento da corrosão é mais sensível ao coeficiente de concentração de cloretos na superfície que as demais variáveis envolvidas no fenômeno. O mesmo resultado foi constatado, anos depois, por Nogueira e Leonel (2013).

Stewart e Rosowsky (1998) desenvolveram em seus trabalhos um modelo para analisar a segurança estrutural de pontes de concreto armado sob ação da corrosão. O modelo foi proposto utilizando a teoria da confiabilidade e possibilita a avaliação da probabilidade de falha estrutural e de serviço para os estados limites na flexão e no lascamento (spalling). Os resultados possibilitaram concluir que a resistência à compressão e a dimensão do cobrimento das armaduras possuem grandes correlações quanto a probabilidade de falha e principalmente no lascamento.

Hansen e Saouma (1999) modelaram numericamente a degradação de lajes de pontes de concreto armado quando submetidas à corrosão. Os autores realizaram concomitantemente análises da corrosão das armaduras e da fissuração do concreto de cobrimento. As simulações numéricas foram feitas utilizando softwares comerciais por meio do método dos elementos finitos (MEF), sendo acoplado um modelo de fratura para o concreto. Os resultados da modelagem foram comparados com os obtidos por meio de modelos analíticos os quais demonstraram que o MEF pode ser usado para simular o processo de corrosão em estruturas de concreto armado. Foi possível, também, verificar que as fissuras causadas 
devido a corrosão podem ser horizontais, verticais e diagonais, e que suas dimensões são dependentes do espaçamento das armaduras e do concreto de cobrimento. Quanto às fissuras, Hansen e Saouma (1999) relatam que as horizontais e verticais são criadas devido a tração ocasionada pelo campo de tensões induzido pela corrosão, e que as diagonais são geradas pelo efeito de cisalhamento.

Maruya et al. (2003) desenvolveram um modelo para representar a deterioração de estruturas de concreto armado submetidas a corrosão por cloretos. O modelo numérico foi criado combinando formulações físico-químicas que descreviam o processo de migração de substâncias, por exemplo, íons cloreto, oxigênio e água, na matriz porosa do concreto. Para a validação do modelo foram realizados ensaios em laboratórios sob distintos cenários quanto a saturação do concreto (estado seco, saturado e com ciclos de molhagem). Os resultados demonstraram que concretos com ciclos de molhagem apresentam maior penetração de cloretos, e consequentemente, maior avanço da corrosão; isso acontece, segundo os autores, devido às condições impostas ao concreto, o qual passa do estado seco para molhado, sendo novamente seco em seguida, e assim sucessivamente, fazendo com que a água com diferentes substâncias presentes na atmosfera adentre na matriz porosa do concreto transportando, por consequência, os cloretos. Os resultados obtidos com o modelo confirmaram a importância da umidade no processo de corrosão e que, para valores altos ou baixos de umidade, a penetração dos íons cloreto são dificultados, retardando, portanto, a despassivação das armaduras e, por conseguinte, a corrosão.

Wang e Liu (2006) propuseram um modelo analítico a fim de verificar os efeitos da corrosão na aderência entre o concreto e o aço em estruturas de concreto armado sem estribos. Para o desenvolvimento do modelo assumiu-se a existência de um campo de tensão na região aço/concreto criada pelas forças expansivas dos produtos de corrosão. Os resultados obtidos com o modelo foram comparados com os experimentais, os quais possibilitaram comprovar que a medida em que se desenvolve a corrosão, o campo de tensão é intensificado, reduzindo a aderência que existe entre os materiais. Com o modelo também foi possível determinar a profundidade crítica de penetração dos íons de cloreto no concreto que levam a sua falha devido à perda de aderência entre o aço e o concreto.

Coronelli e Gambarova (2004) apresentam quais seriam as principais etapas a serem seguidas para avaliar os efeitos da corrosão em estruturas de concreto sujeitas à corrosão por meio do método dos elementos finitos (MEF). Os autores simularam diferentes estruturas, de forma a mostrar quais parâmetros intrínsecos à corrosão eram mais significativos. Verificaram-se diversos aspectos com esse estudo como por exemplo: a importância de determinar as leis constitutivas adequadas para cada material (aço e concreto); a necessidade de conhecer dados reais das condições de exposição das estruturas, a fim de estimar a taxa de corrosão correta e os efeitos que causaram nos elementos de concreto; e adotar um modelo de fratura que melhor se adeque ao problema. Também se observou a necessidade de se analisar uma maior quantidade de danos em simultâneo, 
por exemplo, a redução de seção das armaduras somada à redução de seção do concreto (devido ao surgimento de fissuras), ou então o desenvolvimento de fissuras juntamente com a perda de aderência entre o aço e o concreto.

Bhargava et al. (2005) criaram um modelo analítico para estimar o tempo em que surgem as primeiras fissuras no concreto armado submetido à corrosão. O modelo foi obtido por meio da solução de problemas de valor de contorno onde as equações que governavam os problemas estavam escritas em termos dos deslocamentos radiais. A formulação analítica leva em consideração apenas dois estágios, concreto fissurado e não fissurado. O modelo ainda foi avaliado quanto a sua capacidade de reproduzir os resultados obtidos em experimentos, sendo, em sequência, realizada uma análise de sensibilidade, da qual foi possível mostrar a influência das diferentes variáveis. Os resultados obtidos mostraram que o tempo de surgimento das primeiras fissuras é significativamente afetado pelos tipos e níveis de corrosão e pelas propriedades do concreto de cobrimento (resistência a tração e módulo de elasticidade). Também ficou claro, que o módulo de elasticidade da armadura também possui influência no desenvolvimento das fissuras.

Du, Clark e Chan (2005) investigaram, por meio de ensaios em laboratório, a influência da seção da armadura e o seu formato (lisa ou nervurada) na capacidade residual de barras em estruturas de concreto armado sujeitas à corrosão. Conhecidos os resultados experimentais, os autores propuseram um modelo para a previsão da capacidade residual em função do nível de corrosão, do tempo de progressão do fenômeno e do diâmetro da barra sã (não corroída).

Isgor e Razaqpur (2006) modelaram numericamente, por meio do MEF, o processo de corrosão em estruturas de concreto armado. O modelo foi proposto de forma a integrar as duas fases de degradação do concreto por corrosão: a fase de iniciação e a de progressão. Foram utilizados parâmetros relacionados à umidade relativa do ar, à temperatura, à concentração de íons de cloreto e aos processos de transporte de oxigênio no concreto. A determinação da taxa de corrosão do aço foi obtida resolvendo equações de Laplace referente ao potencial eletroquímico com as apropriadas condições de contorno. Os resultados demonstraram a potencialidade do modelo frente às diferentes geometrias de seção dos elementos de concreto armado, às diferentes disposições das armaduras no concreto, à presença de fissuras e à não linearidade física dos materiais.

Xu, Jiang e Wang (2009) propuseram um modelo não linear, via MEF, para a corrosão de armaduras, embasando-se em análises matemáticas sobre o processo eletroquímico da corrosão do aço presente no concreto. A partir dos resultados constatou-se que o MEF se apresenta como uma ferramenta mais robusta e de fácil manipulação quanto à modelagem da corrosão, quando comparadas com outras técnicas utilizadas pelos autores. Para Xu, Jiang e Wang (2009), apenas com o MEF foi possível obter uma distribuição do potencial e da densidade da corrente de corrosão sobre a superfície do aço.

Yuan e Ji (2009) modelaram a distribuição dos produtos de corrosão ao longo 
da seção transversal de um elemento de concreto armado. Os autores assumiram um padrão de corrosão ao longo de todo o perímetro da seção transversal, analisando, em seguida, os efeitos causados pelo surgimento dos produtos de corrosão na região de contato aço/concreto. Para validar o modelo foram confeccionadas vigas de concreto contendo, em seu interior, armadura longitudinal. As vigas foram submetidas à corrosão acelerada em uma câmara que simulava o ambiente de exposição contendo diferentes agentes agressivos. A partir dos resultados observou-se que a região em que se desenvolve os produtos de corrosão refere-se à zona de transição. Como tal zona possui maior porosidade (geralmente constituída de concretos com menor resistência a esforços mecânicos), existe espaço suficiente para a formação dos produtos de corrosão, consequente a esta formação, surgem altas pressões internas (forças expansivas) que levam ao fissuramento do concreto de cobrimento. Quanto à distribuição dos produtos de corrosão na seção transversal da armadura, a sua configuração é semelhante à de uma elipse, pois há um maior avanço da corrosão nas regiões próximas ao concreto de cobrimento, devido a maior concentração de agentes agressivos.

Sánchez et al. (2010) determinaram dois modelos mesoscópicos capazes de simular o comportamento mecânico de elementos de concreto armado sob corrosão: um para a seção transversal do elemento de concreto (estado plano de deformação) e outro para a seção longitudinal (estado plano de tensão). Os modelos foram concebidos fazendo o uso do MEF, simulando a deterioração do concreto armado causada pela corrosão. As simulações numéricas foram feitas reproduzindo os efeitos mecânicos induzidos pela ação da corrosão, como por exemplo: a expansão do concreto devido ao desenvolvimento dos produtos de corrosão; o desenvolvimento de fissuras no concreto de cobrimento; a degradação da aderência entre o aço e o concreto; a perda de seção das armaduras; e a perda da resistência mecânica do aço. Para a representação do concreto, utilizou-se um modelo constitutivo isotrópico acoplado à um modelo de dano contínuo conhecido como Continuum Strong Discontinuity Approach (CSDA) desenvolvido por Oliver et al. (2002). Também foram utilizados elementos finitos de contato, a fim de simular os efeitos causados pela corrosão na região de contato entre os materiais. O modelo referente à seção transversal possibilitou a determinação dos padrões de fissuras que surgem no concreto ao longo do tempo, além de apresentar as possíveis regiões de lascamento. Com o modelo longitudinal, os autores conseguiram determinar padrões de degradação em vigas de concreto armado quando sob corrosão, assim como, os seus modos de ruptura.

Shodja, Kiani e Hashemian (2010) desenvolveram em seus estudos um modelo matemático não linear para a determinação do deslocamento e do campo de tensões em estruturas de concreto armado submetidas à corrosão. A fim de modelar os efeitos ocasionados pelo surgimento dos produtos de corrosão, determinou-se, por meio de experimentos, uma relação não linear entre tensão e deformação, à qual é utilizada como condição de contorno na resolução de equações diferenciais que governam a relação entre o 
compósito aço-produtos de corrosão-concreto. Nas equações formuladas foram incorporadas relações referentes ao comportamento dos produtos de corrosão, aos mecanismos de transporte dos produtos corrosivos dentro da matriz porosa do concreto, além das fissuras internas às estruturas. Para a resolução do problema de valor de contorno não linear, utilizou-se o método sem malha (com formulação fraca) gradiente reproducing kernel particle method (GRKPM). Os resultados obtidos com o modelo foram comparados com outros da literatura e com resultados experimentais, verificando assim a potencialidade do mesmo em prever o estado de tensão na região de contato aço/concreto e da utilização dos métodos sem malha para a resolução deste tipo de problema.

No trabalho de Balafas e Burgoyne (2010), o modelo foi desenvolvido com o intuito de estimar o tempo da segunda fase do processo de corrosão, i.e., o período de progressão. O modelo proposto foi obtido realizando uma compatibilização entre os volumes presentes no compósito aço-produtos de corrosão-concreto desde o instante em que é iniciada a formação dos produtos de corrosão até o momento em que ocorre o lascamento do concreto de cobrimento. Com a compatibilização dos volumes foi possível também determinar quando surgem as forças de expansão internas ao concreto e como estas se intensificam ao longo do tempo. A formulação é baseada na lei de Faraday e no trabalho de Liu e Weyers (1998). Os resultados demonstraram que o modelo baseado na mecânica da fratura e em termos de energia de deformação apresentava uma nova forma de descrever os danos causados pela corrosão e de prever o momento e os modos de ruptura.

Pengwei et al. (2011) analisaram por meio do método dos elementos finitos os efeitos do desenvolvimento dos produtos de corrosão no concreto de cobrimento. Por meio de simulações, os autores analisaram não somente os padrões de fissuras (desenvolvidas ao longo do avanço da corrosão), mas também o nível de corrosão necessário para o início da fissuração do concreto. Baseando as análises e os resultados obtidos via MEF, os autores propuseram uma formulação para a determinação da taxa de expansão, relacionando-a com a dimensão do concreto de cobrimento, o diâmetro da armadura, o módulo de elasticidade e a resistência à tração do concreto. Os resultados obtidos com a nova formulação foram comparados a outros modelos da literatura, verificando-se que a mesma representa de forma adequada, o comportamento do concreto de cobrimento quando este está sob presença de forças expansivas criadas pela corrosão, apresentando-se, portanto, como uma metodologia alternativa na análise do comportamento mecânico de estruturas de concreto sob corrosão.

Com o propósito de estudar a formação das fissuras em estruturas de concreto sujeitas à corrosão, Šavija et al. (2013) desenvolveram um modelo bidimensional que fosse capaz de representar o comportamento mecânico dos elementos. O modelo foi desenvolvido embasando-se no modelo "Lattice" desenvolvido na Universidade de Delft (SCHLANGEN; GARBOCZI, 1996; SCHLANGEN; GARBOCZI, 1997). O modelo leva em consideração a heterogeneidade do concreto, ou seja, considera sua matriz, representada pela junção da pasta de cimento e os agregados, e a zona de transição. A partir deste modelo os autores 
alcançaram resultados mais reais quando comparados a outros da literatura, uma vez os valores obtidos com o novo modelo foram comparados com dados experimentais presentes em outros estudos, validando, portanto, o mesmo. Ademais, observou-se que melhores correlações eram alcançadas, entre os resultados obtidos por meio do modelo proposto e os obtidos experimentalmente, quando acrescentados dois efeitos nas simulações: o de transporte dos produtos de corrosão ao longo das fissuras e de existência de poros na região entre a armadura e o concreto.

Ožbolt, Oršanić e Balabanić (2014) propuseram um modelo tridimensional via MEF acoplado a uma formulação termo-quimo-higro-mecânico para analisar os processos mecânicos e não-mecânicos relacionados a corrosão de estruturas de concreto. A fim de validar o modelo, os autores analisaram vigas de concreto armado inseridas em ambientes com alto grau de agressividade. Os resultados demonstraram que o modelo representava bem o desenvolvimento das fissuras com o avanço da corrosão e que os resultados se tornavam mais realistas quando consideravam apenas metade da superfície da armadura como um ânodo (parte da seção transversal da armadura que está em contato com o concreto exposto aos agentes agressivos). Assim constatou-se que a distribuição dos produtos de corrosão ao longo da seção transversal da armadura não é linear, como muitos trabalhos consideravam até o momento.

Em um estudo elaborado por Du e Jin (2014) foi realizada a análise de influência da representação da mesoestrutura do concreto na modelagem dos danos causados pelo desenvolvimento dos produtos de corrosão em estruturas de concreto armado. $\mathrm{Na}$ modelagem os autores representaram a matriz do concreto como sendo um material compósito, constituído por três principais fases: os agregados, a matriz cimentícia e a zona de transição. Um modelo de dano com plasticidade foi utilizado para descrever o comportamento mecânico da matriz cimentícia e da zona de transição, e, para a distribuição dos produtos de corrosão ao longo da seção transversal da armadura, foi considerado um modelo linear. Comparando com modelos que representam o concreto como sendo um material homogêneo, o modelo heterogêneo proposto pelos autores obteve resultados mais realistas quanto à propagação das fissuras, assim como dos modos de ruptura dos elementos estruturais. Ainda a partir do modelo heterogêneo foi possível observar que a distribuição das tensões causadas pela expansão não é linear, mesmo quando da utilização de uma distribuição linear no desenvolvimento dos produtos de corrosão. Segundo os autores isso ocorre devido à diferença da rigidez da estrutura de concreto que circunda a armadura.

Muthulingam e Rao (2014) realizaram um estudo paramétrico que levava em conta a influência da concentração de cloretos, a configuração estrutural, a distância do mar, a espessura do cobrimento e o diâmetro das armaduras, no avanço da corrosão em estruturas de concreto armado em ambientes marítimos. Para a realização do estudo, foi desenvolvido um modelo via MEF, acoplado ao modelo numérico de Martın-Pérez, Pantazopoulou e Thomas (2001), o qual possibilitou a representação do processo de difusão de cloretos no 
concreto. Os resultados apontam que o ingresso de cloretos no concreto é uniforme ao longo da face da estrutura exposta à atmosfera. Porém o avanço da corrosão não é uniforme ao longo da seção transversal da armadura, tendo maior avanço nas regiões próximas ao concreto de cobrimento exposto ao agente agressor. Quanto à análise paramétrica, foi possível observar uma relação linear entre a corrosão e a distância da estrutura ao mar, e que é intensificado no avanço da corrosão ao aumentar o diâmetro das armaduras ou diminuir a espessura do concreto de cobrimento. Com a variação do diâmetro das armaduras e da espessura do concreto de cobrimento, pode-se perceber que a corrosão afeta de forma não linear ao longo do perímetro da armadura.

A fim de simular a corrosão em estruturas de concreto armado, Nguyen, Bary e De Larrard (2015) acoplaram às equações que regem o comportamento mecânico de estruturas de concreto formulações referentes à carbonatação, à corrosão, à fluência e ao dano do concreto, desenvolvendo um modelo tridimensional capaz de representar a mesoestrutura do compósito. Os resultados mostraram que a fluência e os agregados presentes na matriz do concreto influenciam significativamente na forma de propagação das fissuras com o avanço da corrosão. Os autores também perceberam que é importante levar em consideração a fluência, uma vez que a mesma representa uma deformação de progressão lenta, semelhante a deformação imposta ao concreto pelos produtos de corrosão.

Pluciński (2015) propôs um modelo matemático não linear para descrever os efeitos mecânicos causados pela formação dos produtos de corrosão em estruturas de concreto armado. A fim de simular diferentes elementos de concreto sob corrosão, fez-se o acoplamento do modelo ao método dos elementos finitos. A partir do modelo proposto, é possível determinar o campo de tensões que se desenvolve no entorno da armadura e os pontos sob os quais iniciam-se o desenvolvimento de fissuras. Plucinski constatou que, à medida em que as fissuras se desenvolvem, a corrosão é acelerada devido a facilidade de transporte dos agentes agressivos, demonstrando, portanto, a importância da análise estrutural de elementos de concreto armado, uma vez que as fissuras se iniciam nos vergalhões, não sendo visíveis nas faces externas do concreto.

Zhao et al. (2016) analisaram a relação entre a camada de concreto que é preenchida pelos produtos de corrosão e a quantidade de produtos que são gerados. Conhecendo esta relação foi possível descrever o processo de preenchimento dos poros da matriz cimentícia e o acúmulo de produtos de corrosão na interface aço/concreto. Baseando-se nessa relação, os autores desenvolveram um modelo capaz de representar a fissuração do concreto de cobrimento devido à formação dos produtos de corrosão. O modelo foi validado por meio de experimentos em laboratório, com elementos de concreto sob exposição acelerada de cloretos. Os resultados demonstram que tanto distribuições lineares de formação dos produtos de corrosão quanto não lineares podem ser modeladas por meio do modelo desenvolvido por eles.

Paul e Zijl (2016) coletaram dados de diversas pesquisas experimentais acerca 
de estruturas de concreto fissuradas expostas à cloretos. Com a análise dos dados, os autores desenvolveram um modelo capaz de representar o avanço da corrosão no concreto, levando em consideração a concentração de cloretos no meio, a espessura de cobrimento e as dimensões das fissuras no concreto. A formulação apresentada possibilitou prever o avanço da corrosão com maior exatidão, uma vez que o desenvolvimento progressivo das fissuras e os vazios que estas criam na matriz cimentícia foram agregadas aos mecanismos de transporte dos cloretos no concreto. Como era esperado, os resultados mostraram que a corrosão é mais significativa em regiões com maior concentração de cloretos e com fissuras de maior dimensão (vazios maiores, logo, maior concentração de cloretos). Paul e Zijl (2016) verificaram ainda que os danos causados pela corrosão podem ser melhor relacionados ao teor de cloretos livres na superfície da armadura do que ao teor total de cloretos presentes no meio agressivo.

Por fim, Min et al. (2017) analisaram e desenvolveram um modelo multi-físico para a representação do processo de difusão do dióxido de carbono no concreto. No modelo os autores incorporaram a influência da porosidade do concreto às equações de difusão do $\mathrm{CO}_{2}$, utilizando para isso, um modelo probabilístico da distribuição e dispersão de vazios em um meio não homogêneo. Os resultados obtidos com o modelo numérico foram comparados com resultados experimentais, comprovando a eficiência da formulação desenvolvida e a sua aplicabilidade para uma representação mais realística da matriz de concreto, considerando suas distintas fases. Diante dos resultados, Min et al. (2017) observaram ainda que a porosidade é um parâmetro de grande influência no processo de difusão do $\mathrm{CO}_{2}$ no concreto, e quanto maior é a concentração de poros em uma região da matriz, maior é a concentração do gás nessa região.

Observa-se de modo geral, que os estudos referentes à corrosão e seus efeitos sobre o comportamento mecânico de estruturas de concreto armado têm de forma contínua, ao longo dos últimos anos, contribuído para o desenvolvimento de novos modelos e formulações. Entretanto, os trabalhos apontam diversos fatores que limitam a determinação destes modelos e os seus domínios de aplicabilidade, por exemplo, a falta de informações referentes às propriedades físicas e mecânicas do material ferruginoso (produtos de corrosão), a correlação da corrente de corrosão natural com a acelerada (utilizada em ensaios laboratoriais) e a determinação dos fatores ambientais que interferem diretamente na progressão da corrosão, assim como a sua influência. 
CAPÍTULO
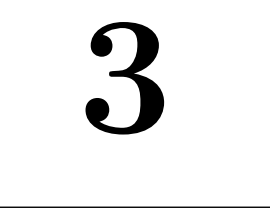

\section{FUNDAMENTOS DA MECÂNICA \\ NÃO-LINEAR}

Neste capítulo são apresentados conceitos referentes à mecânica não linear do contínuo, introduzindo os elementos necessários para o entendimento da formulação utilizada no trabalho, a saber: o Método dos Elementos Finitos Posicional (BONET et al., 2000; CODA, 2003). Os conceitos apresentados ao longo do capítulo se embasam principalmente nas notas de aulas das disciplinas SET5876 - Fundamentos da Mecânica dos Materiais e das Estruturas e SET5884 - Introdução à Dinâmica Não Linear de Estruturas Reticuladas, ambas ministradas pelo professor Titular Humberto Breves Coda, no Departamento de Engenharia de Estruturas da EESC - USP. Para uma melhor descrição do assunto faz-se referência também aos textos (OGDEN, 1997; GERE; TIMOSHENKO, 1997; CRIESFIELD, 1991).

\subsection{Não linearidade geométrica dos sólidos}

As estruturas devem ser projetadas de modo a permanecerem estaticamente equilibradas pelos carregamentos impostos e pelos esforços internos provenientes destes. O equilíbrio descrito pela análise linear geométrica é feito na posição inicial ou sob a configuração indeformada da estrutura.

A obtenção do equilíbrio de estruturas pela análise linear geométrica é considerada fácil e prática (PASCON, 2008). Porém, restringe-se a estruturas sob pequenos deslocamentos, confundindo-se posições iniciais e finais do contínuo.

A medida em que os deslocamentos aumentam, a determinação do equilíbrio de um corpo pela análise linear geométrica deixa de ser coerente, uma vez que as posições iniciais e finais não mais se confundem (CRIESFIELD, 1991). A solução nestes casos é adotar a análise não linear geométrica, onde o equilíbrio passa a ser função da posição 
atual do corpo, levando em consideração os deslocamentos e as deformações impostas.

Criesfield (1991) relata que apesar da análise não linear geométrica apresentar maior complexidade matemática em sua formulação, a mesma torna-se essencial em problemas com grandes deslocamentos, sendo objetivo de estudo em muitos trabalhos (SURANA, 1983; BATHE; DVORKIN, 1986; BÜCHTER; RAMM; ROEHL, 1994; GHALI; NEVILLE; BROWN, 2003; CODA, 2003; CODA; GRECO, 2004; CODA; GRECO, 2008; RIGOBELLO, 2011; SAMPAIO, 2014; KZAM, 2016).

A fim de descrever o movimento de partículas, faz-se necessário adotar uma representação para a mudança de configuração de um corpo. Holzapfel (2000) relata que na mecânica do contínuo duas representações do movimento são amplamente utilizadas, as descrições Lagrangiana e Euleriana.

A descrição Lagrangiana (ou material) melhor se adequa ao movimento das partículas dos sólidos deformáveis, uma vez que o referencial do movimento acompanha o deslocamento das partículas no espaço (OGDEN, 1997).

$\mathrm{Na}$ descrição Euleriana (ou espacial) o referencial é estático (não acompanha o deslocamento das partículas). Esta descrição melhor se adere aos fluídos em movimento, pois é de interesse da mecânica dos fluídos saber o que ocorre em um ponto fixo no espaço a cada intervalo de movimento (COIMBRA, 1978).

Diante do exposto, como no presente trabalho é modelada a deformação de elementos de concreto (i.e., sólidos deformáveis), o movimento será tratado segundo a descrição Lagrangiana, possibilitando a solução de problemas com grandes deslocamentos, com limitação a pequenas deformações. Acrescenta-se ainda que a descrição adotada é a Lagrangiana total, uma vez que o referencial adotado é sempre o inicial, ou seja, a forma indeformada do corpo.

\subsection{Cinemática dos sólidos deformáveis}

A fim de entender e representar o movimento dos sólidos deformáveis, faz-se necessário estudar a cinemática destes corpos. Na cinemática, as causas que geram mudança de configuração de um corpo não são consideradas, e o sólido possuí comportamento semelhante ao de um meio contínuo (um sistema macroscópico sem vazios).

De acordo com Holzapfel (2000) o corpo é representado como um meio totalmente homogêneo e de uma só fase, desconsiderando o fato do material ser constituído de moléculas e átomos. Desta forma, todo o corpo é considerado um conjunto contínuo de pontos materiais, cujas grandezas (posição, velocidade, aceleração, massa e volume) são dadas por meio de funções contínuas (KZAM, 2016).

Segundo Kzam (2016), a determinação de uma função que descreva corretamente as grandezas associadas aos pontos materiais de um contínuo consiste em associar a cada instante do movimento o lugar geométrico dos pontos do corpo, por meio de suas 
coordenadas, em função do referencial espacial, no caso, o espaço Euclidiano.

Assim, para equacionar o equilíbrio de forças na posição atual de um corpo, julga-se necessário descrever o movimento desde a configuração inicial até a atual.

\subsubsection{Configuração de um corpo}

Os corpos são supostos como um conjunto de partículas ou pontos materiais, cujas posições podem ser descritas por intermédio de uma função contínua, que faz correspondência única entre o ponto material e as coordenadas, no espaço Euclidiano, em relação a um referencial.

Na literatura o referencial é denominado de "observador", e possuí origem $\boldsymbol{O}$, fixa no espaço, contendo três eixos, $\hat{\mathrm{e}}_{1}, \hat{\mathrm{e}}_{2}$ e $\hat{\mathrm{e}}_{3}$, os quais formam a base ortonormal do espaço vetorial $\Re^{3}$ (Equações 3.1 e 3.2).

$$
\begin{aligned}
& \hat{\mathrm{e}}_{i} \cdot \hat{\mathrm{e}}_{j}=\delta_{i j} \\
& \hat{\mathrm{e}}_{i} \times \hat{\mathrm{e}}_{j}=\varepsilon_{i j k} \hat{\mathrm{e}}_{k}
\end{aligned}
$$

em que $\delta_{i j}$ é o delta de Kronecker, $\varepsilon_{i j k}$ representa a permutação cíclica de Levi-Civita e $\hat{e}_{i}$, $\hat{\mathrm{e}}_{j}$ e $\hat{\mathrm{e}}_{k}$ representam as componentes cartesianas da base ortonormal.

Para a representação da configuração inicial (indeformada ou de referência), adotase $\vec{X}$, e para a configuração atual (deformada) $\vec{Y}$. Desta forma, a posição de um corpo, especificamente de seus pontos materiais, é dada pelas Equações 3.3 e 3.4.

$$
\begin{aligned}
& \vec{X}=X_{1} \hat{\mathrm{e}}_{1}+X_{2} \hat{\mathrm{e}}_{2}+X_{3} \hat{\mathrm{e}}_{3} \\
& \vec{Y}=Y_{1} \hat{\mathrm{e}}_{1}+Y_{2} \hat{\mathrm{e}}_{2}+Y_{3} \hat{\mathrm{e}}_{3}
\end{aligned}
$$

em que $X_{1}, X_{2}$ e $X_{3}$ representam as coordenadas iniciais de um ponto material no espaço tridimensional, chamadas de coordenadas materiais ou de referência (PASCON, 2008), e $Y_{1}, Y_{2}$ e $Y_{3}$ as coordenadas atuais.

Conhecendo o conceito de configuração de um corpo, pode-se definir e descrever o processo de transformação do estado inicial ao estado atual, ou seja, a mudança de configuração de um corpo.

\subsubsection{Mudança de configuração dos sólidos deformáveis}

Os sólidos deformáveis estão sujeitos a mudanças de configuração quando submetidos a diferentes ações mecânicas (OGDEN, 1997). Na Figura 3.1, $\varphi$ representa uma função mudança de configuração, definida com base na relação entre o mapeamento do sólido na 
configuração de referência e na atual, sendo dada por meio da Equação 3.5.

$$
\varphi=\varphi_{1} \circ\left(\varphi_{0}\right)^{-1}
$$

em que $\varphi_{0}$ é a função referente à mudança da configuração auxiliar à inicial e $\varphi_{0}$ a função de mudança da configuração auxiliar à atual.

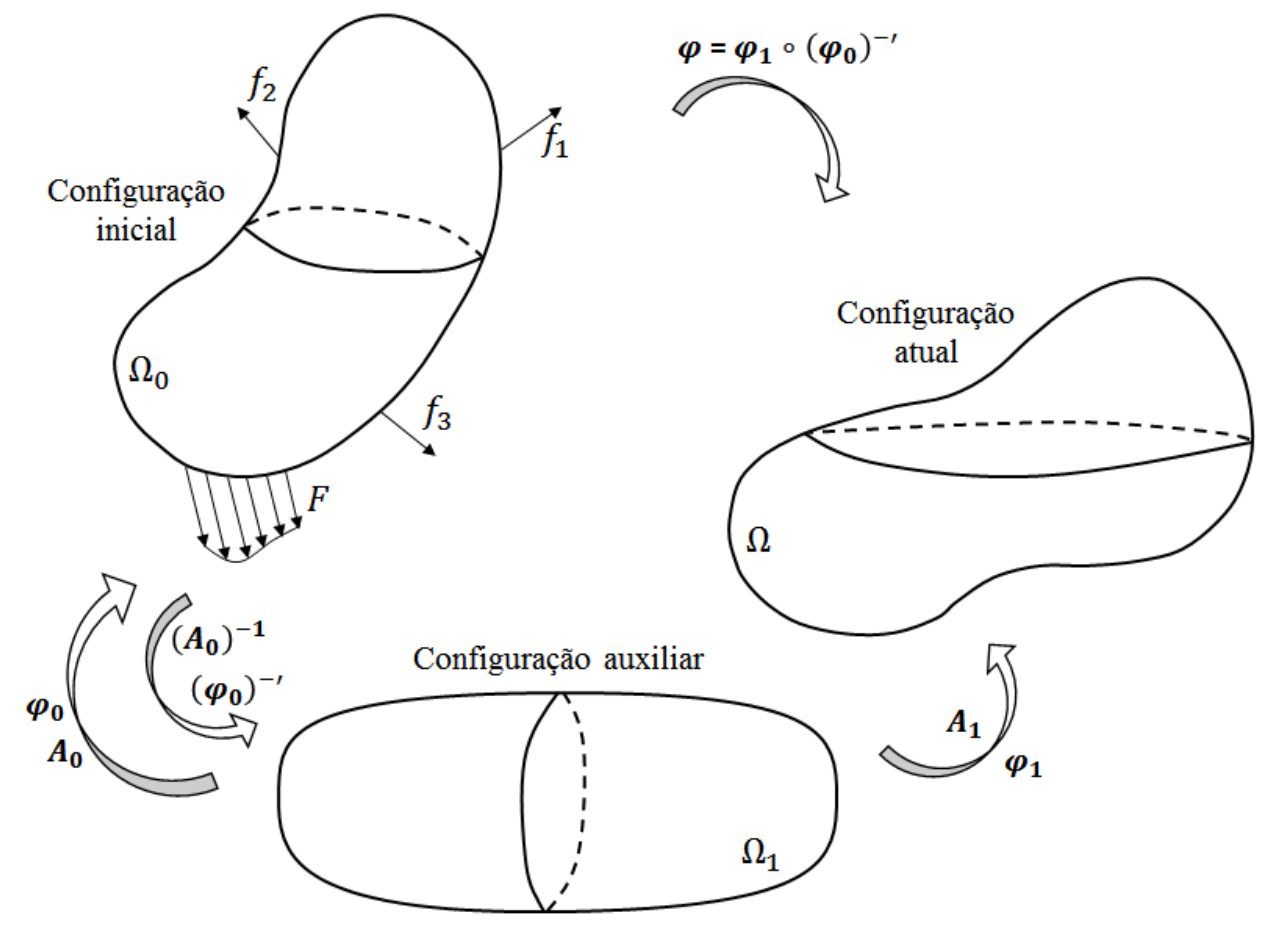

Figura 3.1 - Mudança de configuração de um sólido deformável.

Na maioria dos casos a função mudança de configuração, $\varphi$, é desconhecida, e a sua determinação é feita por meio dos mapeamentos nas configurações indeformada e deformada (Equação 3.5). O mapeamento é determinado de forma única para o cálculo da configuração deformada $\Omega$ e por meio das configurações de referência $\Omega_{0}$ e auxiliar $\Omega_{1}$, que são conhecidas.

\subsubsection{Gradiente de deformação}

Para descrever o processo de mudança de configuração, de $\Omega_{0}$ para $\Omega$, faz-se necessário determinar o gradiente de transformação $\boldsymbol{A}$. O gradiente é um tensor de segunda ordem e fornece informações acerca da variação da função $\varphi$ em relação às coordenadas materiais do corpo. O mesmo pode ser obtido por intermédio da Equação 3.6.

$$
\mathbf{A}=\mathbf{A}_{\mathbf{1}} \cdot\left(\mathbf{A}_{\mathbf{0}}\right)^{-\mathbf{1}}
$$

em que $\mathbf{A}_{\mathbf{0}}=\frac{\partial \overrightarrow{\varphi_{0}}}{\vec{X}}$ e $\mathbf{A}_{\mathbf{1}}=\frac{\partial \overrightarrow{\varphi_{1}}}{\vec{X}}$ são os gradientes de mudança de configuração do corpo no estado inicial e atual, respectivamente. 
De acordo com Coda (2003) a Equação 3.6 possibilita estabelecer uma condição da mecânica do contínuo, a condição local de impenetrabilidade (i.e., o material não penetra em si mesmo e não se aniquila). Para tal, faz-se necessário que o jacobiano da transformação, $J=\operatorname{det}(\mathbf{A})$, seja sempre positivo em todos os pontos materiais do corpo.

O conhecimento do gradiente da função mudança de configuração possibilita a determinação de diferentes medidas de deformação. Fridel (2016) relata que a deformação representa fisicamente as mudanças de forma de um corpo, sendo as principais: a medida de deformação não linear de engenharia, a medida de deformação linear de engenharia e a medida de deformação de Green-Lagrange. Criesfield (1991) apresenta também como principais medidas de deformação o alongamento à direita e à esquerda de Cauchy-Green e a medida de Almansi.

No presente trabalho é adotada a medida de deformação de Green-Lagrange para a descrição e implementação dos elementos finitos, já que a mesma representa coerentemente análises não lineares, por se apresentar na forma de tensor (simétrico), livre da hipótese de pequenos deslocamentos ou rotações, e do movimento de corpo rígido.

\subsubsection{Tensor de estiramento à direita de Cauchy-Green}

Para representar o estiramento quadrático de uma fibra de um sólido na configuração atual, faz-se o uso do tensor à direita de Cauchy-Green $(\mathbf{C})$, visto na Equação 3.7, o qual é fundamental para a obtenção das medidas de deformação utilizadas neste trabalho.

$$
\mathrm{C}=\mathrm{A}^{\mathrm{t}} \cdot \mathbf{A}
$$

Além do tensor de estiramento ser uma medida definida positiva, o mesmo é simétrico e representa a medida Lagrangiana do alongamento de uma fibra do corpo.

\subsubsection{Tensor de deformação Green-Lagrange}

Para Criesfield (1991), o tensor de deformação de Green-Lagrange (Equação 3.8) representa da forma mais simples uma medida não linear de deformação extraída do tensor de estiramento de Cauchy-Green (Equação 3.7). Kzam (2016) relata que a medida de deformação de Green-Lagrange resolve satisfatoriamente boa parte dos problemas da mecânica dos sólidos deformáveis, do ponto de vista da análise não linear geométrica.

$$
\mathbf{E}=\frac{1}{2}(\mathbf{C}-\mathbf{I})
$$

em que $\mathbf{E}$ refere-se a deformação Green-Lagrange, $\mathbf{C}$ é o tensor de estiramento de CauchyGreen e I representa o tensor identidade de segunda ordem.

No caso de elementos unidimensionais (por exemplo, barras de treliça e/ou elementos de fibras), a deformação de Green-Lagrange é dada pela Equação 3.9, definida a partir 
da diferença do quadrado do comprimento de uma fibra do contínuo antes e depois da deformação.

$$
\bar{E}=\frac{1}{2}\left(\frac{\bar{L}^{2}}{{\overline{L_{0}}}^{2}}-1\right)
$$

em que $\bar{E}$ representa a deformação não linear da fibra, ${\overline{L_{0}}}^{2}$ refere-se ao quadrado do comprimento inicial da fibra e $\bar{L}^{2}$ é o quadrado do seu comprimento atual. Destaca-se que ao longo do texto é utilizado termos com barra sobrescrita para referenciar elementos de fibra.

Vale ressaltar que a medida de Green-Lagrange é representativa quando ocorre no corpo uma mudança de configuração com grandes deslocamentos e pequenas deformações. Acrescenta-se que E é uma medida invariante em relação ao sistema de coordenadas e em relação aos movimentos de corpo rígido (OGDEN, 1997).

A fim de mapear o comportamento do material, faz-se necessário adotar a medida de tensão energeticamente conjugada à deformação de Green-Lagrange, o tensor tensão de Piola-Kirchhoff de segunda espécie.

\subsubsection{Lei constitutiva de Saint-Venant-Kirchhoff}

Uma lei constitutiva impõe a relação entre as forças internas de contato, também denominadas tensões, e as mudanças de forma (deformações) do sólido (PASCON, 2008).

No presente trabalho é considerado um modelo constitutivo para materiais elásticos lineares e isotrópicos (Equação 3.10), sendo a energia específica de deformação dada em função da deformação de Green-Lagrange (Equação 3.8).

$$
\begin{aligned}
& u_{e}=\frac{1}{2}(\mathbf{E}: \mathbb{C}: \mathbf{E}) \\
& \mathbb{C}=\left(\frac{2 G \nu}{1-2 \nu}\right) \mathbf{I} \bigotimes \mathbf{I}+G \mathbb{I}
\end{aligned}
$$

em que $u_{e}$ é a energia específica de deformação, $\mathbf{E}$ é a deformação de Green-Lagrange, II é o tensor identidade de quarta ordem, I é o tensor identidade de segunda ordem, $\nu$ é o coeficiente de Poisson, $G$ é o módulo de rigidez transversal do material e $\mathbb{C}$ representa o tensor constitutivo de quarta ordem (Equação 3.11).

\subsubsection{Tensor tensão de Piola-Kirchhoff de segunda espécie}

A partir da energia específica de deformação $u_{e}$, da hipótese de materiais perfeitamente elásticos, e da $2^{a}$ lei da termodinâmica, pode-se estabelecer uma relação entre uma medida apropriada de tensão e de deformação (Equações 3.12 e 3.13).

$$
\mathbf{P}=\frac{\partial u_{e}}{\partial \mathbf{A}}
$$




$$
\mathbf{S}=\frac{\partial u_{e}}{\partial \mathbf{E}}=\mathbb{C}: \mathbf{E}
$$

em que $u_{e}$ refere-se a energia específica de deformação, $\mathbf{E}$ é a deformação de GreenLagrange, $\mathbb{C}$ é o tensor de rigidez elástica (tensor de quarta ordem), $\mathbf{P}$ representa o tensor de tensões de primeira espécie de Piola-Kirchhoff e $\mathbf{S}$ o de segunda espécie.

Observa-se na Equação 3.12 que o tensor tensão de Piola-Kirchhoff, de primeira espécie é o conjugado energético do gradiente da função mudança de configuração. Já na Equação 3.13 apresenta-se o tensor tensão de Piola-Kirchhoff de segunda espécie, como conjugado energético da deformação de Green-Lagrange.

Desta forma, verifica-se que estando o segundo tensor de tensões de Piola-Kirchhoff e a deformação de Green-Lagrange sob a mesma grandeza, denominada energia específica de deformação, torna-se possível derivar uma função em relação ao campo tensorial de deformação ou de tensão e obter uma relação explícita entre tensão e deformação, relação esta denominada por lei constitutiva (CODA, 2003).

Vale lembrar que o tensor $\mathbf{S}$ não possui interpretação física em termos de força de superfície, no entanto é comumente adotado na mecânica computacional na representação dos sólidos deformáveis (CODA, 2003). Entretanto pode-se obter uma relação matemática (Equação 3.14) entre o tensor de tensão de Piola-Kirchhoff de segunda espécie e o tensor de tensões de Cauchy (comumente denominado de medida de tensão verdadeira), a qual possuí interpretação física do estado de tensão do sólido deformável.

$$
\mathbf{S}=J\left(\mathbf{A}^{-\mathbf{1}} \sigma \mathbf{A}^{-\mathbf{t}}\right)^{t}=\operatorname{det}(\mathbf{A})\left(\mathbf{A}^{-\mathbf{1}} \sigma \mathbf{A}^{-\mathbf{t}}\right)^{t}
$$

em que $\mathbf{S}$ é o tensor de tensão de Piola-Kirchhoff de segunda espécie, A é o gradiente de transformação, $\sigma$ é o tensor de tensões de Cauchy e $J$ é o jacobiano do gradiente de transformação.

\subsection{Princípios fundamentais da mecânica dos sólidos}

Determinar o equilíbrio de um corpo é de grande importância em diversos problemas da mecânica computacional (problemas térmicos, fluídos, mecânicos e outros). A fim de equacionar o equilíbrio dos sólidos deformáveis, a seguir apresentam-se dois princípios essenciais da mecânica, sendo eles o princípio da conservação da energia mecânica e o princípio da mínima ação.

\subsubsection{Conservação da energia mecânica}

O princípio da conservação da energia mecânica estabelece que em um sistema físico fechado, no caso o sólido, sob a ação apenas de forças conservativas, a energia mecânica total do sistema permanece constante (OGDEN, 1997). 
Esse enunciado expressa a energia mecânica como a soma da energia cinética e energia potencial total do sistema. Como no presente trabalho é adotado o regime quase estático de aplicação do carregamento, a energia mecânica do sistema é calculada apenas a partir da contribuição da energia potencial total (Equação 3.15), expressa pela soma das parcelas da energia potencial das deformações armazenadas no sólido e da energia potencial das ações externas.

$$
\Pi=U_{e}+\wp
$$

em que $\Pi$ representa a energia potencial total do sistema, $U_{e}$ é a energia potencial das deformações e $\wp$ é a energia potencial externa.

A energia potencial das deformações em termos das quantidades Lagrangianas é calculada sobre o volume inicial por intermédio da Equação 3.16. Já a determinação da energia potencial das forças externas é feita a partir do trabalho realizado pela resultante das forças na configuração atual, dada pela Equação 3.17 .

$$
\begin{aligned}
& U_{e}=\int_{V_{0}} u_{e} d V_{0} \\
& \wp=-\overrightarrow{F_{\text {ext }}} \cdot \vec{Y}
\end{aligned}
$$

em que $U_{e}$ refere-se à energia potencial das deformações internas ao corpo, $u_{e}$ é a energia específica de deformação, $\wp$ é a energia potencial devido às ações externas, $\overrightarrow{F_{\text {ext }}}$ é o vetor de forças externas ao qual o corpo está submetido e $\vec{Y}$ é o vetor das posições atuais dos pontos materiais, nos quais atuam as ações.

O sinal de subtração na Equação 3.17 demonstra que as forças externas ao qual o corpo está submetido são responsáveis por diminuir a capacidade do sólido elástico de armazenar energia potencial de deformação a medida em que se aumenta a intensidade do carregamento.

\subsubsection{Minima ação}

O princípio da mínima ação estabelece que a evolução do sistema da configuração de referência para a configuração atual é tal que a ação é um mínimo (SYMON, 1971). Pela mecânica do contínuo sabe-se que a ação representará um mínimo se e somente se a Equação 3.18 for satisfeita. A Equação 3.18 é denominada na literatura como sendo a equação de Euler-Lagrange e independe do tempo. A mesma serve ainda como base para a formulação Lagrangiana e informa como um sólido deformável evolui da configuração inicial para a atual.

$$
\frac{\partial \mathcal{L}}{\partial \vec{q}}=0
$$

em que $\mathcal{L}$ representa a Lagrangiana do sistema e $\vec{q}$ refere-se ao vetor de coordenadas 
generalizadas.

A Lagrangiana é uma quantidade escalar dada pela diferença entre a energia cinética e a energia potencial total. Como a energia cinética em regime estático de carregamento é desprezada, a Lagrangiana é a própria energia potencial e a Equação 3.18 indica que a energia potencial do sólido é estacionária em relação às coordenadas generalizadas.

Fazendo as substituições do termo à direita da Equação 3.15 na Equação 3.18, obtém-se o princípio da mínima ação (Equação 3.19), que também é conhecido como o princípio da estacionariedade da energia potencial total. É importante ter em mente que a Equação 3.18 representa a segunda lei de Newton para um sistema de forças conservativo em equilíbrio estático.

$$
\frac{\partial \mathcal{L}}{\partial \vec{q}}=-\frac{\partial}{\partial \vec{q}}\left(U_{e}+\wp\right)
$$

Ao substituir a Equação 3.17 na 3.19, considerando a Equação 3.18 e, admitindo que as coordenadas generalizadas estão definidas no espaço Euclidiano, obtém-se que o vetor de coordenadas generalizadas são as posições das partículas na descrição Lagrangiana, ou seja, as posições atuais, que leva à Equação 3.20.

$$
\frac{\partial U_{e}}{\partial \vec{Y}}-\overrightarrow{F_{e x t}}=0
$$

O resultado da Equação 3.20 representa um corolário da lei da ação e reação. Assim, para que o sistema se mantenha em equilíbrio, o conjugado energético das posições deve representar as forças internas que surgem no sólido. Porém o equilíbrio só é satisfeito se o resultado obtido na Equação 3.20 for garantido. Para isso, é necessário se resolver a Equação 3.21, onde as forças externas são igualadas às forças internas, sendo estas dadas em função energia de deformação interna do corpo.

$$
\overrightarrow{F_{\text {ext }}}=\frac{\partial U_{e}}{\partial \vec{Y}}(\vec{Y})=\overrightarrow{F_{\text {int }}}
$$

em que $\overrightarrow{F_{\text {int }}}$ é o vetor de forças internas do corpo.

Como se observa na Equação 3.21, a energia potencial das deformações é uma função não linear das posições. Portanto, é necessário se recorrer a estratégias de solução de sistemas não lineares para se alcançar o equilíbrio das estruturas.

No próximo capítulo é apresentada a estratégia adotada na solução de sistemas não lineares para a determinação do equilíbrio de sólidos deformáveis e o procedimento geral para análise não linear geométrica pelo método dos elementos finitos. 
CAPÍTULO
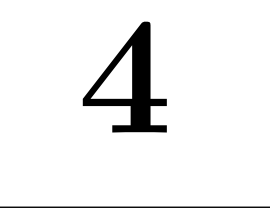

\section{MODELAGEM DE SÓLIDOS \\ COMPÓSITOS VIA MEFP}

Ao longo do presente capítulo apresentam-se conceitos e formulações que dão subsidio à implementação de modelos baseados no MEF para a modelagem de compósitos. Inicialmente define-se o método dos elementos finitos (MEF), o qual é utilizado no presente trabalho para analisar o comportamento mecânico de estruturas de concreto armado. Em seguida, apresentam-se os elementos finitos linear e plano utilizados para a representação dos sólidos. Na sequência são apresentadas as estratégias adotadas no acoplamento entre a matriz e as fibras/partículas.

\subsection{Método dos elementos finitos}

Não se associa ao surgimento do MEF uma data ou um autor. É possível apenas observar que ainda no século XX, com o surgimento e a acelerada evolução da ciência da computação, a utilização do método passou a ser corriqueira na modelagem de diferentes problemas em diversas áreas (mecânica, estrutural, térmica e outras) (ASSAN, 2003).

O método dos elementos finitos (MEF) se apresenta como uma robusta ferramenta numérica para a análise estrutural. A mesma possibilita a discretização de um contínuo (domínio) em uma quantidade finita de elementos (subdomínios). Os elementos responsáveis pela discretização de um domínio (corpo) na modelagem via MEF possuem um determinado número de pontos, sendo denominados de nós. Os nós são caracterizados pela sua localização e possuem parâmetros nodais (os seus graus de liberdade), que, por sua vez, são valores que descrevem a grandeza desejada (força, deslocamento, velocidade, aceleração, entre outras).

De acordo com Pascon (2008) a função aproximadora que descreve a grandeza desejada é descrita somente nos subdomínios do corpo (no domínio dos elementos). Assim, 
não se determina uma aproximação que obedeça às condições de contorno de todo o corpo.

O conhecimento da função aproximadora possibilita a determinação de outras grandezas, por exemplo, da rigidez, pertencentes ao MEF, que possibilita a determinação dos deslocamentos nos nós de cada elemento (utilizado na discretização do corpo), e consequentemente da posição final do corpo. Em conjunto com a mecânica do contínuo podese ainda determinar as deformações causadas em todo o domínio (usando a compatibilidade) e as tensões (com o uso das leis constitutivas).

Como o objetivo deste trabalho é determinar o campo de deformações e consequentemente de tensões em estruturas de concreto armado devido à formação dos produtos de corrosão, faz-se necessário determinar primeiramente o campo de deslocamentos, utilizando para tal o método dos elementos finitos sob formulação Lagrangiana total, o qual é descrito na sequência.

\subsection{Formulação do MEFP}

O método dos elementos finitos utilizado no presente trabalho faz o uso da formulação Lagrangiana total, descrita por Coda (2003). A determinação da posição atual de um corpo, as deformações e as tensões são dadas em função da configuração inicial do corpo e o equilíbrio é expresso pela minimização do funcional da energia de deformação, e obtidas por expressões adequadas a cada material, escritas em função da deformação de Green-Lagrange (Equação 3.8).
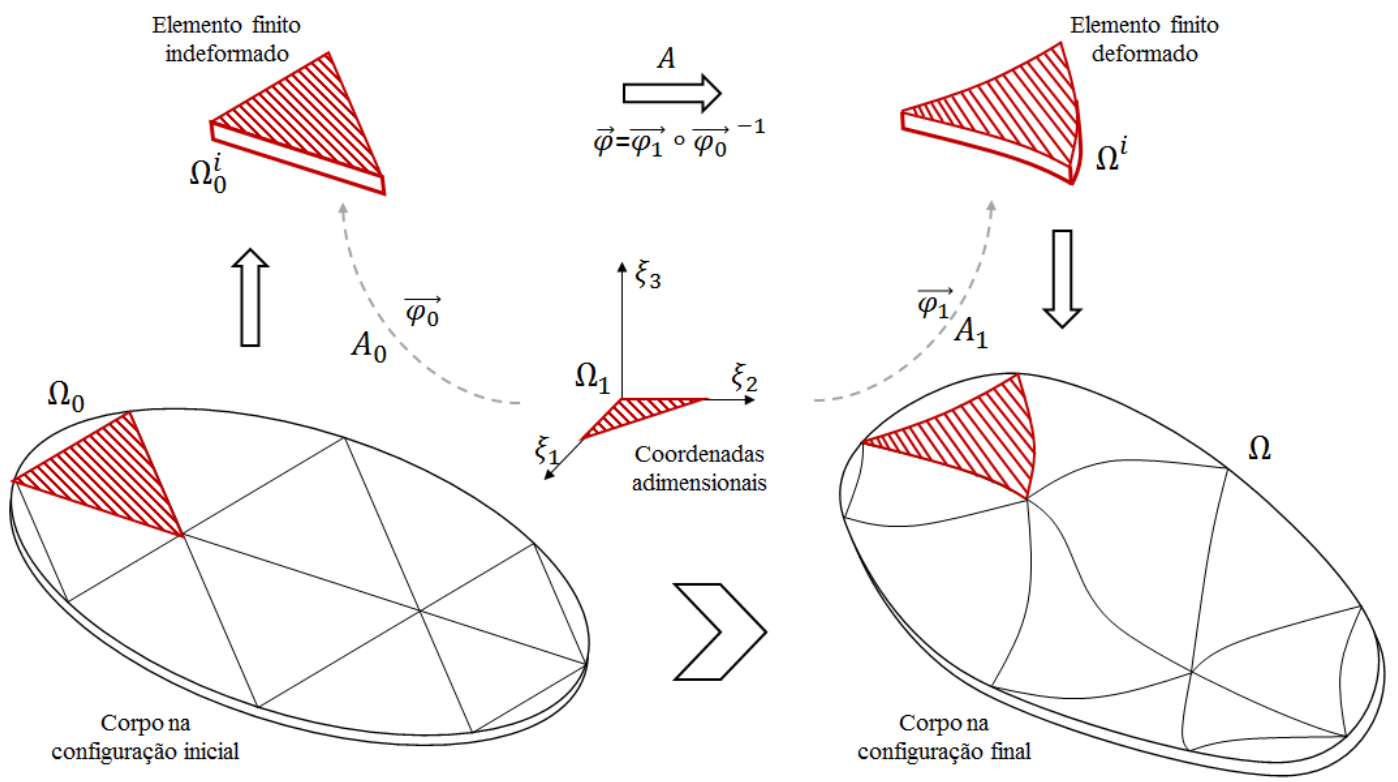

Figura 4.1 - Discretização de um sólido por meio do MEF.

Como relatado anteriormente, a utilização do MEF possibilita a obtenção de uma função aproximadora para a posição atual do corpo, à qual é determinada em cada um elementos finitos que discretizam o sólido. Desta forma, o domínio do corpo discretizado 
por elementos finitos (Figura 4.1), é descrito por meio da união de todos os elementos finitos, conforme mostra a Equação 4.1.

$$
\Omega=\sum_{i=1}^{n e l e m} \Omega_{i}
$$

em que $\Omega$ é o domínio do corpo, $\Omega_{i}$ é o subdomínio do elemento $i$, e nelem refere-se ao número de elementos em que é utilizado na discretização do corpo.

Em seguida, utilizando o artifício de uma configuração auxiliar (Figura 4.1), são escolhidas as funções aproximadoras (Equações 4.2 e 4.3), que descrevem as mudanças de configuração, tanto na posição inicial quanto a atual.

$$
\begin{aligned}
& \overrightarrow{\Omega_{0}}=\overrightarrow{\Omega_{0}}\left(\xi_{1}, \xi_{2}, \xi_{3}\right)=\vec{X}\left(\xi_{1}, \xi_{2}, \xi_{3}\right) \Rightarrow \varphi_{i}^{0}=X_{i}\left(\xi_{1}, \xi_{2}, \xi_{3}\right)=\sum_{j=1}^{n n o s} \phi_{j}\left(\xi_{1}, \xi_{2}, \xi_{3}\right) X_{j i} \\
& \overrightarrow{\Omega_{1}}=\overrightarrow{\Omega_{1}}\left(\xi_{1}, \xi_{2}, \xi_{3}\right)=\vec{Y}\left(\xi_{1}, \xi_{2}, \xi_{3}\right) \Rightarrow \varphi_{i}^{1}=Y_{i}\left(\xi_{1}, \xi_{2}, \xi_{3}\right)=\sum_{j=1}^{n n o s} \phi_{j}\left(\xi_{1}, \xi_{2}, \xi_{3}\right) Y_{j i}
\end{aligned}
$$

em que $\xi_{1}, \xi_{2}$ e $\xi_{3}$ representam as coordenadas adimensionais, nnos é o número de nós do elemento finito, $\vec{X}$ é o vetor posição inicial, $\phi$ é a função de forma, $\vec{Y}$ é o vetor posição atual, $i$ e $j$ referem-se respectivamente à direção e ao nó ao qual a grandeza está associada, $\varphi_{0}$ é o mapeamento da configuração auxiliar à inicial e $\varphi_{1}$, à atual.

É possível observar pelas Equações 4.2 e 4.3 que as funções aproximadoras são dadas em função das funções de forma (conhecidas no método) e pelas posições iniciais (também conhecidas) e atuais (incógnitas do problema). Desta forma, pode-se mostrar que as funções aproximadoras para um certo tipo de elemento finito (por exemplo, barra, chapa ou casca) são descritas em função das suas posições nodais.

Fazendo o uso das Equações 4.2 e 4.3 e da definição do gradiente da função mudança de configuração (Equação 3.6), obtém-se o gradiente de transformação da configuração auxiliar (adimensional) para a configuração inicial (Equação 4.4) e atual (Equação 4.5), e assim, obter os tensores de alongamento à direita de Cauchy-Green (Equação 3.7) e de deformação Green-Lagrange (3.8). Nas Equações 4.4 e 4.5 empregaram-se as notações diádica e indicial, de forma a facilitar a leitura do texto.

$$
\begin{aligned}
& \mathbf{A}_{\mathbf{0}}=\mathbf{\mathbf { A } _ { \mathbf { 0 } }}\left(\xi_{1}, \xi_{2}, \xi_{3}\right) \Rightarrow\left(A_{0}\right)_{i j}=\frac{\partial \varphi_{i}^{0}}{\partial \xi_{j}} \\
& \mathbf{A}_{\mathbf{1}}=\mathbf{A}_{\mathbf{1}}\left(\xi_{1}, \xi_{2}, \xi_{3}\right) \Rightarrow\left(A_{1}\right)_{i j}=\frac{\partial \varphi_{i}^{1}}{\partial \xi_{j}}
\end{aligned}
$$

Utilizando as Equações 3.7, 3.8, 4.4 e 4.5, escrevem-se os tensores de alongamento à direita de Cauchy-Green (Equação 4.6) e de deformação Green-Lagrange (Equação 4.7).

$$
\mathbf{C}=\mathbf{A}^{\mathbf{T}} \mathbf{A}=\left[\mathbf{A}_{\mathbf{1}}\left(\mathbf{A}_{\mathbf{0}}\right)^{-1}\right]^{T}\left[\mathbf{A}_{\mathbf{1}}\left(\mathbf{A}_{\mathbf{0}}\right)^{-1}\right]
$$




$$
\mathbf{E}=\frac{1}{2}(\mathbf{C}-\mathbf{I})
$$

em que $\mathbf{C}$ é o tensor de estiramento à direita de Cauchy-Green, E é a deformação de Green-Lagrange e I é o tensor identidade de segunda ordem.

Para a determinação da tensão de Piola-Kirchhoff de segunda espécie, usa-se o fato desta ser conjugada à deformação de Green-Lagrange, sendo descrita pela Equação 3.13.

O equilíbrio estático de forças na configuração final é obtido por meio do princípio da mínima ação (Equação 3.18) e da consideração de forças conservativas. Para tal, faz-se o uso da energia potencial total (Equação 3.15), à qual é função da solicitação estrutural, da geometria e das propriedades do material.

A solução de problemas segundo a análise não linear geométrica utilizando o MEFP, resume-se na determinação da posição de equilíbrio do corpo (posição atual) à qual a Equação 3.16 deve ser satisfeita.

Como o objetivo principal é a obtenção do vetor de posição atual, $\vec{Y}$, torna-se necessário resolver a Equação 3.21. Porém a sua solução é de difícil obtenção devido ao caráter não linear que a mesma apresenta. Desta forma é imprescindível a utilização de estratégias numéricas que contornem e resolvam o problema. No presente trabalho é utilizado o método de Newton-Raphson, o qual é descrito na sequência.

\subsubsection{Método de solução do sistema não linear}

Sejam $F^{e x t}$ e $F^{i n t}$ os vetores que contém as forças nodais externas e internas, respectivamente, agindo no corpo. O sistema a ser resolvido é o exposto na Equação 4.8.

$$
g_{j}=\frac{\partial \Pi}{\partial Y_{j}}=\frac{\partial U_{e}}{\partial Y_{j}}-F_{j}=F_{j}^{i n t}-F_{j}^{e x t}=0
$$

em que $F_{j}^{i n t}$ é o vetor de força interna, $F_{j}^{e x t}$ é o vetor de forças externas dado pelas condições de carregamento do problema, $g_{j}$ representa o vetor de desbalanceamento (resíduos) e $j$ os graus de liberdade do problema.

Como as posições atuais são as incógnitas do problema no MEFP, utiliza-se o método de Newton-Raphson para encontrá-las. Para isso, adota-se uma posição estimativa para o equilíbrio, e em seguida calcula-se o valor do vetor de desbalanceamento (Equação 4.8), o qual será não nulo. Para aproximar o vetor inicialmente estimado do valor real, devese expandir em série de Taylor (Equação 4.9) o vetor de desbalanceamento na vizinhança da posição tentativa $Y^{0}$.

$$
g_{j}(Y)=g_{j}\left(Y^{0}\right)+\left.\frac{\partial g_{j}}{\partial Y_{i}}\right|_{Y^{0}} \Delta Y_{i}+O_{j}^{2}=g_{j}\left(Y^{0}\right)+H_{i j} \Delta Y_{j}+O_{j}^{2}=0
$$

em que $\Delta Y$ é o vetor de incremento (correção) da posição, $O_{j}^{2}$ representa os termos de ordem superior à dois da série de Taylor e $H_{i j}$ refere-se à matriz Hessiana. 
Desprezando os termos da série de Taylor de ordem quadrática ou superior (ver Equação 4.9), obtém-se o incremento em posição a ser dado na posição estimativa (ver Equação 4.10), e assim iterativamente por meio da Equação 4.11 alcança-se a posição de equilíbrio de tal modo que o vetor de desbalanceamento ou o incremento se tornem suficientemente pequenos, dentro de uma tolerância estipulada.

$$
\begin{aligned}
& H_{i j} \Delta Y_{i}=g_{j}(Y)-g_{j}\left(Y_{0}\right) \\
& Y_{i}=Y_{0}+\Delta Y_{i}=Y_{0}+\frac{-g\left(Y_{0}\right)}{g^{\prime}\left(Y_{0}\right)}
\end{aligned}
$$

Salienta-se que na análise não linear geométrica o carregamento externo aplicado na estrutura é constantemente incrementado de modo a encontrar todas as configurações em que a estrutura, percorrendo o caminho de equilíbrio do corpo.

\subsubsection{Elemento Finito Plano (chapa)}

A Figura 4.2 representa um elemento plano em sua configuração de referência, $\Omega_{0}$, em sua configuração deformada, $\Omega$, e na configuração em coordenadas adimensionais a ser utilizada como configuração auxiliar, $\Omega_{1}$.

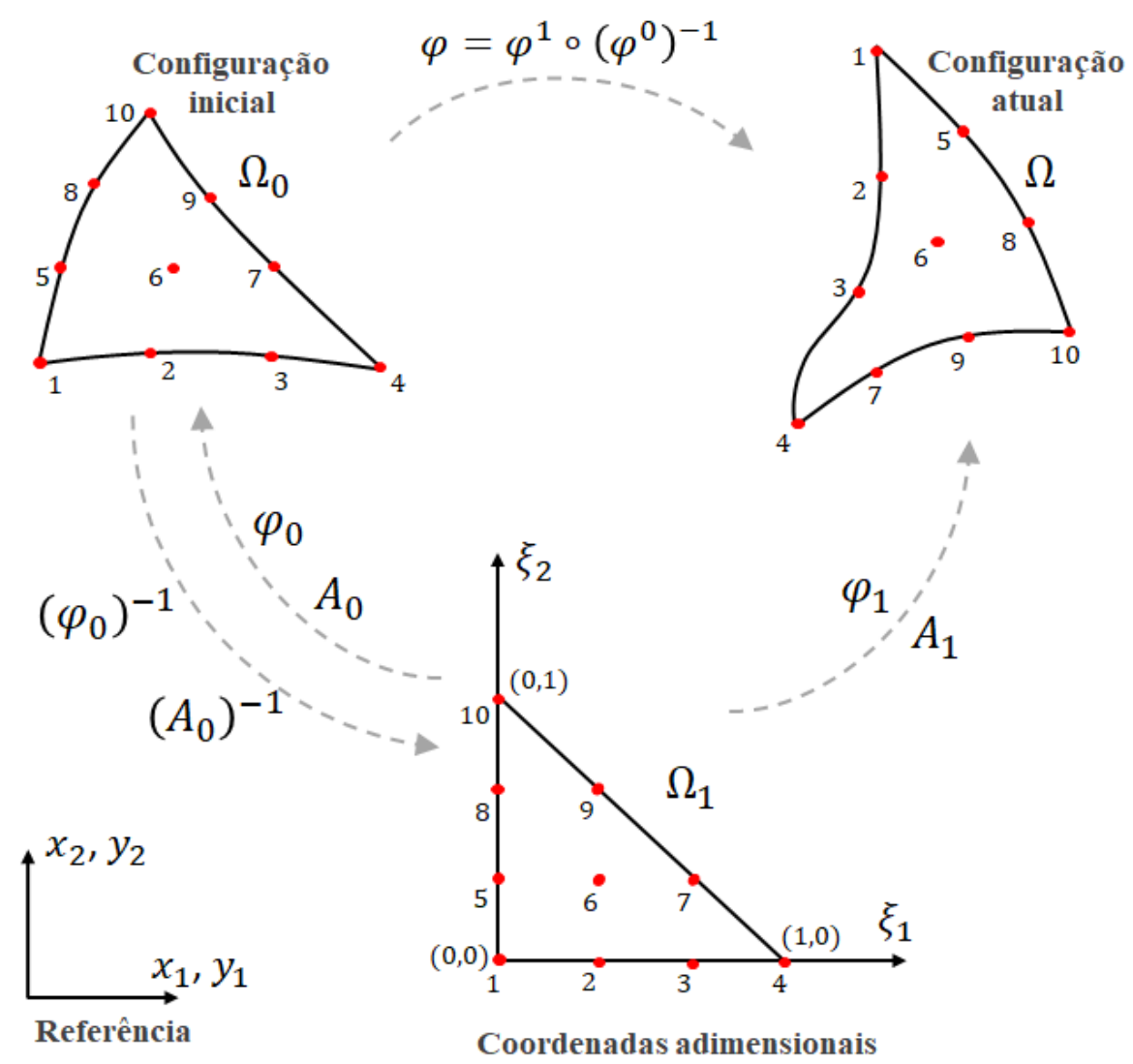

Figura 4.2 - Elemento finito bidimensional do tipo chapa com aproximação cúbica. 
A configuração de referência, $\Omega_{0}$, cujas posições nodais são dadas por $x_{i}$, é mapeada a partir do espaço adimensional via funções de forma, conforme mostra a Equação 4.12.

$$
x_{i}=\varphi_{i}^{0}=\phi_{j}\left(\xi_{1}, \xi_{2}\right) X_{i}^{j}
$$

em que $\varphi$ representa a função que mapeia a configuração auxiliar na de referência, $\xi_{1}$ e $\xi_{2}$ referem-se às coordenadas adimensionais, $\phi_{j}$ são as funções de forma e $X_{i}^{j}$ são as coordenadas nodais dos elementos finitos que discretizam o corpo.

Da mesma forma, a configuração final, $\Omega$, pode ser mapeada em função do espaço adimensional, $\Omega_{1}$, conforme mostra a Equação 4.13 .

$$
y_{i}=\varphi_{i}^{1}=\phi_{j}\left(\xi_{1}, \xi_{2}\right) Y_{i}^{j}
$$

em que $Y$ refere-se às coordenadas nodais atuais. Nas Equações 4.12 e 4.13, os termos $j$ e $i$ referem-se respectivamente aos nós do elemento finito de chapa e às direções e aos graus de liberdade associados a estes nós.

Como já comentado no início do capítulo, a função mudança de configuração que mapeia as posições nodais da configuração inicial para a deformada é desconhecida. Porém, por intermédio da configuração auxiliar, a mesma pode ser escrita pela composição dos mapeamentos da configuração auxiliar à inicial e à atual, conforme Equação 4.14.

$$
\varphi=\varphi^{1} \circ\left(\varphi^{0}\right)^{-1}
$$

Como não é necessário conhecer o mapeamento, os gradientes das funções mudança de configuração podem ser facilmente calculados por intermédio das Equações 4.3 e 4.4.

O elemento finito apresentado na Figura 4.2 pode ter ordem de aproximação $(G R)$ qualquer, e o número de nós do elemento $(N P E)$ pode ser determinado pela Equação 4.15.

$$
N P E=\frac{(G R+1)(G R+2)}{2}
$$

Como no presente trabalho é utilizado elemento finito triangular com ordem de aproximação três, o número de nós por elemento é $N P E=10$, conforme Figura 4.2.

\subsubsection{Energia de deformação}

A energia específica de deformação empregada neste trabalho é descrita pela lei constitutiva de Saint-Venant-Kirchhoff (Equação 3.10), sendo função das componentes do tensor de quarta ordem das constantes elásticas do material (Equação 4.16) e do tensor de segunda ordem das deformações de Green-Lagrange (Equação 4.17).

$$
\begin{aligned}
& \mathbb{C}_{i j k l}=\frac{2 G \nu}{1-2 \nu} \delta_{i j} \delta_{k l}+G\left(\delta_{i k} \delta_{j l}+\delta_{i l} \delta_{j k}\right) \\
& E_{i j}=\frac{1}{2}(\mathbf{C}-\mathbf{I})=\frac{1}{2}\left(A_{k i} A_{k j}-\delta_{i j}\right)
\end{aligned}
$$


Substituindo as Equações 4.16 e 4.17 na Equação 3.10, obtém-se a energia específica de deformação para o Estado Plano de Deformação (EPD) (Equação 4.18) e para o Estado Plano de Tensão (EPT) (Equação 4.19).

$$
\begin{aligned}
& u_{e}=\frac{G}{1-2 \nu}\left\{(1-\nu)\left(E_{11}^{2}+E_{22}^{2}\right)+2 \nu E_{11} E_{22}+(1-2 \nu)\left(E_{12}^{2}+E_{21}^{2}\right)\right\} \\
& u_{e}=\frac{G}{1-\nu^{2}}\left\{E_{11}^{2}+E_{22}^{2}+2 \nu E_{11} E_{22}+\left(1-\nu^{2}\right)\left(E_{12}^{2}+E_{21}^{2}\right)\right\}
\end{aligned}
$$

em que $G$ é o módulo de elasticidade transversal e $\nu$ é o coeficiente de Poisson.

A energia de deformação acumulada em um elemento finito é obtida integrando a energia específica de deformação (Equação 3.10). A integração é feita no volume inicial do elemento, conforme mostra a Equação 4.20.

$$
U_{e}=\int_{V_{0}} u_{e} d V_{0}
$$

Como as funções de forma e o gradiente de transformação estão escritos em função das coordenadas adimensionais, faz-se necessário reescrever a energia especifica de deformação também em função das coordenadas adimensionais, conforme expressa a Equação 4.21.

$$
U_{e}=\int_{0}^{1} \int_{0}^{1-\xi_{2}} u_{e}\left(\xi_{1}, \xi_{2}\right) J_{0}\left(\xi_{1}, \xi_{2}\right) d \xi_{1} d \xi_{2}
$$

em que $J_{0}\left(\xi_{1}, \xi_{2}\right)=\operatorname{det}\left(A_{0}\right)$ é o jacobiano do mapeamento do espaço adimensional na configuração inicial, obtido pelo determinante do gradiente de transformação da configuração auxiliar à inicial.

A Equação 4.21 é resolvida numericamente por meio da quadratura de Hammer (Equação 4.22), substituindo a integral pelo somatório dos valores de $U_{e}$ calculados em pontos pré-estabelecidos do espaço adimensional $\left(\xi_{1}, \xi_{2}\right)$, denominados pontos de Hammer e multiplicados pelos seus respectivos pesos de integração, $w_{i}$.

$$
U_{e}=\sum_{i=1}^{N P H} u_{e}\left(\xi_{1}, \xi_{2}\right) J_{0}\left(\xi_{1}, \xi_{2}\right) w_{i}
$$

No presente trabalho, para a integração numérica via quadratura de Hammer, serão utilizados sete pontos $(N P H=7)$, onde seus valores e respectivos pesos de integração podem ser visualizados no Anexo B.

Assim, a energia total de deformação é obtida como sendo a soma das energias de deformação nos nós do domínio, acumuladas em todos os elementos finitos que discretizam o corpo bidimensional, conforme apresentado na Equação 4.22.

Para a solução do problema mecânico definido pelo sistema não linear apresentado na Equação 3.20, via processo iterativo de Newton-Raphson, faz-se necessário determinar 
a matriz Hessiana, à qual é obtida através da Equação 4.23.

$$
H=\frac{\partial^{2} U_{e}}{\partial y^{2}}
$$

\subsubsection{Elemento Finito linear (Fibras)}

Para modelar elementos lineares, com a finalidade da representação de fibras longas ou curtas, a seguir é apresentada a formulação via MEFP para um elemento de barra simples.

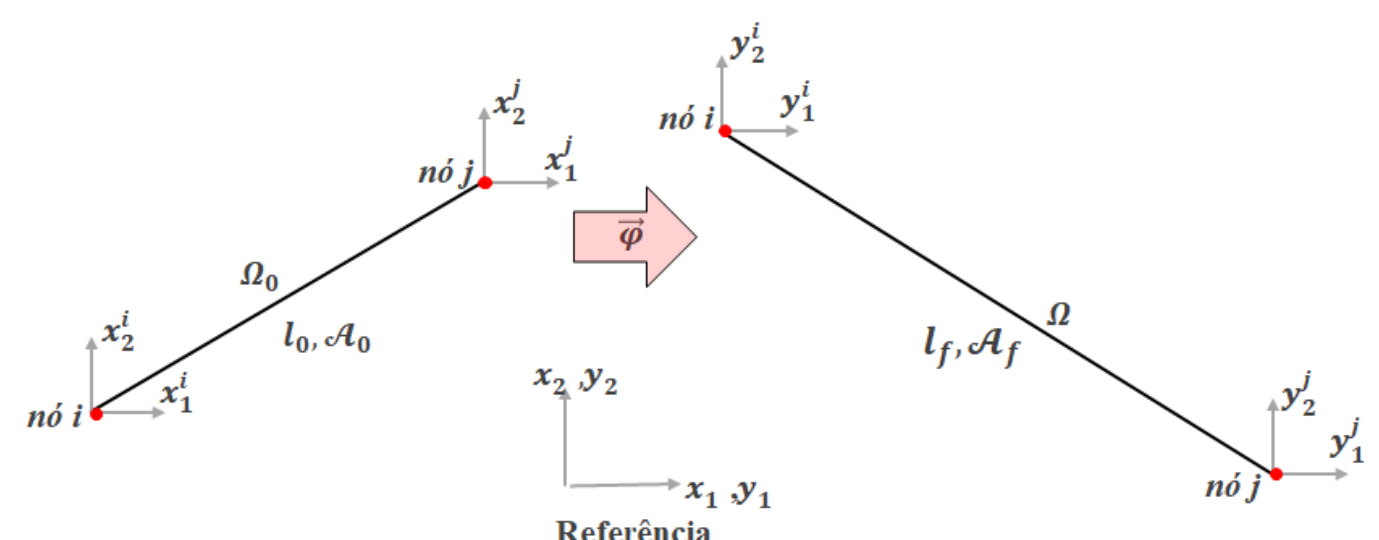

Figura 4.3 - Elemento finito linear (barra de treliça).

Seja o elemento linear, na sua configuração inicial $\Omega_{0}$, e sob determinado carregamento externo, o mesmo se apresentará na forma deformada, $\Omega_{0}$ (Figura 4.3). O elemento apresentado possui aplicação limitada, já que não oferece resistência à flexão.

Sendo $x_{i}^{j}$ as coordenadas referentes às posições nodais do nó $j$ e direção $i$ de um elemento de barra na configuração indeformada e $y_{i}^{j}$ as posições nodais do elemento na configuração deformada, o elemento finito de barra simples, também denominado de treliça, é definido como uma barra, com seção transversal $\mathcal{A}$, conforme mostra a Figura 4.3.

A fim de obter uma função aproximadora para a configuração final do elemento de barra através do MEFP, necessita-se inicialmente determinar a energia interna do elemento de barra. Para isso faz-se necessário conhecer o comprimento da barra nas configurações inicial (Equação 4.24) e final (Equação 4.25).

$$
\begin{aligned}
& l_{0}=\sqrt{\left(x_{1}^{2}-x_{1}^{1}\right)^{2}+\left(x_{2}^{2}-x_{2}^{1}\right)^{2}} \\
& l_{f}=\sqrt{\left(y_{1}^{2}-y_{1}^{1}\right)^{2}+\left(y_{2}^{2}-y_{2}^{1}\right)^{2}}
\end{aligned}
$$

Por meio do comprimento atual e inicial é possível determinar a deformação uniaxial de Green do elemento de barra (Equação 4.26), que se confunde com a deformação não linear de engenharia (Equação 4.27) quando sob pequenos deslocamentos. As Equações 
4.26 e 4.27 se apresentam como medidas objetivas, uma vez que não variam com a direção, sendo dependentes apenas do comprimento da fibra deformada.

$$
\begin{aligned}
& \bar{E}=\frac{1}{2}\left(\frac{l_{f}^{2}}{l_{0}^{2}-1}\right) \\
& \varepsilon=\frac{l_{f}-l_{0}}{l_{0}}
\end{aligned}
$$

A relação constitutiva de Saint-Venant-Kirchhoff também é empregada para o elemento finito linear, cuja energia específica de deformação, para o elemento de barra simples, é expresso pela Equação 4.28. A Equação 4.29 apresenta a energia de deformação total armazenada em um corpo, que é obtida pela integração da Equação 4.28 no volume inicial do elemento.

$$
\begin{aligned}
& u_{e}=\frac{E \bar{E}^{2}}{2} \\
& U_{e}=\int_{V_{0}} u_{e} d V_{0}=\frac{E \bar{E}^{2} V_{0}}{2}=\frac{E \bar{E}^{2} \mathcal{A} l_{0}}{2}
\end{aligned}
$$

em que $\bar{E}$ representa a deformação de Green para o elemento de barra, $V_{0}$ é o volume inicial das barras, $\mathcal{A}_{0}$ é a área do elemento na configuração inicial, $l_{0}$ é o comprimento da barra na configuração inicial e $E$ é o módulo de elasticidade do material.

A primeira derivada da energia de deformação em relação aos parâmetros nodais do elemento finito considerado representa o vetor de forças internas do corpo, sendo dada pela Equação 4.30, ou, de forma expandida, Equação 4.31.

$$
\begin{aligned}
& \frac{\partial U_{e}}{\partial y_{i}^{j}}=\frac{\partial \bar{E}}{\partial l_{f}} \frac{\partial l_{f}}{\partial y_{i}^{j}} \\
& \frac{\partial U_{e}}{\partial y_{i}^{j}}=\frac{\partial}{\partial y_{i}^{j}}\left(\frac{E \bar{E}^{2} \mathcal{A}_{0} l_{0}}{2}\right)=E \bar{E} \mathcal{A}_{0} l_{0} \frac{\partial \bar{E}}{\partial y_{i}^{j}}
\end{aligned}
$$

A matriz Hessiana da barra é dada pela segunda derivada da energia de deformação em relação aos parâmetros nodais do elemento finito considerado (Equação 4.32), ou pela primeira derivada das forças internas em relação às posições nodais. Os termos $i$ e $p$ são referentes às direções (variam de 1 a 2) e $j$ e $m$ referem aos nós de um elemento de barra, que também variam de 1 a 2 , no caso linear.

$$
H_{i j p m}=\frac{\partial^{2} U_{e}}{\partial y_{i}^{j} \partial y_{p}^{m}}=\frac{\partial}{\partial y_{i}^{j}}\left(E \bar{E} \mathcal{A}_{0} l_{0} \frac{\partial \bar{E}}{\partial y_{i}^{j}}\right)=E \mathcal{A}_{0} l_{0}\left(\frac{\partial \bar{E}}{\partial y_{i}^{j}} \frac{\partial \bar{E}}{\partial y_{p}^{m}}+E \frac{\partial^{2} \bar{E}}{\partial y_{i}^{j} \partial y_{p}^{m}}\right)
$$

Os termos referentes à primeira e à segunda derivada da deformação de Green em relação às posições nodais do elemento são dados pelas Equações 4.33 e 4.34 .

$$
\frac{\partial \bar{E}}{\partial y_{i}^{j}}=\frac{(-1)^{j}}{l_{0}^{2}}\left(y_{i}^{1}-l_{i}^{2}\right)
$$




$$
\frac{\partial^{2} \bar{E}}{\partial y_{i}^{j} \partial y_{p}^{m}}=\frac{(-1)^{j}(-1)^{m}}{l_{0}^{2}} \delta_{i p}
$$

em que $\delta_{i p}$ é o delta de Kronecker.

\subsubsection{Acoplamento Fibra-Matriz}

Foi apresentado até agora como obter a energia de deformação (forças internas) e a matriz Hessiana para os elementos finitos do tipo chapa e fibra (barra simples) de forma isolada. Porém ao trabalharmos com os elementos com fibras inseridas no domínio, deve-se garantir a correta interação entre suas partes. Assim, a seguir apresentam-se as estratégias adotadas para a determinação das forças internas e da matriz Hessiana considerando as contribuições em simultâneo de ambos elementos.

O procedimento utilizado para garantir a correta interação entre a fibra e o meio ao qual está inserida (matriz), foi apresentada inicialmente por Vanalli (2004). A formulação proposta garante que as fibras podem ser inseridas no domínio em qualquer posição, sem a necessidade de coincidência dos nós da chapa que discretiza a matriz, e sem aumentar o número de graus de liberdade do problema a ser resolvido.

A representação de elementos de fibras no domínio pode ser feita de diferentes formas (ver Figura 4.4), a depender do arranjo das fibras (descontinuas unidirecionais, descontinuas aleatoriamente orientadas, continuas unidirecionais, bidirecionais e/ou multidirecionais) e da discretização adotada. Assim, um elemento de fibra está inserido no domínio (matriz) de forma que:

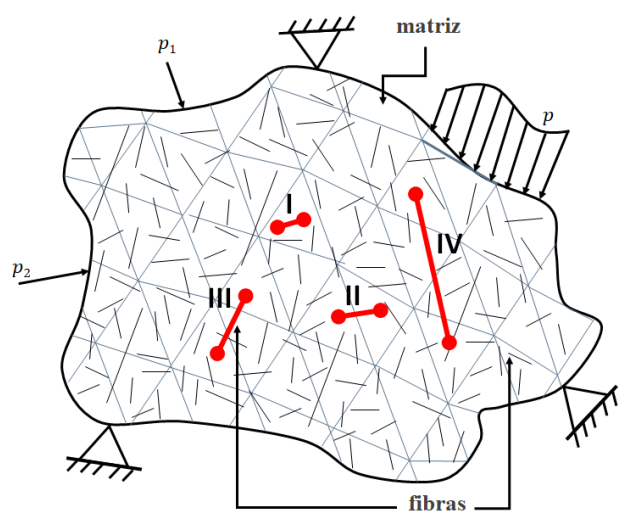

Figura 4.4 - Arranjo das fibras no domínio bidimensional (matriz).

i Os dois nós da fibra estão sob um mesmo elemento da matriz;

ii Os nós da fibra estão em elementos adjacentes com quatro nós em comum;

iii Os nós da fibra estão em elementos adjacentes com um nó em comum;

iv Os nós da fibra estão em elementos que não possuem nós em comum. 
A estratégia adotada por Vanalli (2004) e Vanalli, Paccola e Coda (2008) consiste em escrever as posições nodais do elemento de fibra em função das posições dos nós do elemento da matriz ao qual as fibras estão imersas.

Na configuração inicial escrevem-se as posições nodais do elemento de fibra em função dos pontos nodais da matriz (Equação 4.35), assim como na configuração final (Equação 4.36). A Equação 4.36 garante a aderência dos nós do elemento de fibra à matriz, sem escorregamento.

$$
\begin{aligned}
& \bar{X}_{i}=\widetilde{\phi}_{j}\left(\xi_{1}^{p}, \xi_{2}^{p}\right) \widetilde{X}_{i}^{j} \\
& \bar{Y}_{i}=\widetilde{\phi}_{j}\left(\xi_{1}^{p}, \xi_{2}^{p}\right) \tilde{Y}_{i}^{j}
\end{aligned}
$$

em que $\widetilde{\phi}_{j}$ são as funções de forma do elemento finito da matriz calculadas para as coordenadas adimensionais $\xi_{i}^{p}$ do nó $p$ do elemento de fibra, $\widetilde{X}_{i}^{j}$ e $\tilde{Y}_{i}^{j}$ são as posições nodais do elemento da matriz na configuração inicial e atual respectivamente e $\bar{X}_{i}$ e $\bar{Y}_{i}$ são as posições nodais (inicial e atual) do elemento de fibra dado em função das posições nodais da matriz.

Sampaio (2014) descreve que é possível considerar qualquer quantidade de fibras dispersas no domínio sem que haja acréscimo do número de graus de liberdade do problema, e que a condição de aderência entre a matriz e as fibras permanece garantida. Para facilitar a leitura do texto decidiu-se por escrever os termos referentes à matriz sobrescritos por uma barra curva e os termos referentes a fibra sobrescritos por uma barra reta.

Sabendo disso, é apresentado a seguir como determinar a energia de deformação armazenada no elemento compósito e consequentemente as forças internas.

De modo geral, a energia de deformação interna de um sólido composto com fibras é dada pela soma das energias armazenadas na fibra e na matriz, conforme Equação 4.37.

$$
U_{e}=\widetilde{U_{e}}+\overline{U_{e}}
$$

em que $\widetilde{U_{e}}$ é a energia de deformação armazenada no elemento de chapa e $\overline{U_{e}}$ é a energia armazenada no elemento de fibra.

Desta forma, a força interna no elemento de chapa composto de fibras na direção $i$ e no nó $j$ é obtido por meio da Equação 4.38. A energia de deformação pode ser calculada usando a Equação 4.39. Note que, na Equação 4.39, a energia especifica de deformação da fibra é dada em função da posição nodal da matriz ao qual está associada.

$$
\begin{aligned}
& F_{i}^{j}{ }^{i n t}=\frac{\partial U_{e}}{\partial \widetilde{y}_{i}^{j}}=\frac{\partial\left(\widetilde{U_{e}}+\overline{U_{e}}\right)}{\partial \widetilde{y}_{i}^{j}} \\
& U_{e}=\int_{\widetilde{V}_{0}} \widetilde{u_{e}} d \widetilde{V_{0}}+\int_{\bar{V}_{0}} \overline{u_{e}}\left(\overline{y_{j}}\right) d \overline{V_{0}}=\int_{\widetilde{V}_{0}} \widetilde{u_{e}} d \widetilde{V_{0}}+\int_{\overline{V_{0}}} \overline{u_{e}}(\bar{y}(\widetilde{y})) d \overline{V_{0}}
\end{aligned}
$$


Substituindo a Equação 4.39 na Equação 4.38, obtém-se finalmente a força interna da matriz (Equação 4.40) considerando a inserção de fibras em seu domínio.

$$
F^{i n t}=\frac{\partial U_{e}}{\partial \widetilde{y}}=\int_{\widetilde{V}_{0}} \frac{\partial \widetilde{u_{e}}}{\partial \widetilde{y}} d \widetilde{V_{0}}+\int_{\overline{V_{0}}} \frac{\partial \overline{u_{e}}}{\partial \widetilde{y}}(\bar{y}(\widetilde{y})) d \overline{V_{0}}
$$

A primeira derivada da energia de deformação do elemento de barra simples (fibra) em relação às posições nodais do elemento bidimensional (matriz), é obtida utilizando a regra da cadeia (Equação 4.41). Vale lembrar novamente que a derivada da energia de deformação em relação as posições nodais resulta nas forças internas, e que o vetor de forças internas do elemento de barra simples é diretamente obtido pela Equação 4.29.

$$
\frac{\partial \bar{u}_{e}}{\partial \widetilde{y}_{i}^{j}}=\frac{\partial \bar{u}_{e}}{\partial \bar{y}_{k}^{l}} \frac{\partial \bar{y}_{k}^{l}}{\partial \widetilde{y}_{i}^{j}}
$$

Já o termo referente à derivada das posições nodais da fibra em relação às posições nodais da matriz, são obtidas por meio da Equação 4.42, exceto quando $i \neq k$, que resulta em 0 .

$$
\frac{\partial \bar{y}_{k}^{p}}{\partial \widetilde{y}_{i}^{j}}=\widetilde{\phi}_{j}\left(\xi_{1}^{p}, \xi_{2}^{p}\right)
$$

A matriz Hessiana é definida como a segunda derivada da energia de deformação em relação às posições nodais, ou a derivada das forças internas em relação às posições nodais. No caso do elemento compósito fibra-matriz, deve-se derivar a Equação $4.40 \mathrm{em}$ relação as posições nodais da matriz, obtendo a Equação 4.43.

$$
H_{i j k l}=\frac{\partial^{2} U_{e}}{\partial \widetilde{y}_{i}^{j} \partial \widetilde{y}_{k}^{l}}=\int_{\widetilde{V}_{0}} \frac{\partial^{2} \widetilde{U}_{e}}{\partial \widetilde{y}_{i}^{j} \partial \widetilde{y}_{k}^{l}} d \widetilde{V_{0}}+\int_{\overline{V_{0}}} \frac{\partial^{2} \overline{U_{e}}}{\partial \widetilde{y}_{i}^{j} \partial \widetilde{y}_{k}^{l}}\left(\overline{y_{j}}\left(\widetilde{y}_{i}\right)\right) d \overline{V_{0}}
$$

O primeiro termo da segunda igualdade da Equação 4.43, refere-se à matriz Hessiana de um elemento bidimensional, já descrito na Equação ??.

A segunda derivada da energia de deformação da fibra em relação aos parâmetros nodais da matriz, pode ser expandida conforme Equação 4.44. A segunda derivada da energia especifica de deformação de um elemento de fibra em relação a ele mesmo, referemse a matriz Hessiana do elemento de fibra, já obtida pela Equação 4.32. Os termos restantes da Equação 4.43 são calculados de acordo com a Equação 4.41.

$$
\begin{aligned}
\frac{\partial^{2} \bar{U}_{e}}{\partial \widetilde{y}_{i}^{j} \partial \widetilde{y}_{k}^{l}} & =\frac{\partial^{2} \overline{U_{e}}}{\partial \bar{y}_{\omega}^{\rho} \partial \bar{y}_{\omega}^{\rho}} \frac{\partial \bar{y}_{\omega}^{\rho}}{\partial \widetilde{y}_{i}^{j}} \frac{\partial \bar{y}_{\omega}^{\rho}}{\partial \widetilde{y}_{k}^{l}}+\frac{\partial^{2} \overline{U_{e}}}{\partial \bar{y}_{\omega}^{\rho} \partial \bar{y}_{\pi}^{\eta}} \frac{\partial \bar{y}_{\omega}^{\rho}}{\partial \widetilde{y}_{i}^{j}} \frac{\partial \bar{y}_{\pi}^{\eta}}{\partial \widetilde{y}_{k}^{l}}+ \\
& +\frac{\partial^{2} \overline{U_{e}}}{\partial \bar{y}_{\pi}^{\eta} \partial \bar{y}_{\omega}^{\rho}} \frac{\partial \bar{y}_{\pi}^{\eta}}{\partial \widetilde{y}_{i}^{j}} \frac{\partial \bar{y}_{\omega}^{\rho}}{\partial \widetilde{y}_{k}^{l}}+\frac{\partial^{2} \overline{U_{e}}}{\partial \bar{y}_{\pi}^{\eta} \partial \bar{y}_{\pi}^{\eta}} \frac{\partial \bar{y}_{\pi}^{\eta}}{\partial \widetilde{y}_{i}^{j}} \frac{\partial \bar{y}_{\pi}^{\eta}}{\partial \widetilde{y}_{k}^{l}}
\end{aligned}
$$

Maiores informações acerca da formulação utilizada e da técnica de embutimento adotada no acoplamento dos elementos de fibras ao de chapa (plano), são obtidos em Vanalli (2004) e Sampaio (2014). 


\subsubsection{Elemento Finito Bidimensional (Partículas)}

Com o objetivo de modelar compósitos particulados, são implementados também, elementos de partículas bidimensionais. As partículas são inspiradas em elementos de chapa, tendo a mesma configuração triangular, porém imersos na matriz (ver Figura 4.5), assim como os elementos de fibras descritos na seção anterior.

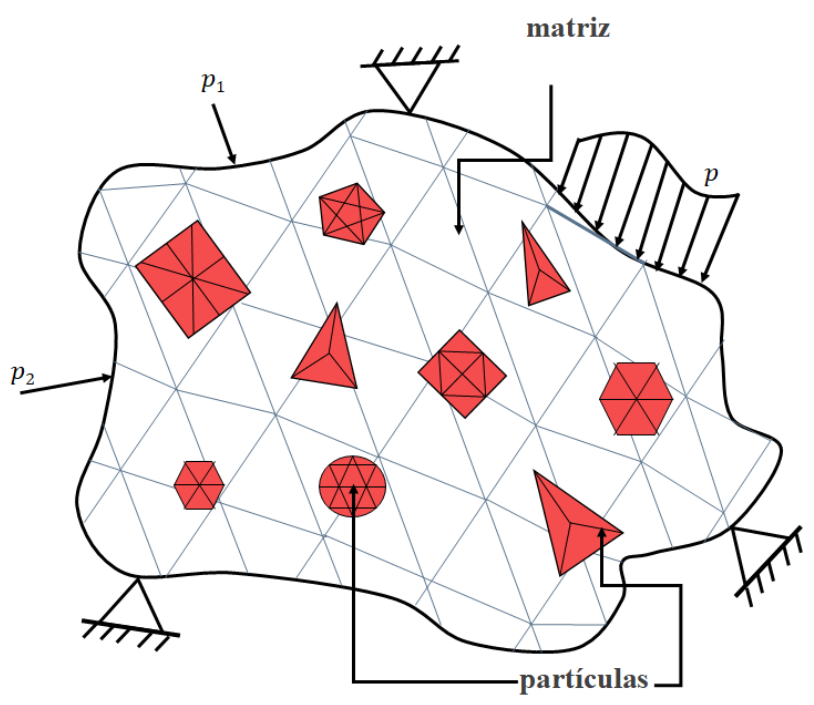

Figura 4.5 - Matriz com elementos finitos de partículas dispersos.

Como a representação das partículas é semelhante à da malha, ou seja, por meio de elementos triangulares e com ordem de aproximação cúbica, as funções de forma, os gradientes de transformação, a energia de deformação interna, as forças internas e a matriz Hessiana, são determinadas de forma análoga ao apresentado na seção 4.2.2, sendo desnecessário a sua reapresentação nesta seção. Assim, na sequência é descrito apenas a estratégia de acoplamento entre os dois elementos finitos.

\subsubsection{Acoplamento Partícula-Matriz}

O procedimento utilizado para garantir a correta interação entre o elemento de partícula e o meio ao qual está inserida, é idêntico ao apresentado no acoplamento fibramatriz proposto por Vanalli (2004).

A formulação é descrita por Paccola e Coda (2016), e garante que as partículas podem ser inseridas no domínio em qualquer posição, sem a necessidade de coincidência dos nós da chapa que discretizam a matriz, e sem aumentar o número de graus de liberdade do problema.

Inicialmente faz-se necessário determinar as coordenadas adimensionais dos nós das partículas em relação aos elementos bidimensionais que representam a matriz. A determinação das coordenadas adimensionais $\left(\xi_{1}^{p_{t}}, \xi_{2}^{p_{t}}\right)$ das partículas é feita igual às dos elementos de fibras (Equações 4.35 e 4.36). 
A determinação das coordenadas adimensionais recai em um sistema de equações que, a depender do grau de aproximação do elemento usado na discretização da matriz, torna-se não linear, sendo então o processo iterativo de Newton-Raphson necessário para a sua resolução. Maiores detalhes são obtidos em Sampaio (2014) e Paccola e Coda (2016).

Determinadas as coordenadas adimensionais, pode-se relacionar as grandezas atribuídas às partículas com as pertencentes à matriz, realizando assim a compatibilização entre os elementos que constitui o compósito.

Assim, devido a consideração de aderência perfeita entre as partículas e a matriz, pode-se determinar a qualquer instante a posição dos nós das partículas em função das posições nodais dos elementos da matriz, conforme descreve a Equação 4.36.

Para a determinação das forças internas (Equação 4.45) é necessário determinar primeiramente a energia de deformação, à qual é calculada pela soma de duas parcelas: uma referente a energia advinda da matriz e outra das partículas (Equação 4.46). Pela Equação 4.46, a energia de deformação da partícula é dada em função das posições nodais da matriz. Para facilitar a leitura decidiu-se por escrever os termos referentes à matriz sobrescritos por uma barra curva e os termos referentes a partícula sobrescritos por um acento circunflexo.

$$
\begin{aligned}
& F_{i}^{j i n t}=\frac{\partial U_{e}}{\partial \widetilde{y}_{i}^{j}}=\frac{\partial\left(\widetilde{U_{e}}+\widehat{U_{e}}\right)}{\partial \widetilde{y}_{i}^{j}} \\
& U_{e}=\int_{\widetilde{V}_{0}} \widetilde{u_{e}} d \widetilde{V_{0}}+\int_{\widehat{V}_{0}} \widehat{u_{e}}\left(\widehat{y_{j}}\right) d \widehat{V_{0}}=\int_{\widetilde{V}_{0}} \widetilde{u_{e}} d \widetilde{V_{0}}+\int_{\widehat{V_{0}}} \widehat{u_{e}}\left(\widehat{y_{j}}\left(\widetilde{y_{i}}\right)\right) d \widehat{V_{0}}
\end{aligned}
$$

Para a determinação dos termos presentes nas Equações 4.45 e 4.46, utiliza-se o mesmo procedimento descrito na seção 4.4, utilizando as Equações 4.38, 4.39 e 4.40.

Assim, pode-se então obter a matriz Hessiana do elemento compósito (partículamatriz). No caso do elemento compósito partícula-matriz, deve-se derivar a Equação 4.45 em relação as posições nodais da matriz, resultando na Equação 4.47.

$$
H_{i j k l}=\frac{\partial^{2} U_{e}}{\partial \widetilde{y}_{i}^{j} \partial \widetilde{y}_{k}^{l}}=\int_{\widetilde{V}_{0}} \frac{\partial^{2} \widetilde{U}_{e}}{\partial \widetilde{y}_{i}^{j} \partial \widetilde{y}_{k}^{l}} d \widetilde{V_{0}}+\int_{\widehat{V}_{0}} \frac{\partial^{2} \widehat{U}_{e}}{\partial \widetilde{y}_{i}^{j} \partial \widetilde{y}_{k}^{l}}\left(\widehat{y_{j}}\left(\widetilde{y}_{i}\right)\right) d \widehat{V}_{0}
$$

O primeiro termo da segunda igualdade da Equação 4.47, refere-se à matriz Hessiana de um elemento de matriz, que pode ser obtido por meio da Equação 4.23.

A segunda derivada da energia de deformação da partícula em relação aos parâmetros nodais da matriz, pode ser expandida conforme Equação 4.48.

A segunda derivada da energia especifica da partícula em relação a suas posições nodais refere-se à matriz Hessiana da partícula, obtida por meio da Equação 4.23. Os termos restantes da Equação 4.48 (derivada das posições da partícula em relação às 
posições da matriz) são calculados de acordo com a Equação 4.44 .

$$
\begin{aligned}
\frac{\partial^{2} \widehat{U}_{e}}{\partial \widetilde{y}_{i}^{j} \partial \widetilde{y}_{k}^{l}} & =\frac{\partial^{2} \widehat{U}_{e}}{\partial \widehat{y}_{\omega}^{\rho} \partial \widehat{y}_{\omega}^{\rho}} \frac{\partial \widehat{y}_{\omega}^{\rho}}{\partial \widetilde{y}_{i}^{j}} \frac{\partial \widehat{y}_{\omega}^{\rho}}{\partial \widetilde{y}_{k}^{l}}+\frac{\partial^{2} \widehat{U}_{e}}{\partial \widehat{y}_{\omega}^{\rho} \partial \widehat{y}_{\pi}^{\eta}} \frac{\partial \widehat{y}_{\omega}^{\rho}}{\partial \widetilde{y}_{i}^{j}} \frac{\partial \widehat{y}_{\pi}^{\eta}}{\partial \widetilde{y}_{k}^{l}}+ \\
& +\frac{\partial^{2} \widehat{U}_{e}}{\partial \widehat{y}_{\pi}^{\eta} \partial \widehat{y}_{\omega}^{\rho}} \frac{\partial \widehat{y}_{\pi}^{\eta}}{\partial \widetilde{y}_{i}^{j}} \frac{\partial \widehat{y}_{\omega}^{\rho}}{\partial \widetilde{y}_{k}^{l}}+\frac{\partial^{2} \widehat{U}_{e}}{\partial \widehat{y}_{\pi}^{\eta} \partial \widehat{y}_{\pi}^{\eta}} \frac{\partial \widehat{y}_{\pi}^{\eta}}{\partial \widetilde{y}_{i}^{j}} \frac{\partial \widehat{y}_{\pi}^{\eta}}{\partial \widetilde{y}_{k}^{l}}
\end{aligned}
$$

Conhecidas as forças internas e a matriz Hessiana do sistema compósito (partículamatriz), determina-se a configuração de equilíbrio estático do corpo (Equação 3.20), obtendo as posições finais e, portanto, a solução do problema.

Na Figura 4.6 é apresentado um fluxograma no qual são descritos os principais processos de cálculo e de processamento de informações do algoritmo para a solução de problemas mecânicos sob o ponto de vista da análise não linear geométrico para sólidos compósitos particulados ou com fibras, baseado no método dos elementos finitos posicional. 


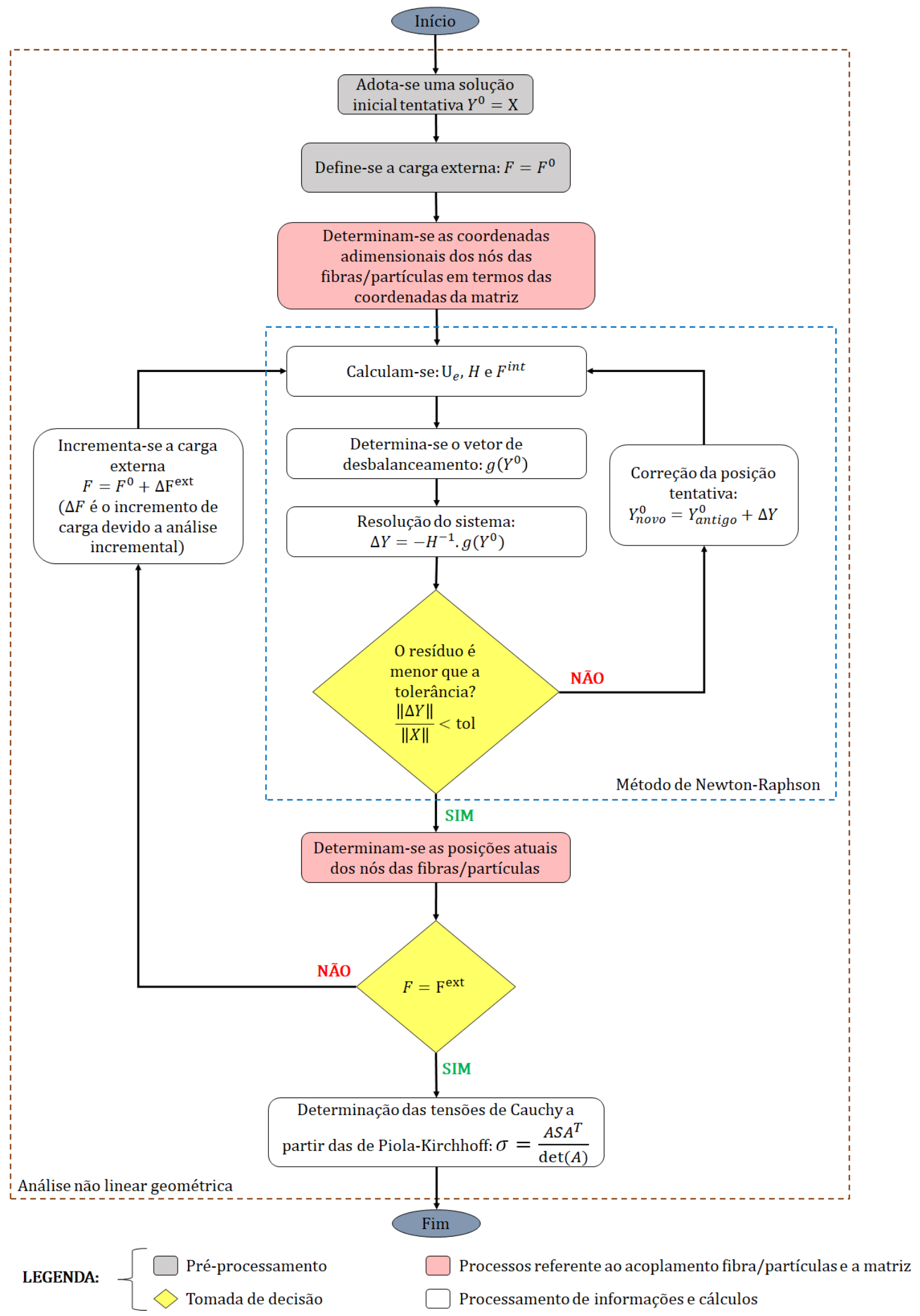

Figura 4.6 - Algoritmo do MEFP para compósitos com partículas. 
CAPÍTULO

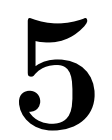

\section{EXEMPLOS DE VALIDAÇÃO}

Com o propósito de validar as formulações implementadas e demonstrar a potencialidade dos programas gerados, alguns exemplos numéricos são apresentados ao longo deste capítulo.

As malhas dos exemplos, foram geradas por intermédio do software desenvolvido no Departamento de Engenharia de Estruturas da EESC-USP, AcadMesh2D ${ }^{1}$.

Para o pós-processamento dos resultados, utilizou-se o software AcadView ${ }^{2}$, também desenvolvido pelo Departamento de Engenharia de Estruturas da EESC-USP.

\subsection{Exemplo 1: Viga sob grandes deslocamentos}

O primeiro exemplo apresenta a análise de uma viga bi-engastada com um grau de liberdade horizontal em uma de suas extremidades, a saber, a direita e, carga transversal aplicada no centro, conforme mostra a Figura 5.1. O mesmo problema foi analisado por Lima e Garcia (2003) e Marques (2006).

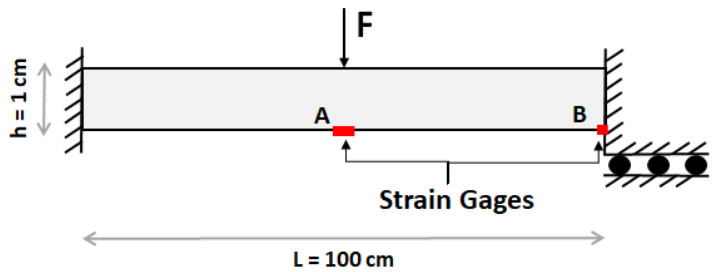

(a) Representação esquemática da viga.

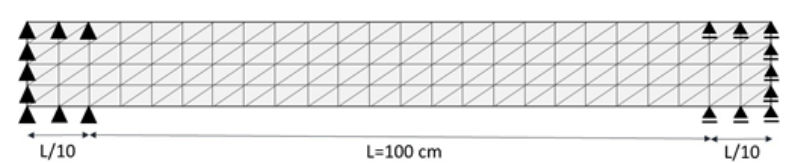

(b) Malha utilizada e condições de contorno.

Figura 5.1 - Geometria e condições de contorno da viga.

1 Disponível para download em: <http://www.set.eesc.usp.br/portal/pt/softwares/27pesquisa/softwares/410-acadmesh $>$. Acesso em janeiro de 2018.

2 Disponível para download em: <http://www.set.eesc.usp.br/portal/pt/softwares/27pesquisa/softwares/157-acadview>. Acesso em janeiro 2018. 
Para a análise, o sólido foi discretizado em 264 elementos finitos e o carregamento foi feito em 48 passos, com incrementos de $0,5 \mathrm{kN}$. As propriedades geométricas da viga são: $L=100 \mathrm{~cm}, h=1 \mathrm{~cm}$ e espessura unitária. O módulo de elasticidade e o coeficiente de Poisson são dados, respectivamente, por $E=24000 \mathrm{kN} / \mathrm{cm}^{2}$ e $\nu=0$.

Nas Figuras 5.2a, 5.2b e 5.2c são apresentadas as configurações deformadas da viga para diferentes níveis de carregamento.
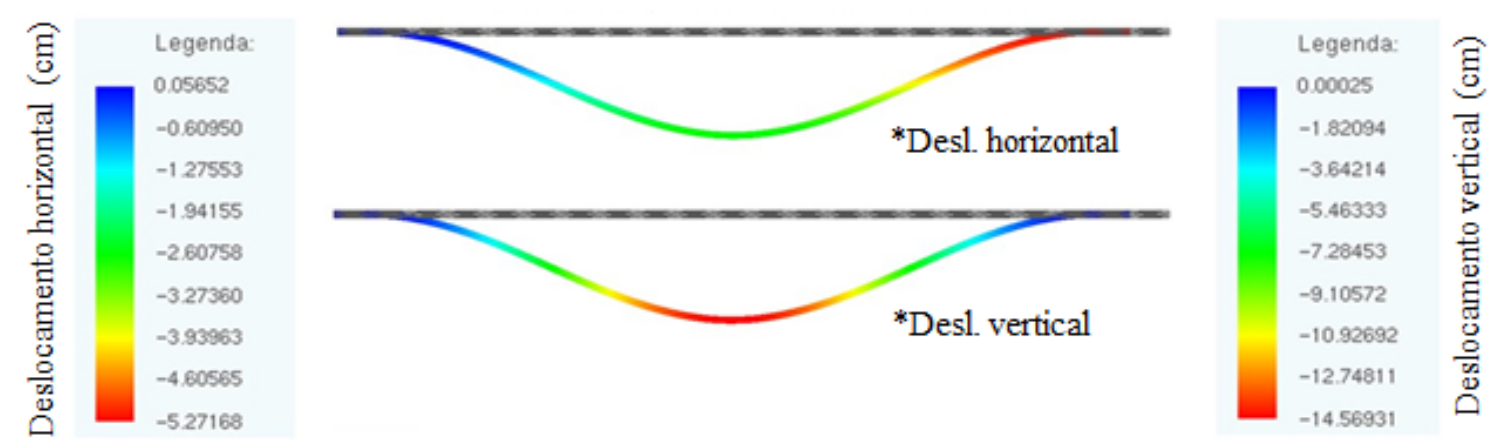

(a) Viga com $\mathrm{F}=6 \mathrm{kN}$.
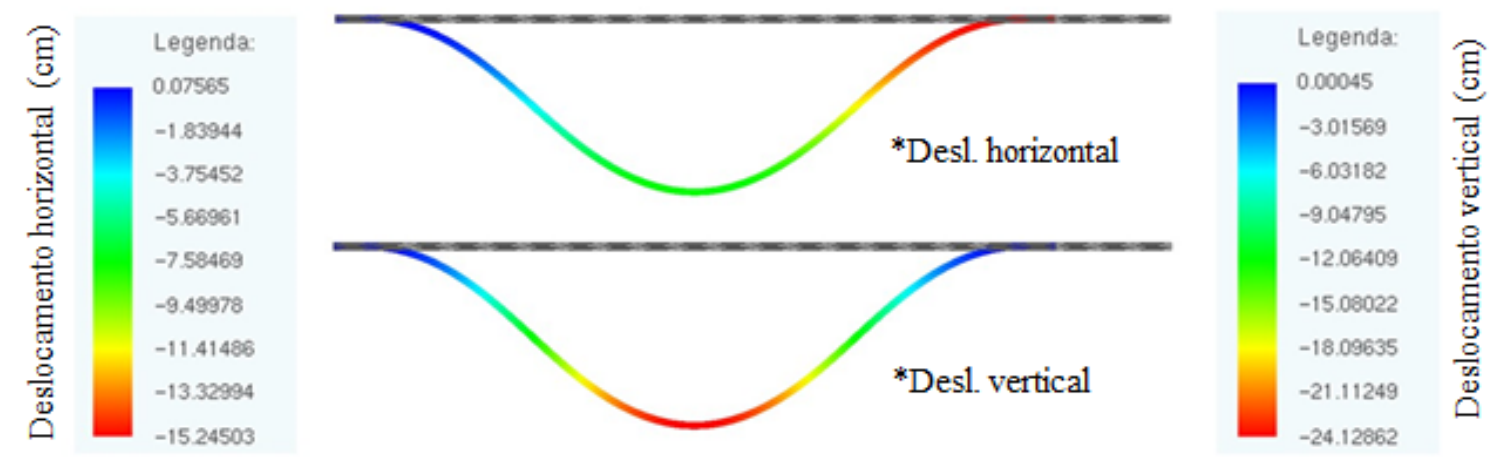

(b) Viga com $\mathrm{F}=12 \mathrm{kN}$.
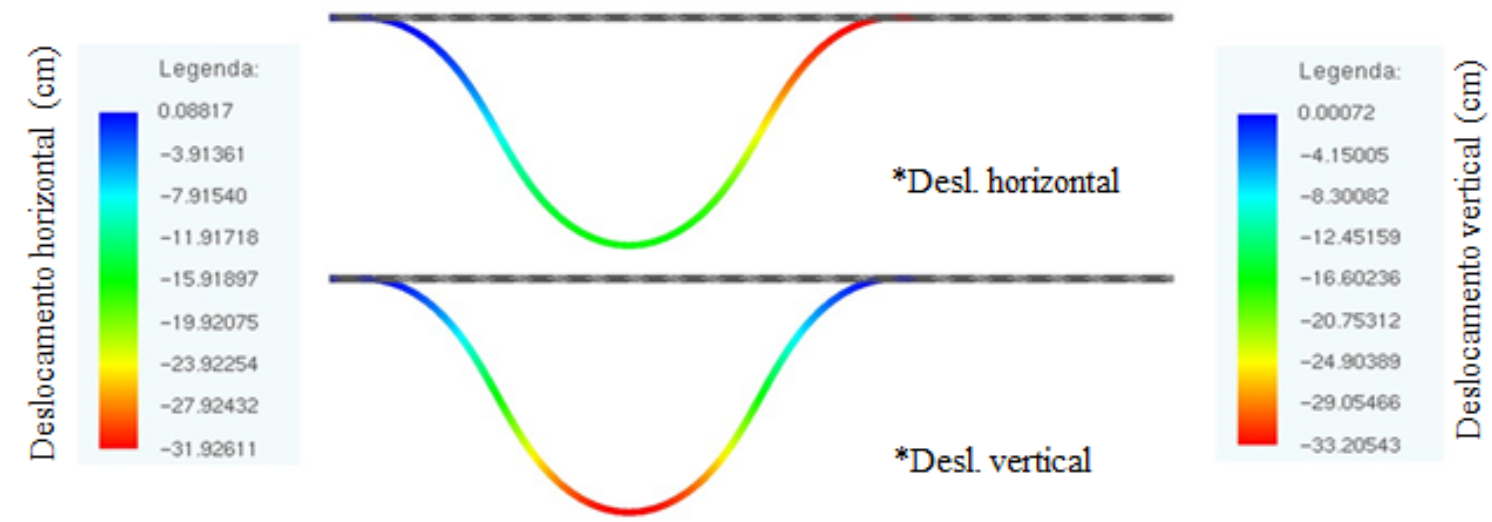

(c) Viga com $\mathrm{F}=24 \mathrm{kN}$.

Figura 5.2 - Configurações deformadas da viga para distintos níveis de carregamento. 
A seguir investigam-se os deslocamentos horizontal (do ponto B) e vertical (do ponto A), conforme indicado na Figura 5.1. Os resultados são apresentados na Figura 5.3 e comparados com os obtidos por Lima e Garcia (2003) e Marques (2006). Cabe ressaltar, que em Marques (2006) foi utilizado o MEF para a resolução do problema mecânico, enquanto que Lima e Garcia (2003) utilizaram a técnica das diferenças finitas.

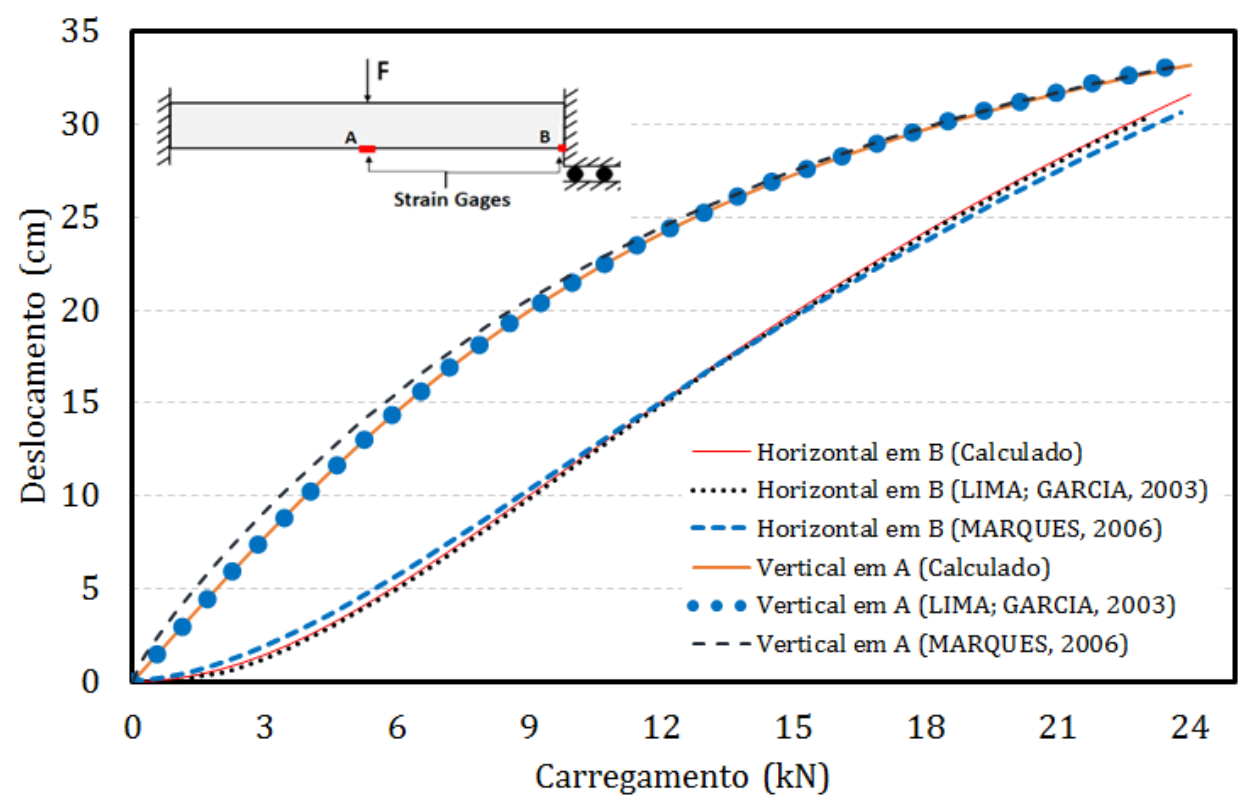

Figura 5.3 - Comparação dos resultados - Exemplo 1.

Na Tabela 5.1, é possível verificar os valores para os deslocamentos horizontal no ponto $\mathrm{B}$, e vertical no ponto A, em cada trabalho. Os deslocamentos referem-se ao último nível de carga, com $F=24 \mathrm{kN}$. Os resultados alcançados no presente trabalho foram mais próximos aos apresentados por Lima e Garcia (2003) do que os Marques (2006). Uma justificativa plausível para esse resultado, seria a maneira como foram impostas as condições de contorno da viga (Figura 5.1b), garantindo de maneira eficiente que a mesma não apresentasse rotações em suas extremidades, e perfeita simetria quanto à sua configuração deformada.

Tabela 5.1 - Comparação entre os resultados - Exemplo 1.

\begin{tabular}{cccc}
\hline Parâmetro & $\begin{array}{c}\text { Presente } \\
\text { Formulação }\end{array}$ & $\begin{array}{c}\text { Lima e Garcia } \\
\mathbf{( 2 0 0 3 )}\end{array}$ & $\begin{array}{c}\text { Marques } \\
\mathbf{( 2 0 0 6 )}\end{array}$ \\
\hline Deslocamento vertical em A (cm) & 33,20 & 33,29 & 33,11 \\
Desvio médio (\%) & - & 0,15 & 0,06 \\
Deslocamento vertical em B (cm) & 31,62 & 31,48 & 30,66 \\
Desvio médio (\%) & - & 0,22 & 1,57 \\
\hline
\end{tabular}

Analisando os resultados, é possível verificar que o código implementado consegue, satisfatoriamente, representar o campo de deslocamentos da estrutura, sendo capaz de 
mapear a configuração deformada do elemento a medida em que é aplicado o carregamento, realizando assim, uma análise estática geométrica não linear.

\subsection{Exemplo 2: Chapa reforçada com fibras}

Baseando-se no exemplo apresentado em Sampaio (2014) e Posterlli (2017), analisase a seguir, uma chapa de argamassa com diferentes configurações de reforço, conforme Figura 5.5. A chapa é solicitada por dois carregamentos uniformemente distribuídos, conforme ilustra a Figura 5.4.

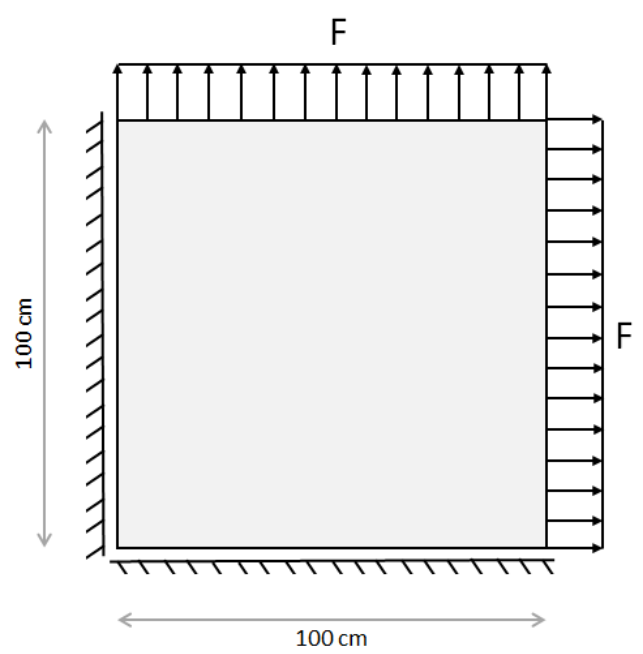

Figura 5.4 - Geometria e condições de contorno da chapa.

Para a representação da chapa de argamassa sem reforço, o sólido foi discretizado em 238 elementos finitos triangulares, com ordem de aproximação cúbica. O carregamento foi feito em 20 passos, com incrementos de carga de $50 \mathrm{kN} / \mathrm{cm}$. O módulo de elasticidade e o coeficiente de Poisson são dados, respectivamente, por $E_{m}=2500 \mathrm{kN} / \mathrm{cm}^{2}$ e $\nu_{m}=0$.

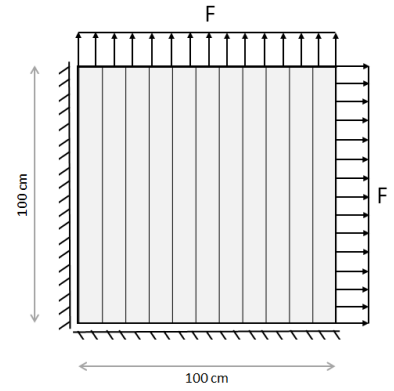

(a) Chapa com fibras longas ordenadas verticalmente.

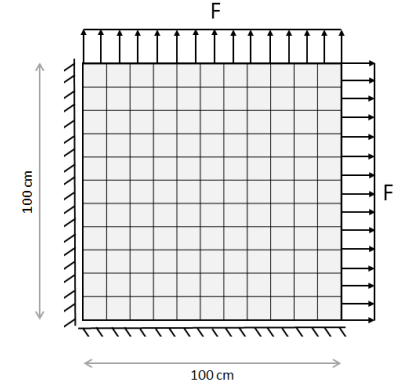

(b) Chapa com fibras longas ordenadas verticalmente e horizontalmente.

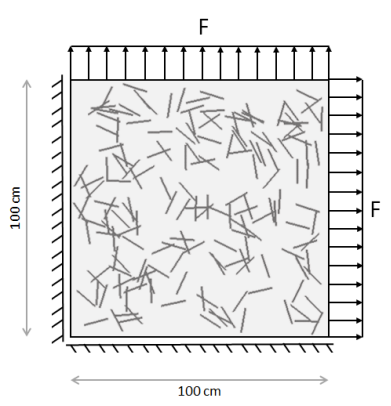

(c) Chapa com fibras curtas dispersas aleatóriamente.

Figura 5.5 - Configurações do reforço nas chapas de argamassa. 
Nas Figuras 5.6a e 5.6b são apresentados os deslocamentos horizontais para o primeiro $(F=50 \mathrm{kN} / \mathrm{cm})$ e último $(F=1000 \mathrm{kN} / \mathrm{cm})$ carregamento, respectivamente, para a placa sem inclusão de fibras.
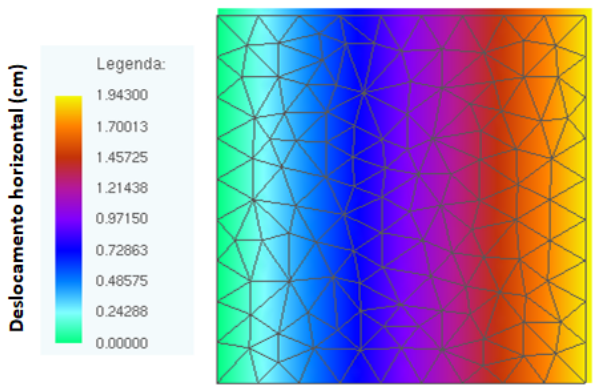

(a) Carregamento de $F=50 \mathrm{kN} / \mathrm{cm}$.
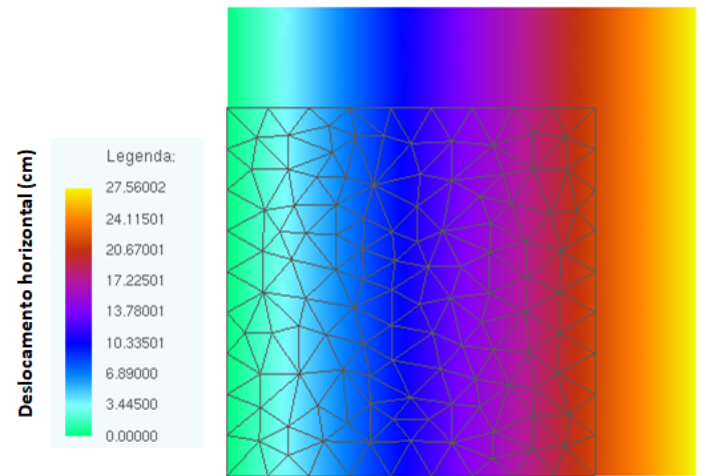

(b) Carregamento de $F=1000 \mathrm{kN} / \mathrm{cm}$.

Figura 5.6 - Deslocamento horizontal da chapa sem fibras.

Nas Figuras 5.7a e 5.7b são apresentados os deslocamentos verticais para o primeiro $(F=50 \mathrm{kN} / \mathrm{cm})$ e último $(F=1000 \mathrm{kN} / \mathrm{cm})$ carregamento, respectivamente, para a placa sem inclusão de fibras.
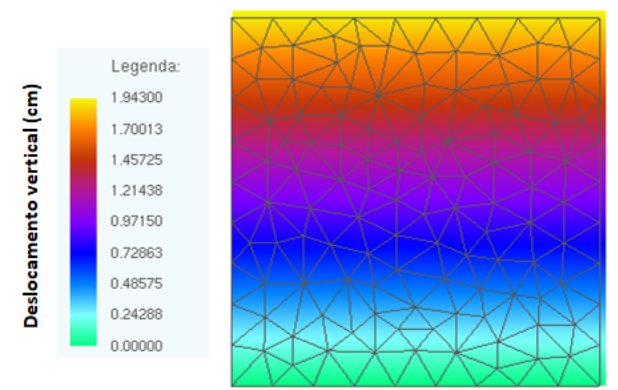

(a) Carregamento de $F=50 \mathrm{kN} / \mathrm{cm}$.

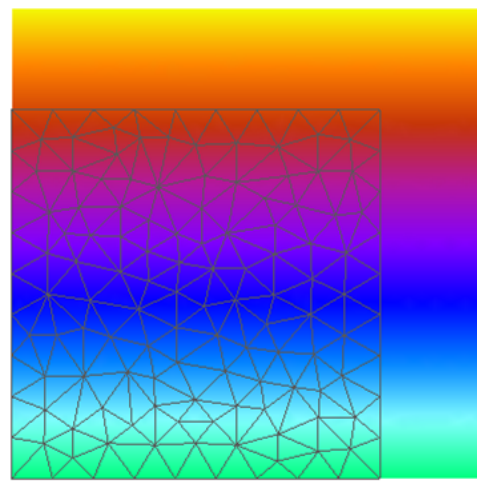

(b) Carregamento de $F=1000 \mathrm{kN} / \mathrm{cm}$.

Figura 5.7 - Deslocamento vertical da chapa sem fibras.

Em seguida, analisou-se a consideração de fibras inseridas na chapa de argamassa. Primeiramente, considerou-se fibras longas ordenadas verticalmente na matriz de argamassa, conforme Figura 5.5a.

A representação da matriz segue idêntica ao do caso anterior. Quanto às fibras longas, cada uma delas foi discretizada por meio de dez elementos finitos lineares. Foram utilizadas ao todo dez fibras longas igualmente espaçadas na matriz. O módulo de elasticidade e área da seção transversal são, respectivamente, $E_{f}=20000 \mathrm{kN} / \mathrm{cm}^{2}$ e $A_{f}=0,1 \mathrm{~cm}^{2}$. 
Os resultados obtidos para os deslocamentos horizontais e verticais, referentes ao último passo de carga, são apresentados nas Figuras 5.8a e 5.9a, respectivamente. Já nas figuras $5.8 \mathrm{~b}$ e $5.9 \mathrm{~b}$, são apresentadas as configurações deformadas das fibras.

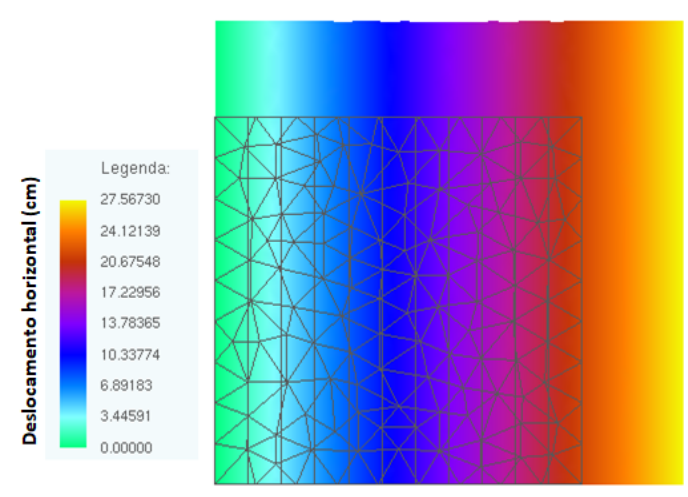

(a) Deslocamento horizontal.

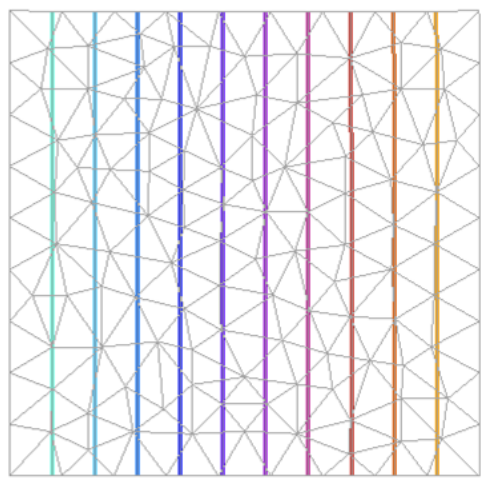

(b) Configuração deformada das fibras.

Figura 5.8 - Deslocamento horizontal da chapa com fibras longas ordenadas verticalmente.

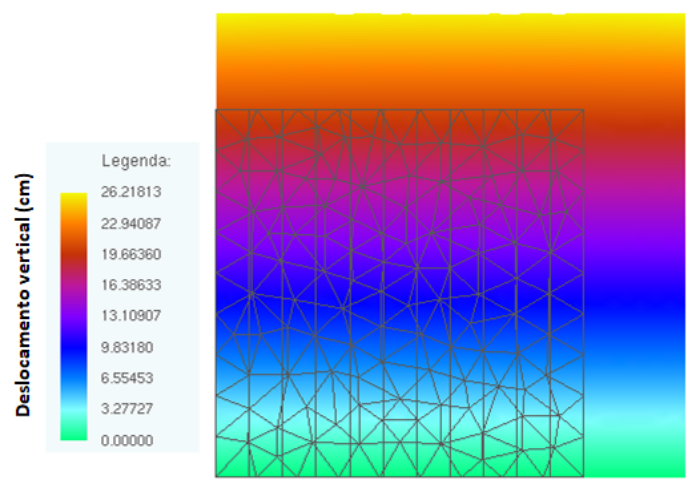

(a) Deslocamento vertical.

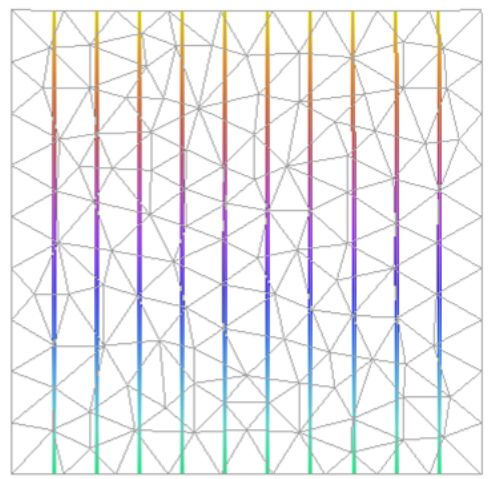

(b) Configuração deformada das fibras.

Figura 5.9 - Deslocamento vertical da chapa com fibras longas ordenadas verticalmente.

Ainda sobre a consideração de fibras longas, analisou-se o reforço da chapa de argamassa, com as fibras ordenadas verticalmente e horizontalmente, conforme mostra a Figura 5.5b.

A representação da matriz segue idêntica ao caso em que não haviam fibras em seu domínio. Quanto às fibras longas, cada uma delas foi discretizada por meio de dez elementos finitos lineares. Foram utilizadas ao todo vinte fibras longas, sendo dispostas dez fibras na direção horizontal e dez na vertical. O módulo de elasticidade e área da seção transversal são, respectivamente, $E_{f}=20000 \mathrm{kN} / \mathrm{cm}^{2}$ e $A_{f}=0,05 \mathrm{~cm}^{2}$.

Os resultados obtidos para os deslocamentos horizontais e verticais, referentes ao último passo de carga, são apresentados nas Figuras 5.10a e 5.11a, respectivamente. Nas figuras $5.10 \mathrm{~b}$ e $5.11 \mathrm{~b}$, são apresentadas as configurações deformadas das fibras. 


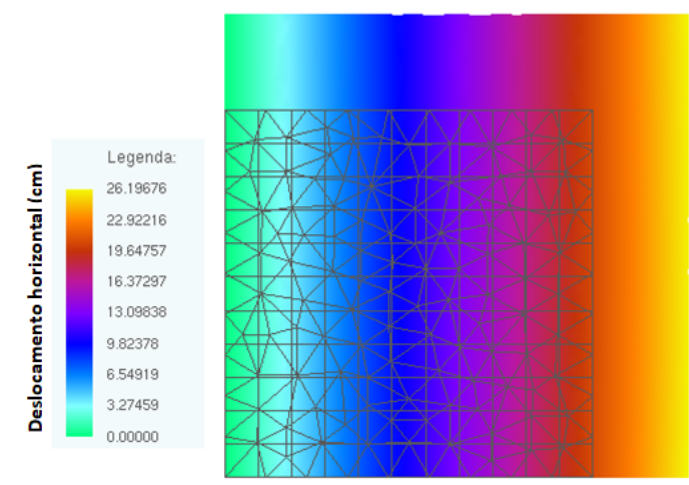

(a) Deslocamento horizontal.

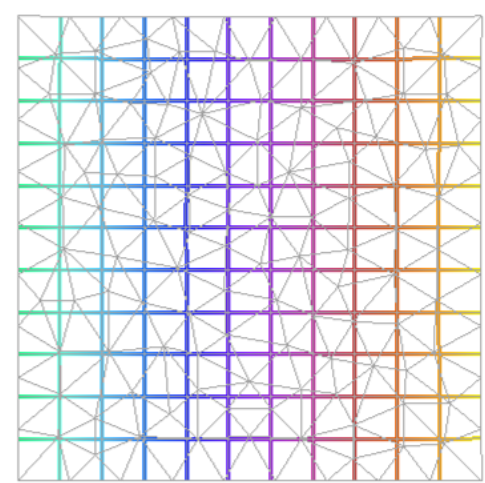

(b) Configuração deformada das fibras.

Figura 5.10 - Deslocamento horizontal da chapa com fibras nas duas direções.

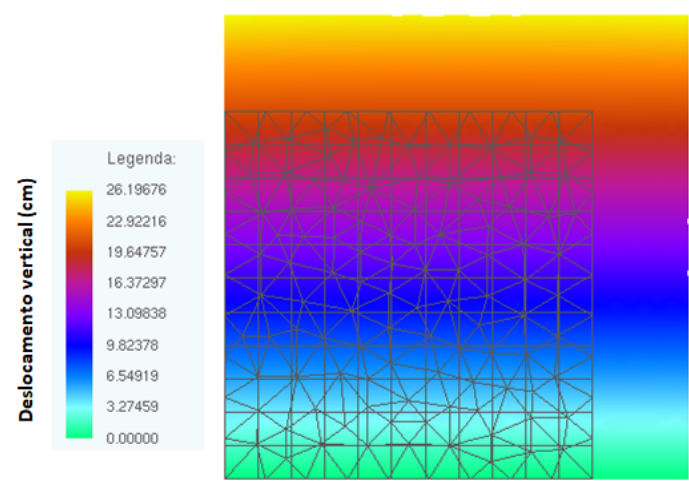

(a) Deslocamento vertical.

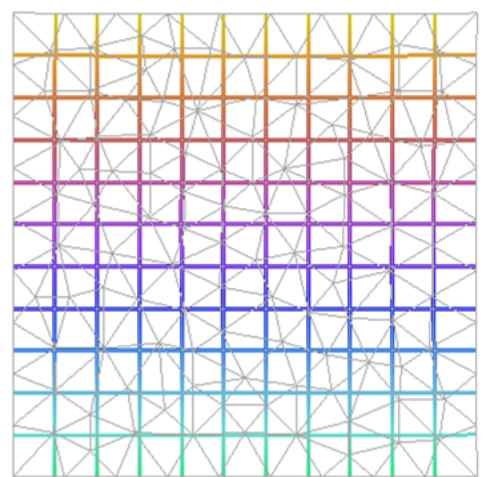

(b) Configuração deformada das fibras.

Figura 5.11 - Deslocamento vertical da chapa com fibras nas duas direções.

Por fim, considerou-se fibras dispersas aleatoriamente como reforço da chapa de argamassa, conforme mostra a Figura 5.5c.

A representação da matriz segue idêntica ao caso em que não haviam fibras em seu domínio. Quanto às fibras, foram dispersas aleatoriamente na matriz 200 fibras curtas (com comprimento de $10 \mathrm{~cm}$ ), com disposição apresentada na Figura 5.5c. O módulo de elasticidade e área da seção transversal são, respectivamente, $E_{f}=20000 \mathrm{kN} / \mathrm{cm}^{2}$ e $A_{f}=0,05 \mathrm{~cm}^{2}$, a área da seção transversal das fibras foi definida de modo a manter a taxa de reforço semelhante aos casos das placas com fibras longas.

Os resultados obtidos para os deslocamentos horizontais e verticais, referentes ao carregamento de $F=1000 \mathrm{kN} / \mathrm{cm}$, são apresentados nas Figuras 5.12a e 5.13a, respectivamente. Já nas figuras 5.12b e 5.13b, são apresentadas as configurações deformadas das fibras.

Na Figura 5.14 são apresentadas as curvas referentes aos deslocamentos horizontais (máximos) obtidos para cada nível de carregamento, para cada um dos casos analisados.

Na Tabela 5.2 são apresentados numericamente os valores máximos obtidos para 


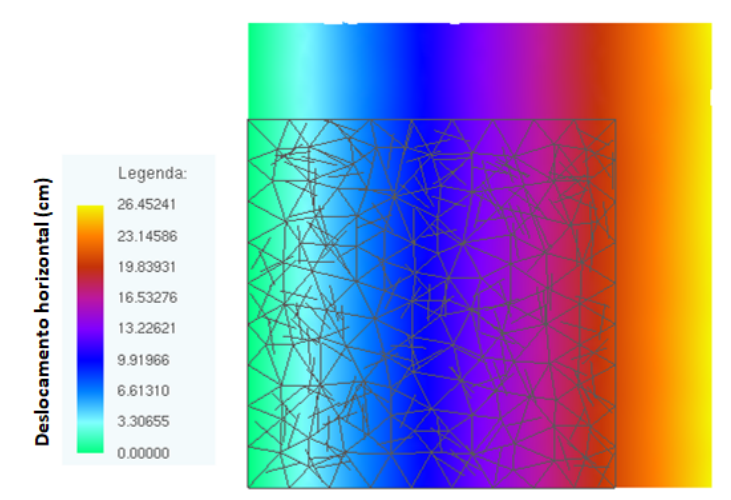

(a) Deslocamento horizontal.

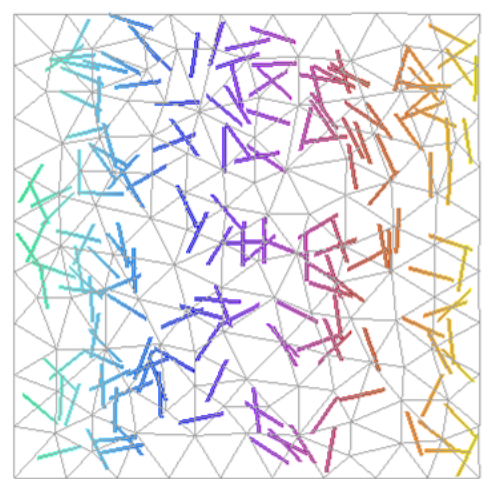

(b) Configuração deformada das fibras.

Figura 5.12 - Chapa com fibras curtas dispersas aleatoriamente.

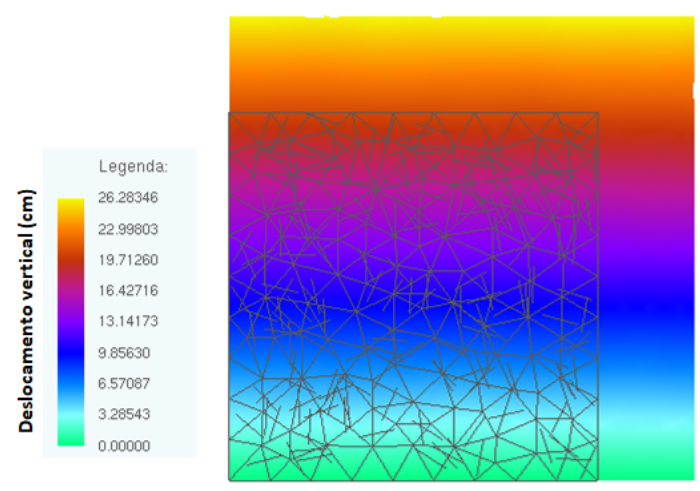

(a) Deslocamento vertical.

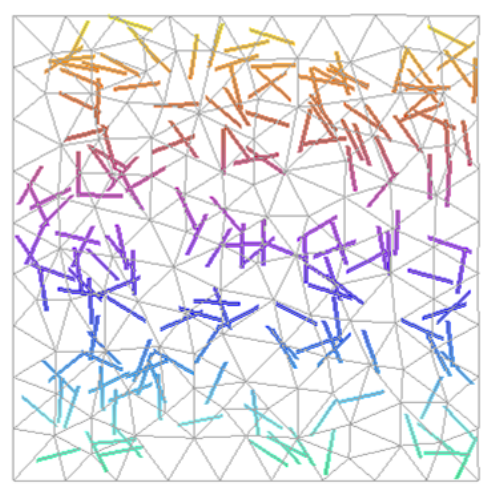

(b) Configuração deformada das fibras.

Figura 5.13 - Chapa com fibras curtas dispersas aleatoriamente.

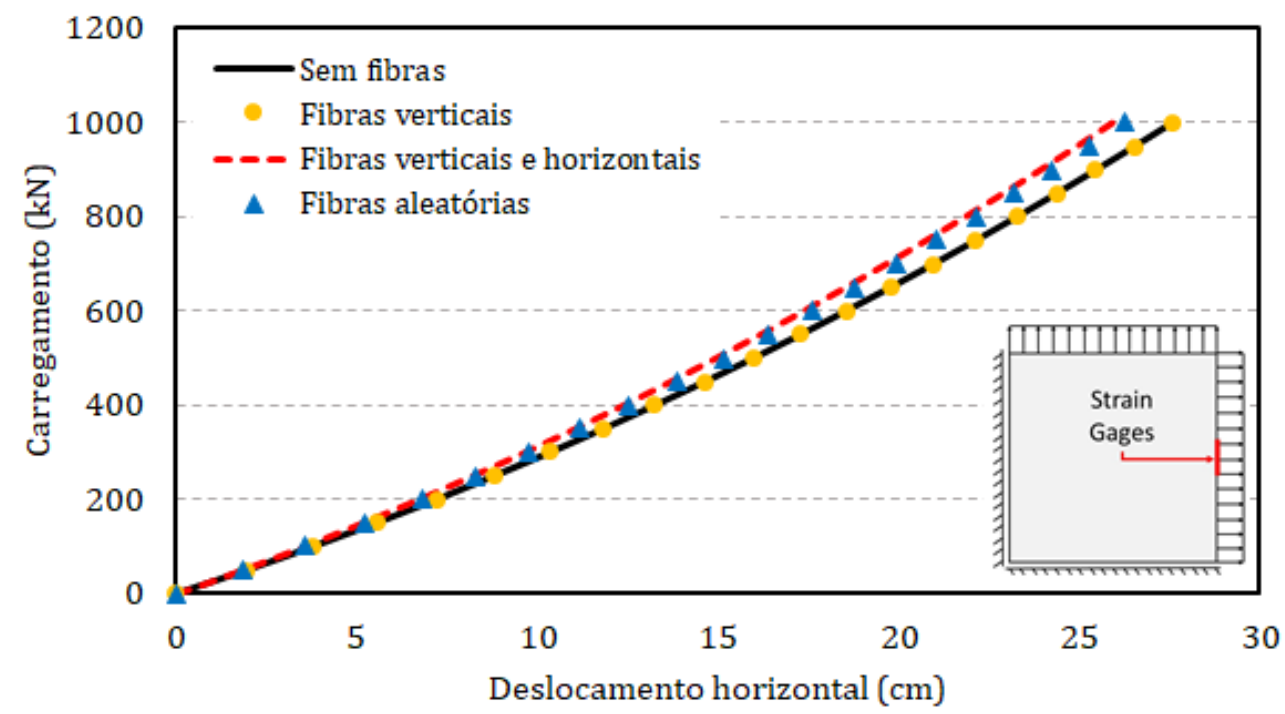

Figura 5.14 - Deslocamentos horizontais máximos da chapa. 
os deslocamentos (considerando $F=1000 \mathrm{kN} / \mathrm{cm}$ ), assim como o módulo de elasticidade equivalente da chapa (nas direções vertical e horizontal).

Tabela 5.2 - Deslocamentos máximos da chapa.

\begin{tabular}{|c|c|c|c|c|}
\hline \multirow[t]{2}{*}{ CHAPA } & \multicolumn{2}{|c|}{ Deslocamento $(\mathrm{cm})$} & \multicolumn{2}{|c|}{$\begin{array}{l}\text { Módulo de Elasticidade } \\
\text { equivalente (GPa) }\end{array}$} \\
\hline & Horizontal & Vertical & Horizontal & Vertical \\
\hline Sem fibras & 27,56 & 27,56 & 25,49 & 25,49 \\
\hline $\begin{array}{l}\text { Fibras ordenadas } \\
\text { verticalmente }\end{array}$ & 27,57 & 25,96 & 25,46 & 27,57 \\
\hline $\begin{array}{l}\text { Fibras ordenadas } \\
\text { verticalmente e horizontalmente }\end{array}$ & 25,97 & 25,97 & 27,55 & 27,55 \\
\hline $\begin{array}{l}\text { Fibras dispersas } \\
\text { aleatoriamente }\end{array}$ & 26,26 & 26,12 & 27,12 & 27,33 \\
\hline
\end{tabular}

Dos resultados obtidos pode-se retirar as seguintes informações:

- As fibras proporcionam aumento de rigidez do sólido apenas na direção longitudinal ao qual foram inseridas na matriz, uma vez que são representadas por elementos finitos lineares, do tipo treliça;

- No caso em que as fibras foram dispostas apenas na direção vertical, observou-se nessa direção um ganho de rigidez de 6,14\%, enquanto que na horizontal, a rigidez manteve-se a mesma do caso sem reforço;

- Na terceira análise, fibras dispostas ordenadamente na direção vertical e horizontal, o ganho de rigidez foi de $6,14 \%$, em ambas as direções;

- Ao analisar o último caso (fibras aleatórias), o ganho de rigidez foi de 5,52\% na direção vertical e 5,05\% na horizontal;

Dessa forma, os resultados demonstram a aplicabilidade do código desenvolvido para a representação de sólidos compósitos com fibras, validando o reforço de sólidos bidimensionais, tanto por fibras longas (ordenadas) quanto por fibras curtas (dispersas aleatoriamente).

\subsection{Exemplo 3: Avaliação do módulo de elasticidade}

Este exemplo possui como objetivo a determinação do módulo de elasticidade longitudinal de um elemento de concreto e, consequentemente, a validação do código implementado para a representação de sólidos compósitos com partículas.

Analisou-se, inicialmente, a deformação de uma chapa constituída somente de argamassa, engastada em uma de suas extremidades e, solicitada por um carregamento uniformemente distribuído em outra, conforme ilustra a Figura 5.15. 


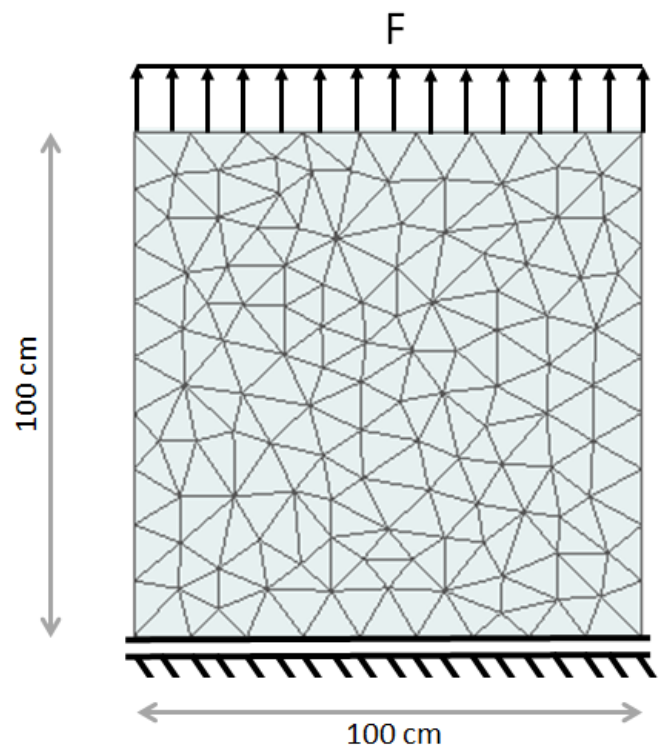

Figura 5.15 - Geometria, malha e condições de contorno da chapa de argamassa.

Para a representação da matriz de argamassa (sem partículas), foram empregados 238 elementos finitos triangulares, com ordem de aproximação cúbica, e o carregamento foi feito em 10 passos, com incrementos de carga de $5 \mathrm{kN} / \mathrm{cm}$. O módulo de elasticidade e o coeficiente de Poisson são dados, respectivamente, por $E_{m}=2500 \mathrm{kN} / \mathrm{cm}^{2}$ e $\nu_{m}=0$.

Nas Figuras 5.16a e 5.16b são apresentadas as configurações deformadas da chapa para o primeiro e último passo de carga. Comenta-se que para uma melhor visualização dos resultados, aplicou-se um fator de escala de 5x nas imagens.
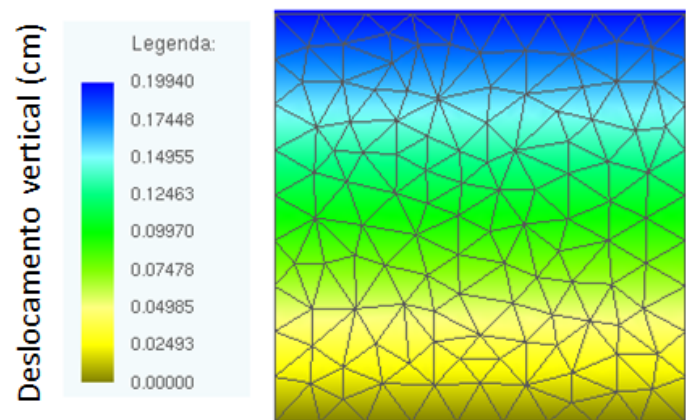

(a) Carregamento de $F=5 \mathrm{KN} / \mathrm{cm}$.
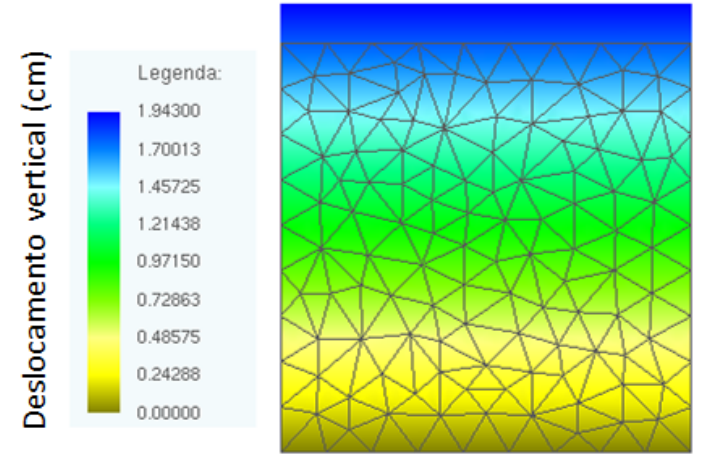

(b) Carregamento de $F=50 \mathrm{KN} / \mathrm{cm}$.

Figura 5.16 - Deslocamento vertical da chapa para o primeiro e último passo de carga. 
Em seguida, com o propósito em representar o concreto, levando em consideração a sua não homogeneidade, acrescentou-se elementos de partículas à matriz, de forma a representar os agregados. Para isso, foram considerados diferentes arranjos representativos, como ilustra as Figuras 5.17a, 5.17b e 5.17c. Contudo, em todos os casos, manteve-se constante a proporção volumétrica de agregados (40\%).

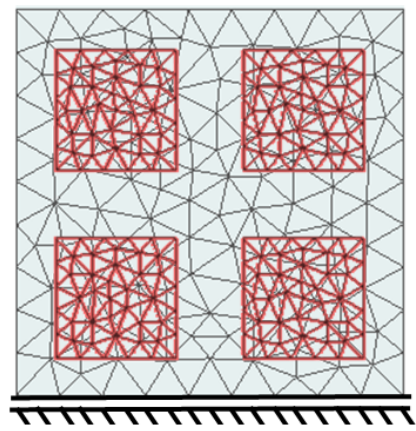

(a) 4 partículas.

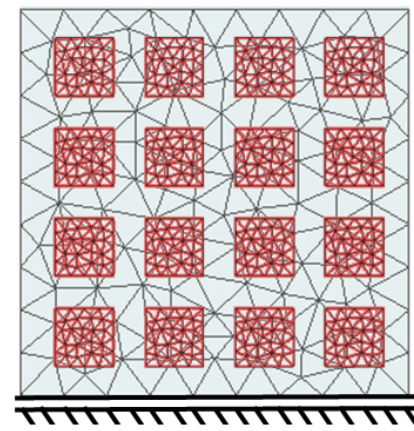

(b) 16 partículas.

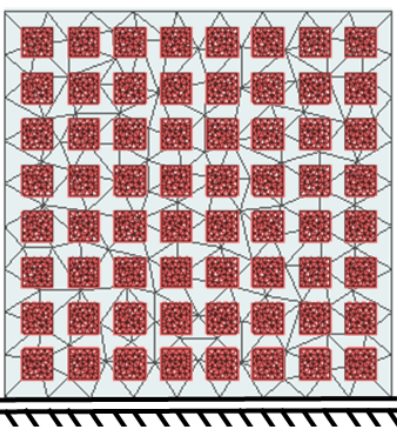

(c) 64 partículas.

Figura 5.17 - Configurações das chapas compósitas (matriz cimentícia + agregados).

A representação da chapa de argamassa permanece a mesma, enquanto que, para a representação dos agregados, foram utilizados 294, 800 e 3200 elementos finitos triangulares com ordem de aproximação cúbica para os casos com 4, 16 e 64 partículas, respectivamente. O módulo de elasticidade e o coeficiente de Poisson dos agregados, são: $E_{p}=7000 \mathrm{kN} / \mathrm{cm}^{2}$ e $\nu_{p}=0$. O carregamento segue o mesmo que da análise anterior.

Os deslocamentos verticais, referentes ao carregamento de $F=50 \mathrm{kN} / \mathrm{cm}$, para as chapas com 4, 16 e 64 elementos de partículas, são apresentados nas Figuras 5.18a, 5.19a e 5.20a, respectivamente. Já nas figuras 5.18b, 5.19b e 5.20b são apresentadas as configurações deformadas das partículas de cada caso.

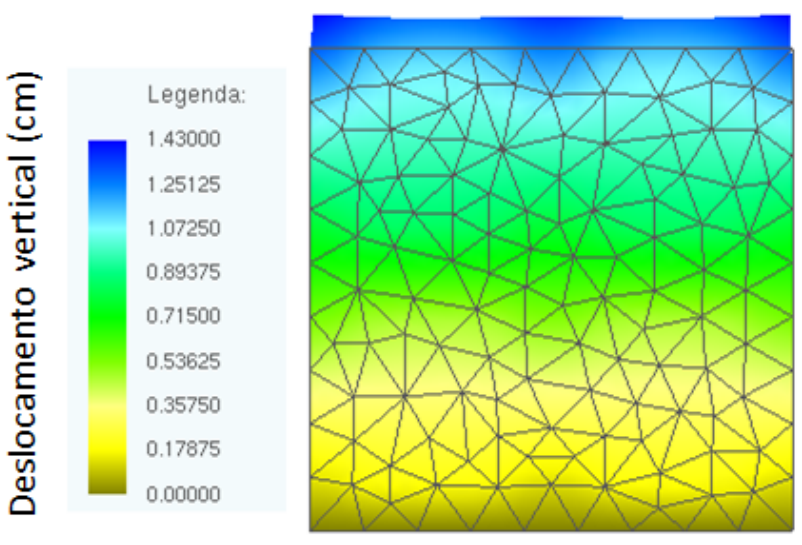

(a) Deslocamento da matriz.

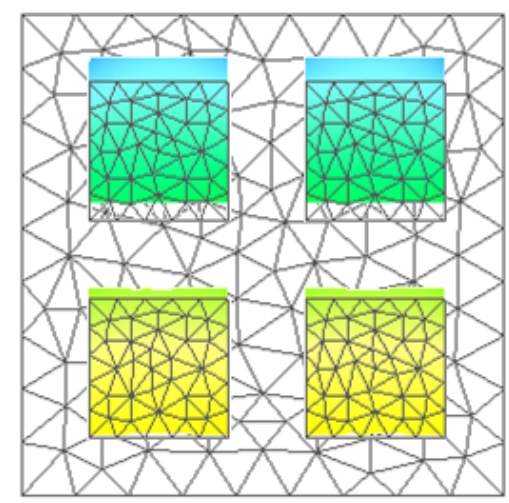

(b) Deslocamentos das partículas.

Figura 5.18 - Configuração deformada da chapa com 4 partículas. 


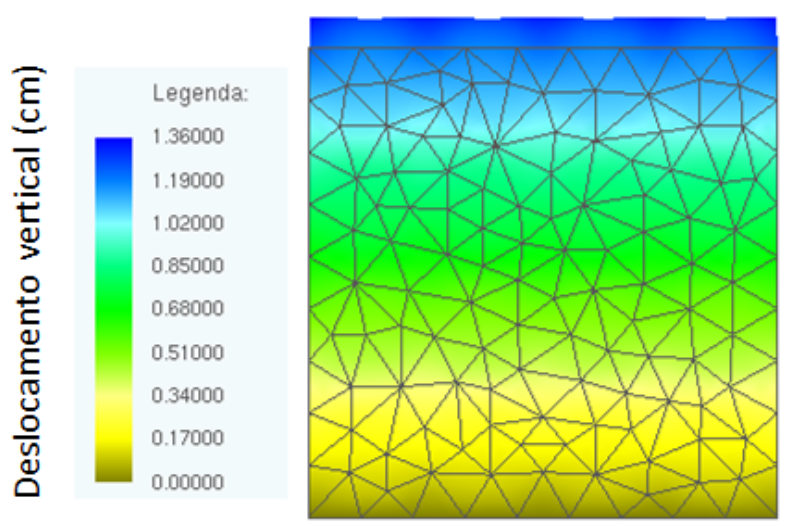

(a) Deslocamento da matriz.

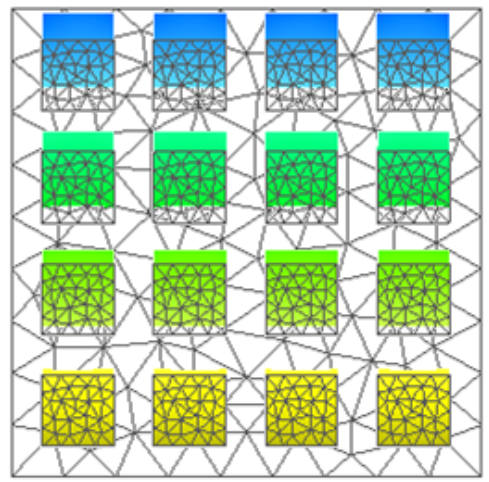

(b) Deslocamentos das partículas.

Figura 5.19 - Configuração deformada da chapa com 16 partículas.
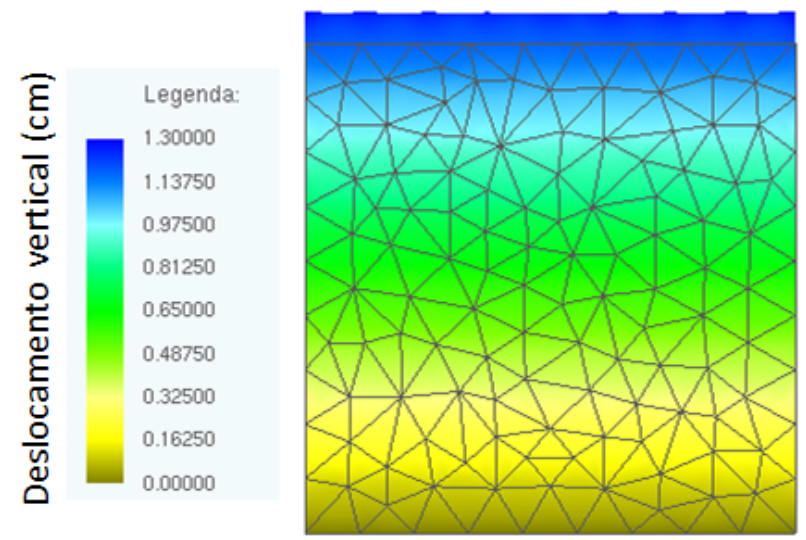

(a) Deslocamento da matriz.

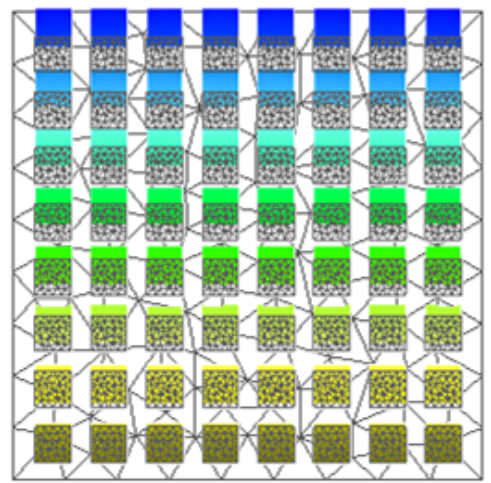

(b) Deslocamentos das partículas.

Figura 5.20 - Configuração deformada da chapa com 64 partículas.

É possível observar nas Figuras 5.18a, 5.19a e 5.20a, que os deslocamentos da chapa decrescem a medida em que é aumentado o número de partículas para a representação dos agregados, uma vez que um maior número de partículas, proporciona uma melhor dispersão destas na matriz. Isso também pode ser observado na Figura 5.21, onde são apresentadas as curvas força vs. deformação, para cada um dos casos analisados. A deformação do elemento de concreto foi determinada pela média dos valores obtidos em dois pontos do elementos de concreto (ver Figura 5.21).

A fim de analisar se a contribuição das partículas na matriz proporciona um aumento de rigidez coerente, comparou-se os resultados obtidos para o módulo de elasticidade longitudinal da chapa de concreto (com e sem partículas) com modelos matemáticos baseados em modelos reológicos para a representação do comportamento de compósitos apresentados em Mehta e Monteiro (2014). Os modelos reológicos utilizados neste trabalho, 
para efeito de comparação, são os de Voigt, Reuss, Hirsch, Couto e Hansen, conforme ilustra a Figura 5.22. Os resultados são apresentados na Figura 5.23.

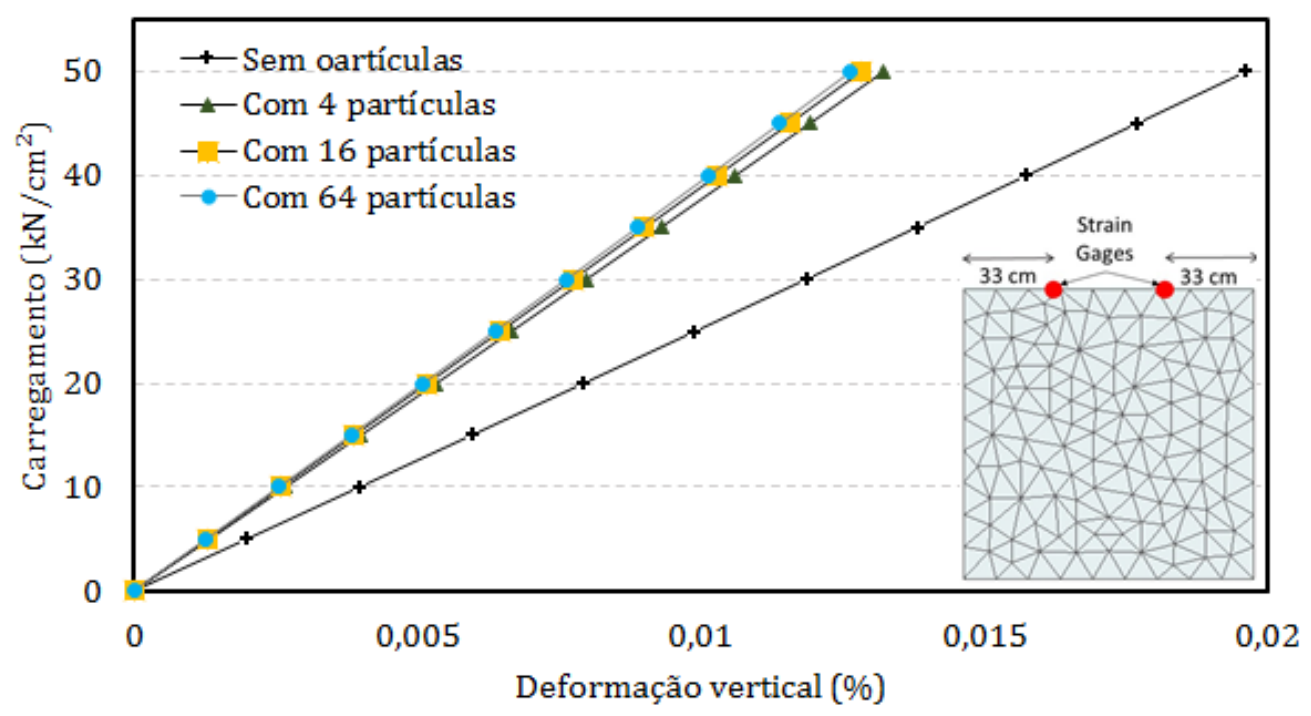

Figura 5.21 - Carregamento versus deformação (chapa de concreto).

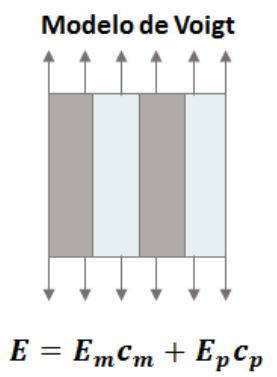

Modelo de Hirsch

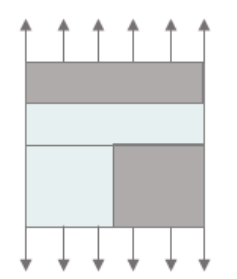

Modelo de Hansen

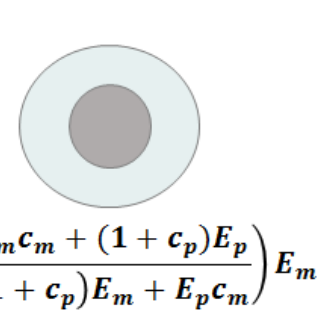

Modelo de Reuss

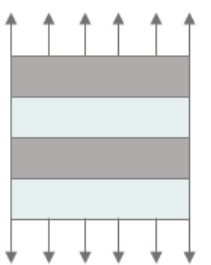

$\frac{1}{E}=\frac{c_{m}}{E_{m}}+\frac{c_{p}}{E_{p}}$

Modelo de Couto

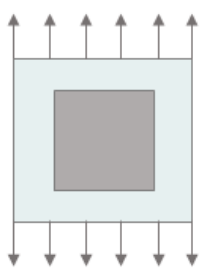

$\frac{1}{E}=\left(\frac{1}{2}\right)\left[\left(\frac{c_{p}}{E_{p}}+\frac{1-c_{p}}{E_{m}}\right)+\left(\frac{1}{c_{p} E_{p}+\left(1-c_{p}\right) E_{m}}\right)\right] \quad \frac{1}{E}=\frac{1-\sqrt{c_{p}}}{E_{m}}+\frac{1}{\left(\frac{1-\sqrt{c_{p}}}{\sqrt{c_{p}}}\right) E_{m}+E_{p}}$

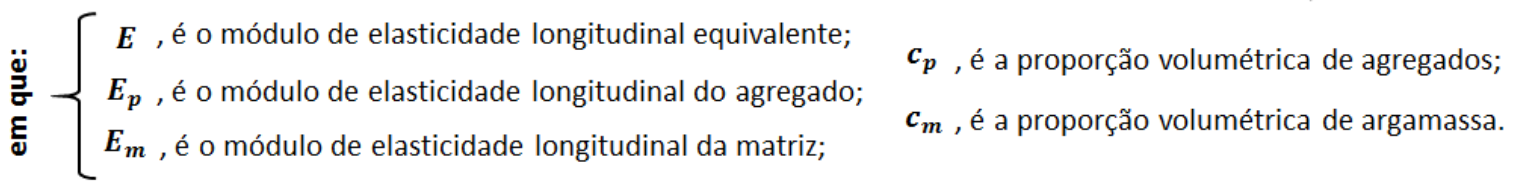

Figura 5.22 - Modelos reológicos para a representação de compósitos. 
Pelos valores apresentados na Figura 5.23, observa-se que o módulo de elasticidade obtido pelo código para todos os casos modelados estão dentro dos valores obtidos com os modelos matemáticos, cujo valores mínimo e máximo foram de 33,94 (modelo de Reuss) e 43,43 GPa (modelo de Voigt), respectivamente.

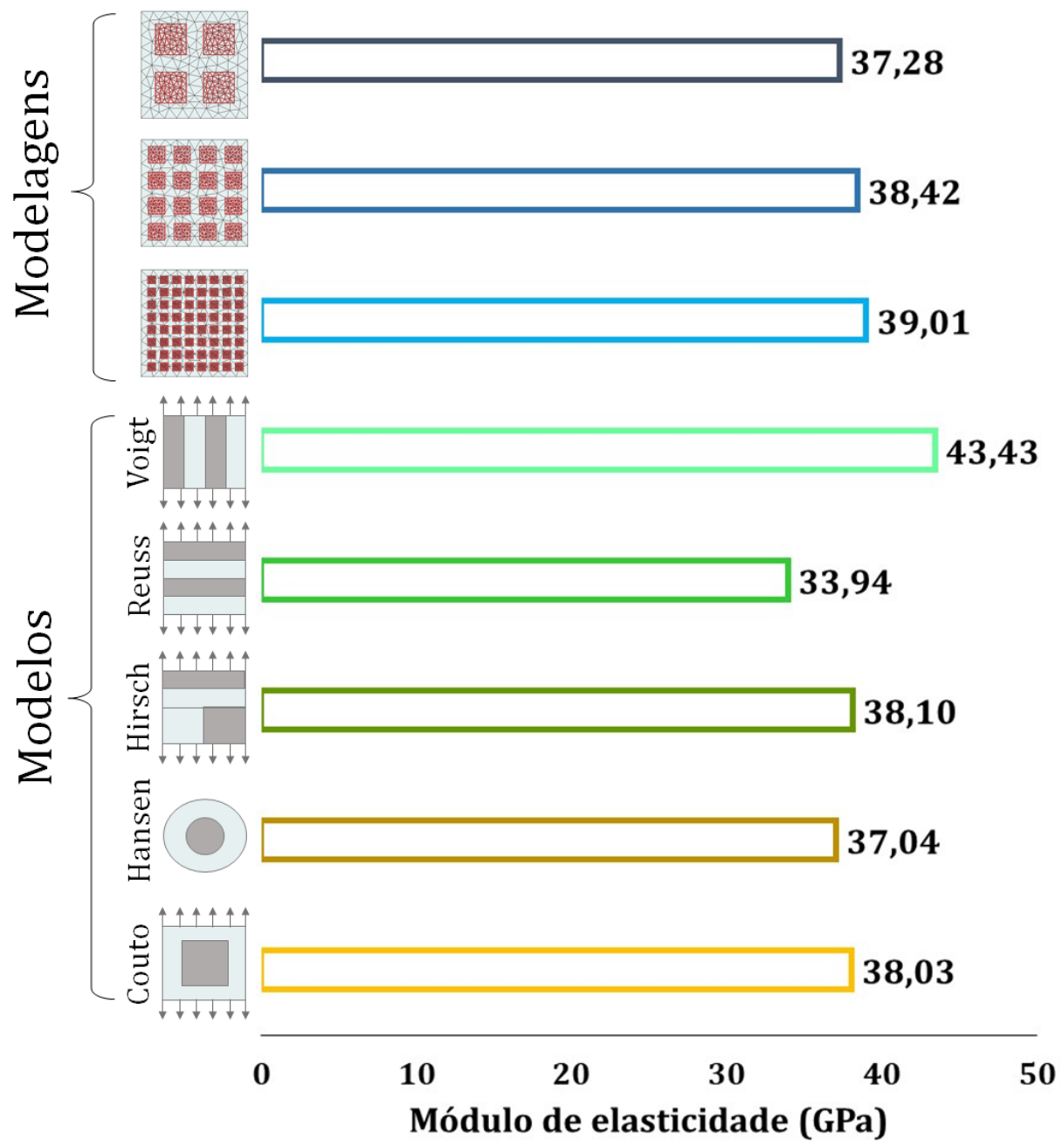

Figura 5.23 - Módulos de elasticidade do compósito obtido nas modelagens e modelos.

Ao comparar os resultados com os demais modelos (derivados dos de Reuss e Voigt), observa-se que o módulo, encontrado pelo programa desenvolvido, apresenta um valor semelhante, com uma diferença máxima de 7,8\% (chapa com 4 partículas vs. modelo de Hirsch), mostrando que o código implementado representa coerentemente a rigidez de elementos compósitos, desde que a representação das diferentes fases constituintes do material, seja feita de forma coerente.

Diante do exposto, os resultados demonstram a aplicabilidade do código desenvolvido para a representação de sólidos compósitos com partículas. 


\subsection{Exemplo 4: Viga de concreto armado}

No quarto exemplo, uma viga de concreto armado engastada, sob carregamento linearmente distribuído (ver Figura 5.24), é utilizada para validar os acoplamentos fibramatriz e partícula-matriz para análises mecânicas de estruturas sob pequenos e grandes deslocamentos.

As propriedades geométricas adotadas para a viga são: $L=300 \mathrm{~cm}, h=10 \mathrm{~cm}$, $d=2,5 \mathrm{~cm}, h^{\prime}=5 \mathrm{~cm}$ e espessura unitária, $e=1 \mathrm{~cm}$. O módulo de elasticidade e o coeficiente de Poisson da matriz são dados, respectivamente, por $E_{m}=21 \mathrm{GPa}$ e $\nu_{m}=0$. Para a representação das armaduras longitudinais, foram utilizadas fibras ou partículas. No caso em que foram utilizadas fibras para a representação das armaduras, o módulo de elasticidade e a área transversal são, respectivamente, $E_{f}=210 \mathrm{GPa}$ e $A_{f}=0,1 \mathrm{~cm}^{2}$. Já para o caso em que se utilizaram partículas, o módulo de elasticidade e e o coeficiente de Poisson são, respectivamente, $E_{p}=210 \mathrm{GPa}$ e $\nu_{p}=0$.

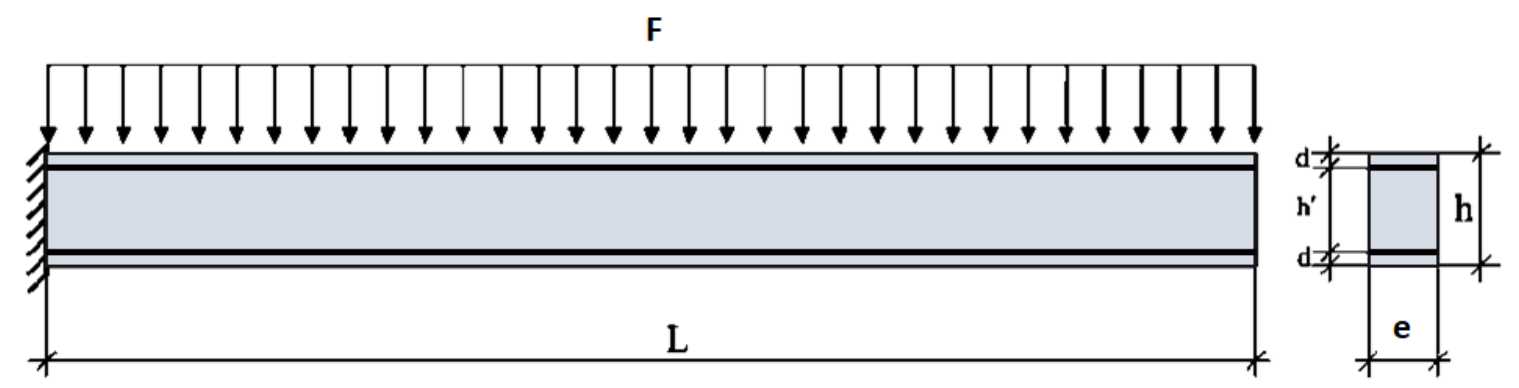

Figura 5.24 - Geometria e condições de contorno da viga de concreto.

O problema foi analisado considerando os regimes linear e não linear geométrico, para a viga sem reforço, reforçada com fibras ou partículas. Para o caso linear, o carregamento transversal aplicado é $F=5 \mathrm{~N} / \mathrm{cm}$ e para o caso não linear aplicou-se $F=50 \mathrm{~N} / \mathrm{cm}$.

Para a análise e validação dos resultados considerando pequenos deslocamentos, utilizou-se expressões analíticas. Quanto a análise dos resultados referentes aos grandes deslocamentos, estes são comparados com os obtidos via formulação denominada barra geral 3D, com cinemática de Timoshenko-Reissner, apresentada por Coda (2009), Coda e Paccola (2010) e Coda e Paccola (2011).

Para a representação do problema, a matriz foi discretizada em 600 elementos finitos triangulares, com ordem de aproximação cúbica, totalizando 2.821 nós e 5.642 graus de liberdade. Para a representação de cada uma das fibras foram adotados 120 elementos finitos de barra simples, enquanto que para as partículas foram adotados 848 elementos finitos com ordem de aproximação cúbica. Para a formulação em barra geral $3 D$ foram utilizados 10 elementos com aproximação de quinto grau. A análise não linear foi realizada em 50 passos de carga. 
A Figura 5.25 apresenta os deslocamentos obtidos para todos os casos. Já na Figura 5.26, apresentam-se as tensões máximas de tração e compressão na extremidade engastada das vigas em todos os casos modelados.

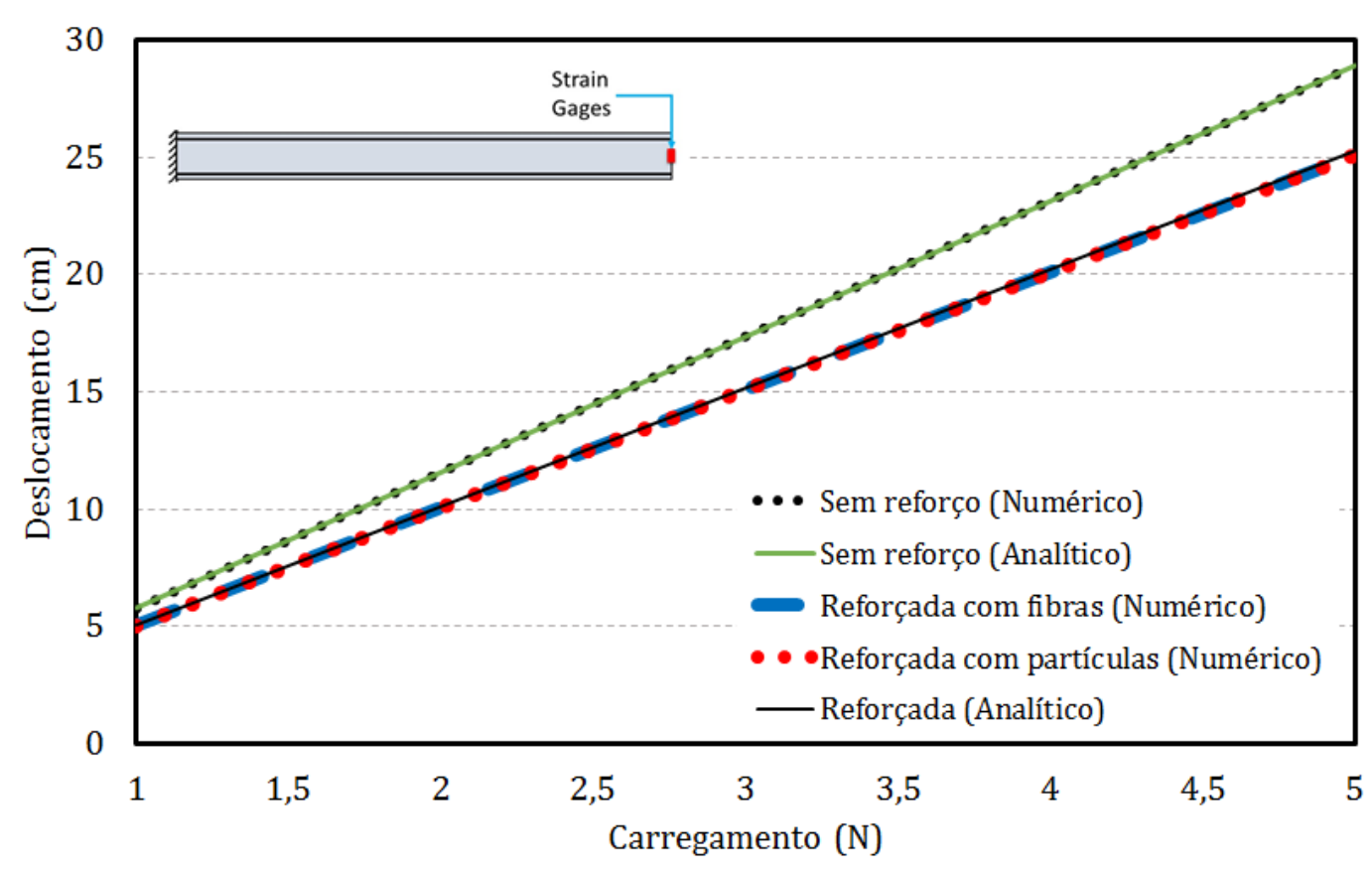

Figura 5.25 - Deslocamento vertical (análise linear geométrica).

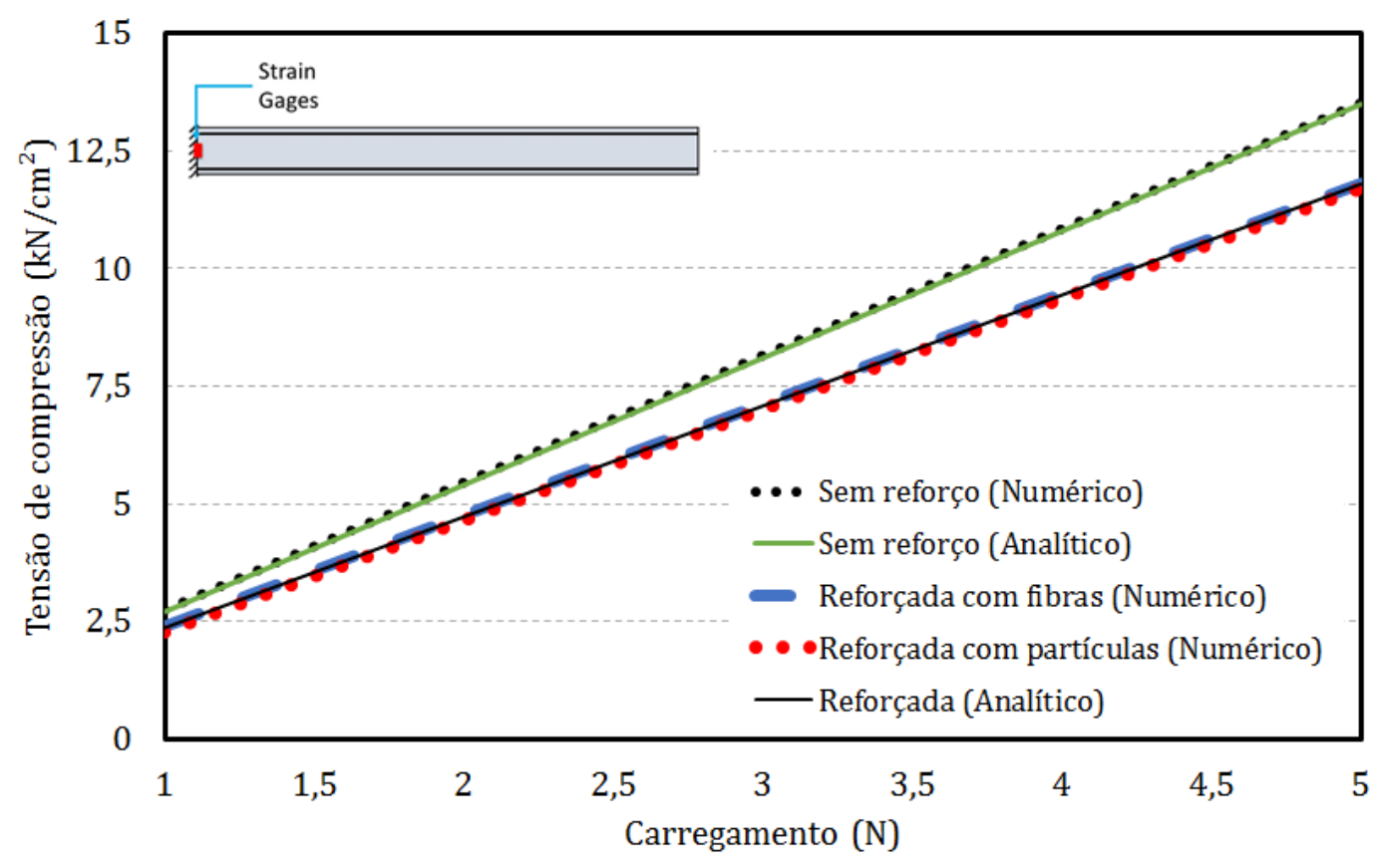

Figura 5.26 - Tensão de compressão máxima.

Na Figura 5.27 são apresentados os deslocamentos obtidos na análise não linear para as vigas com e sem reforço. Os resultados são comparados aos obtidos por meio da 
formulação de barra geral $3 D$.

$\mathrm{Na}$ análise não linear da viga sem reforço, o deslocamento máximo na extremidade livre da viga obtida com a presente formulação foi de 193,10 cm, enquanto que pela formulação de barra geral $3 D$ foi de $189,20 \mathrm{~cm}$, com a uma diferença de $2,12 \%$ entre as duas formulações. Sampaio (2014) analisou o mesmo exemplo, obtendo um deslocamento de 193,05 cm, o que representa um desvio de $0,12 \%$ com a presente formulação.

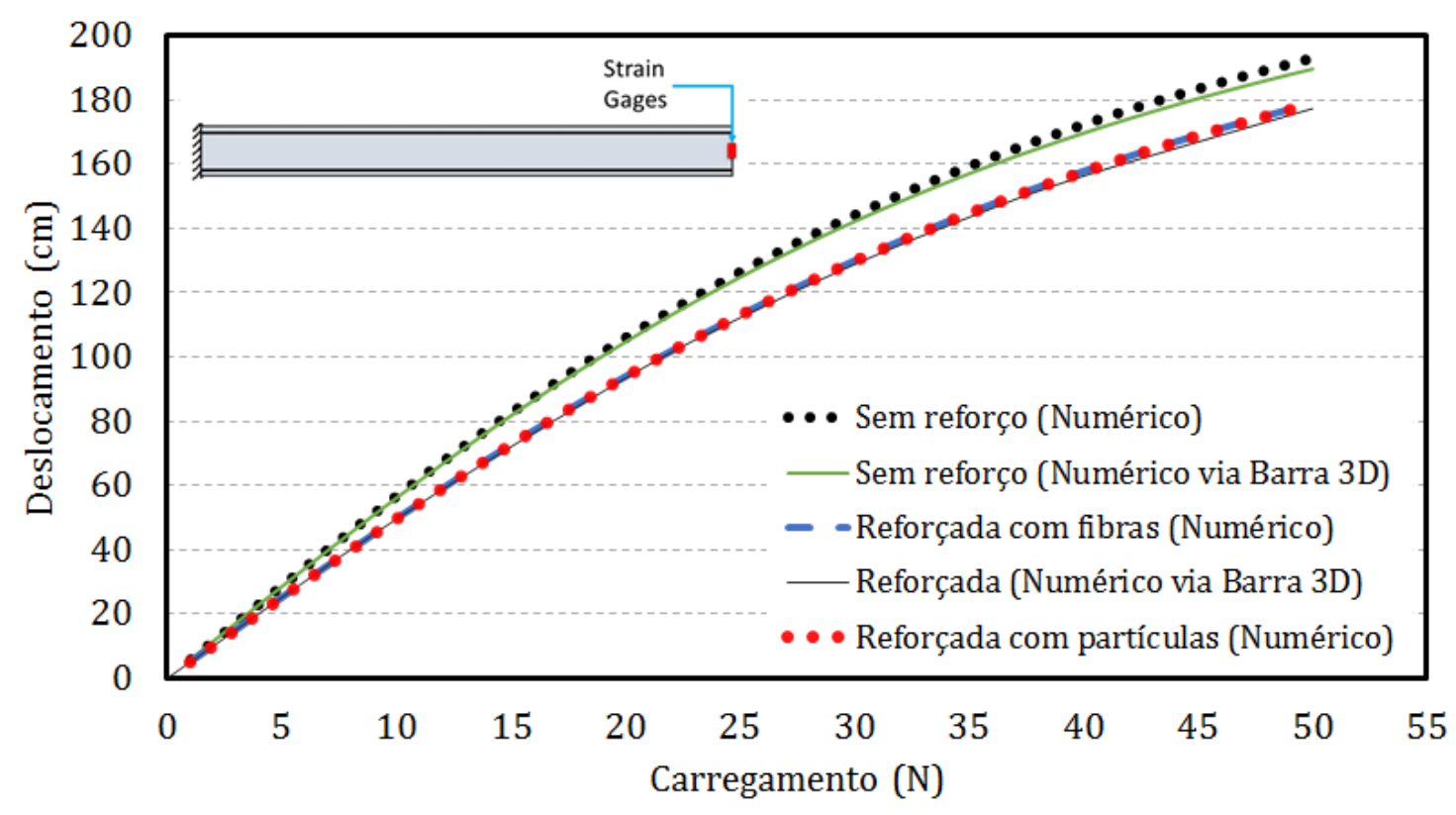

Figura 5.27 - Deslocamento vertical (análise não linear geométrica).

Para a análise não linear com reforço, a flecha máxima no nó central da extremidade livre da viga, foi de 178,74 cm para o caso em que foram utilizadas fibras e 178, $12 \mathrm{~cm}$ para as partículas, enquanto que a flecha obtida pela formulação de barra $3 D$ foi de 177,32 cm. Na Tabela 5.3 são apresentados os resultados obtidos para todos os casos analisados.

Tabela 5.3 - Comparação entre os deslocamento máximos $(\mathrm{cm})$.

\begin{tabular}{|c|c|c|c|c|}
\hline \multirow{3}{*}{ Discretização } & \multicolumn{4}{|c|}{ Tipo de análise } \\
\hline & \multicolumn{2}{|c|}{ Linear } & \multicolumn{2}{|c|}{ Não linear } \\
\hline & $\begin{array}{c}\text { Presente } \\
\text { formulação }\end{array}$ & $\begin{array}{c}\text { Resistência } \\
\text { dos Materiais }\end{array}$ & $\begin{array}{c}\text { Presente } \\
\text { formulação }\end{array}$ & $\begin{array}{c}\text { Barra } \\
\text { geral 3D }\end{array}$ \\
\hline Sem fibras & 28,88 & 28,92 & 193,1 & 189,2 \\
\hline Desvio médio (\%) & \multicolumn{2}{|c|}{0,138} & \multicolumn{2}{|c|}{2,061} \\
\hline Com fibras & 25,12 & 25,28 & 178,74 & 177,32 \\
\hline Desvio médio (\%) & \multicolumn{2}{|c|}{0,633} & \multicolumn{2}{|c|}{0,801} \\
\hline Com Partículas & 25,1481 & 25,28 & 178,12 & 177,32 \\
\hline Desvio médio (\%) & \multicolumn{2}{|c|}{0,522} & \multicolumn{2}{|c|}{0,451} \\
\hline
\end{tabular}

Por meio da Figura 5.27 e dos resultados obtidos, é possível observar que a estrutura se mostrou mais flexível com as formulações implementadas do que com o modelo de 
barra geral 3D, o que comprova que os modelos proporcionam maior liberdade ao contínuo modelado, o mesmo verificado por Sampaio (2014). Na Figura 5.28 são apresentadas as configurações deformadas para todos os casos.

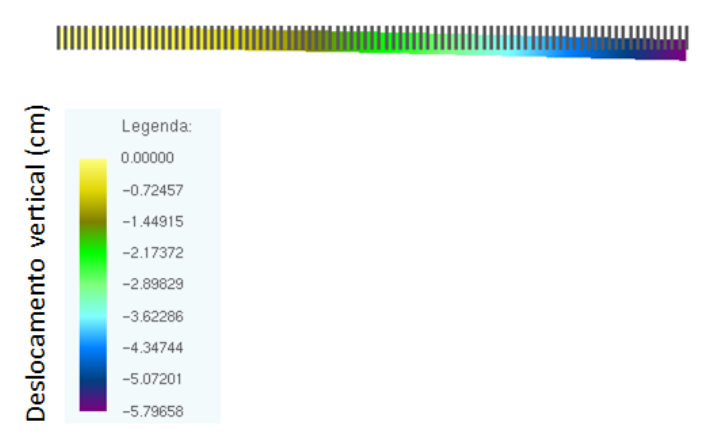

(a) Deslocamento da viga sem reforço (linear).

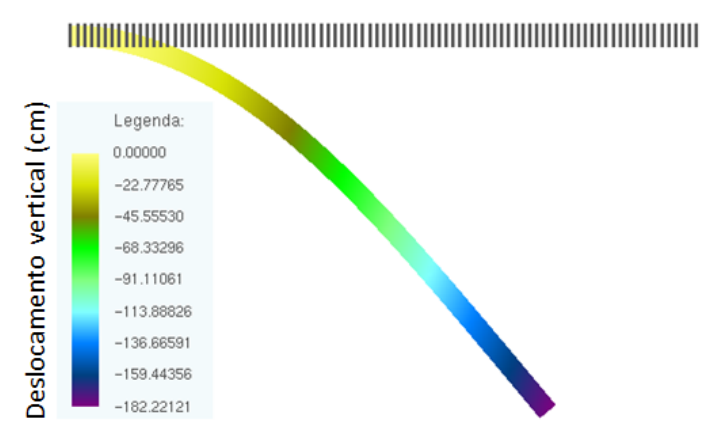

(c) Deslocamento da viga com fibras.

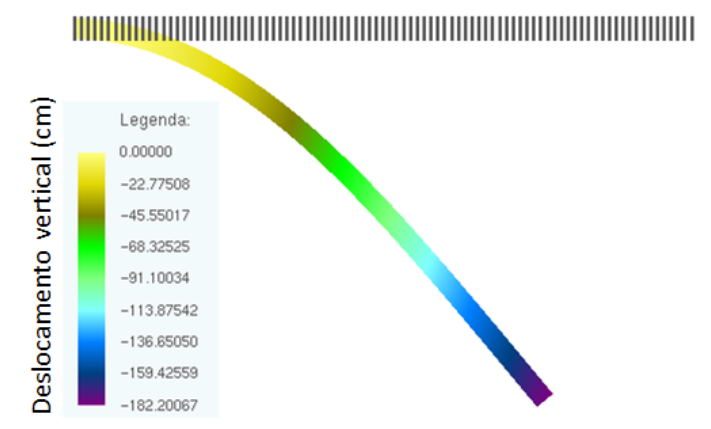

(e) Deslocamento da viga com partículas.

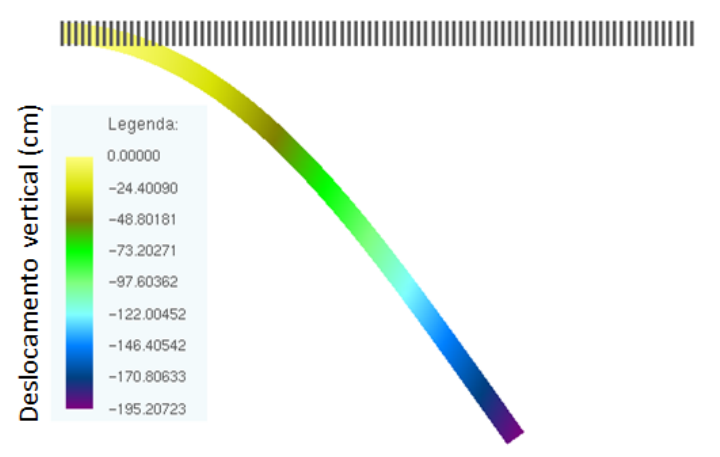

(b) Deslocamento da viga sem reforço (não linear).

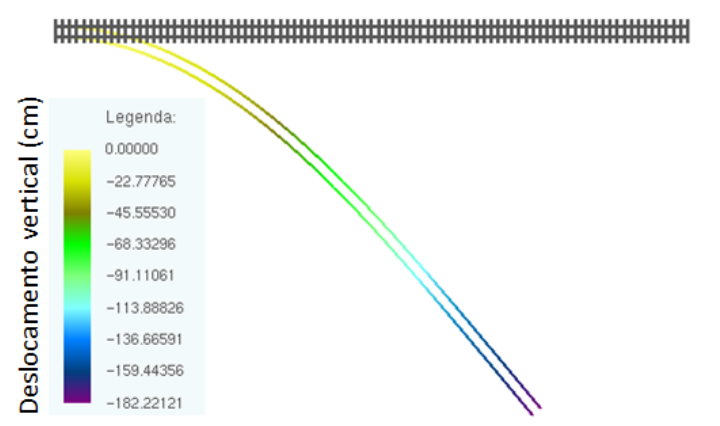

(d) Deslocamento das fibras.

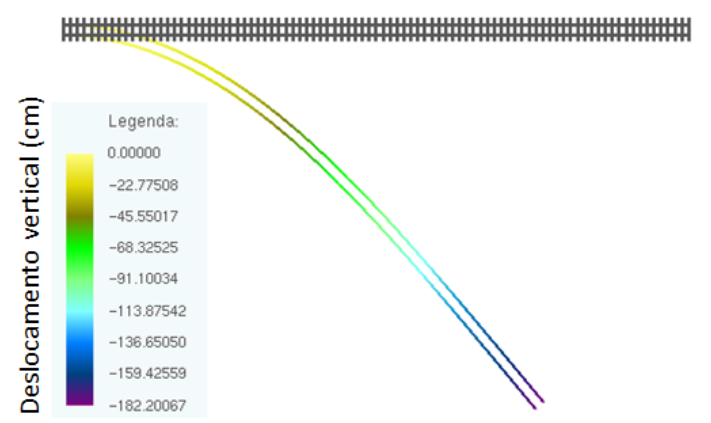

(f) Deslocamento das partículas.

Figura 5.28 - Deslocamento vertical da viga para cada análise.

De maneira geral os resultados obtidos por meio dos códigos desenvolvidos apresentam boa concordância e pequenas diferenças quando comparados com as soluções analíticas e numéricas obtidas por meio de elementos de barra geral $3 D$, validando os modelos numéricos desenvolvidos. 


\subsection{Exemplo 5: Representação de vazios em sólidos}

O quinto exemplo analisa a potencialidade do código desenvolvido quanto à modelagem de sólidos compósitos particulados, frente à inclusão de vazios no contínuo, um caso extremo da relação entre as propriedades físicas da matriz e das partículas. Este problema foi analisado por Moura (2015).

Inicialmente foram analisados os deslocamentos da barragem considerando-a sem vazios, conforme mostra a Figura 5.29. Em seguida, os deslocamentos da barragem com um vazio foram analisados (ver Figura 5.30a). Para a modelagem, considerou-se primeiro uma barragem com o vazio já inserido no elemento de chapa. Na sequência, a barragem com vazio foi modelada por meio da inclusão de partículas, conforme mostra a Figura $5.30 \mathrm{~b}$.

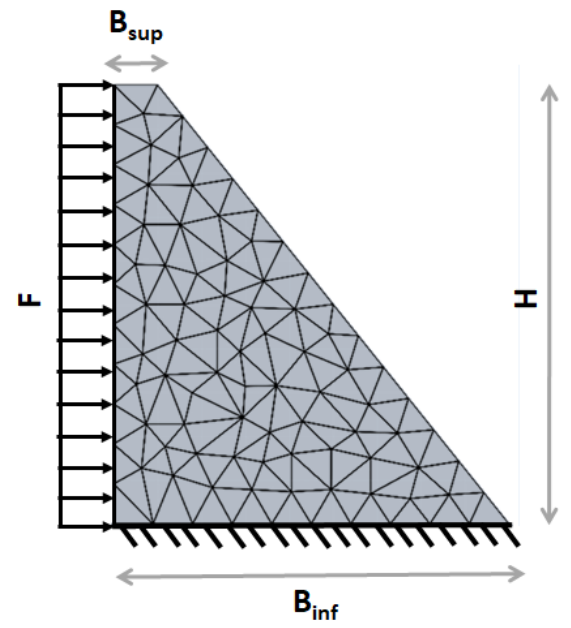

Figura 5.29 - Geometria e condições de contorno da barragem maciça.

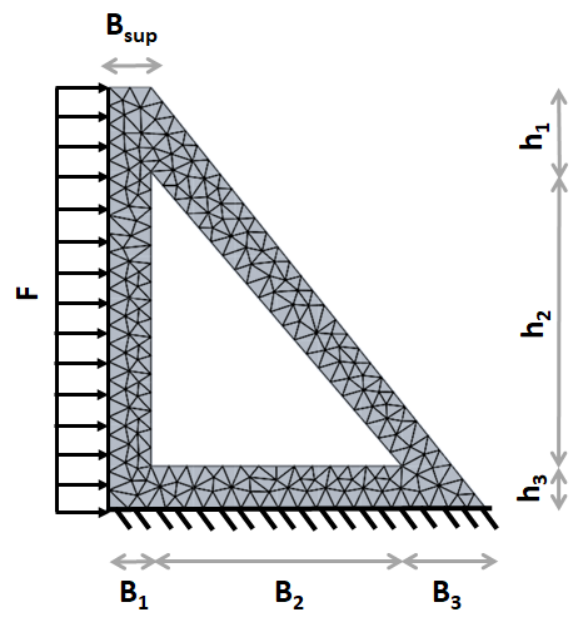

(a) Chapa com vazio triangular.

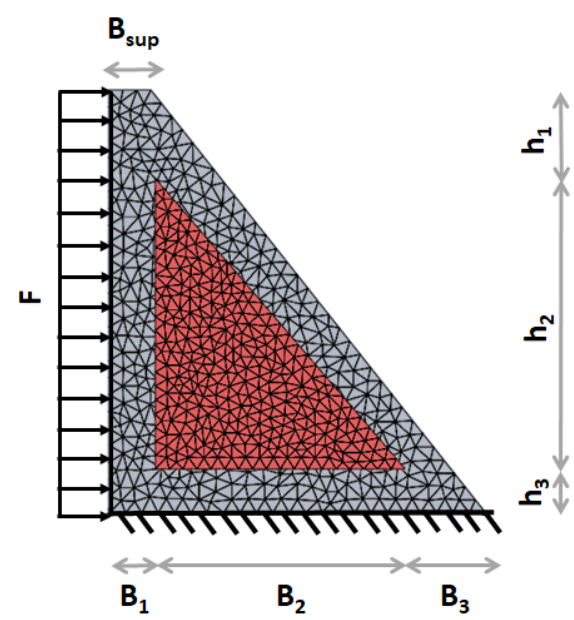

(b) Partículas simulando o vazio.

Figura 5.30 - Geometria e condições de contorno da barragem. 
Para a primeira análise, barragem maciça (Figura 5.29), as propriedades geométricas adotadas para a barragem são: $H=100 \mathrm{~cm}, B_{\text {inf }}=90 \mathrm{~cm}, B_{\text {sup }}=10 \mathrm{~cm}$ e espessura unitária $(e=1 \mathrm{~cm})$. O módulo de elasticidade e o coeficiente de Poisson da matriz são dados, respectivamente, por $E_{m}=408 \mathrm{GPa}$ e $\nu_{m}=0$.

Para a representação do problema, a matriz foi discretizada em 152 elementos finitos triangulares, com ordem de aproximação cúbica, totalizando 739 nós. O carregamento foi feito em 10 passos, sendo que no último passo de carga, a intensidade da carga era de $F=5 \mathrm{kN} / \mathrm{cm}$. Os deslocamentos obtidos na modelagem para o primeiro e último passo de carga são ilustrados nas Figuras 5.31 e 5.32, respectivamente.

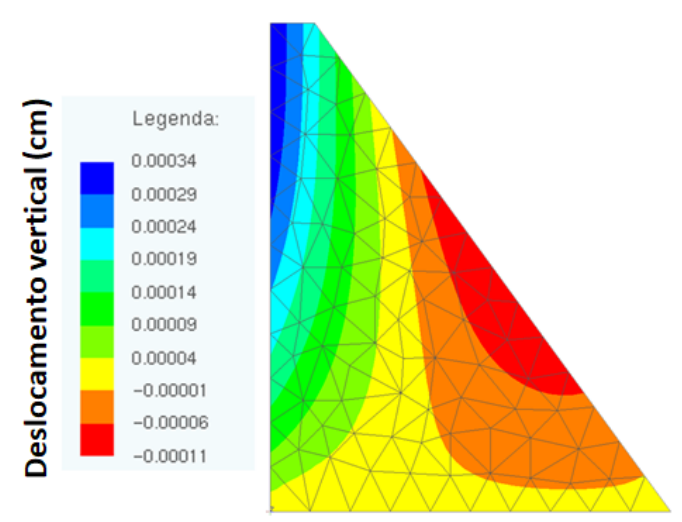

(a) Deslocamento vertical.

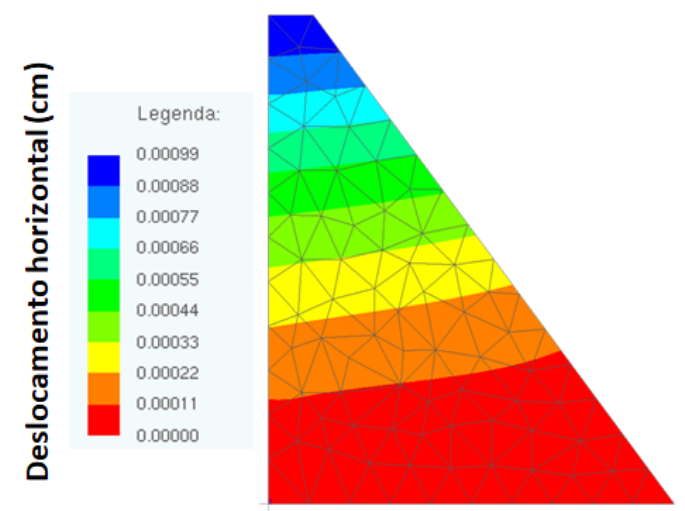

(b) Deslocamento horizontal.

Figura 5.31 - Deslocamentos da barragem para o primeiro passo de carga.

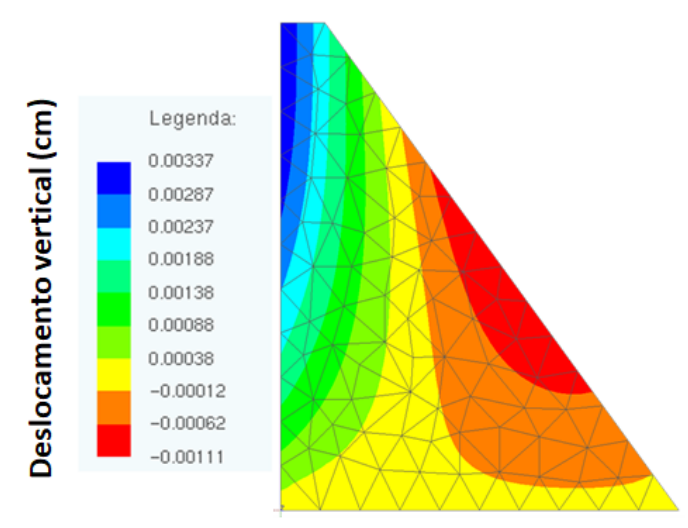

(a) Deslocamento vertical.

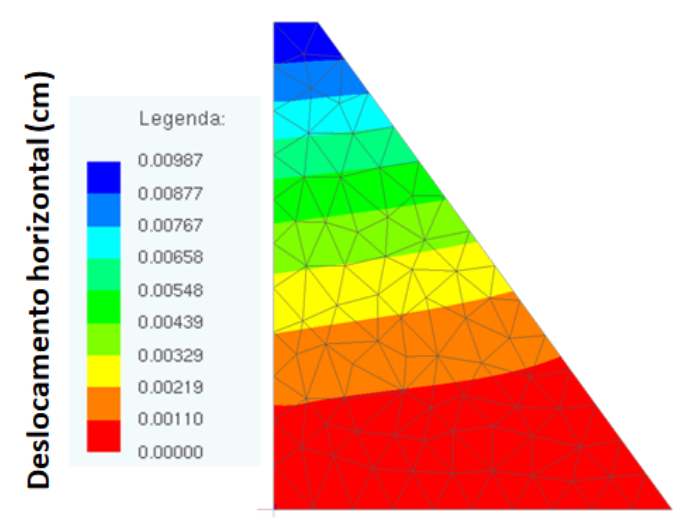

(b) Deslocamento horizontal.

Figura 5.32 - Deslocamentos da barragem para o último passo de carga.

Na segunda análise, barragem com vazio triangular inserido na chapa (Figura 5.30a) ou representado por partículas (Figura 5.30b), as propriedades geométricas adotadas em ambos os casos são: $h_{1}=20 \mathrm{~cm}, h_{2}=70 \mathrm{~cm}, h_{3}=10 \mathrm{~cm}, B_{1}=10 \mathrm{~cm}, B_{2}=60 \mathrm{~cm}, B_{3}=20$ 
$\mathrm{cm}, B_{\text {sup }}=10 \mathrm{~cm}$ e espessura unitária $(e=1 \mathrm{~cm})$. O módulo de elasticidade e o coeficiente de Poisson da matriz são dados, respectivamente, por $E_{m}=408 \mathrm{GPa}$ e $\nu_{m}=0$.

Para o caso em que o vazio é representado por partículas, foram adotados módulo de elasticidade e coeficiente de Poisson para as partículas de $E_{p}=-407,7796$ GPa e $\nu_{m}=0$, respectivamente. O módulo de elasticidade adotado para as partículas apresenta uma proporção de 0,9995 em relação ao módulo adotado para a matriz. A justificativa para tal é que não era possível adotar valores idênticos para as propriedades físicas da partícula e matriz em virtude dos problemas numéricos que aparecem decorrente ao desacoplamento das malhas.

Para a representação da chapa considerando o vazio, a discretização do sólido foi feita em 367 elementos finitos triangulares, com ordem de aproximação cúbica, totalizando 1839 nós. Para o caso em que foram utilizadas as partículas, a matriz foi representada por 593 elementos finitos, enquanto a malha do vazio foi discretizada com 1329 elementos finitos. Em ambos os casos foram utilizados elementos finitos triangulares com ordem de aproximação cúbica. Quanto ao carregamento, este segue idêntico ao caso da barragem sem vazio.

Comenta-se que para uma melhor representação do vazio, quando considerada a inclusão de partículas, as dimensões da malha das partículas foram diminuídas em 0,001\%, evitando que se produzissem uma sombra de vazio além das dimensões reais do vazio triangular.

Na Figura 5.33 é apresentada uma comparação entre os deslocamentos horizontal obtidos na simulação da barragem com vazio representado na malha e por partículas em três pontos do elemento estrutural, ponto A, B e C, conforme mostra a Figura 5.33. Observa-se pela 5.33 a equivalência entre os deslocamentos obtidos em ambas simulações, demonstrando a eficiência das partículas.

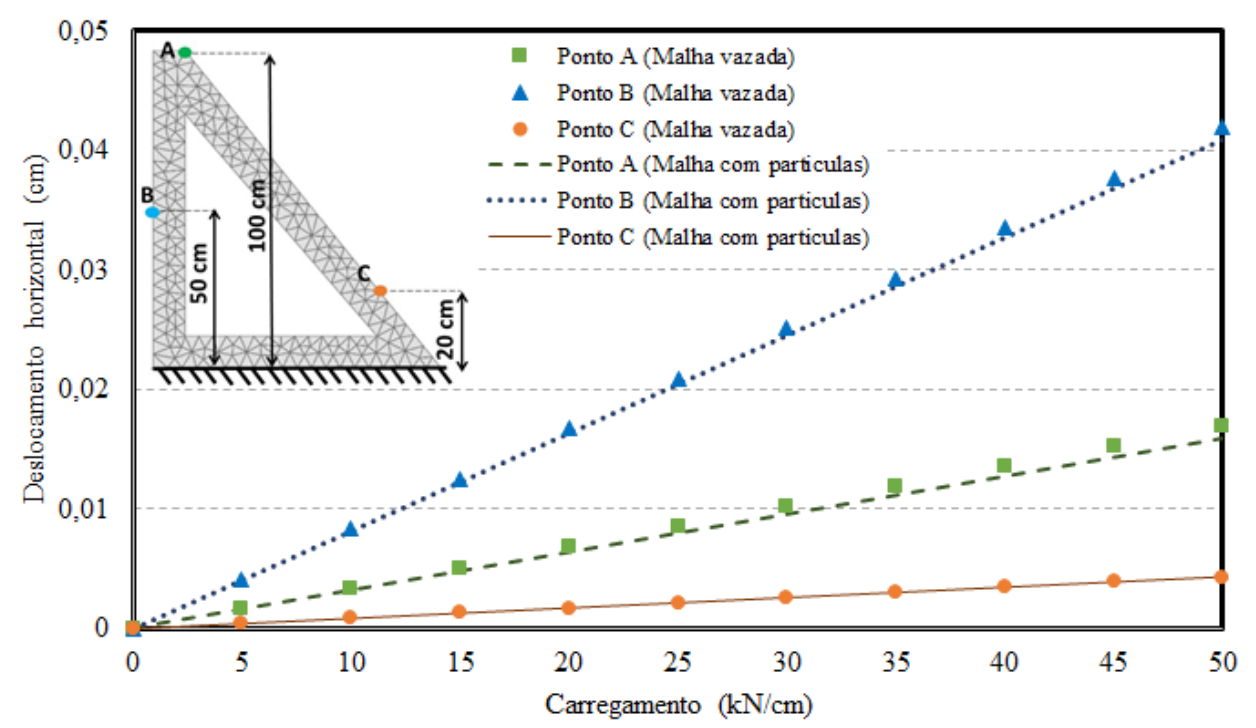

Figura 5.33 - Deslocamento horizontal da barragem com malha vazada e com partículas. 
Os deslocamentos horizontais e verticais obtidos para cada um dos casos, matriz com vazios e vazio representado por partículas, são apresentados nas Figuras 5.34 e 5.35.

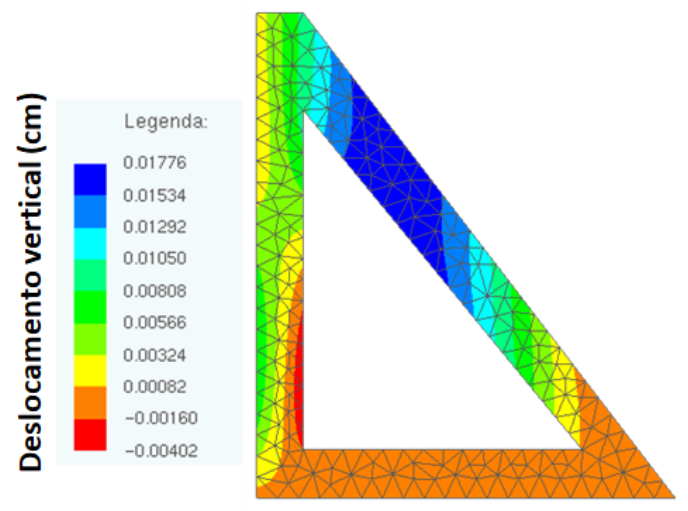

(a) Chapa com vazio.
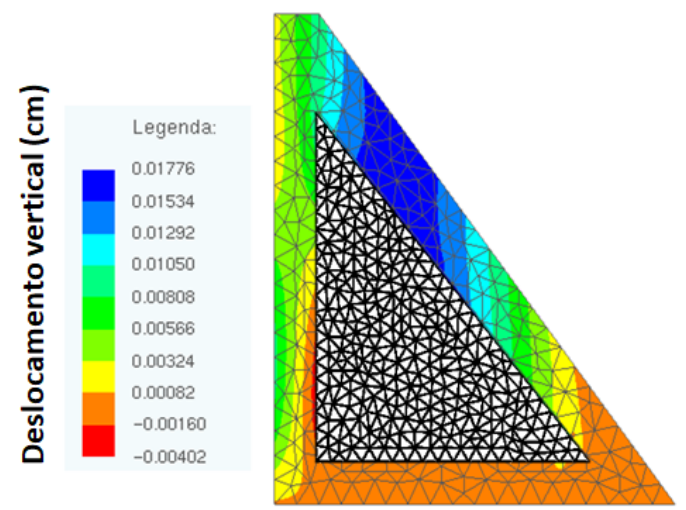

(b) Chapa com partículas simulando o vazio.

Figura 5.34 - Deslocamento vertical.

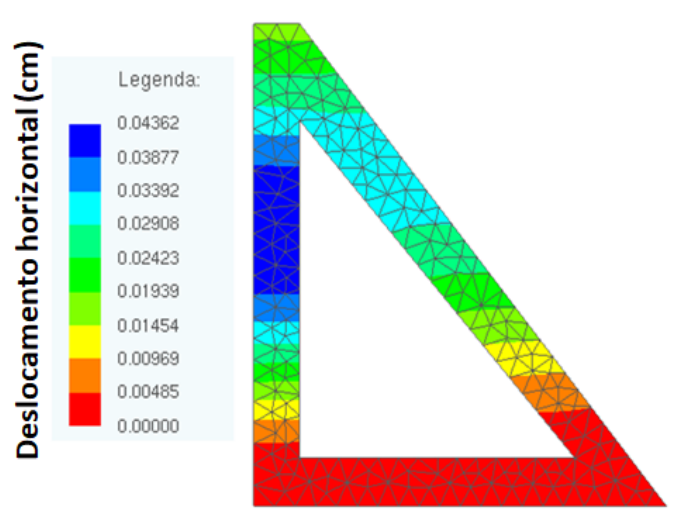

(a) Chapa com vazio.
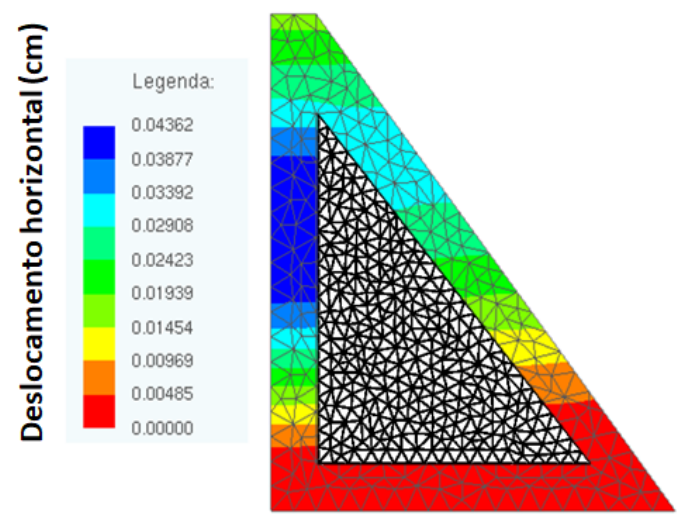

(b) Chapa com partículas simulando o vazio.

Figura 5.35 - Deslocamento horizontal.

De maneira geral, os resultados obtidos permitem concluir que a formulação utilizada para modelagem de meios contínuos com inclusões de vazios, fornece bons resultados. Acredita-se que o fato de ter reduzido as dimensões da malha de partículas (para a representação do vazio triangular) em 0,001\% tenham proporcionado melhores resultados, comparados aos obtidos por Moura (2015).

Acredita-se ainda que um refinamento das malhas utilizadas no problema podem gerar resultados melhores para os casos analisados. Vale lembrar que o refinamento das discretizações das partículas não acarreta em acréscimo do número de graus de liberdade global do problema, considerada uma das características positivas da formulação utilizada. 


\subsection{Exemplo 6: Descontinuidades em sólidos}

Diante dos resultados obtidos no exemplo anterior, decidiu-se avaliar a aplicabilidade do código desenvolvido na representação de descontinuidades em estruturas, como fissuras. Assim, são avaliados os efeitos de uma descontinuidade elíptica em uma chapa submetida a um estado de tração uniforme. A geometria da chapa simulada, assim como a disposição da descontinuidade e a malha utilizadas nas modelagens são apresentadas na Figura 5.36.

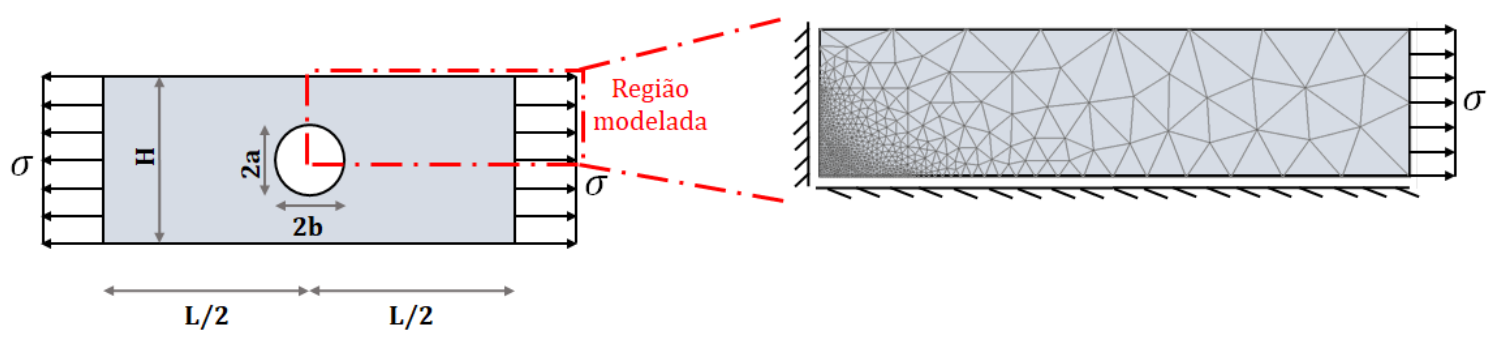

Figura 5.36 - Geometria, condições de contorno e malha utilizadas para a matriz.

Para a análise do efeito que uma descontinuidade causa no comportamento mecânico de uma chapa tracionada, foram modeladas três chapas com diferentes configurações, variando a relação entre as dimensões do diâmetro perpendicular e paralelo à direção de carregamento (ou seja, variando a relação $2 a / 2 b$ ). Para a análise adotou-se as relações $2 a / 2 b=1,2$ ou 4, sendo estas configurações apresentadas na Figura 5.37.

As propriedades geométricas adotadas para a chapa são: $L=400 \mathrm{~cm}, H=100 \mathrm{~cm}$ e espessura unitária, $e=1 \mathrm{~cm}$.

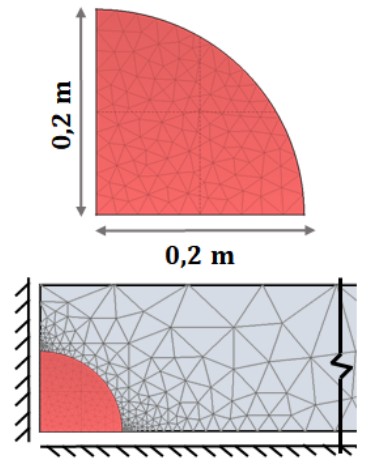

(a) Descontinuidade I.

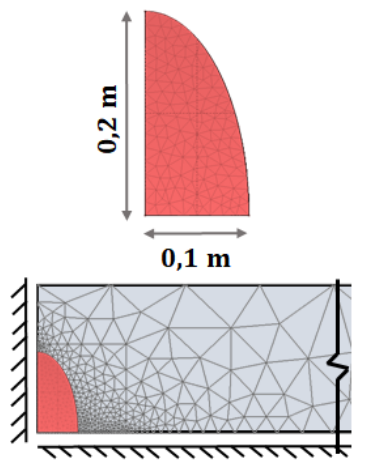

(b) Descontinuidade II.

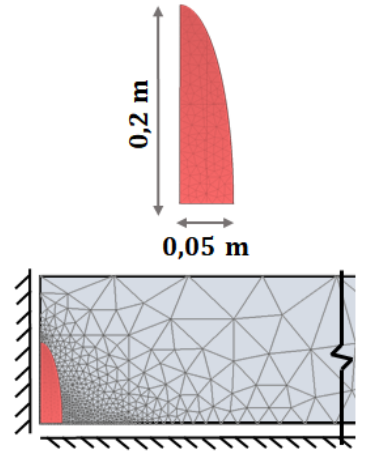

(c) Descontinuidade III.

Figura 5.37 - Malha das chapas considerando a configuração das descontinuidades.

Para a representação da chapa, a matriz foi discretizada em 1129 elementos finitos triangulares, com ordem de aproximação cúbica e o carregamento foi feito em 10 passos, com incrementos de carga de $\sigma=1 \mathrm{kN} / \mathrm{m}$. O módulo de elasticidade e o coeficiente de Poisson são dados, respectivamente, por $E_{m}=1000 \mathrm{kN} / \mathrm{m}^{2}$ e $\nu_{m}=0$.

Para a representação das partícula I, II e III, foram adotadas malhas discretizadas em 667, 607 e 567 elementos finitos triangulares, respectivamente. Em todos os casos 
a ordem de aproximação dos elementos finitos é cúbica. O módulo de elasticidade e o coeficiente de Poisson das partículas que simulam a descontinuidade são, $E_{p}=-999,95$ $\mathrm{GPa}$ e $\nu_{p}=0$.

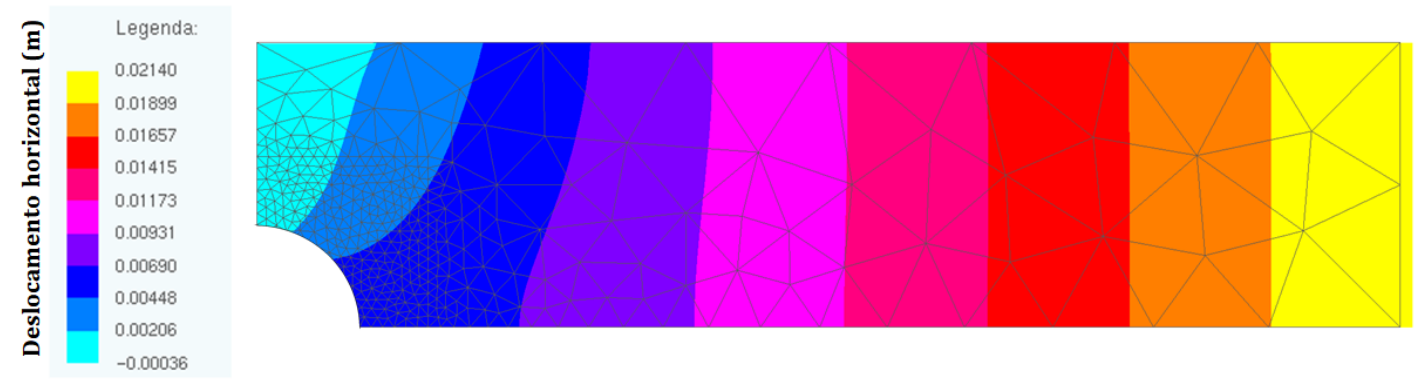

Figura 5.38 - Deslocamento vertical da chapa com descontinuidade (CASO I).

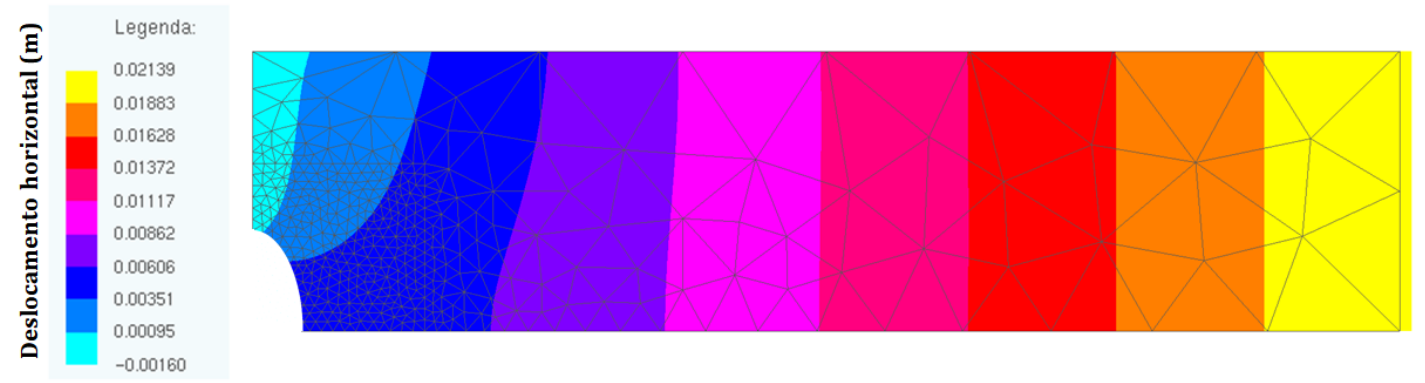

Figura 5.39 - Deslocamento vertical da chapa com descontinuidade (CASO II).

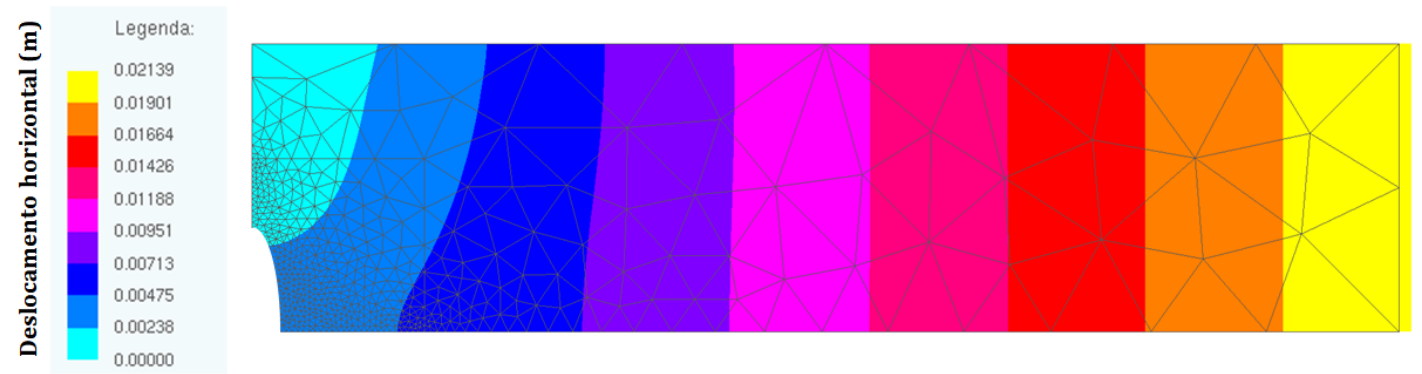

Figura 5.40 - Deslocamentos vertical da chapa com descontinuidade (CASO III).

Nas Figuras 5.38, 5.39 e 5.40 são apresentados os deslocamentos horizontais da chapa para os três casos, caso I $(2 a / 2 b=1)$, caso II $(2 a / 2 b=2)$ e caso III $(2 a / 2 b=4)$, respectivamente. Observa-se nas figuras que os deslocamentos horizontais da chapa estão coerentes, de acordo com a teoria da Elasticidade, já que o valor previsto para o máximo deslocamento horizontal, considerando o comportamento de materiais elástico-lineares, é de $\delta=\sigma L /\left(A E_{m}\right)=0,02 \mathrm{~m}$ e, o deslocamento máximo encontrado na modelagem foi de 
0,021 m (em todos os casos). Também observa-se que os deslocamento em regiões distantes das descontinuidades não são afetados, o que condiz com a Teoria da Elasticidade e da Mecânica da Fratura.

Em seguida, na Figura 5.41, são apresentadas as tensões longitudinais na chapa, considerando as três configurações de fissuras, enquanto que na Tabela 5.4 são dados os valores obtidos para a tensão longitudinal na ponta da fissura, por meio da presente modelagem e da Equação 5.1, desenvolvida por Inglis (1913).

$$
\sigma_{p}=\sigma\left(1+\frac{2 a}{b}\right)
$$

em que $\sigma_{p}$ é a tensão na ponta da fissura, $\sigma$ é uniformemente aplicada na chapa e $a$ e $b$ são, respectivamente, o semieixo maior e menor da elipse.

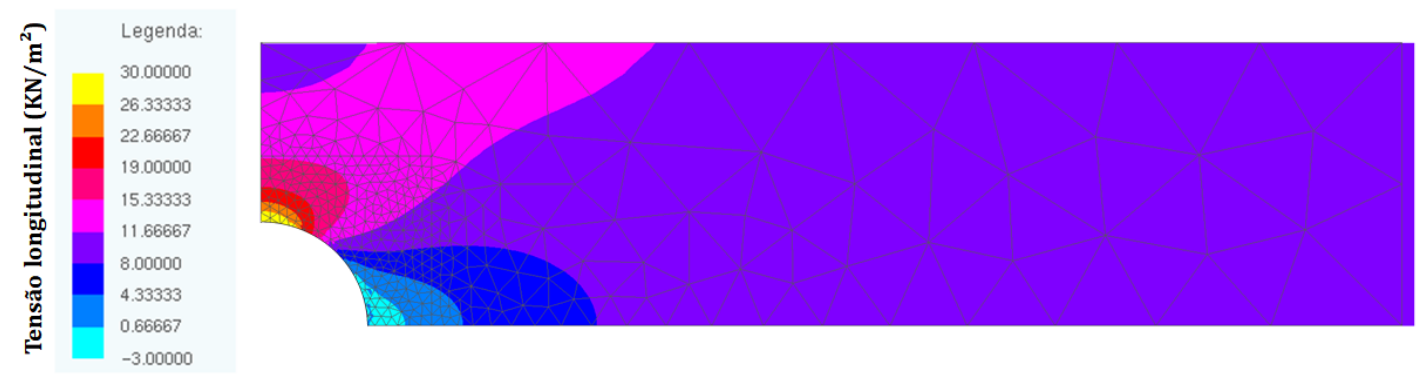

(a) Chapa do Caso I.

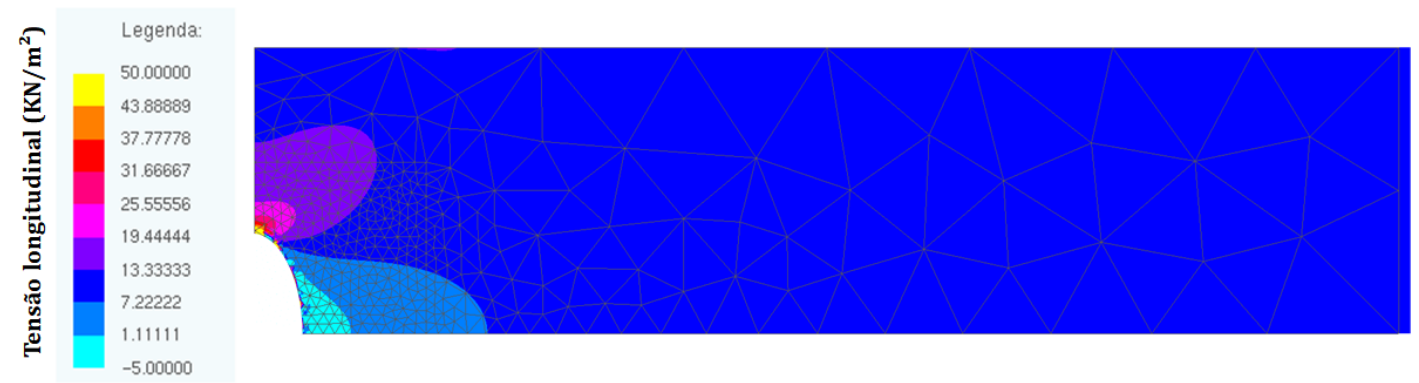

(b) Chapa do Caso II.
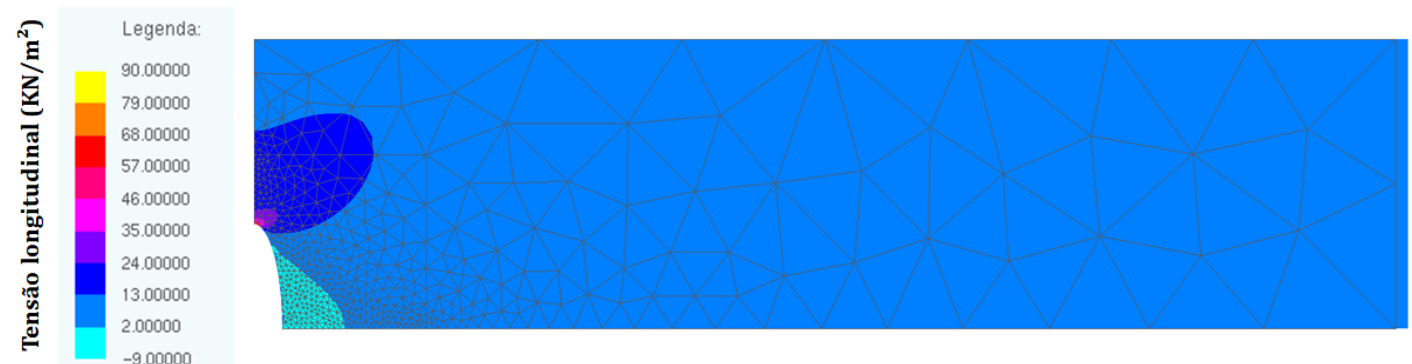

(c) Chapa do Caso III.

Figura 5.41 - Distribuição das tensões longitudinais na chapa com descontinuidade. 
Tabela 5.4 - Comparação entre as tensões $\left(k N / m^{2}\right)$ na ponta da fissura.

\begin{tabular}{ccccc}
\hline Caso & 2a/2b & $\begin{array}{c}\text { Tensão analítica } \\
\text { (INGLIS, 1913) }\end{array}$ & $\begin{array}{c}\text { Tensão } \\
\text { determinada }\end{array}$ & Desvio (\%) \\
\hline I & 1 & 30,00 & 29,61 & 1,30 \\
II & 2 & 50,00 & 50,63 & 1,26 \\
III & 4 & 90,00 & 90,94 & 1,04 \\
\hline
\end{tabular}

A comparação entre as tensões obtidas analiticamente (via Equação 5.1) e com o código desenvolvido, demonstram que além de representar vazios em grande escala (caso apresentado no exemplo anterior), o código desenvolvido possibilita também a representação de fissuras (pequenas descontinuidades materiais) e, que os resultados obtidos quanto ao campo de tensões demonstram que o mesmo representa coerentemente as pertubações destas descontinuidades no contínuo.

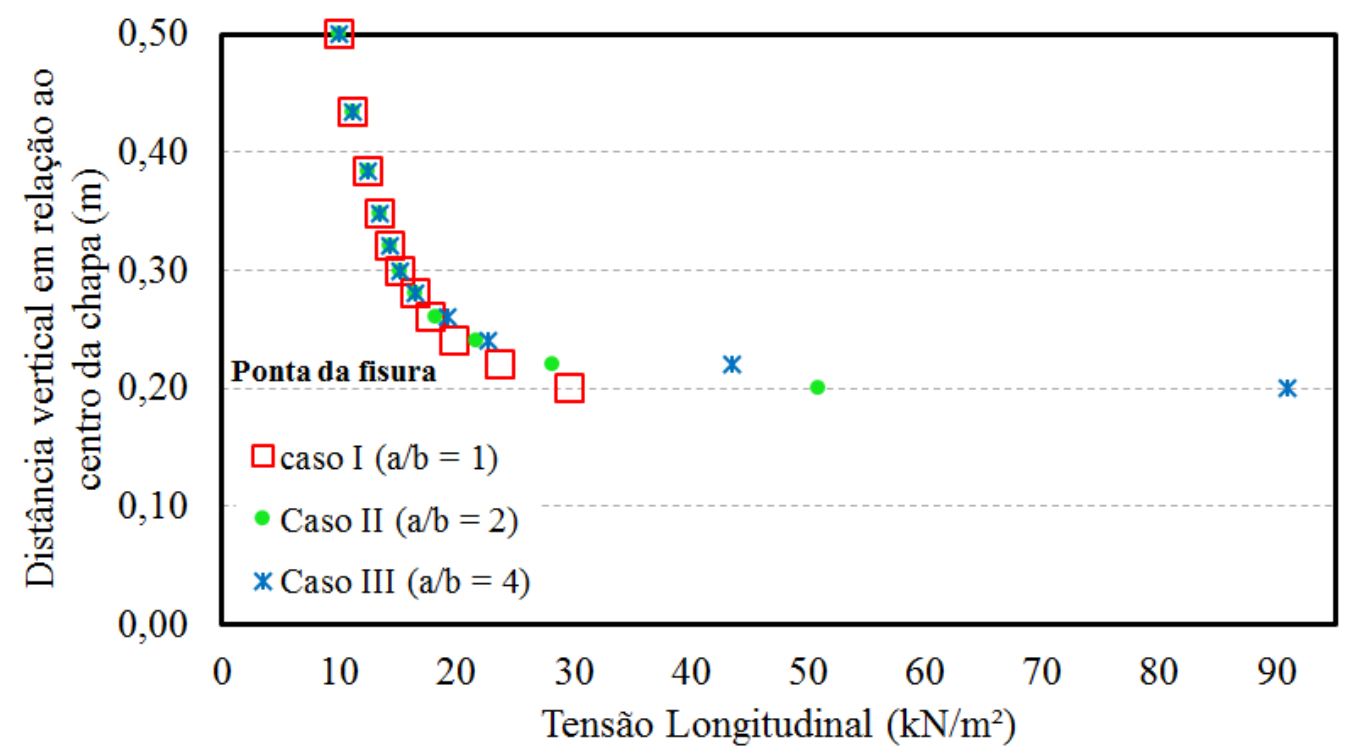

Figura 5.42 - Tensão longitudinal em diferentes regiões da chapa.

Na Figura 5.42 são apresentadas as tensões longitudinal da chapa para pontos situados a diferentes distâncias do centro da fissura. Observa-se que a tensão varia exponencialmente de $\sigma$ até $\sigma_{p}$, o mesmo comportamento visualizado por Inglis (1913), onde o autor relata que a tensão varia exponencialmente, tendo o seu valor correlacionado com a distância da extremidade da chapa ao ponto de análise. Ademais, Inglis (1913) descreve que o valor máximo da tensão se encontra na interface da fissura, com magnitude ponderada pelo fator de concentração de tensão (parcela em parênteses da Equação 5.1).

No geral, os resultados obtidos permitem concluir que a formulação desenvolvida permite representar satisfatoriamente o comportamento mecânico de sólidos com descontinuidades materiais, e que a mesma fornece bons resultados quando comparada às formulações da mecânica da fratura. Relata-se que neste exemplo também foram reduzidas 
as dimensões das malhas referente às partículas em 0,001\% (para a representação das descontinuidades), como relatado e discutido no exemplo anterior. Por fim, acredita-se que um refinamento das malhas utilizadas no problema podem gerar resultados ainda melhores para os casos analisados. 
CAPÍTULO

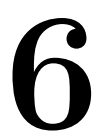

\section{MODELAGEM DA FORMAÇÃO DOS PRODUTOS DE CORROSÃO}

Neste capítulo é apresentado o modelo desenvolvido para a representação da expansão do concreto devido à formação dos produtos de corrosão. Inicialmente descrevemse as formulações utilizadas para a determinação da perda de seção das armaduras e da formação dos produtos de corrosão. Ao final, é apresentado a técnica numérica desenvolvida para a representação da expansão do concreto devido à corrosão uniforme.

\subsection{Considerações iniciais}

Ao dar-se início o período de progressão da corrosão, período subsequente à despassivação das armaduras, o aço começa a perder massa. Concomitantemente, desenvolve-se na interface entre o aço e o concreto um material ferruginoso de maior volume, denominado produto de corrosão (Figura 6.1a).

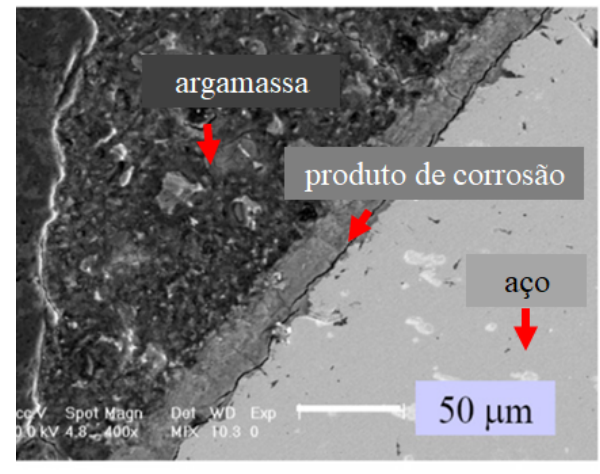

(a) Formação dos produtos de corrosão.

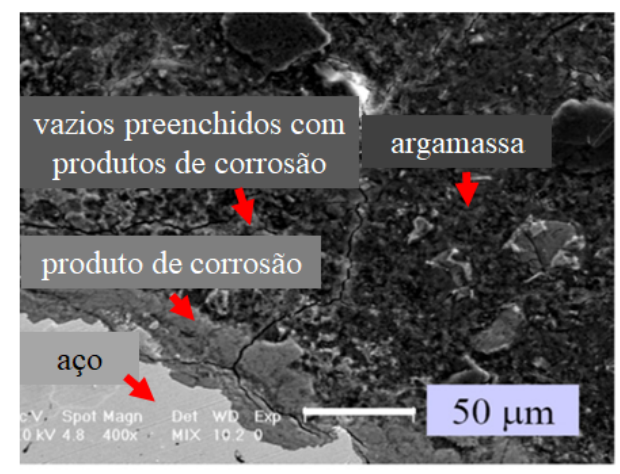

(b) Acomodação dos produtos nos vazios.

Figura 6.1 - Desenvolvimento dos produtos de corrosão na matriz de concreto.

Fonte: Adaptado de Caré et al. (2008). 
Os produtos de corrosão tendem, inicialmente, a se acomodarem nos espaços vazios existentes na matriz porosa do concreto, até que estes não mais existam (Figura 6.1b). Devido a continuidade da formação dos produtos de corrosão e, da falta de vazios para a sua acomodação, surgem no concreto de cobrimento deformações ocasionadas pela pressão interna exercida pelo material ferruginoso.

Entender como se desenvolvem e se distribuem os produtos de corrosão ao redor da seção da armadura, possibilita a determinação de modelos e ferramentas que sejam capazes de descrever os campos de deformação e de tensão que surgem nas estruturas de concreto armado, quando sob ação da corrosão. Estes modelos auxiliam nos estudos referentes aos efeitos da corrosão sobre o comportamento mecânico do concreto e da durabilidade e vida útil destas estruturas.

Ao longo dos últimos anos alguns modelos foram propostos com objetivo de representar e descrever o perfil de distribuição dos produtos de corrosão no entorno das armaduras, à exemplo, Liu e Weyers (1998), Pantazopoulou e Papoulia (2001), Bhargava et al. (2006), Yuan e Ji (2009), Balafas e Burgoyne (2010) e Kiani e Shodja (2011). Quanto ao perfil da formação e distribuição dos produtos de corrosão, eles são divididos em homogêneo e não homogêneo, conforme mostra a Figura 6.2.

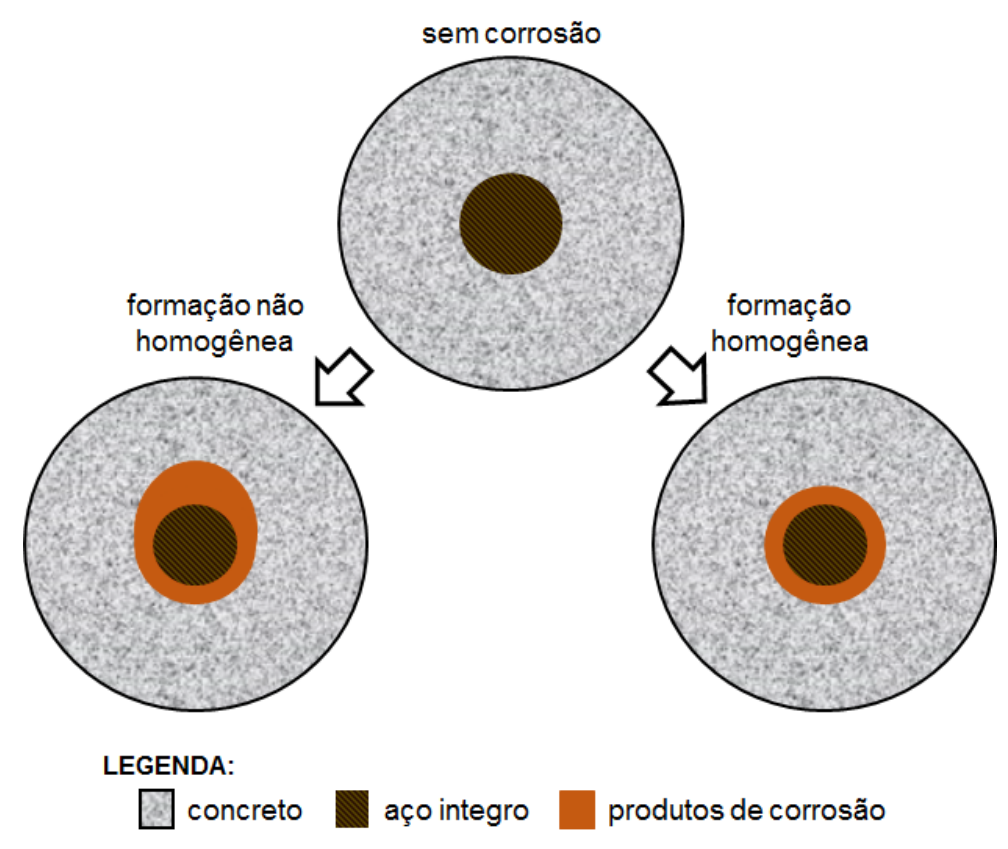

Figura 6.2 - Formação dos produtos de corrosão.

Os modelos homogêneos são aqueles que descrevem a formação e distribuição dos produtos de corrosão de forma homogênea no entorno da seção transversal da armadura, diferente dos modelos não não homogêneos, em que o desenvolvimento não ocorre de forma homogênea, apresentando um perfil de distribuição elíptico. 


\subsection{Modelos da perda de seção de aço e formação dos produtos de corrosão}

A seguir são apresentados os dois modelos, ambos com distribuição homogênea dos produtos de corrosão, utilizados no presente trabalho. Os modelos foram selecionados devido à facilidade de implementação, manipulação e obtenção dos seus parâmetros de entrada.

\subsubsection{Modelo I - Kiani e Shodja (2011)}

Kiani e Shodja (2011) desenvolveram um modelo para a formação homogênea dos produtos de corrosão em estruturas de concreto armado, utilizando dados experimentais referentes a corpos de prova cilíndricos de concreto contendo em seu centro uma armadura de diâmetro e propriedades físicas conhecidas. A Figura 6.3 apresenta esquematicamente o modelo proposto pelos autores.

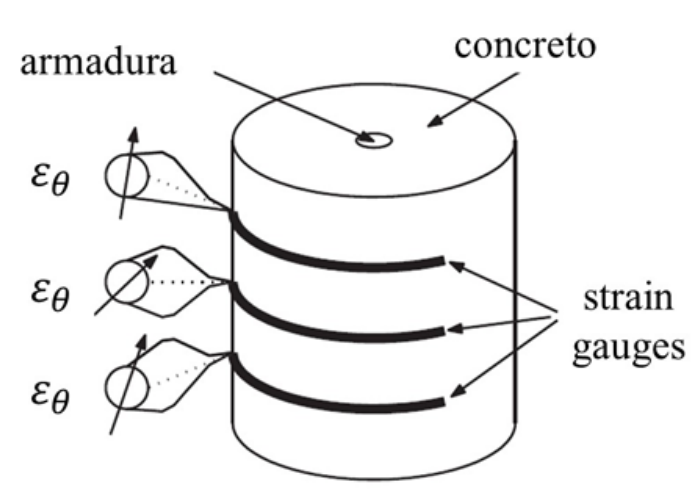

(a) Corpo de prova ensaiado.

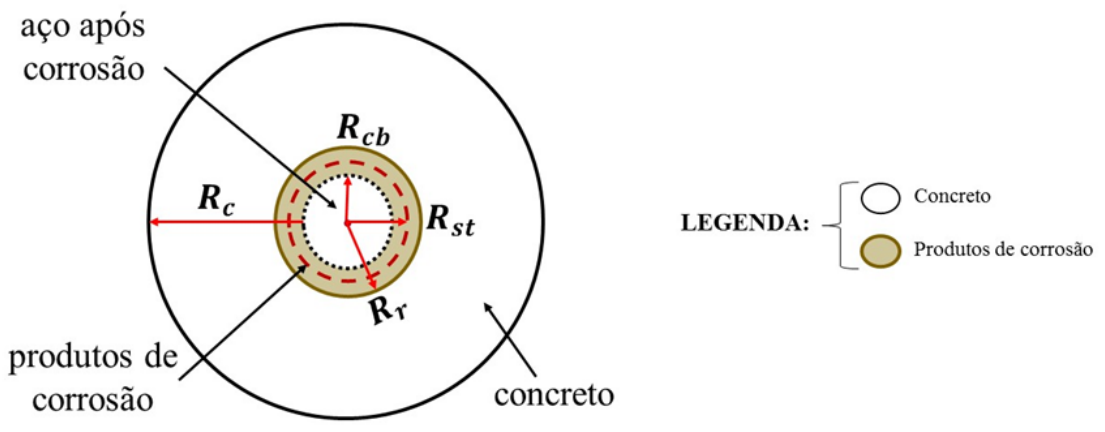

(c) Seção do corpo de prova depois da corrosão.

Figura 6.3 - Representação do modelo de Kiani e Shodja (2011)

Na Figura 6.3a é apresentado um modelo dos corpos de prova utilizados nos ensaios em laboratório, na Figura 6.3b pode-se ver a seção transversal do concreto antes de iniciar 
o processo de corrosão. Com o desenvolvimento da corrosão os produtos são formados no entorno da armadura reduzindo o seu diâmetro, como mostra a Figura 6.3c.

O modelo resume-se na determinação do raio residual de aço, $R_{c b}$, e do raio da frente de avanço dos produtos de corrosão, $R_{r}$, que podem ser obtidos respectivamente pelas Equações 6.1 e 6.2. Para a determinação destes parâmetros faz-se necessário calcular o volume gerado pelos produtos de corrosão (Equação 6.3) e a perda em volume de aço das armaduras (Equação 6.4).

$$
\begin{aligned}
& R_{c b}=\sqrt{R_{s t}^{2}-\frac{V_{s}}{\pi}} \\
& R_{r}=\sqrt{R_{c b}^{2}-\frac{V_{r}}{\pi}} \\
& V_{r}(t)=\frac{\alpha}{\rho s t} \sqrt{\int_{0}^{t} 13,56 \times 10^{-10} \times \pi \times R_{s t} \times i_{c o r r} d t} \\
& V_{s}(t)=\frac{r_{m}}{\rho s t} \sqrt{\int_{0}^{t} 13,56 \times 10^{-10} \times \pi \times R_{s t} \times i_{c o r r} d t}
\end{aligned}
$$

em que $R_{s t}$ refere-se ao raio inicial da armadura $(\mathrm{m}), \alpha$ é a razão entre a densidade do aço e dos produtos de corrosão, $\rho_{s t}$ é a densidade do aço $\left(\mathrm{kg} / \mathrm{m}^{3}\right)$, $i_{c o r r}$ é a densidade da corrente de corrosão $\left(A / m^{2}\right), r_{m}$ é a proporção de massa de ferro para a massa molecular dos produtos de corrosão e $t$ (s) refere-se ao tempo de análise, sendo dado a partir do momento em que ocorre a despassivação da armadura.

\subsubsection{Modelo II - Rodriguez e Andrade (1990)}

Rodriguez e Andrade (1990) desenvolveram um modelo (Equação 6.5) para a perda de seção de aço de estruturas de concreto armado sob corrosão uniforme. A formulação foi obtida por meio da análise de dados experimentais, e descreve o diâmetro integro de aço (diâmetro residual), no período de progressão da corrosão.

$$
D_{c b}=D_{s t}-0,023 \times i_{c o r r} \times t
$$

em que $D_{s t}$ refere-se ao diâmetro inicial da armadura $(\mathrm{mm}), D_{c b}$ é o diâmetro integro de aço, no instante de análise $(\mathrm{mm}), i_{\text {corr }}$ é a densidade da corrente de corrosão $\left(\mu \mathrm{A} / \mathrm{cm}^{2}\right)$ e $t$ é o período de progressão da corrosão (anos).

Assim, conhecendo o diâmetro integro de aço em um determinado instante, após o início da corrosão, e sabendo que a camada de produtos de corrosão que surge na interface entre o aço e o concreto é proporcional à razão entre o volume de óxidos e de Ferro que compõe o aço (também denominado de razão em volume da expansão dos produtos de corrosão), Rodriguez e Andrade (1990) determinam o avanço dos produtos de corrosão 
por meio da Equação 6.6.

$$
R_{r}=R_{s t}+\left(\frac{V_{o x}}{V_{F e}}\right)\left(R_{s t}-R_{c b}\right)=R_{s t}+\left(R_{s t}-R_{c b}\right) V_{e x p}
$$

em que $R_{s t}$ refere-se ao raio inicial da armadura $(\mathrm{mm}), R_{c b}$ é o raio integro de aço $(\mathrm{mm})$, $R_{r}$ é o raio da frente de avanço dos produtos de corrosão $(\mathrm{mm}), V_{o x}$ é o volume de óxido, $V_{F e}$ é o volume de ferro e $V_{\text {exp }}$ é a razão em volume da expansão dos produtos de corrosão.

\subsection{Modelo numérico baseado no MEFP}

Para modelar e analisar em nível macroscópico os efeitos causados pela corrosão uniforme, utiliza-se neste trabalho o Método dos Elementos Finitos Posicional (MEFP). O MEFP foi implementado com o propósito de simular o comportamento mecânico de estruturas de concreto armado sujeitas à ação da corrosão, em especial, da expansão causada pela formação dos produtos de corrosão. Assim, na sequência é apresentada a técnica numérica utilizada no acoplamento das formulações referentes à corrosão, no modelo de análise mecânica de sólidos compósitos particulados, apresentado no capítulo 4.

Considerando que a seção transversal de um elemento de concreto armado seja representado por um elemento compósito particulado, sendo o concreto é representado por uma única fase (homogêneo), conforme mostra a Figura 6.4, a expansão do concreto devido à formação dos produtos de corrosão, é simulada por meio da expansão do elemento de partícula, uma vez que a armadura está perfeitamente aderida à matriz de concreto (condição decorrente da técnica de embutimento adotada no acoplamento entre a partícula e a matriz).

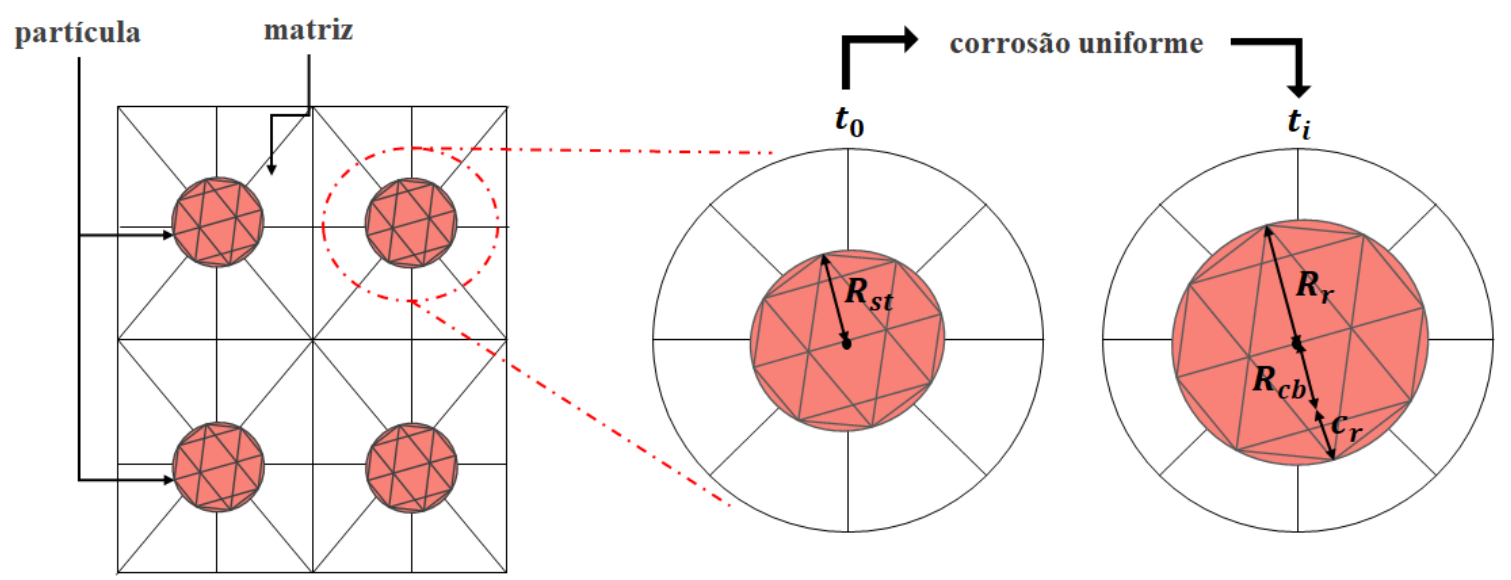

Figura 6.4 - Elemento de concreto armado e a expansão das armaduras. 
Para que a expansão da armadura corresponda coerentemente à expansão causada pelos produtos de corrosão, a expansão da partícula é determinada pela Equação 6.7.

$$
\varepsilon_{r}=\frac{1}{2} \frac{\left(R_{r}^{2}-R_{s t}^{2}\right)}{R_{s t}^{2}}=\frac{1}{2} \frac{\left(\left(R_{c b}+C_{r}\right)^{2}-R_{s t}^{2}\right)}{R_{s t}^{2}}
$$

em que $\varepsilon_{r}$ é a expansão da partícula, $R_{s t}$ refere-se ao raio inicial da armadura $(\mathrm{mm}), R_{r}$ é o raio da frente de avanço dos produtos de corrosão $(\mathrm{mm}), R_{c b}$ é o raio integro de aço $(\mathrm{mm})$ e $C_{r}$ é a camada de produtos de corrosão formada entre o aço e o concreto $(\mathrm{mm})$.

Entretanto observa-se pela Figura 6.4 e Equação 6.7 que, após iniciado o processo de corrosão, a dimensão da partícula que representa a armadura passa a ser equivalente à dimensão da seção integra de aço mais a camada de produtos de corrosão, que se forma entre o aço e o concreto. Assim, faz-se necessário corrigir o módulo de elasticidade do elemento de partícula, de forma que sejam inseridos os efeitos da corrosão no que diz respeito à perda de seção integra de aço. Para isso, o valor do módulo da partícula é ponderado em função da perda de seção de aço, conforme mostra a Equação 6.8.

$$
E_{p}(t)=E_{p}(0)\left(\frac{R_{c b}}{R_{s t}}\right)+E_{r}\left(\frac{R_{r}-R_{c b}}{R_{s t}}\right)
$$

em que $E_{p}(0)$ é o módulo de elasticidade inicial da partícula, $E_{p}(t)$ é o módulo de elasticidade da partícula no instante de análise, $E_{r}$ é o módulo de elasticidade dos produtos de corrosão, $R_{s t}$ refere-se ao raio inicial da armadura $(\mathrm{mm}), R_{r}$ é o raio da frente de avanço dos produtos de corrosão $(\mathrm{mm})$ e $R_{c b}$ é o raio integro de aço $(\mathrm{mm})$.

Por fim, para que seja considerada a expansão do concreto devido à formação dos produtos de corrosão, uma decomposição aditiva do tensor de deformações de Green (Equação 3.8) é empregada. Assim, os termos do tensor de deformação dos elementos de partículas são calculados de acordo com a Equação 6.9. Cabe mencionar que a decomposição do tensor só é possível devido a consideração de pequenas deformações.

$$
E_{i j}=\frac{1}{2}\left(C_{i j}-\delta_{i j}\right)-\varepsilon_{r} \delta_{i j}
$$

em que $E_{i j}$ representa a parcela elástica da deformação e $\varepsilon_{r}$ é a deformação dos elementos de partícula (que representa as armaduras) e $\delta_{i j}$ representa o delta de Kronecker.

Na Figura 6.5 é apresentado um fluxograma no qual são descritos os principais processos de cálculo e de processamento, do código desenvolvido para a análise mecânica de estruturas de concreto armado sujeitas à corrosão uniforme. 


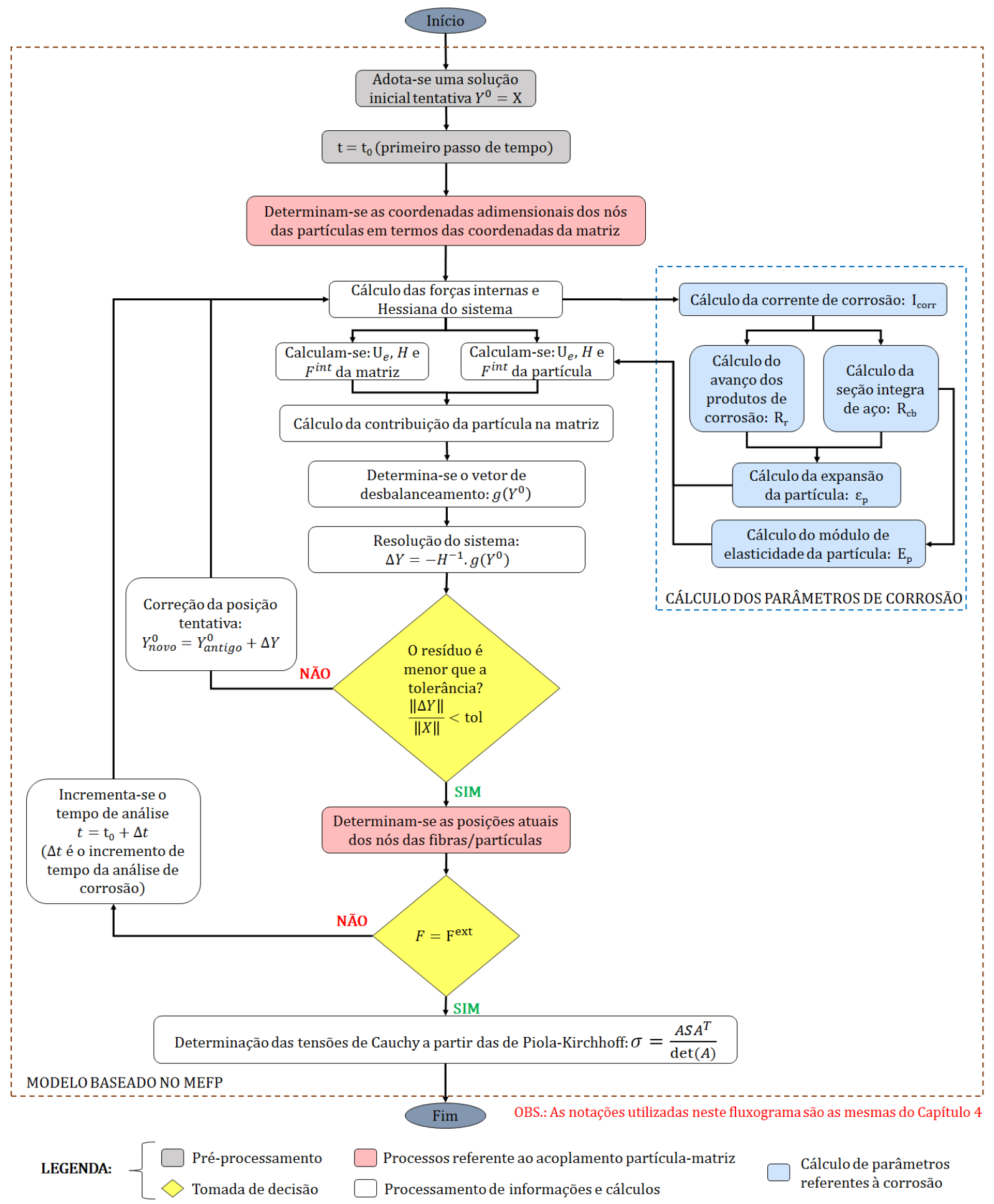

Figura 6.5 - Algoritmo baseado no MEFP para a modelagem de elementos de concreto armado sujeitos à corrosão. 
CAPÍTULO

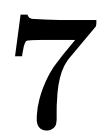

\section{EXEMPLOS DE APLICAÇÃO}

Ao longo deste capítulo, exemplos numéricos são apresentados com o intuito de demonstrar a aplicabilidade e potencialidade dos programas desenvolvidos frente à modelagem da corrosão uniforme do concreto armado.

As malhas dos exemplos foram geradas por intermédio do software desenvolvido no Departamento de Engenharia de Estruturas da EESC-USP, AcadMesh2D.

Para o pós-processamento dos resultados, utilizou-se o software AcadView, também desenvolvido no Departamento de Engenharia de Estruturas da EESC-USP.

\subsection{Placa de concreto armado sujeita à corrosão}

Este primeiro exemplo tem como objetivo avaliar os dois modelos implementados, descritos no capítulo 6, quanto à modelagem da corrosão, em especial, quanto à formação dos produtos de corrosão e expansão do concreto de cobrimento. Assim, foi modelada numericamente a corrosão de uma placa de concreto armado (Figura 7.1a), à qual foi experimentalmente analisada por Nguyen et al. (2007).

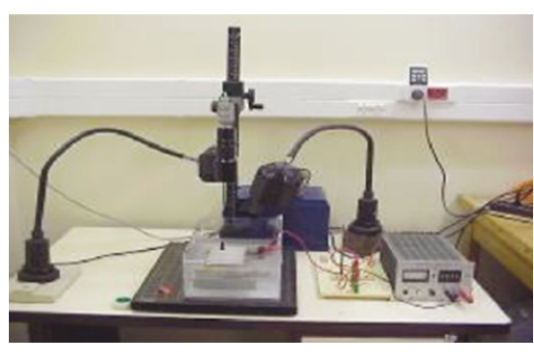

(a) Ensaio de corrosão acelerada.

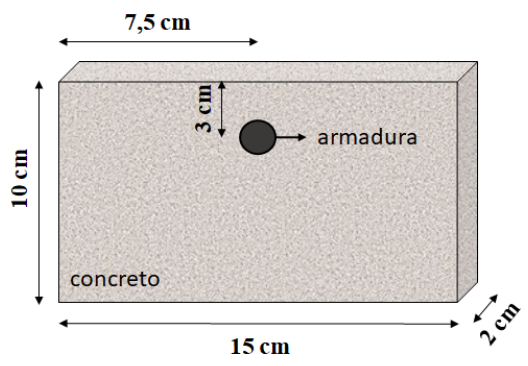

(b) Dimensões da placa.

Figura 7.1 - Dimensões e condições de ensaio da placa de concreto armado.

Fonte: Adaptado de Nguyen et al. (2007). 
A placa contém uma armadura com diâmetro de $10 \mathrm{~mm}$ localizada na região central, conforme mostra a Figura 7.1b. A placa foi produzida com um concreto de resistência à compressão de $39 \mathrm{MPa}$ e aço com limite de escoamento de $500 \mathrm{MPa}$.

Para a realização do ensaio de corrosão acelerada, Nguyen et al. (2007) submeteram a placa de concreto armado, após cura úmida de 28 dias, à uma corrente com densidade constante de $100 \mu \mathrm{A} / \mathrm{cm}^{2}$, durante 92 horas.

Para a modelagem numérica, apenas metade da placa de concreto foi simulada (ver Figura 7.2), devido a simetria do problema. A placa foi discretizada por meio de um elemento compósito particulado, sendo utilizados 680 elementos finitos triangulares para a representação da matriz de concreto e, 826 elementos finitos triangulares para a discretização da armadura. A Figura 7.2 representa graficamente as malhas utilizadas na discretização.

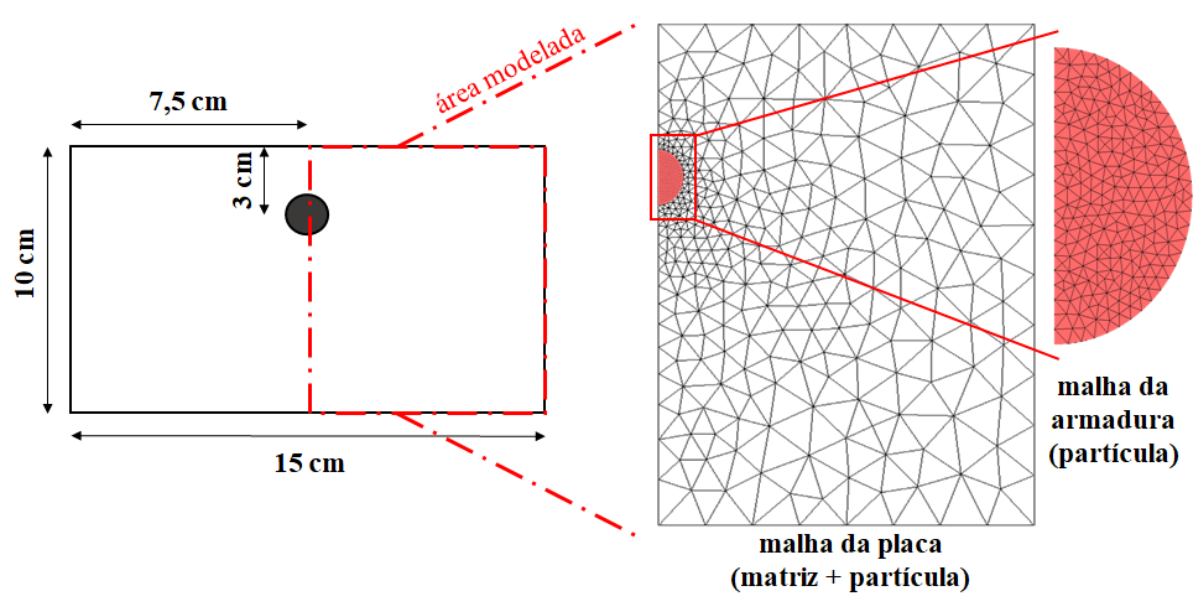

Figura 7.2 - Representação da região da placa modelada e da sua discretização.

Para a representação da formação dos produtos de corrosão, foram utilizados os modelos I e II (descritos no capítulo 6). A Tabela 7.1 apresenta os parâmetros utilizados para a modelagem do problema. Todos os parâmetros foram extraídos de Nguyen et al. (2007).

O comportamento do concreto foi considerado elástico-linear, com módulo de elasticidade de 25 GPa e coeficiente de Poisson de 0,2. Para o aço, o módulo de elasticidade adotado foi de 210 GPa e coeficiente de Poisson de 0,3.

Na Figura 7.3 é apresentada a deformação medida em um ponto situado na região superior da placa, obtida numericamente, por meio dos diferentes modelos implementados e no experimento realizado por Nguyen et al. (2007).

Comparando as deformações observadas experimentalmente e as obtidas por meio dos modelos numéricos implementados (Figura 7.3), verificou-se que o modelo II é o que melhor representa a expansão do concreto devido à corrosão uniforme, uma vez que a taxa de variação média foi de 4,02\%, enquanto que para o modelo I, a taxa foi de 16,23\%. 
Tabela 7.1 - Parâmetros de entrada dos modelos.

\begin{tabular}{ccc}
\hline Parâmetro & Valor & Unidade \\
\hline $\begin{array}{c}\text { Densidade do aço } \\
\text { Valência }\end{array}$ & 7860,00 & $\mathrm{~kg} / \mathrm{m}^{3}$ \\
$\begin{array}{c}\text { Razão entre densidade do aço e } \\
\text { dos produtos de corrosão }\end{array}$ & 3,70 & - \\
$\begin{array}{c}\text { Módulo de elasticidade } \\
\text { dos produtos de corrosão } \\
\text { Massa atômica do aço }\end{array}$ & 0,15 & $\mathrm{GPa}$ \\
$\begin{array}{c}\text { Razão em volume da expansão dos } \\
\text { produtos de corrosão }\end{array}$ & 55,84 & - \\
\hline
\end{tabular}

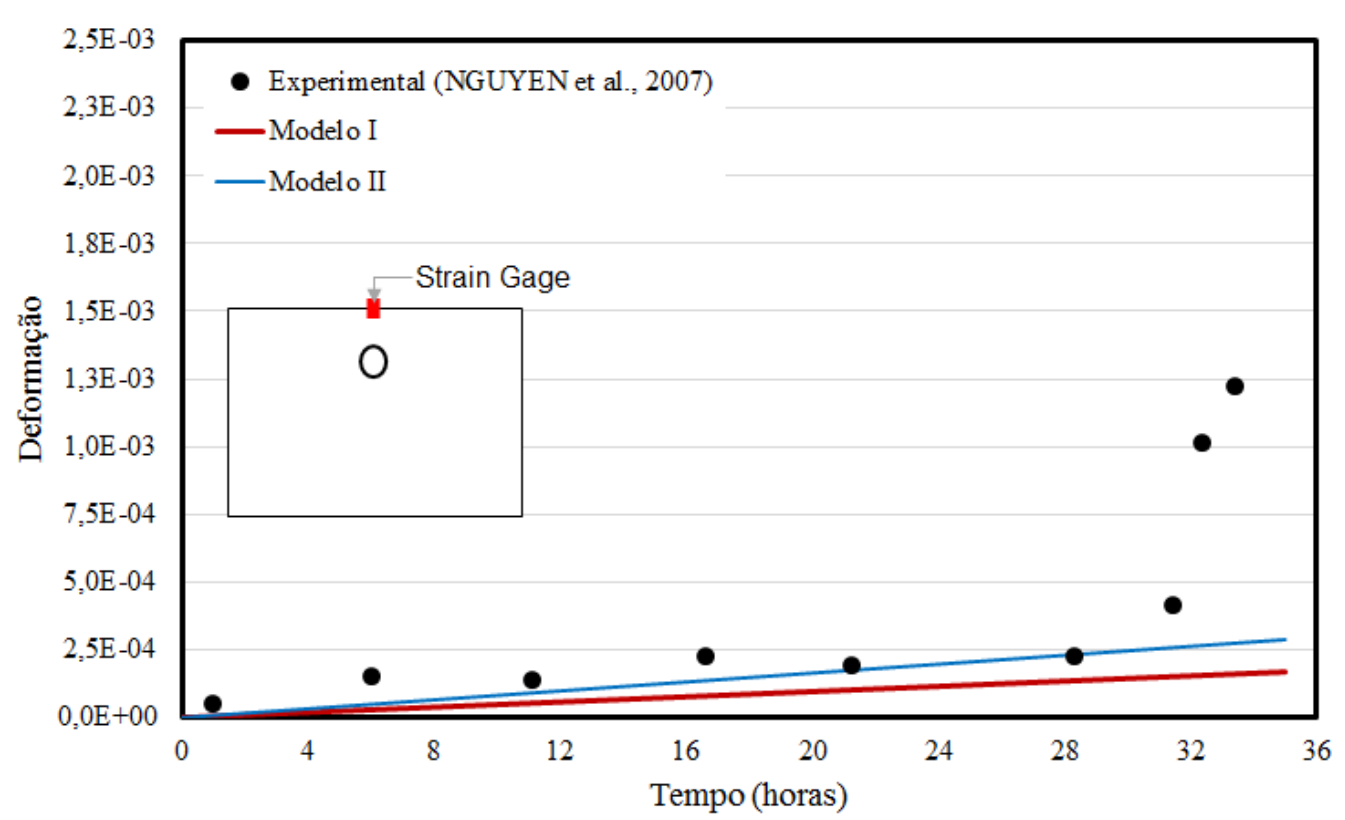

Figura 7.3 - Comparação entre os resultados numéricos e experimental.

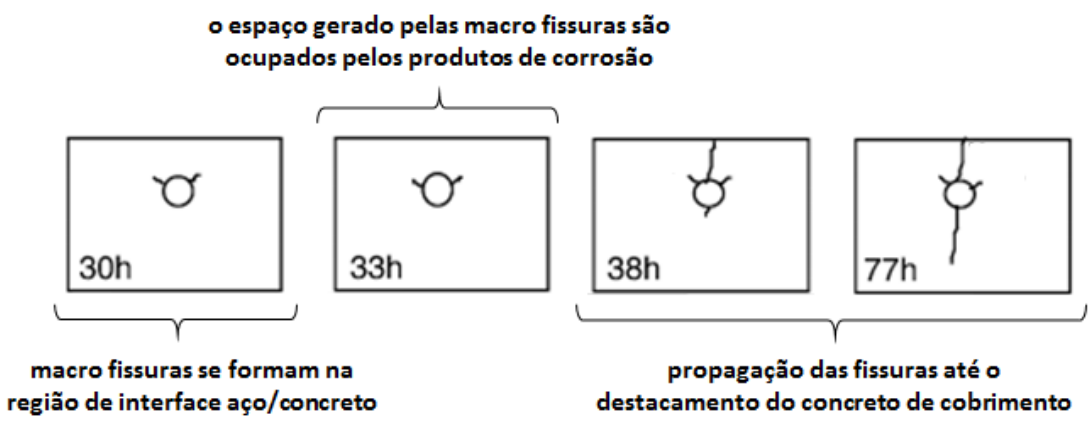

Figura 7.4 - Formação das fissuras ao longo do tempo.

Fonte: Adaptado de Nguyen et al. (2007).

Ainda sobre a Figura 7.3, observa-se que após o tempo de 30 horas, os modelos não conseguem representar coerentemente as deformações impostas pela corrosão. Isso ocorre devido ao fato de que nesse instante macro fissuras se formam na região de interface 
entre o aço e o concreto, conforme é visto nos mapas de fissuras (Figura 7.4), descritos em Nguyen et al. (2007), para o problema em análise. Assim, perante o regime elástico-linear do concreto, o modelo II descreve de forma eficiente as deformações impostas pela corrosão. As Figuras 7.5 e 7.6 ilustram os deslocamentos horizontal e vertical, respectivamente, da placa de concreto após 15 e 30 horas de corrosão acelerada, considerando o modelo II.

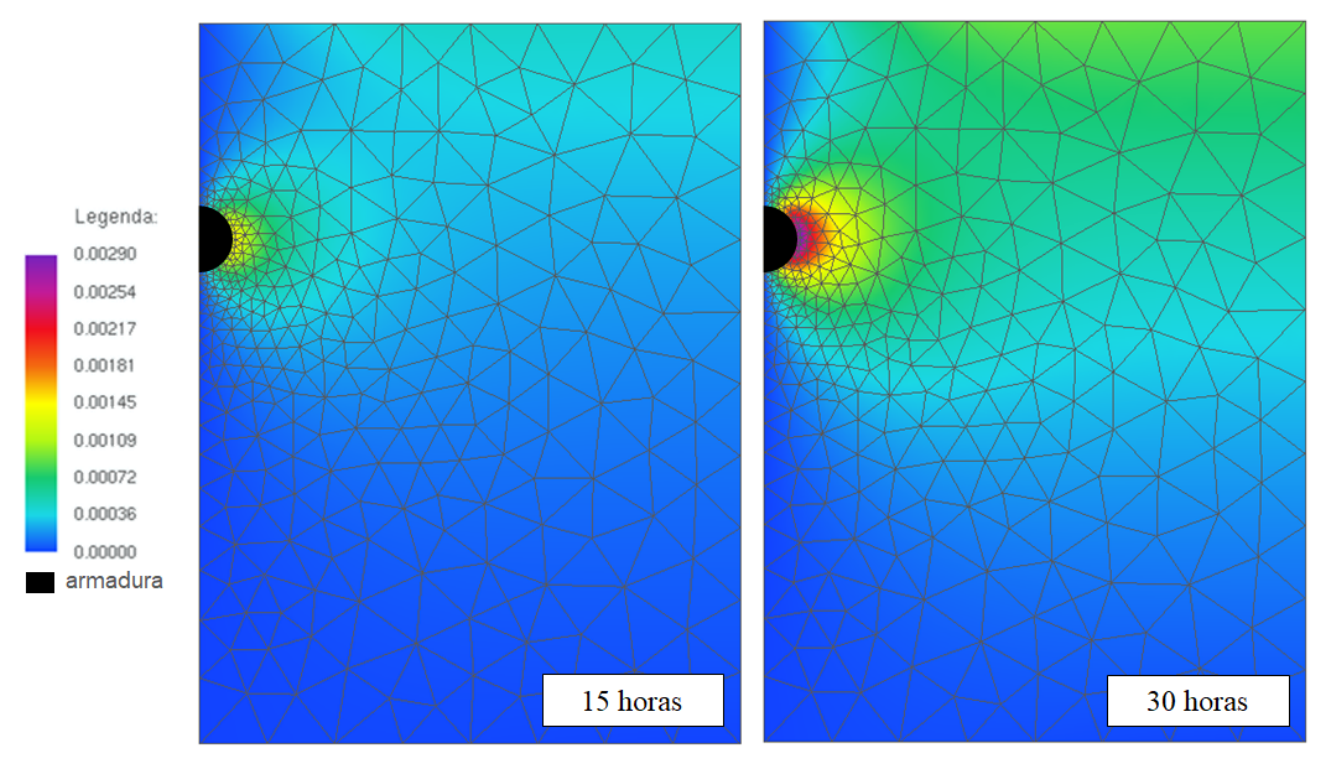

Figura 7.5 - Deslocamento horizontal (em cm).

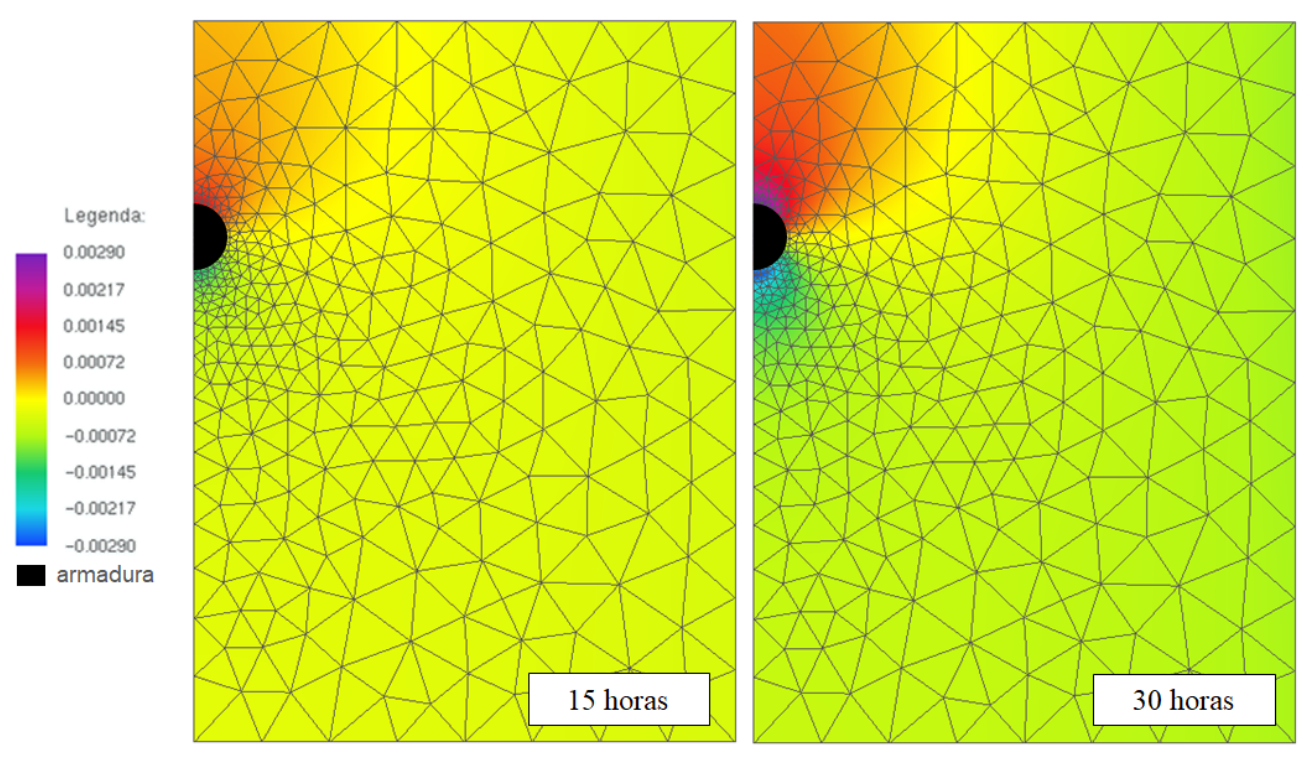

Figura 7.6 - Deslocamento vertical (em $\mathrm{cm})$.

As Figuras 7.7 e 7.8 apresentam as tensões na direção horizontal e vertical, respectivamente, da placa de concreto após 15 e 30 horas de corrosão acelerada. 


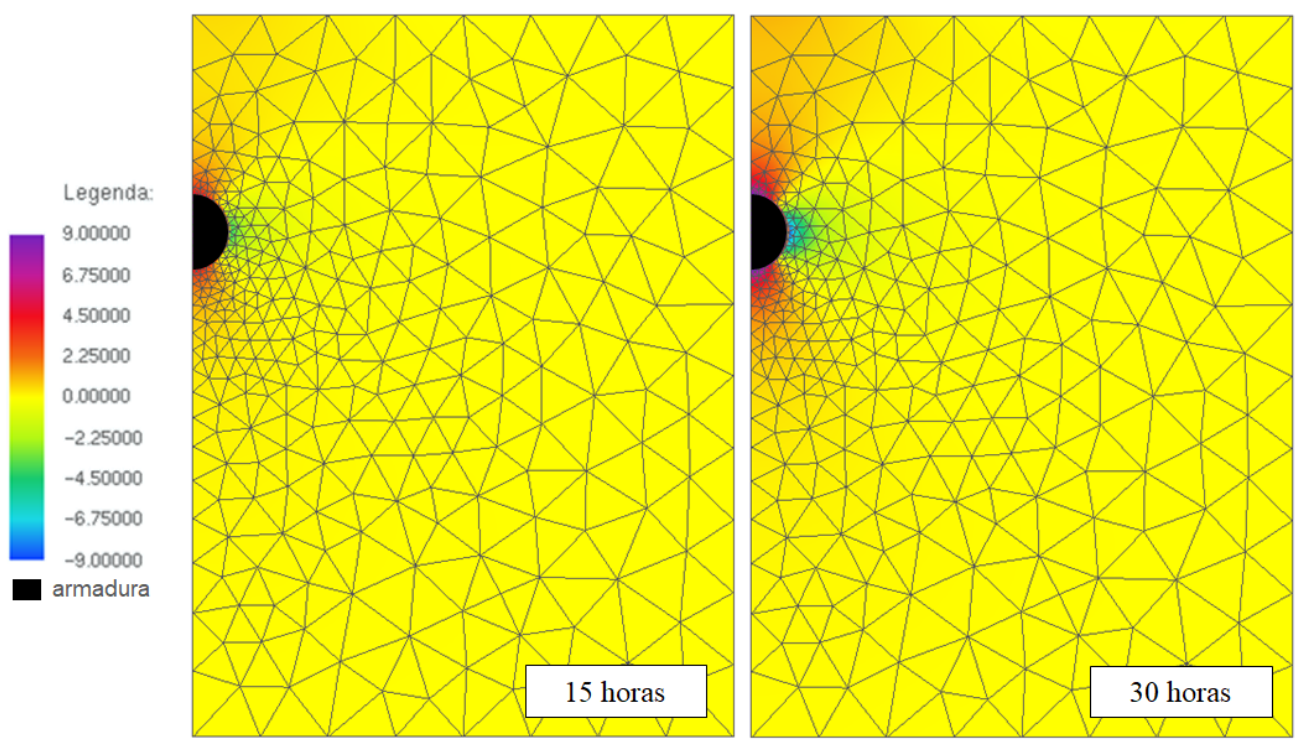

Figura 7.7 - Tensão horizontal (em MPa).

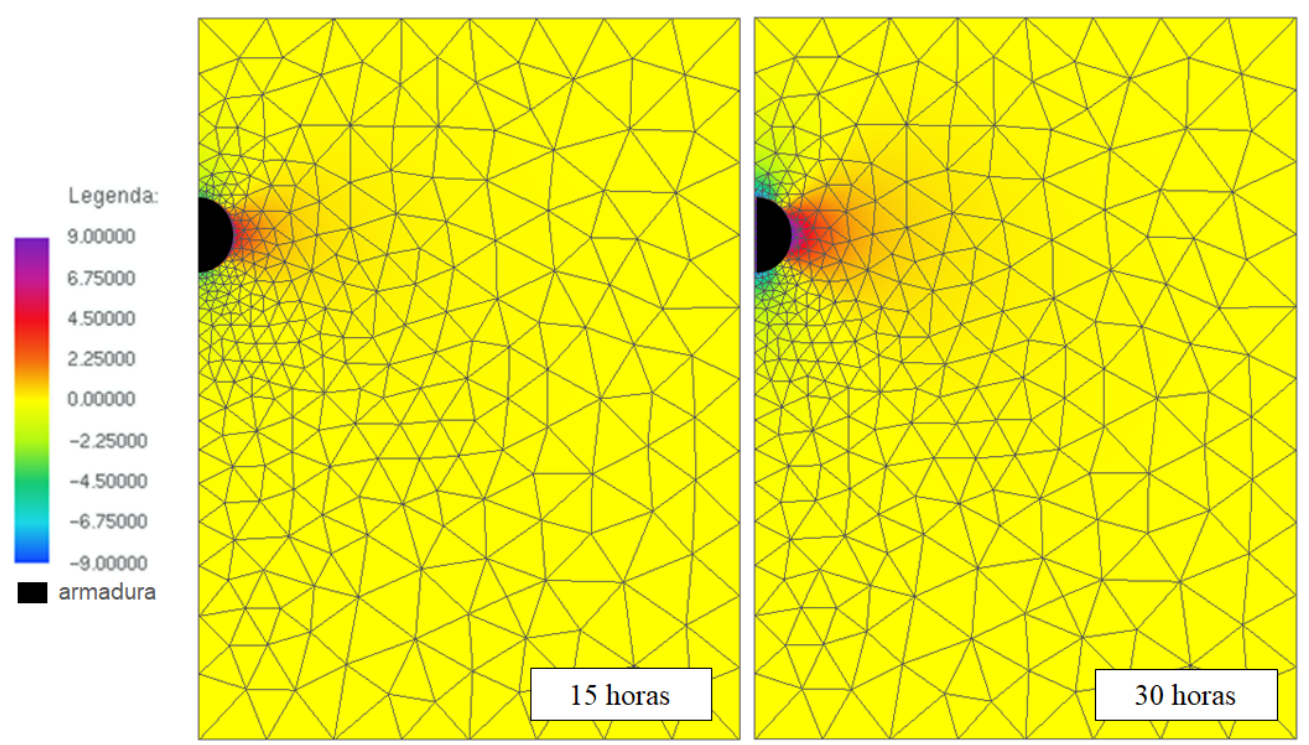

Figura 7.8 - Tensão vertical (em MPa).

Como esperado, é possível observar por meio das Figuras 7.7 e 7.8 que, para o instante de 30 horas, após iniciada a corrosão da armadura, tensões de tração já superam valores superiores aos $3 \mathrm{MPa}$, valor correspondente à resistência à tração do concreto, demonstrando a existência neste instante de macro fissuras na região próxima à armadura.

Por fim, conclui-se que o modelo II apresenta um comportamento adequado frente à representação da expansão do concreto devido à formação dos produtos de corrosão, e consequentemente, da corrosão uniforme, considerando o regime elástico linear dos materiais. Diante do exposto, nos demais exemplos apresentados neste capítulo, empregouse o modelo II para a modelagem da corrosão uniforme. 


\subsection{Corpo de prova sob corrosão sujeito a diferentes níveis de tensão aplicada}

Este exemplo tem por objetivo avaliar o efeito de tensões aplicadas externamente em corpos de prova de concreto armado sob corrosão uniforme. Analisa-se para quais níveis de tensão aplicada as solicitações mecânicas (advindas do carregamento) exercem maior influência que as solicitações químico-mecânicas impostas pela corrosão.

Assim, foi modelado numericamente um corpo de prova cilíndrico de concreto armado sob corrosão acelerada, o mesmo analisado experimentalmente por Nguyen et al. (2007).

O corpo de prova modelado está livre para se deformar, sem restrições e vinculações. O elemento de concreto possui seção transversal com diâmetro de $10 \mathrm{~cm}$ e $10 \mathrm{~cm}$ de comprimento. O corpo de prova tem uma armadura com diâmetro de $10 \mathrm{~mm}$ na região central, conforme mostra a Figura 7.9, e foi produzido com um concreto com resistência à compressão de $39 \mathrm{MPa}$ e aço com limite de escoamento de $500 \mathrm{MPa}$.

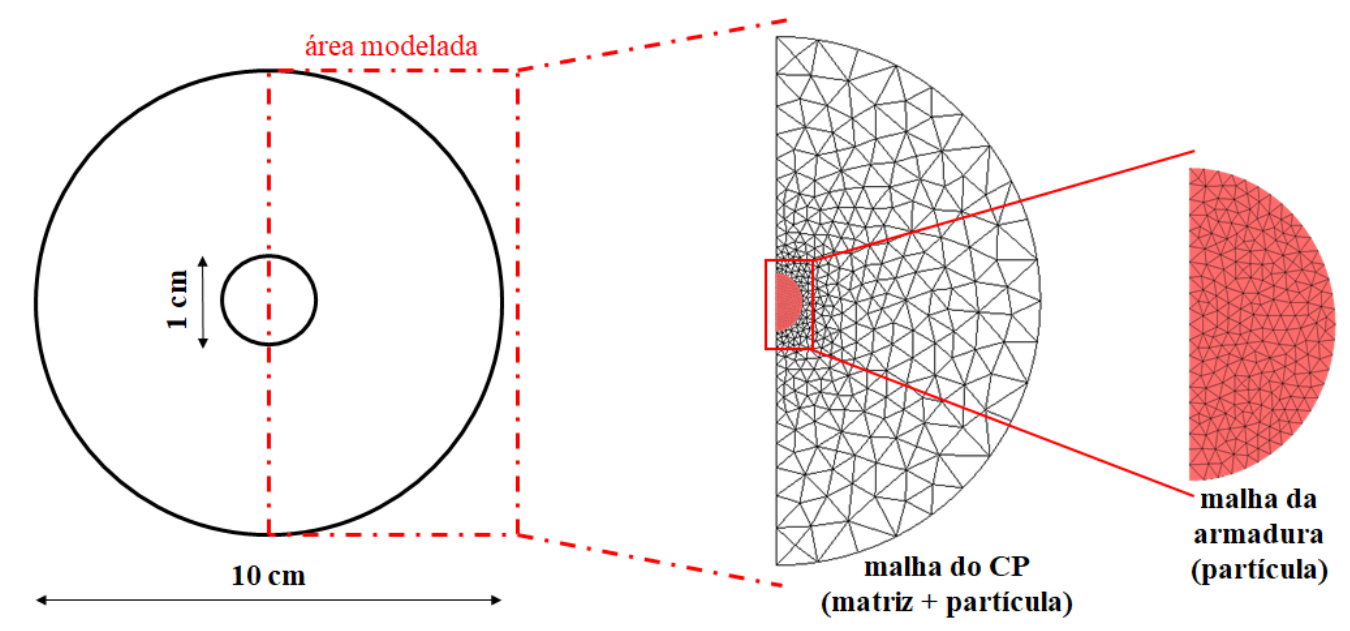

Figura 7.9 - Geometria e malha do corpo de prova modelado.

No experimento realizado por Nguyen et al. (2007), o cilindro de concreto armado foi submetido, após cura úmida de 28 dias, à uma corrente com densidade constante de $10 \mu \mathrm{A} / \mathrm{cm}^{2}$, durante 40 horas. Nguyen et al. (2007) observou em seus experimentos que o módulo de elasticidade dos produtos de corrosão era de 0,15 GPa, sendo este o valor utilizado neste e nos demais exemplos deste trabalho.

Para a modelagem numérica, realizada neste trabalho, apenas metade do cilindro de concreto foi simulado (ver Figura 7.9), devido à simetria do problema. O corpo de prova foi discretizado por meio de um elemento compósito particulado, sendo utilizados 706 elementos finitos triangulares para a representação da matriz de concreto, e 422 
elementos finitos triangulares para a discretização da armadura. A Figura 7.9 apresenta esquematicamente as malhas utilizadas para a representação do corpo de prova.

O comportamento do concreto foi considerado elástico-linear (desconsiderando a degradação das propriedades físicas) com módulo de elasticidade de 20 GPa e coeficiente de Poisson de 0,2. Para a armadura, o módulo de elasticidade é de 210 GPa e coeficiente de Poisson de 0,3 .

Como mencionado no exemplo anterior, o modelo II é utilizado em todas as modelagens neste capítulo, assim, faz-se necessário informar como parâmetro de entrada do modelo a razão em volume da expansão dos produtos de corrosão, porém esta não é conhecida, sendo necessário inicialmente determiná-la. Assim, como Molina, Alonso e Andrade (1993) e Nguyen et al. (2007) relatam que a razão em volume da expansão dos produtos de corrosão varia entre 2,5 e 5,5, decidiu-se modelar o corpo de prova com as razões variando dentro desse intervalo, determinando assim o valor que melhor se adéqua ao problema.

Na Figura 7.10 são apresentadas as curvas do deslocamento vertical de um ponto situado na parte inferior da região de contato entre o aço e o concreto, obtidas numericamente por meio do modelo implementado, para os diferentes valores da razão em volume da expansão dos produtos de corrosão analisadas. Os deslocamentos são comparados com os valores obtidos no experimento realizado por Nguyen et al. (2007).

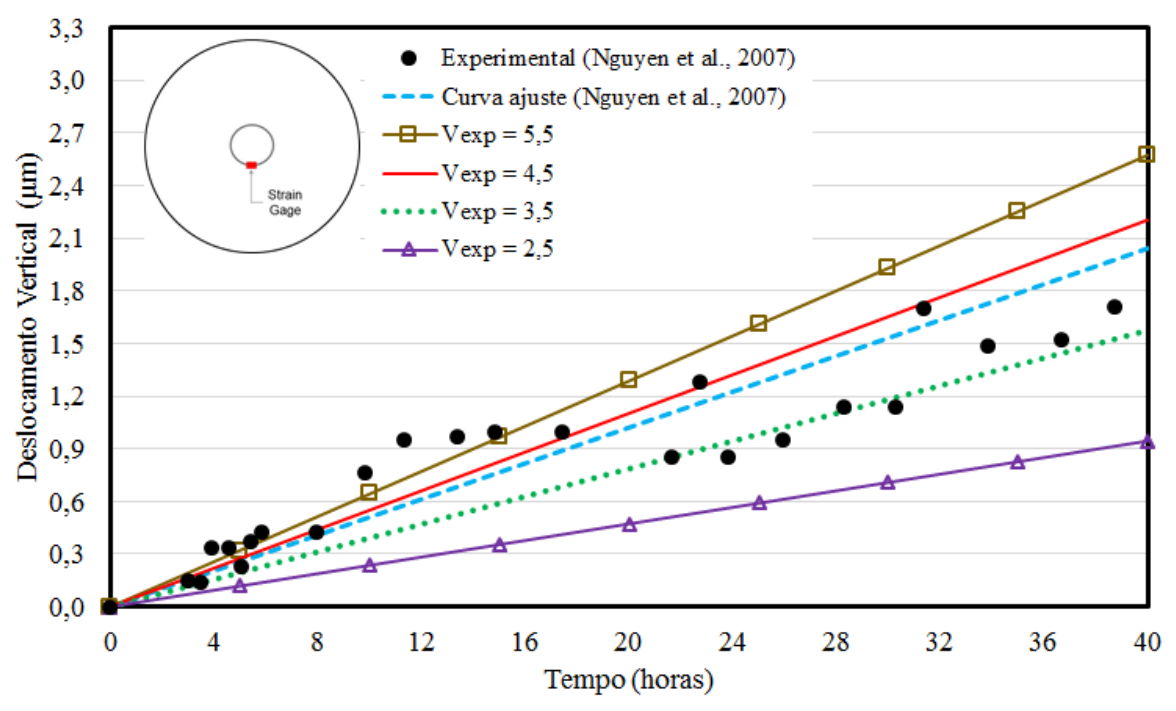

Figura 7.10 - Deslocamento vertical do corpo de prova.

Por meio da Figura 7.10, observa-se visualmente que para o problema em análise, os valores da razão em volume da expansão dos produtos de corrosão de 3,5 e 4,5 são os que proporcionam os melhores resultados. Porém, ao analisar a taxa de variação entre os deslocamento obtidos numericamente e experimentalmente, a razão em volume de 4,5 proporcionou uma variação de $16,71 \%$, enquanto que para a razão em volume de 3,5 a variação foi de $26,81 \%$. 
É possível notar na Figura 7.10 a aleatoriedade nos valores obtidos no ensaio experimental. Nguyen et al. (2007) descrevem que para o período em que o material tem um comportamento elástico-linear, a curva de deslocamento deve ter um comportamento linear. A curva feita pelo ajuste linear dos dados é apresentada na Figura 7.10. Diante dos resultados obtidos, neste exemplo é adotada a razão em volume, para a expansão dos produtos de corrosão de 4,5 .

As Figuras 7.11 e 7.12 ilustram os deslocamentos horizontal e vertical, respectivamente, da placa de concreto após 20 e 40 horas de corrosão acelerada.
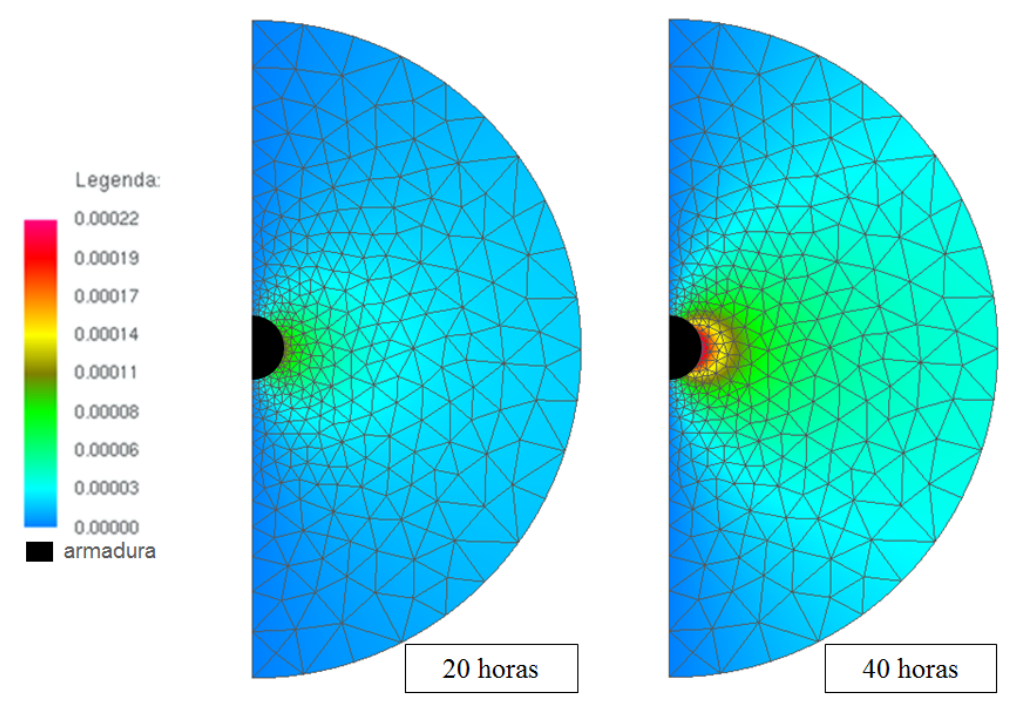

Figura 7.11 - Deslocamento horizontal (em cm).
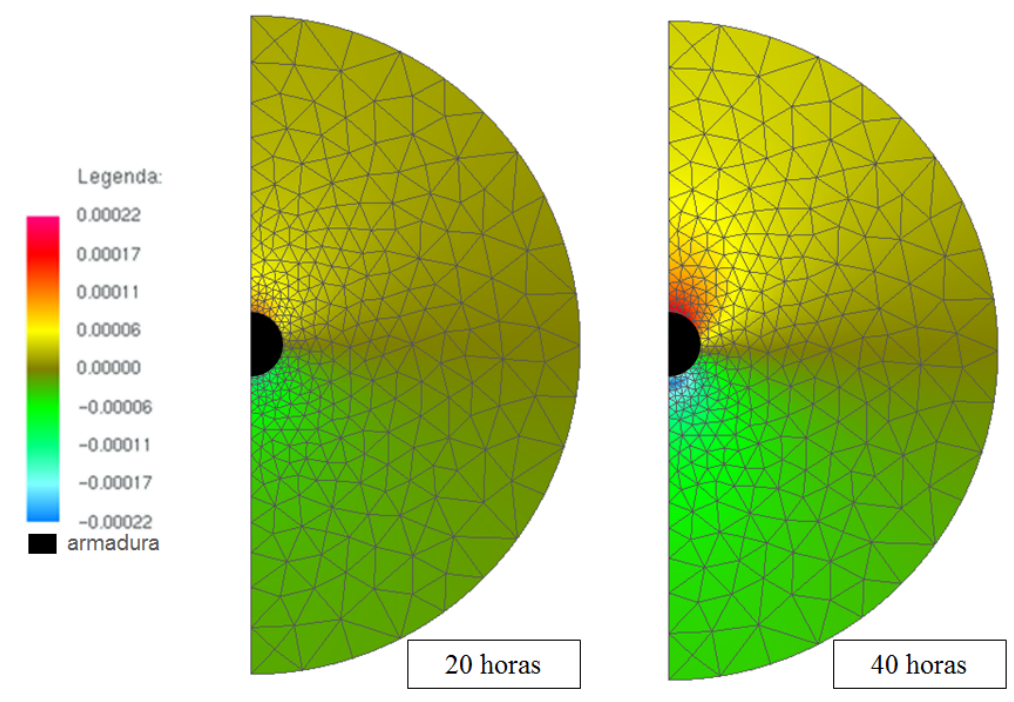

Figura 7.12 - Deslocamento vertical (em cm).

Por meio dessa modelagem, pode-se verificar novamente que o modelo implementado representa coerentemente a expansão do concreto em função da corrosão, e assim, da formação dos produtos de corrosão. Sabendo disso, na sequência utiliza-se como base 
o mesmo corpo de prova cilíndrico, submetido ao mesmo nível de corrosão, porém com a aplicação de diferentes carregamentos $(0,5,1,0,1,5$ e 2,0 kN). A configuração do carregamento, vínculos e malhas utilizadas para as simulações são apresentadas na Figura 7.13 .

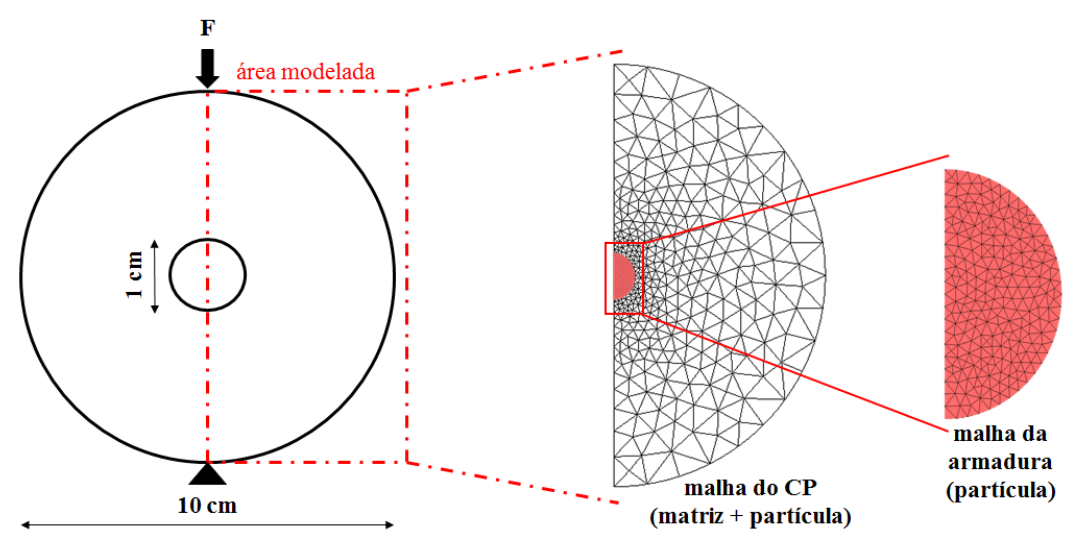

Figura 7.13 - Geometria, configuração de carregamento e malha do corpo de prova.

Considerando que as propriedades do concreto e da armadura seguem análogas às da modelagem do corpo de prova sem aplicação do carregamento, nas Figuras 7.14 e 7.15 são apresentadas as tensões observadas na região de interface entre o aço e o concreto após 40 horas de corrosão acelerada, para os diferentes níveis de carregamento aplicado.

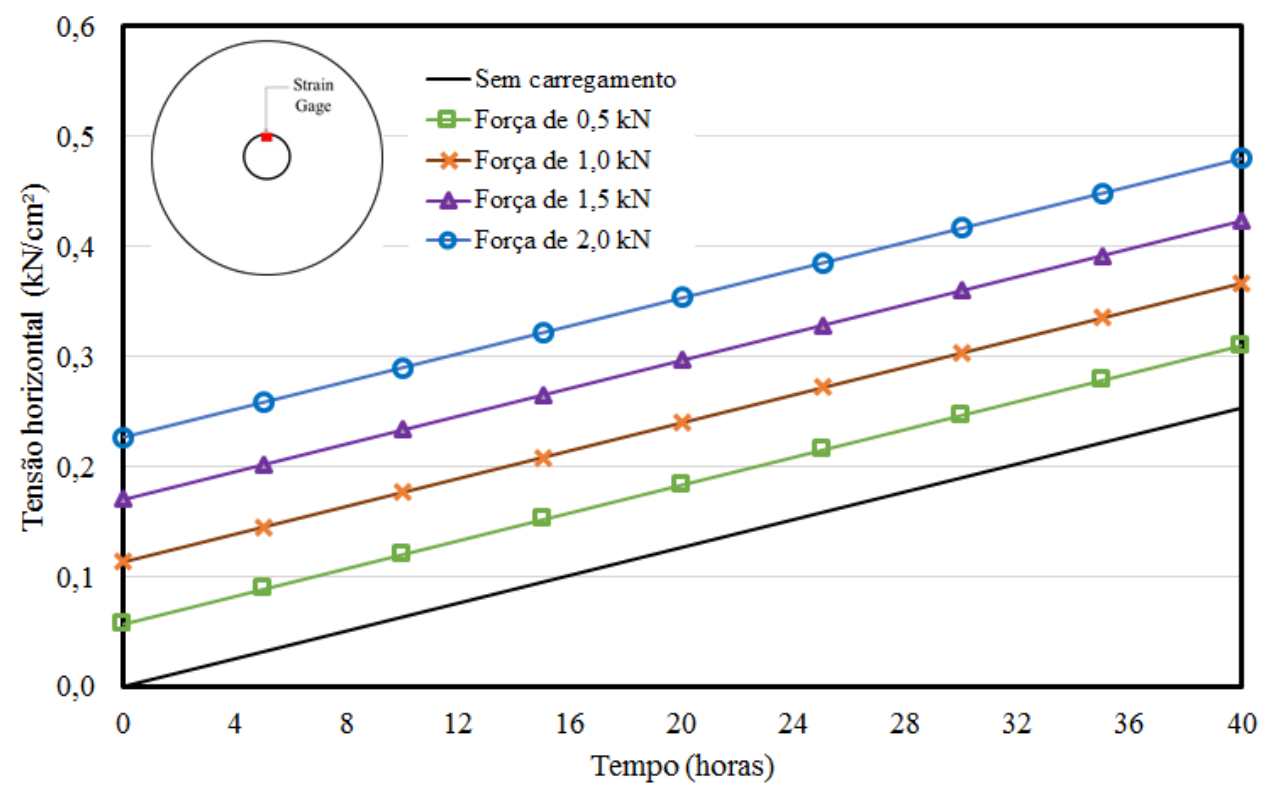

Figura 7.14 - Tensão horizontal na região de interface aço/concreto.

A Figura 7.14 mostra que a tensão de um ponto situado na parte superior da região de contato entre o concreto e a armadura é sempre de tração (positiva), independente do estado de tensão aplicado no corpo de prova. A medida que o carregamento aplicado 
aumenta, em magnitude, a tensão de tração sofre um acréscimo proporcional. Assim, considerando a teoria da mecânica linear da fratura, pode-se dizer que nessa região fissuras ortogonais se formam e têm sua propagação em função do acréscimo da solicitação químico-mecânica imposta pela corrosão.

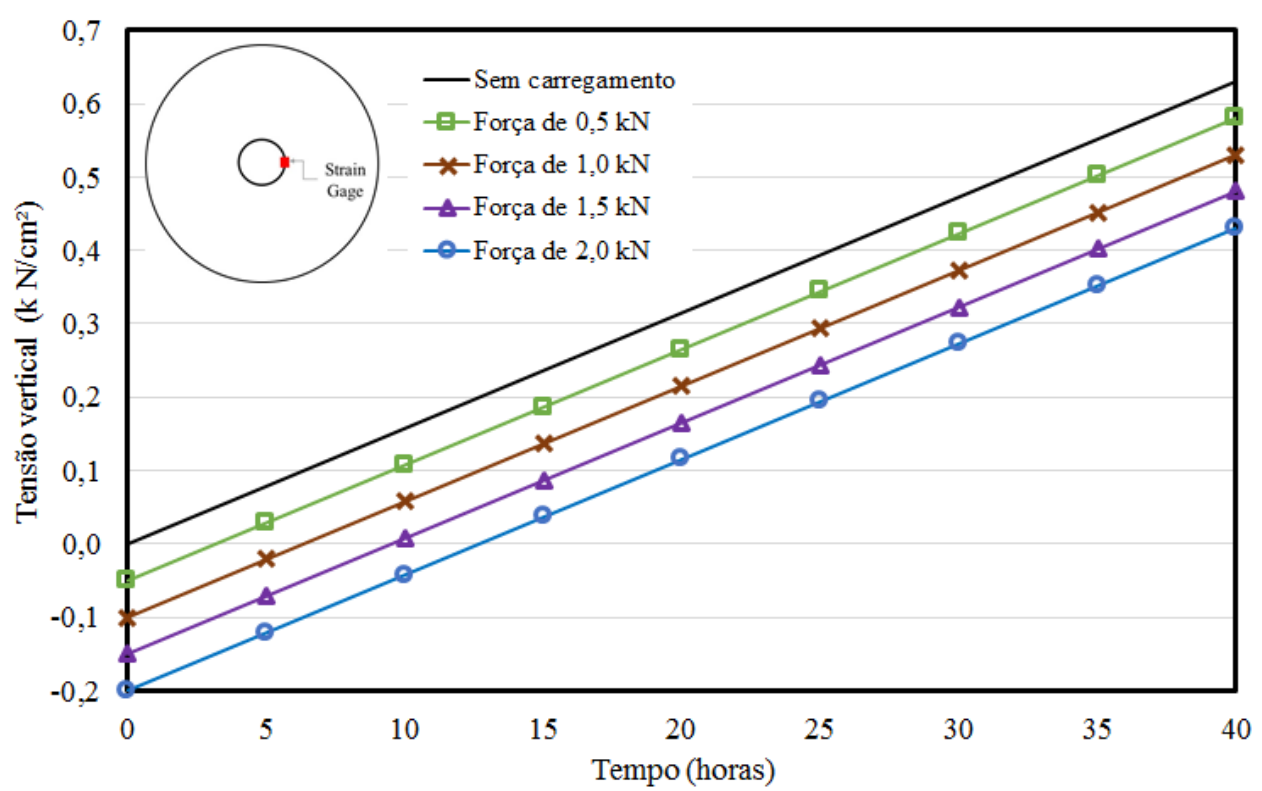

Figura 7.15 - Tensão vertical na região de interface aço/concreto.

Por meio da Figura 7.15 observa-se que a tensão de um ponto de análise, situado na região de contato entre o aço e o concreto, é inicialmente de compressão (até 12 horas após o inicio da corrosão). Assim, durante este período de tempo, fissuras não se formariam nessa região, já que o seu aparecimento está condicionado à existência de tensões de tração superiores à resistência à tração do concreto, que geralmente se situa entre 1,7 e 3,3 $\mathrm{MPa}$ (MEHTA; MONTEIRO, 2014). Entretanto, observa-se que à medida que a corrosão se desenvolve, a região de análise sai do estado de compressão e passa ao estado de tração, o que provoca o surgimento de fissuras na horizontal, quando a magnitude da tensão supera à resistida pelo material.
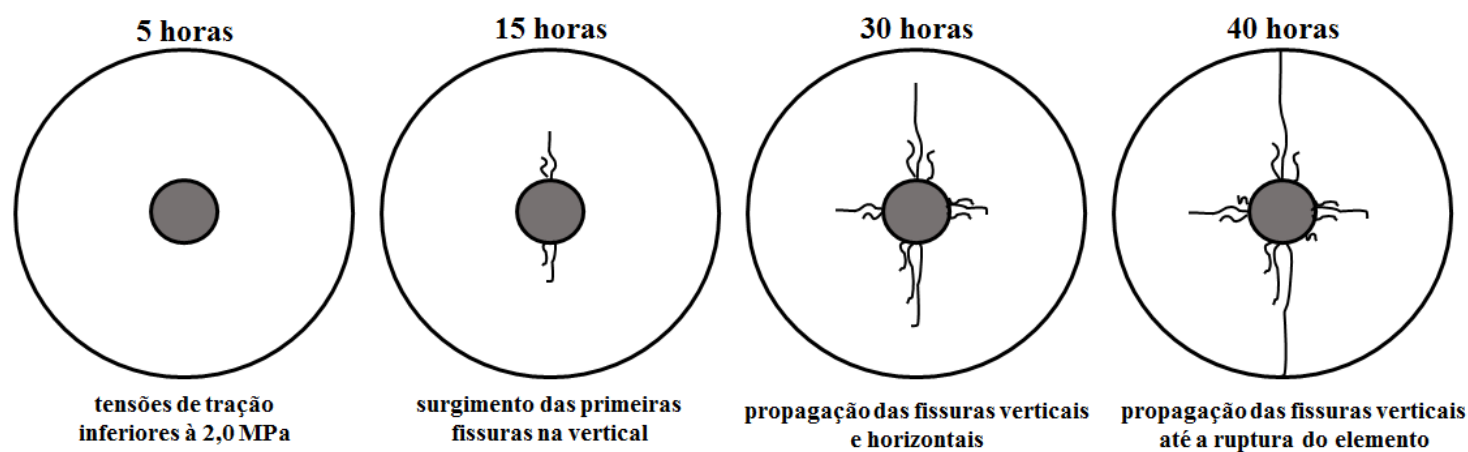

Figura 7.16 - Desenvolvimento teórico das fissuras. 
Na Figura 7.16 é representado graficamente o avanço das fissuras no corpo de prova, considerando os preceitos da mecânica linear da fratura, para o caso em que a carga aplicada é de $1,0 \mathrm{kN}$ e diante da consideração de que a resistência à tração do concreto é de 2,0 MPa.

Por fim, apresentam-se nas Figuras 7.17 e 7.18 os campos de tensão atuando no corpo de prova em função dos diferentes níveis de carregamento.
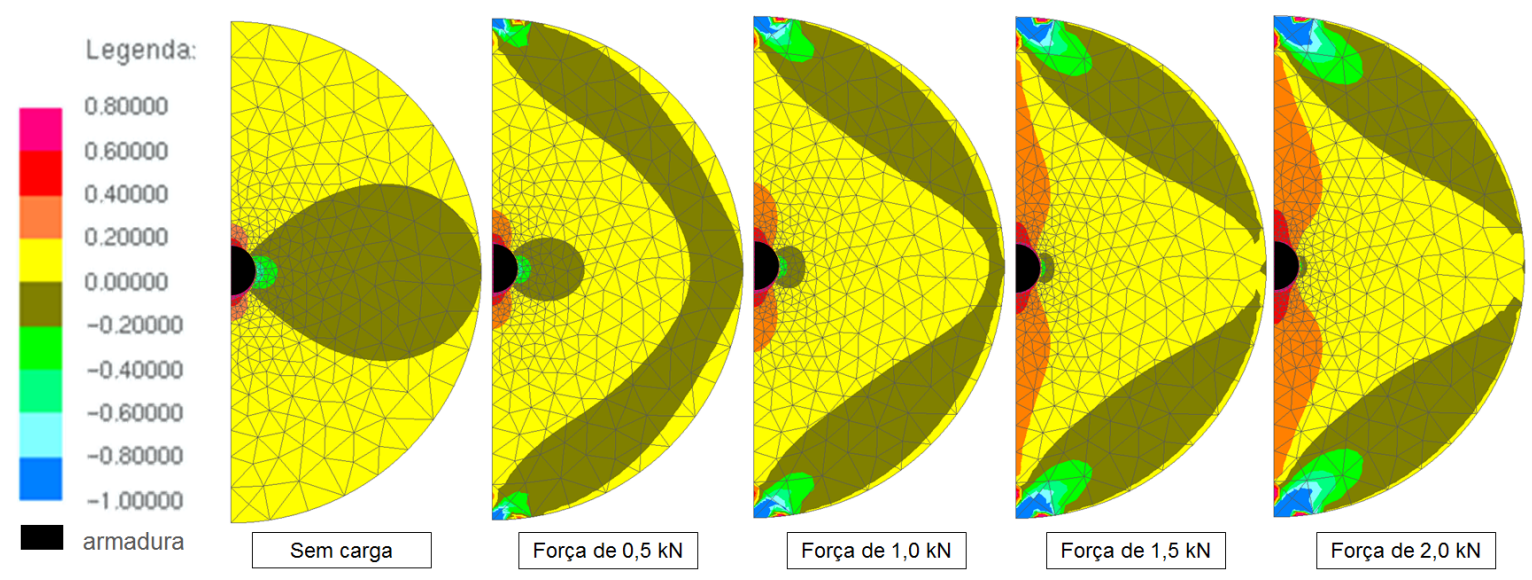

Figura 7.17 - Tensão horizontal $\left(\mathrm{kN} / \mathrm{cm}^{2}\right)$.
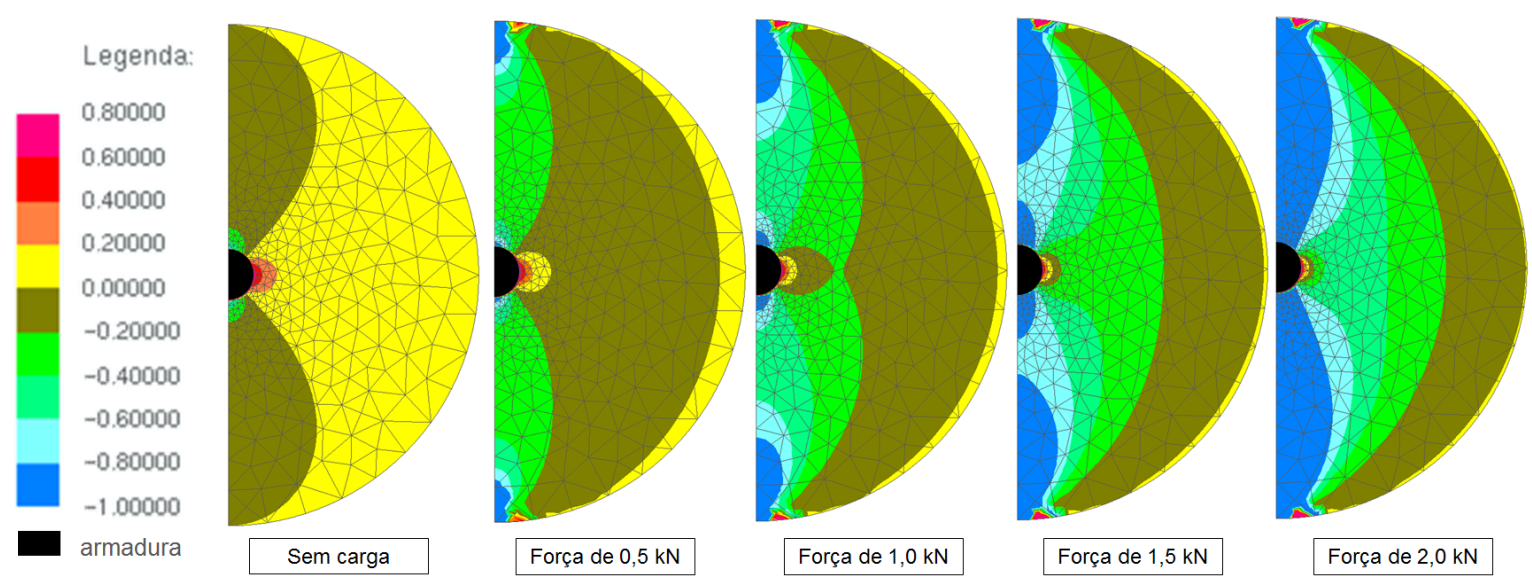

Figura 7.18 - Tensão vertical $\left(\mathrm{kN} / \mathrm{cm}^{2}\right)$.

Com os resultados observados neste exemplo, foi possível verificar que o código implementado para a modelagem da corrosão, e em especial, para a formação dos produtos de corrosão, está coerente segundo os preceitos da teoria da elasticidade, mesmo quando considerado a aplicação de cargas externas.

Os resultados demonstram ainda que a corrosão tende a alterar o campo de tensão do elemento estrutural, fazendo com que algumas regiões do material passem a trabalhar sob tração, à medida que a corrosão das armaduras progride. 


\subsection{Viga de concreto armado sujeita à corrosão}

O terceiro exemplo tem por objetivo avaliar o feito da corrosão uniforme nos campos de deslocamento e tensão de uma viga de concreto armado, com e sem carregamento externo. A geometria da viga e suas dimensões são apresentadas na Figura 7.19.

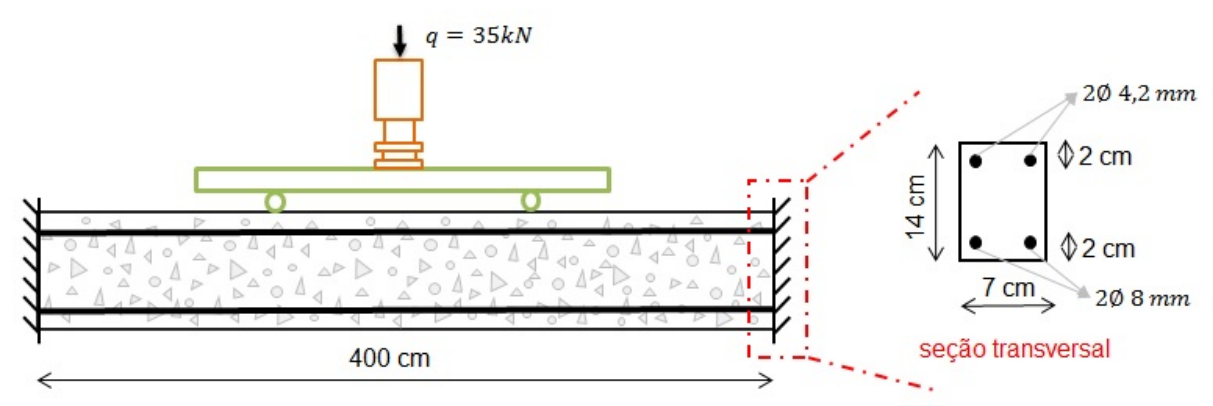

Figura 7.19 - Geometria e dimensões da viga de concreto.

Inicialmente para a modelagem, a corrosão é imposta de forma acelerada, utilizando uma corrente constante de $100 \mu \mathrm{A} / \mathrm{cm}^{2}$. Em seguida, avaliam-se os efeitos da expansão do concreto da viga simulada em ambiente de laboratório (corrosão acelerada), comparando-os com os efeitos da corrosão da viga quando em ambiente natural, utilizando uma corrente variável no tempo, com formulação proposta por Vu e Stewart (2000) (Equação 7.1).

$$
i_{\text {corr }}(t)=0,85\left[\frac{37,8\left(1-\frac{a}{c}\right)^{-1,64}}{c o b}\right] t^{-0,29}
$$

em que $i_{\text {corr }}$ representa a taxa de corrosão $\left(\mu A / \mathrm{cm}^{2}\right), t$ refere-se ao tempo de progressão da corrosão (anos), $\frac{a}{c}$ é a relação água/cimento e cob é o cobrimento do concreto $(\mathrm{cm})$.

A discretização da malha de elementos finitos da viga de concreto armado foi feita com 2230 nós e 468 elementos triangulares para a representação da matriz de concreto, e com 952 elementos de triangulares (partículas) para a representação das armaduras.

Quanto às propriedades dos materiais, o concreto possuí módulo de elasticidade de $2600,0 \mathrm{kN} / \mathrm{cm}^{2}$, resistência à compressão de $2,5 \mathrm{kN} / \mathrm{cm}^{2}$, resistência à tração de 0,179 $k N / \mathrm{cm}^{2}$ e coeficiente de Poisson de 0,2. Já as armaduras possuem módulo de elasticidade $21000,0 \mathrm{kN} / \mathrm{cm}^{2}$ e resistência à tração de $50,0 \mathrm{kN} / \mathrm{cm}^{2}$.

Para a simulação da corrosão foram considerados tanto a perda de seção de aço quanto a formação de produtos de corrosão. Para a formação dos produtos de corrosão, considerou-se uma razão em volume da expansão dos produtos de corrosão de 4,5, por motivos comentados no exemplo 2 deste capítulo.

Na Figura 7.20 são apresentados os resultados obtidos referente ao deslocamento vertical, em função do tempo, para três diferentes regiões da viga de concreto, considerando apenas solicitações químico-mecânicas impostas pela corrosão. 


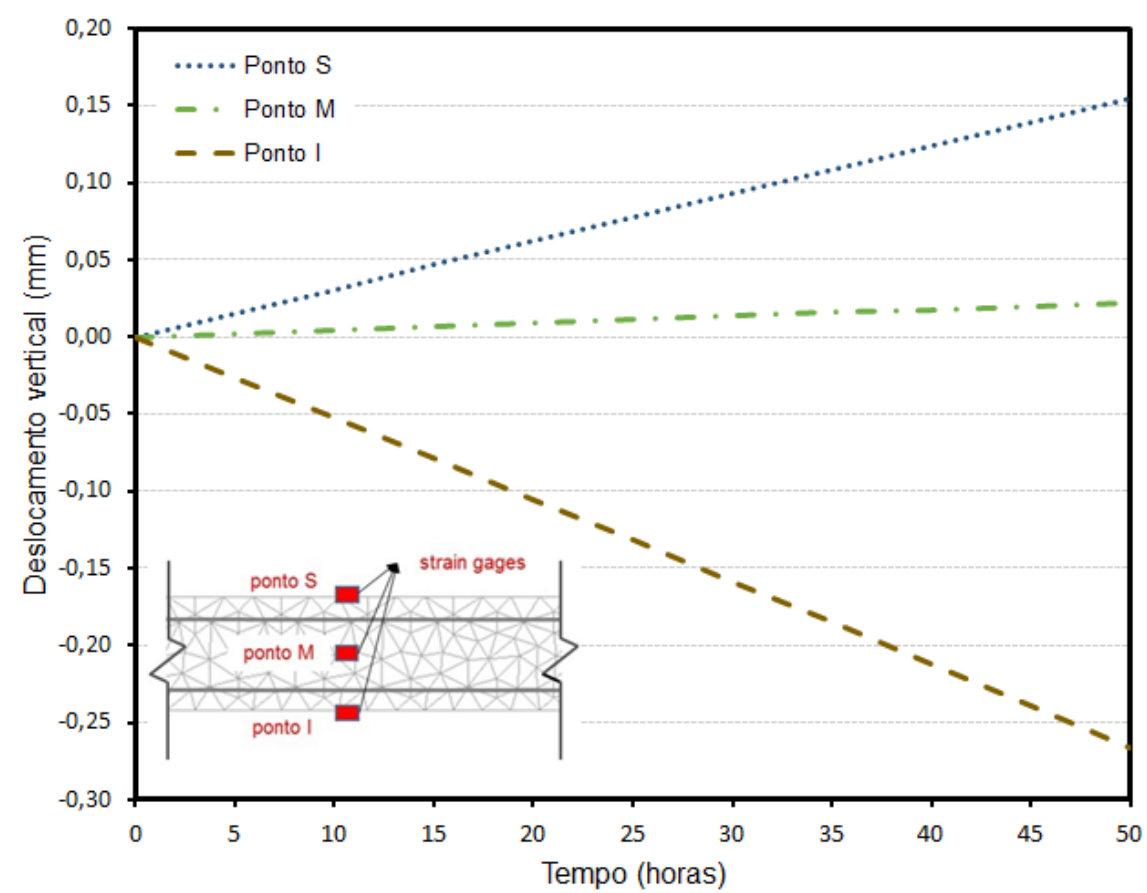

Figura 7.20 - Deslocamento vertical da viga de concreto sob corrosão acelerada.

Oberva-se pela Figura 7.20 que após 50 horas de corrosão acelerada, a estrutura experimenta uma flecha de 0,26 mm, para um ponto situado na parte inferior do centro da viga (ponto I). Para um ponto situado na parte superior do centro da viga (ponto S), o deslocamento é de 0,14 mm, quase a metade do valor observado no ponto inferior.

Na Figura 7.21 são apresentadas as configurações deformadas das vigas no instante de 25 e 50 horas, onde é possível verificar que a região inferior da viga é a mais afetada.

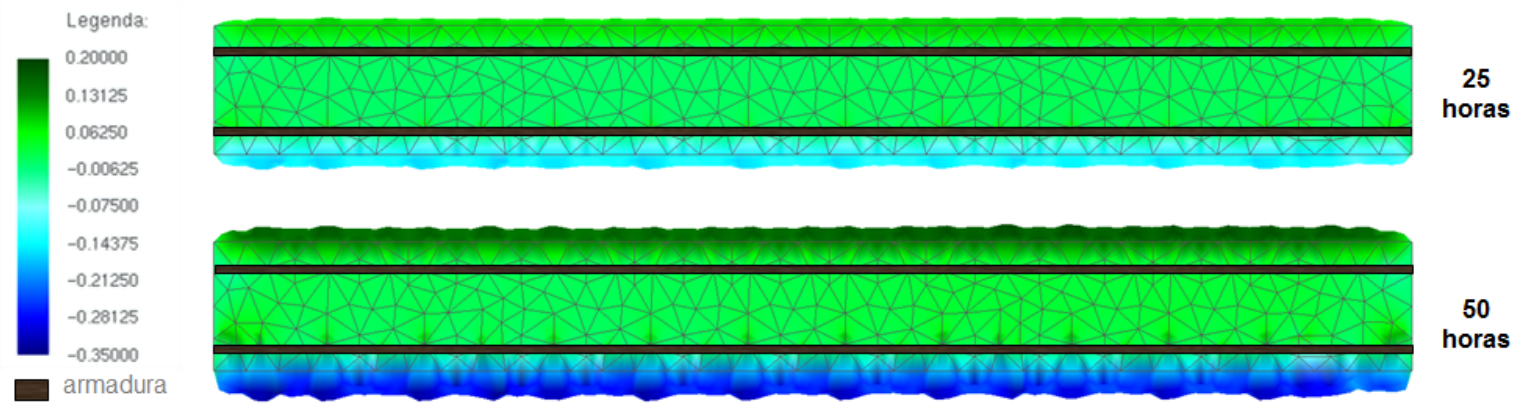

Figura 7.21 - Configuração deformada da viga de concreto sob corrosão acelerada.

Em seguida, a viga de concreto foi modelada novamente sob corrosão acelerada, adicionando a ação do carregamento externo $(q=35 \mathrm{kN})$, aplicado conforme mostra a Figura 7.19. As Figuras 7.22, 7.23 e 7.24 apresentam o deslocamento da viga, em função da corrosão. 


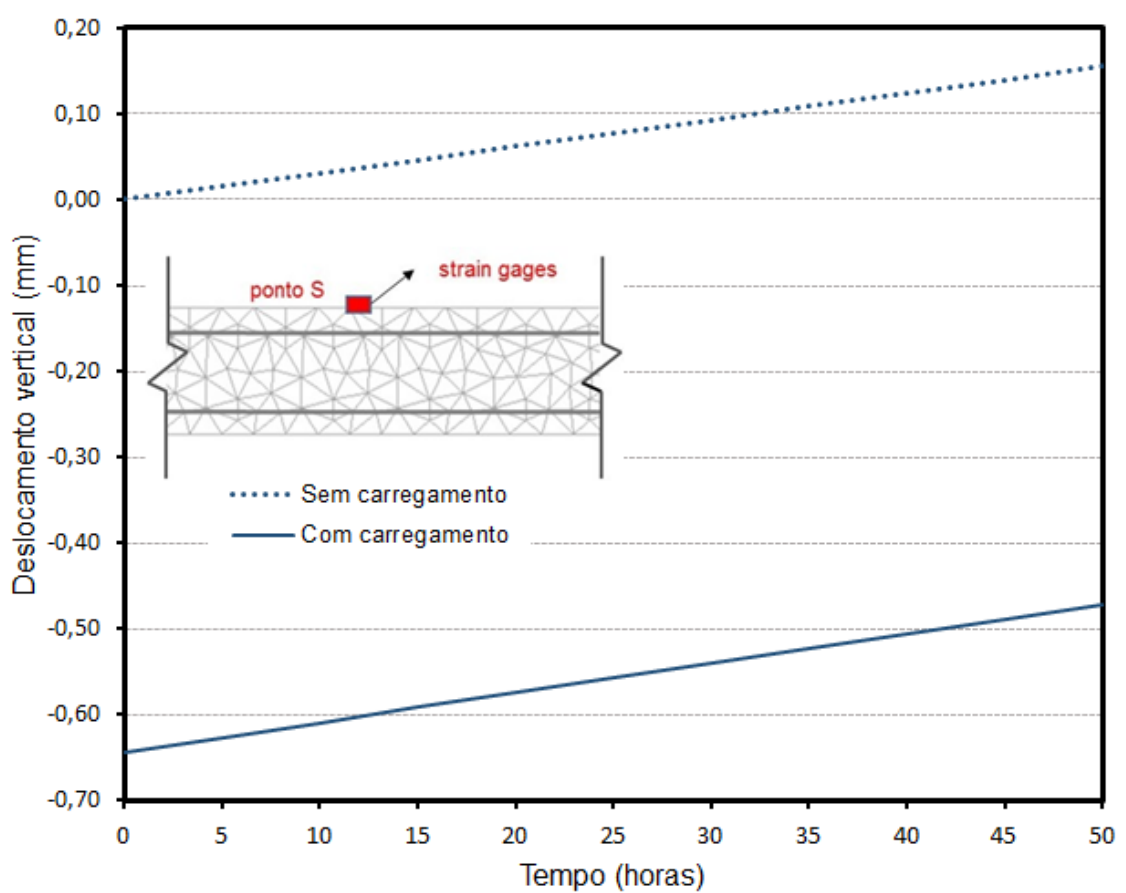

Figura 7.22 - Deslocamento vertical da viga no ponto "S".

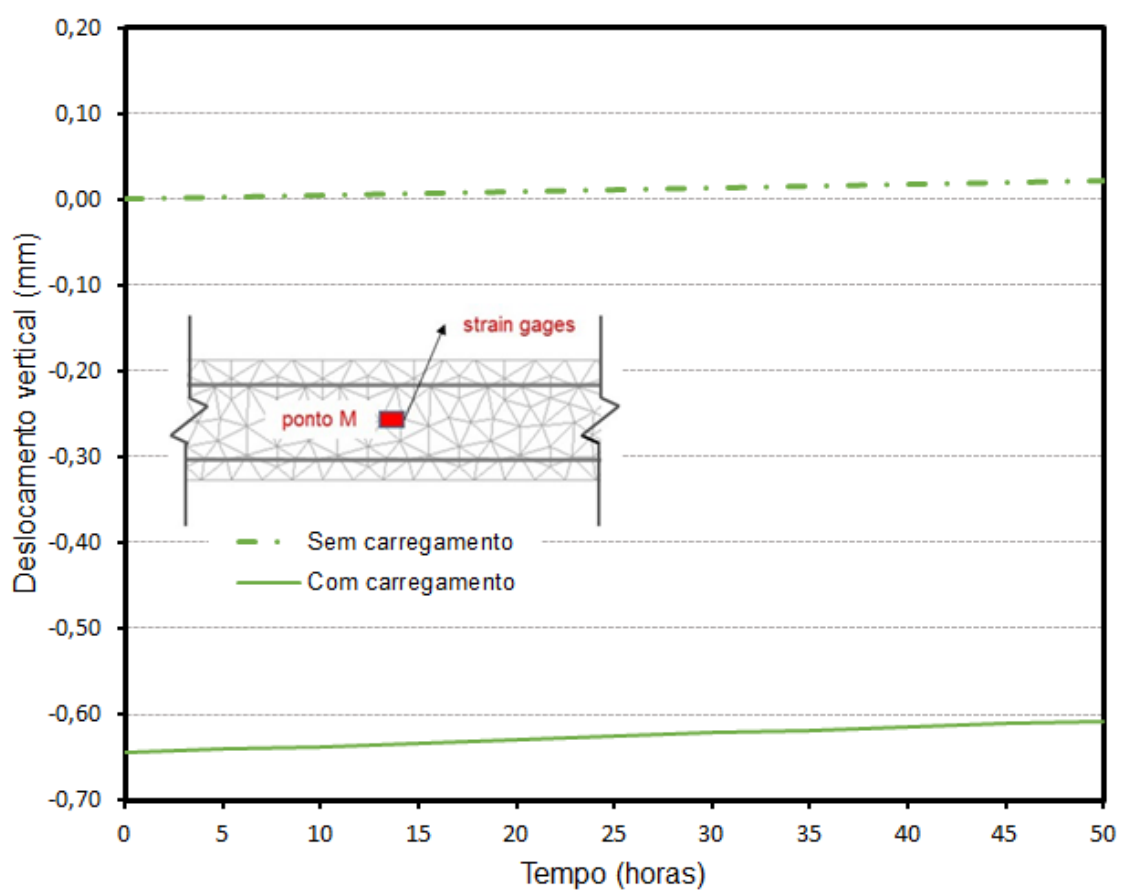

Figura 7.23 - Deslocamento vertical da viga no ponto "M".

As Figuras 7.22, 7.23 e 7.24 mostram também que o efeito da corrosão, no que se refere ao campo de deslocamento da viga, quando considerado o carregamento externo, possui o mesmo comportamento da estrutura sem carregamento, isto é, o carregamento aplicado não altera a forma como os produtos de corrosão se formam e deformam o concreto 
armado. Ao contrário, os efeitos se sobrepõem e tendem a ser significativos, à depender do nível de corrosão das armaduras, conforme vê-se na Figura 7.25.

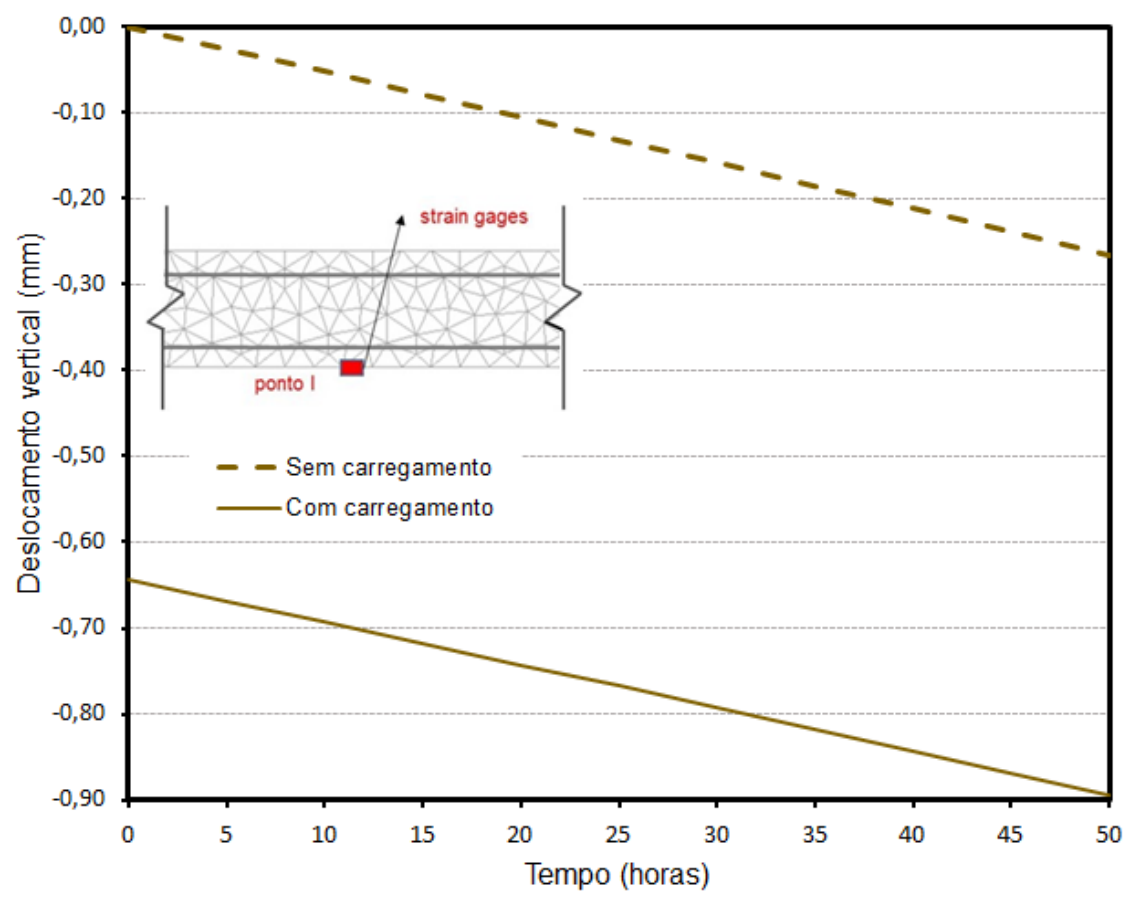

Figura 7.24 - Deslocamento vertical da viga no ponto "I".

É possível observar pelas Figuras 7.22, 7.23 e 7.24 que para todos os casos, os deslocamentos da viga podem ser descritos pela sobreposição das solicitações mecânicas, devido ao carregamento externo e das solicitações químico-mecânicas, consequência da corrosão.
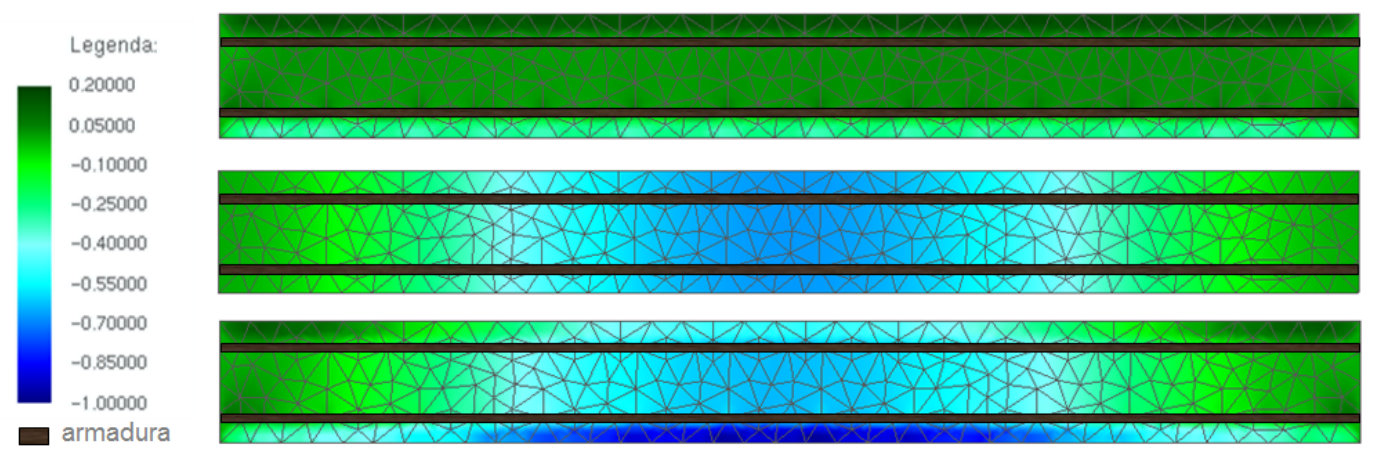
apenas
corrosão

apenas carregamento carregamento

Figura 7.25 - Configuração deformada da viga de concreto.

Diante do exposto, decidiu-se analisar também o comportamento da corrosão quanto ao campo de tensão, considerando para tal a viga com e sem o carregamento externo. A Figura 7.26 apresenta as tensões observadas em três diferentes regiões da viga. 


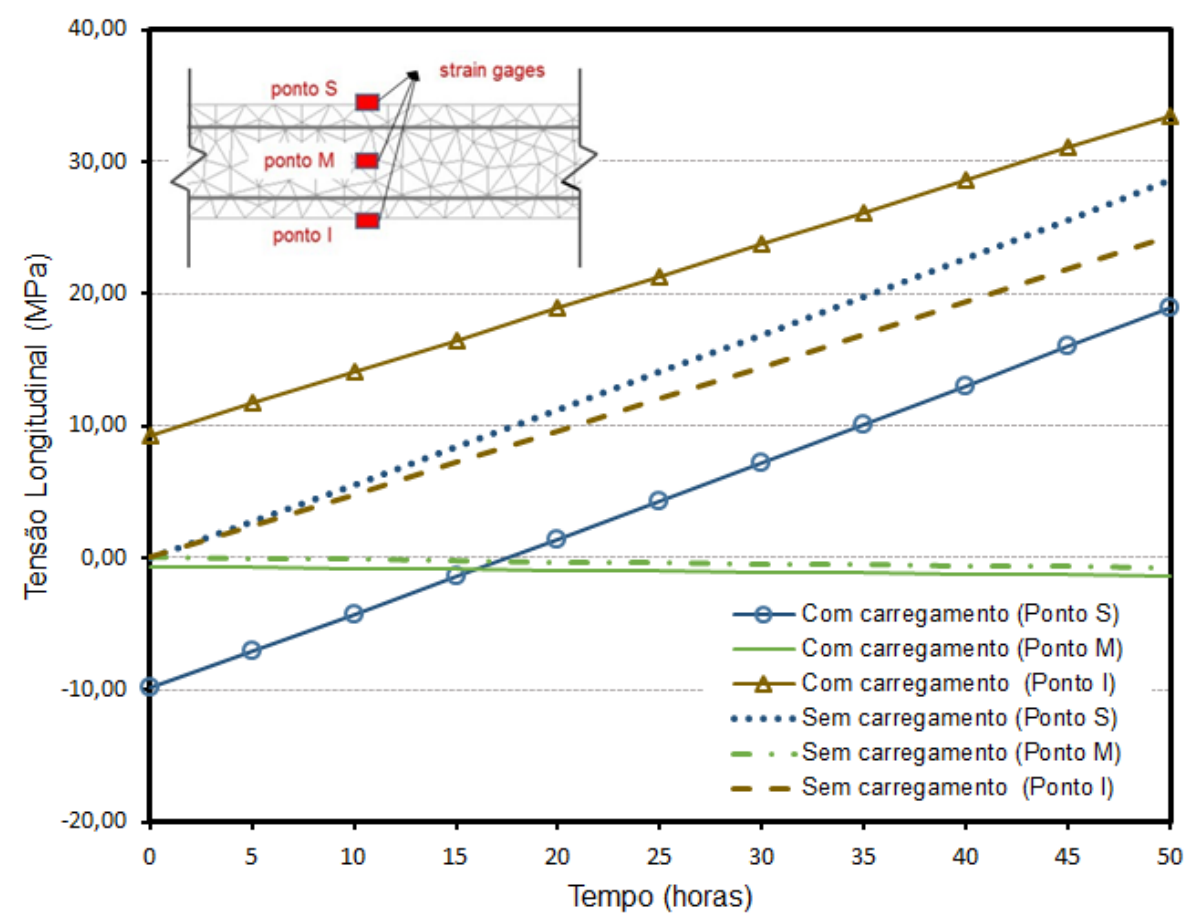

Figura 7.26 - Tensão longitudinal em diferentes regiões da viga.

Os resultados mostrados na Figura 7.26, demonstram a influência da corrosão no campo de tensão das vigas sob corrosão, quando considerada a aplicação de um carregamento externo. Observa-se que para o caso em que há apenas corrosão, as tensões independem do ponto de análise. Isso pois a formação dos produtos de corrosão causam a expansão do concreto de cobrimento (STREHBLOW; MARCUS, 1995). No entanto, com a aplicação de um carregamento de serviço (carregamento para o qual a estrutura foi projetada), o campo de tensão passa a ter comportamento controlado pelo nível de corrosão das armaduras. Por exemplo, analisando o ponto S, situado na parte superior da viga (ver Figura 7.26), a tensão sai do estado de compressão para o de tração após 15 horas de corrosão acelerada. Os demais pontos analisados (ponto I e M) sofrem alteração apenas na magnitude das tensões, sendo sempre de tração.

Observa-se aqui a principal influência da corrosão quanto ao comportamento mecânico de estruturas de concreto armado, o campo de tensão. Essa influência tem efeitos secundários que corroboram com a redução da vida útil destas estruturas, à exemplo, a fissuração do concreto de cobrimento. De acordo com teoria da mecânica da fratura, o estado de fissuração de um elemento de concreto armado é altamente dependente do seu estado de tesão, e assim, se a corrosão altera o campo de tensão de um elemento estrutural, a mesma pode vir a modificar e/ou acelerar os mecanismos de degradação do mesmo (ALMUSALLAM et al., 1996).

Por fim, a Figura 7.27 apresenta os resultados obtidos para o deslocamento vertical, para a mesma viga de concreto armado (Figura 7.19), considerando corrosão natural. Cabe 
mencionar que, para essa análise, foram considerados apenas os efeitos da corrosão.

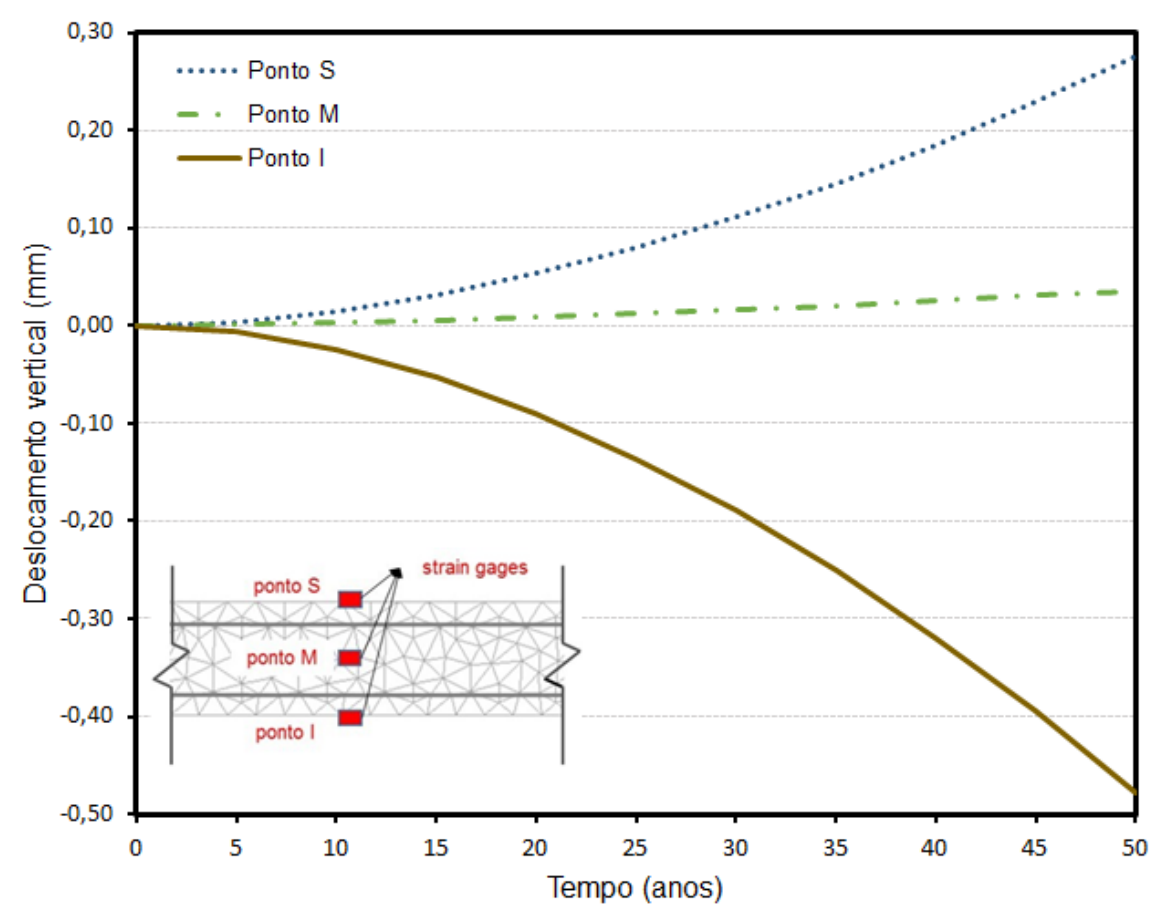

Figura 7.27 - Deslocamento vertical da viga de concreto sob corrosão natural.

Pela Figura 7.27 vê-se que o campo de deslocamento da viga quando sob corrosão natural apresenta um comportamento exponencial, influência da Equação 7.1, já que a corrente de corrosão é variável no tempo.

É possível ver ainda, que o deslocamento do ponto I, após 50 anos de corrosão natural, é de 0,47 mm, 79\% maior que o deslocamento observado após 50 horas de corrosão acelerada.

Ao comparar os resultados obtidos pela corrosão natural e acelerada, não foi possível encontrar uma relação entre os resultados. Sendo assim, não é possível quantificar os danos causados pela ação da corrosão para estruturas reais por meio de ensaios acelerados, porém estes auxiliam no estudo do seu comportamento mecânico.

\subsection{Análise da vida útil de vigas de concreto armado sob corrosão}

Este exemplo de aplicação tem o intuito de analisar e modelar numericamente o processo de corrosão, estimando a vida útil de vigas de concreto armado. Pretende-se também mostrar a aplicabilidade dos códigos desenvolvidos, e que estes corroboram com os estudos referentes à durabilidade de estruturas de concreto armado ${ }^{1}$.

$\overline{1}$ Destaca-se que a presente aplicação é fruto de um trabalho apresentado no XIV Congresso LatinoAmericano de Patología de Construcción, sediado em Assunção, Paraguai, em setembro de 2017. 
Assim, como a determinação da vida útil de vigas de concreto armado é escopo deste exemplo, verifica-se inicialmente a eficiência do modelo desenvolvido quanto à determinação da redução da capacidade mecânica do concreto amardo.

A verificação do modelo é feita comparando a taxa de aumento do deslocamento vertical do centro de uma viga de concreto armado (ver Figura 7.28), à medida que a corrosão se desenvolve, obtidas pelo modelo desenvolvido e implementado neste trabalho (ver Seção 6.2.2) e pelos resultados obtidos por Graeff (2007).

A estrutura analisada consiste em uma viga de seção retangular, de dimensão $7 x 14 x 130 \mathrm{~cm}$. Na Figura 7.28 é apresentado um detalhamento simplificado da viga e o esquema referente ao carregamento imposto.

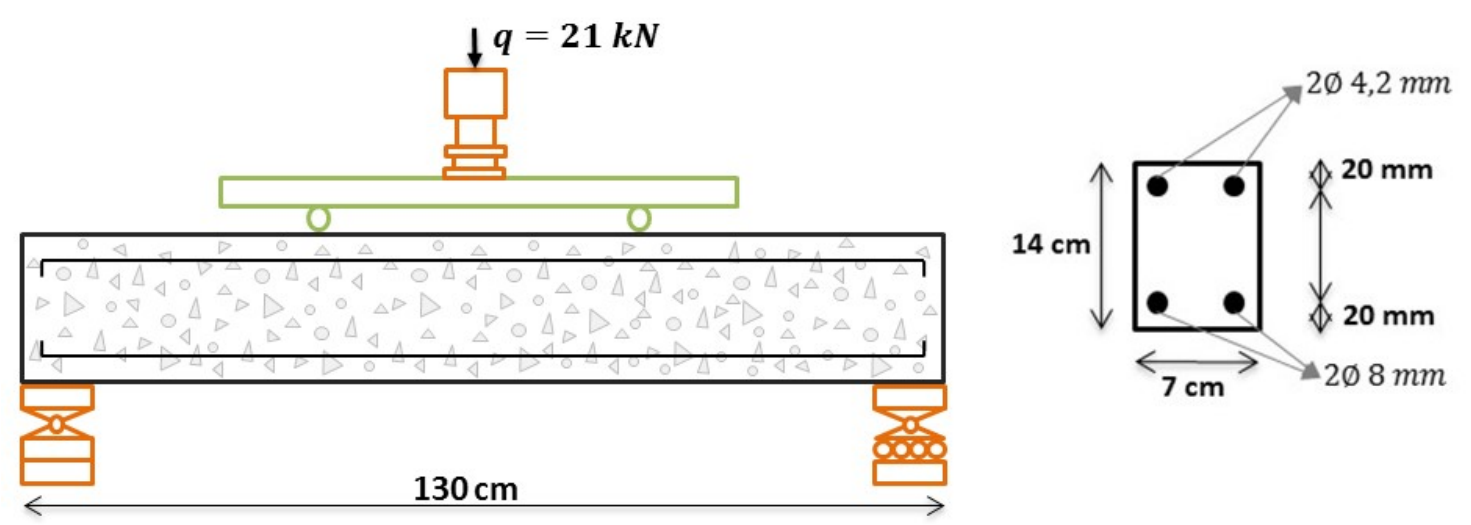

Figura 7.28 - Detalhamento da viga de concreto armado.

A discretização da malha de elementos finitos da viga de concreto armado foi feita com 134 nós e 34 elementos triangulares com ordem de aproximação cúbica para a representação da matriz de concreto e, com 340 elementos de triangulares (partículas) para a representação das armaduras.

Quanto às propriedades dos materiais, o concreto possui módulo de elasticidade de $2600,0 \mathrm{kN} / \mathrm{cm}^{2}$, resistência à compressão de $2,5 \mathrm{kN} / \mathrm{cm}^{2}$, resistência à tração de 0,179 $k N / \mathrm{cm}^{2}$ e coeficiente de Poisson de 0,2. Já as armaduras possuem módulo de elasticidade $21000,0 \mathrm{kN} / \mathrm{cm}^{2}$ e resistência à tração de $50,0 \mathrm{kN} / \mathrm{cm}^{2}$.

Em seu modelo numérico, Graeff (2007) considerou o comportamento não linear do concreto. Como efeitos de degradação da corrosão, Graeff considerou a perda de seção de aço e a perda de aderência entre o aço e o concreto.

Para a simulação, foram consideradas duas situações, uma em que os efeitos da corrosão remetem apenas à perda de seção de aço, e outra em que a corrosão causa a perda de seção de aço e expansão do concreto devido à formação de produtos de corrosão. Na Figura 7.29 comparam-se os resultados obtidos na modelagem com os de Graeff (2007). 


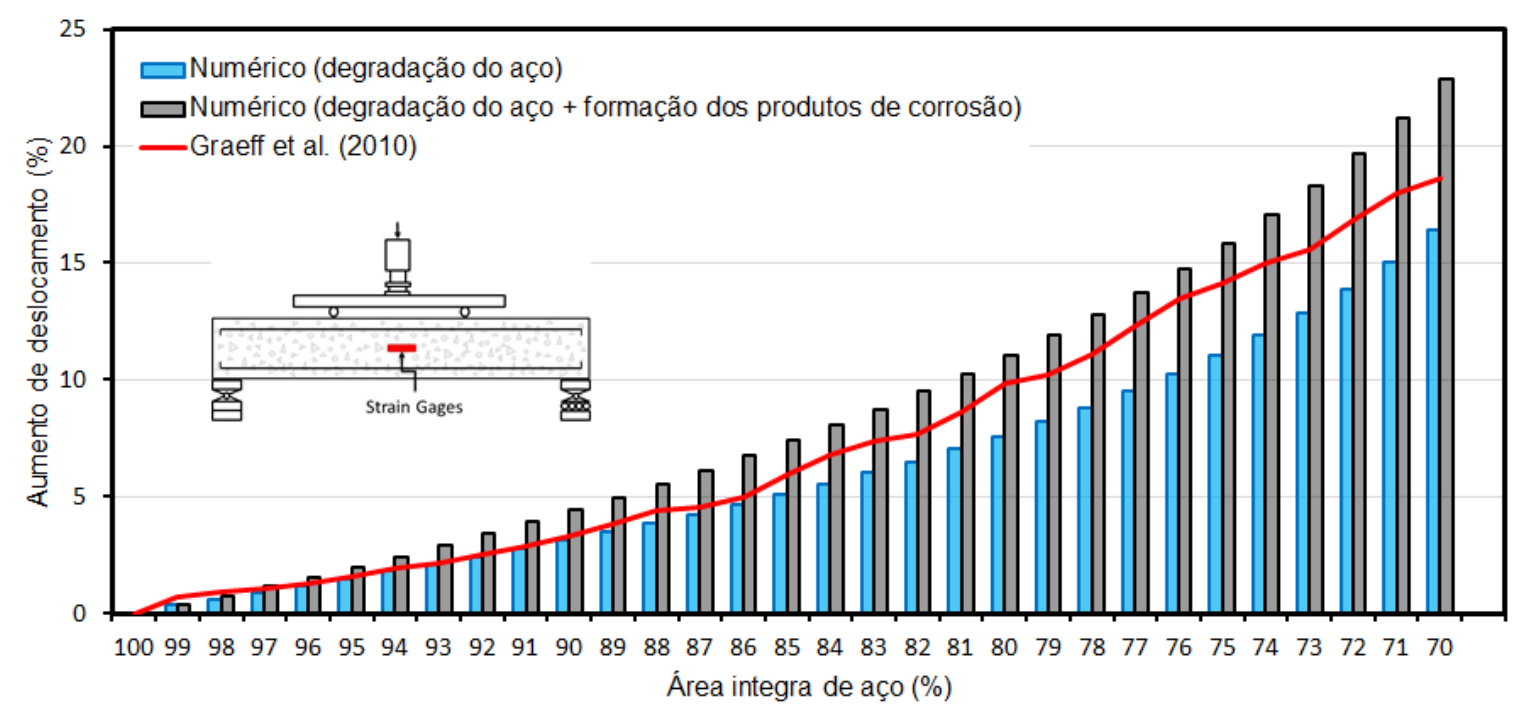

Figura 7.29 - Comparação entre as taxas de aumento dos deslocamentos.

Observa-se pela Figura 7.29, que é crescente a diferença entre os resultados, à medida que aumenta a degradação das armaduras, principalmente quando comparam-se os resultados com modelo desenvolvido e os obtidos por Graeff (2007). Uma explicação para tal diferença deve-se ao fato de Graeff adotar em seu modelo uma lei constitutiva não-linear para o concreto e o aço, diferente do modelo implementado.

Acrescenta-se que todas as curvas possuem comportamento semelhante, quanto ao avanço da perda da capacidade mecânica da estrutura, e que, se considerado o período inicial da corrosão (até o instante em que a armadura perde 15\% de área útil), ou o momento em que os materiais ainda trabalham em regime elástico-linear, o modelo implementado apresenta resultados equivalentes aos de Graeff (2007).

Por meio da Figura 7.29 é possível ver que a consideração combinada de mais de um efeito de degradação da corrosão acarreta em uma maior deslocabilidade da viga, e que, quando considerada a expansão do concreto devido à formação dos produtos de corrosão, a perda da capacidade mecânica do concreto passa a ser maior com o avanço da corrosão. Tal fato demonstra a importância da consideração deste fenômeno na modelagem da corrosão de estruturas de concreto.

Assim, após verificado a eficiência do modelo, o mesmo é utilizado na determinação da vida útil de vigas de concreto armado.

A estrutura analisada consiste em uma viga de concreto armado dimensionada de acordo com os procedimentos da NBR 6118 (ABNT, 2014). O esquema que representa o carregamento utilizado para o dimensionamento (obtido no ELU) e para a análise da vida útil (obtido no ELS) da viga é apresentado na Figura 7.30, assim como os detalhes construtivos da mesma.

Como o objetivo é determinar a vida útil da viga exposta a um ambiente com agressividade média, a mesma foi dimensionada para três cobrimentos, 20, 25 e $30 \mathrm{~mm}$. 


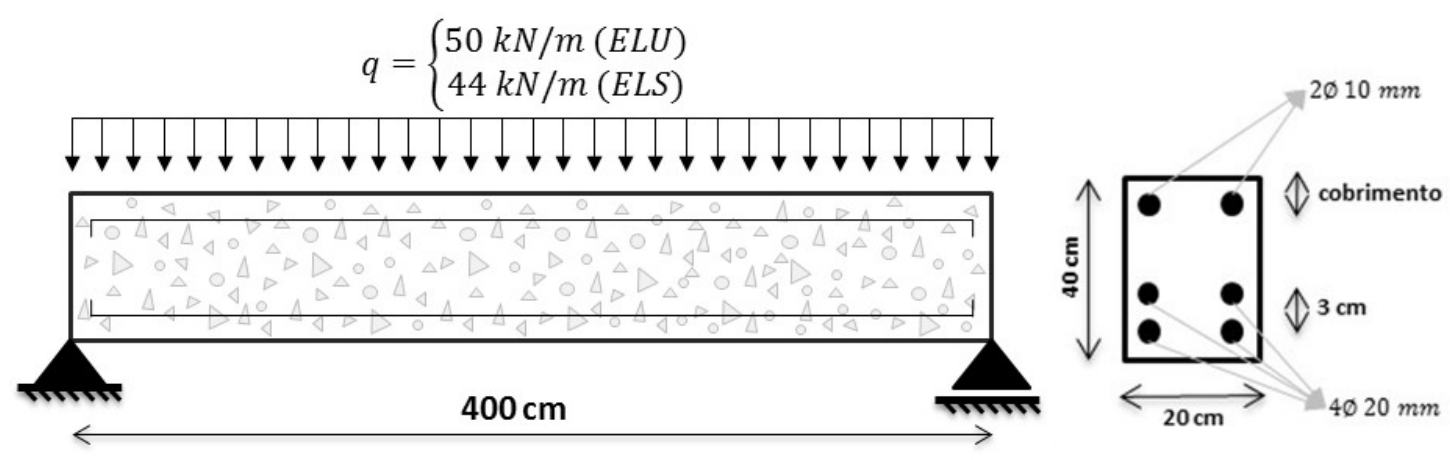

Figura 7.30 - Detalhamento da viga.

A discretização da malha de elementos finitos da viga de concreto armado foi feita com 2317 nós e 486 elementos triangulares com ordem de aproximação cúbica para a representação da matriz de concreto e, com 900 elementos triangulares (partículas) para a representação das armaduras.

Os dados referentes às propriedades dos materiais são apresentados na Tabela 7.2, enquanto que na Tabela 7.3 são descritos os dados referentes ao concreto e o ambiente de exposição da estrutura.

Tabela 7.2 - Propriedades dos materiais.

\begin{tabular}{ccc}
\hline Material & Propriedade & Valor \\
\hline \multirow{2}{*}{ Concreto } & Módulo de elasticidade $\left(\mathrm{kN} / \mathrm{cm}^{2}\right)$ & 2607,16 \\
(C30) & Coeficiente de Poisson & 0,2 \\
& Resistência à compressão $\left(k N / \mathrm{cm}^{2}\right)$ & 3,00 \\
Aço & Resistência à tração $\left(k N / \mathrm{cm}^{2}\right)$ & 0,21 \\
Módulo de elasticidade $\left(k N / \mathrm{cm}^{2}\right)$ & 21000,00 \\
(CA-50) & Resistência à tração $\left(k N / \mathrm{cm}^{2}\right)$ & 50,00 \\
\hline
\end{tabular}

Tabela 7.3 - Dados referentes ao concreto e ambiente de exposição.

\begin{tabular}{cc}
\hline Característica & Condição \\
\hline Tipo de cimento & CP III \\
Teor de adições (\%) & 0,00 \\
Umidade relativa (\%) & 60,00 \\
Ambiente & Externo, desprotegido da chuva \\
Teor de $\mathrm{CO}_{2}(\%)$ & 0,04 (ambiente urbano) \\
\hline
\end{tabular}

Para a determinação da vida útil, o processo de modelagem foi dividido em duas etapas, uma referente à determinação do período de iniciação da corrosão, tempo necessário para que a armadura seja despassivada devido à redução do pH da matriz de cimento, consequência da carbonatação, e outra referente à determinação do período de progressão da corrosão, tempo que compreende desde o instante em que ocorre a despassivação da armadura até o momento em que o estado limite de serviço (ELS) é atingido. 
Para a determinação do período de iniciação, utilizou-se um modelo desenvolvido por Felix (2015), baseado em Redes Neurais Artificiais (RNAs) do tipo MultiLayer Perceptron. As variáveis de entrada do modelo e a topologia da rede responsável por mapear o comportamento da carbonatação são apresentadas na Figura 7.31.
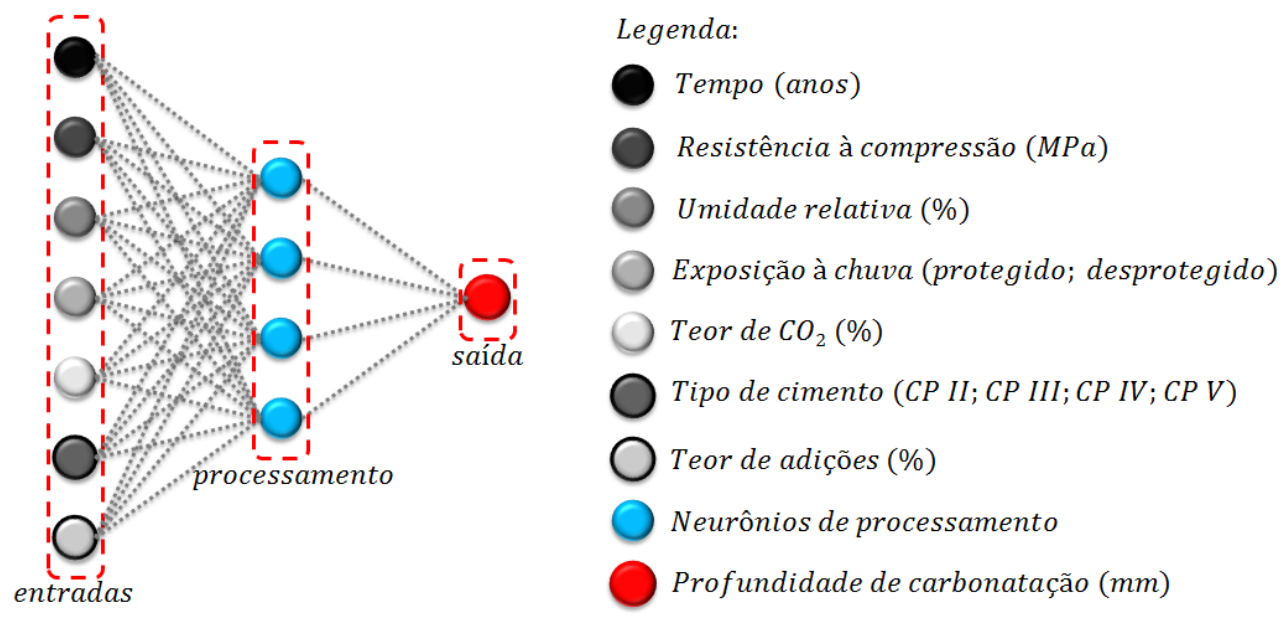

Figura 7.31 - Variáveis do modelo de predição e topologia da RNA.

Fonte: Adaptado de Felix, Carrazedo e Possan (2017).

Quanto a determinação do período de progressão da corrosão, o mesmo é estimado no presente trabalho como sendo o instante de tempo em que o elemento de concreto sob corrosão tem a sua abertura de fissura característica, dada pela Equação 7.2, maior que os valores aceitáveis e/ou os deslocamentos da estrutura ultrapassam os deslocamentos limites, valores estes recomendados pela NBR 6118 (ABNT, 2014).

$$
w \leq\left\{\begin{array}{c}
w_{1}=\frac{\phi_{i}}{12,5 \lambda_{i}} \frac{\sigma_{s i}}{E_{s i}} \frac{3 \sigma_{s i}}{f_{c t m}} \\
w_{2}=\frac{\phi_{i}}{12,5 \lambda_{i}} \frac{\sigma_{s i}}{E_{s i}}\left(\frac{4}{\rho_{r i}}+45\right)
\end{array}\right.
$$

em que $w$ é a abertura de fissura característica $(\mathrm{mm}), \phi_{i}$ é o diâmetro da armadura (mm), $\lambda_{i}$ é o coeficiente de conformação superficial da armadura (1,0 para barras lisas, 1,4 para barras dentadas e 2,5 para barras nervuradas), $\sigma_{s i}$ é a tensão de tração da armadura $\left(k N / c^{2}\right), E_{s i}$ é o módulo de elasticidade da barra de aço $\left(k N / \mathrm{cm}^{2}\right), f_{c t m}$ é a tensão de tração média do concreto $\left(k N / \mathrm{cm}^{2}\right)$ e $\rho_{r i}$ é a taxa de armadura em relação à área envolvente.

Na Figura 7.32 é apresentado por meio de um fluxograma os processos de cálculos realizados para a obtenção da vida útil das vigas de concreto armado sob corrosão.

Na Figura 7.33 é apresentado o avanço da profundidade de carbonatação do concreto das vigas com os diferentes cobrimentos (20, 25 e $30 \mathrm{~mm})$. De imediato nota-se a importância da utilização de um cobrimento adequado em função da agressividade do meio ao qual a estrutura de concreto é exposta, uma vez que o cobrimento adequado aumenta o tempo de despassivação da armadura. 


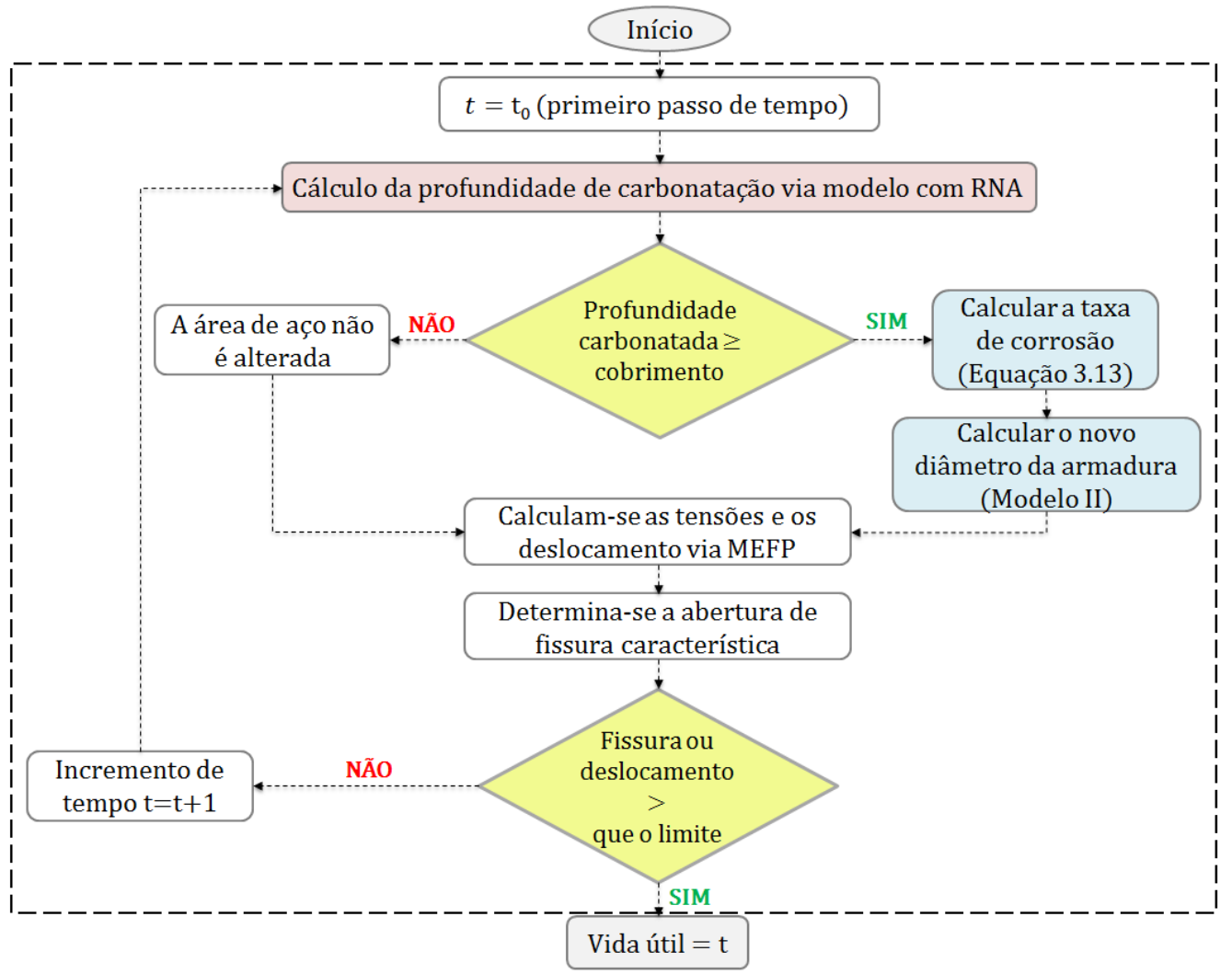

LEGENDA:

$\square$ Processamento $\quad \square$ Processos de cálculos do período de iniciação da corrosão
$\diamond$ Tomada de decisão $\quad \square$ Processos de cálculo do período de propagação da corrosão

Figura 7.32 - Processos de cálculos para a obtenção da vida útil.

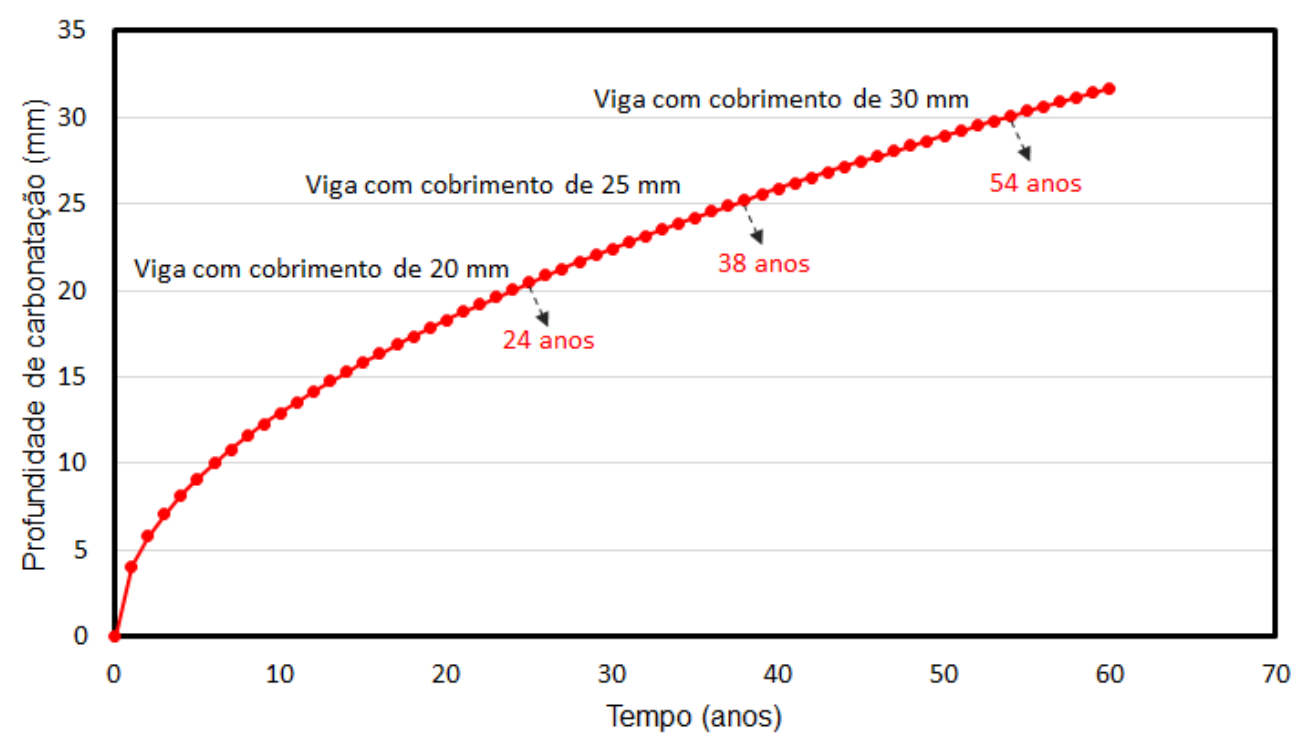

Figura 7.33 - Frente de carbonatação do concreto das vigas modeladas.

Na Figura 7.34 é possível analisar o avanço da degradação das armaduras devido à ação da corrosão. Observa-se que durante a fase de iniciação da corrosão, a área útil de 
aço das armaduras não é reduzida, e que a perda de seção é significativa nos primeiros anos do período de propagação da corrosão, conforme verificaram Vu e Stewart (2000).

Vu e Stewart (2000) descrevem que existe uma tendência de ocorrer maior perda de seção no período inicial da corrosão devido à taxa de corrosão das armaduras ser maior, e que a mesma decresce ao longo do tempo apresentando um comportamento exponencial, sendo este coerente com o observado na Figura 7.34.

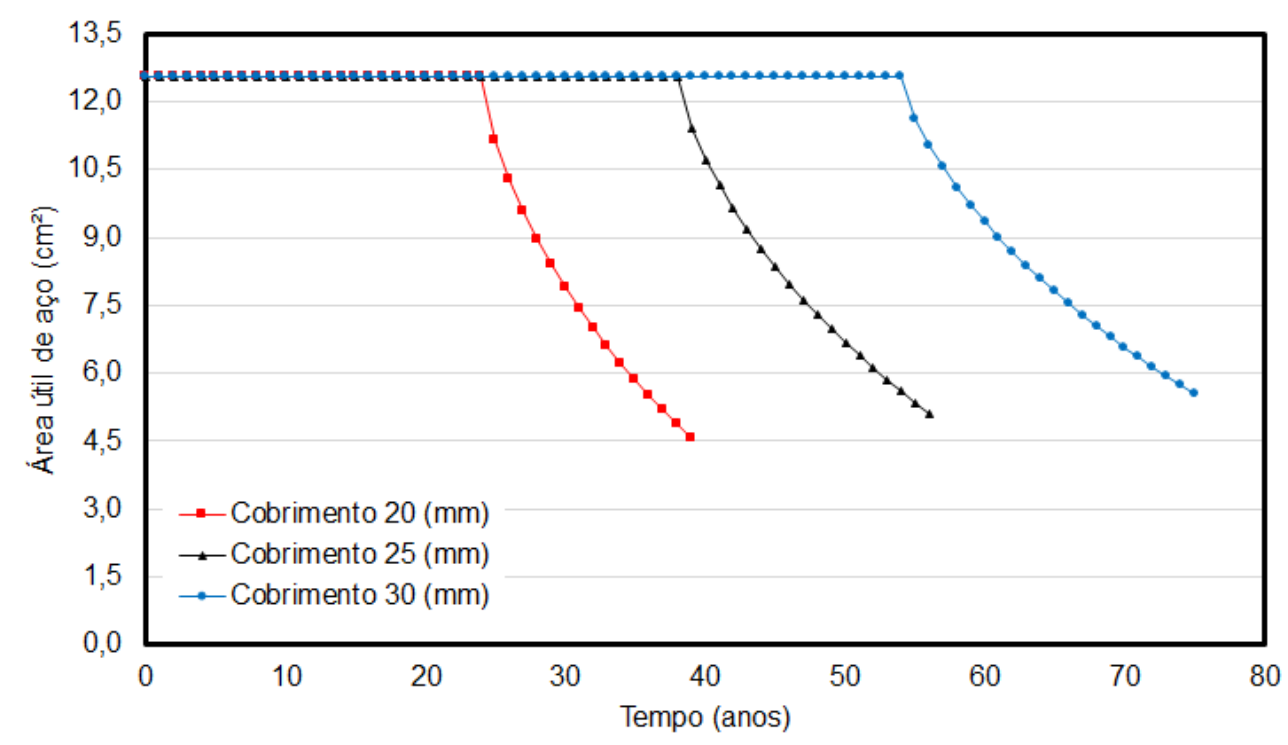

Figura 7.34 - Avanço da degradação das armaduras ao longo do tempo.

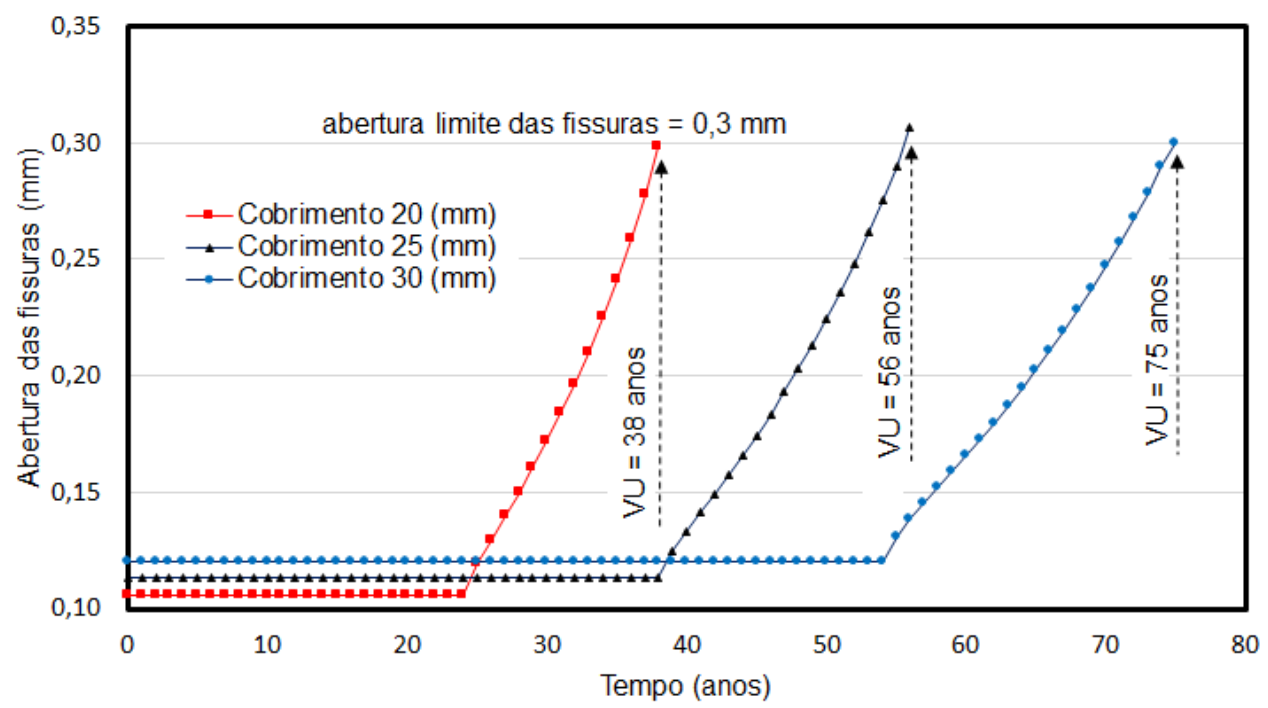

Figura 7.35 - Abertura de fissuras ao longo da vida útil.

Na Figura 7.35 é apresentada a evolução da abertura máxima das fissuras no decorrer do tempo e o instante em que termina a vida útil das vigas de concreto armado analisadas. $\mathrm{O}$ valor limite de abertura de fissuras adotado para as análises foi $w_{\text {lim }}=0,3$ 
mm, conforme prescreve a NBR 6118 (ABNT, 2014), para estruturas de concreto com classe de agressividade ambiental II (agressividade moderada).

Observa-se que a declividade das curvas da Figura 7.35 decresce em função do acréscimo do cobrimento da armadura, o que gera um aumento do tempo necessário para que a estrutura alcance o estado limite de abertura de fissuras.

Por fim, apresentam-se nas Figuras 7.36, 7.37 e 7.38 a tensão longitudinal e o deslocamento vertical das vigas de concreto armado, no instante em que as fissuras alcançam o valor limite, $w_{l i m}=0,3 \mathrm{~mm}$.

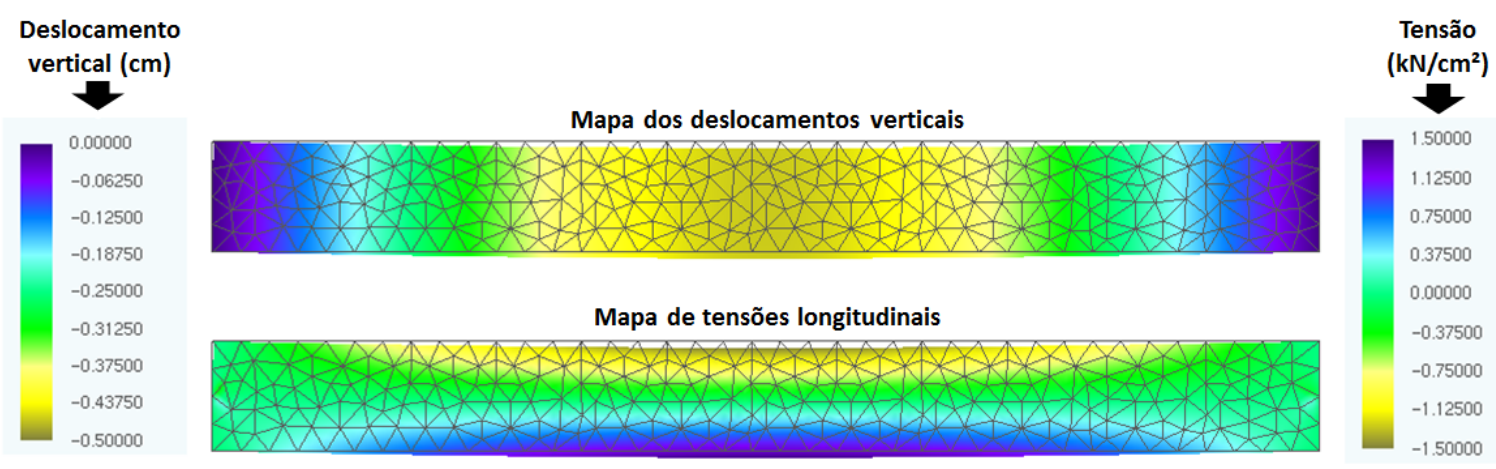

Figura 7.36 - Tensão e deslocamento da viga com cobrimento de $20 \mathrm{~mm}$.
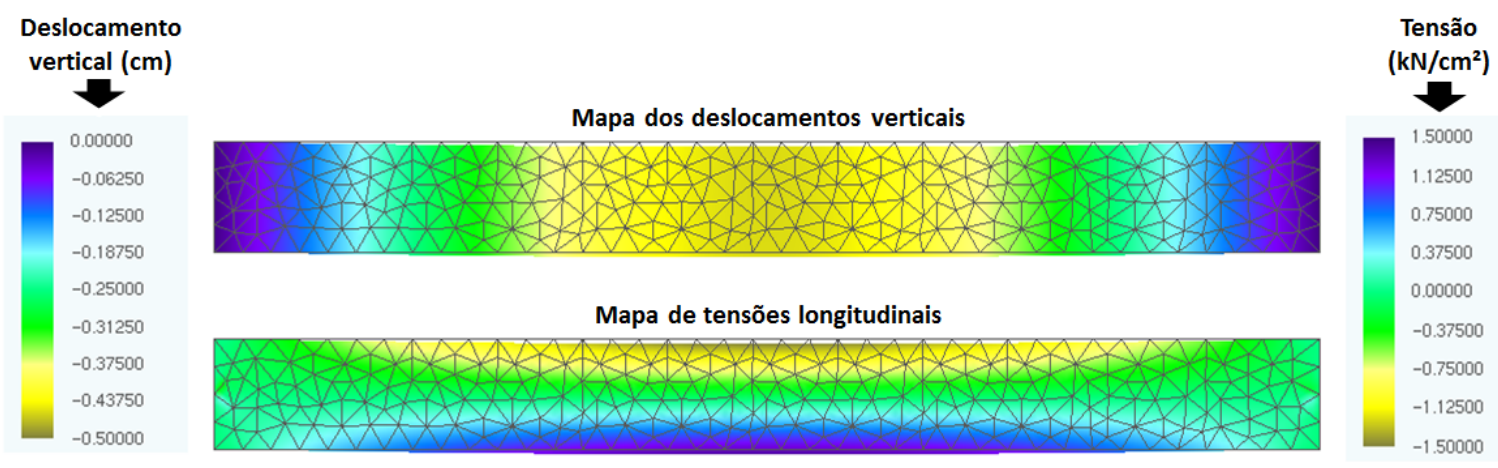

Figura 7.37 - Tensão e deslocamento da viga com cobrimento de $25 \mathrm{~mm}$.
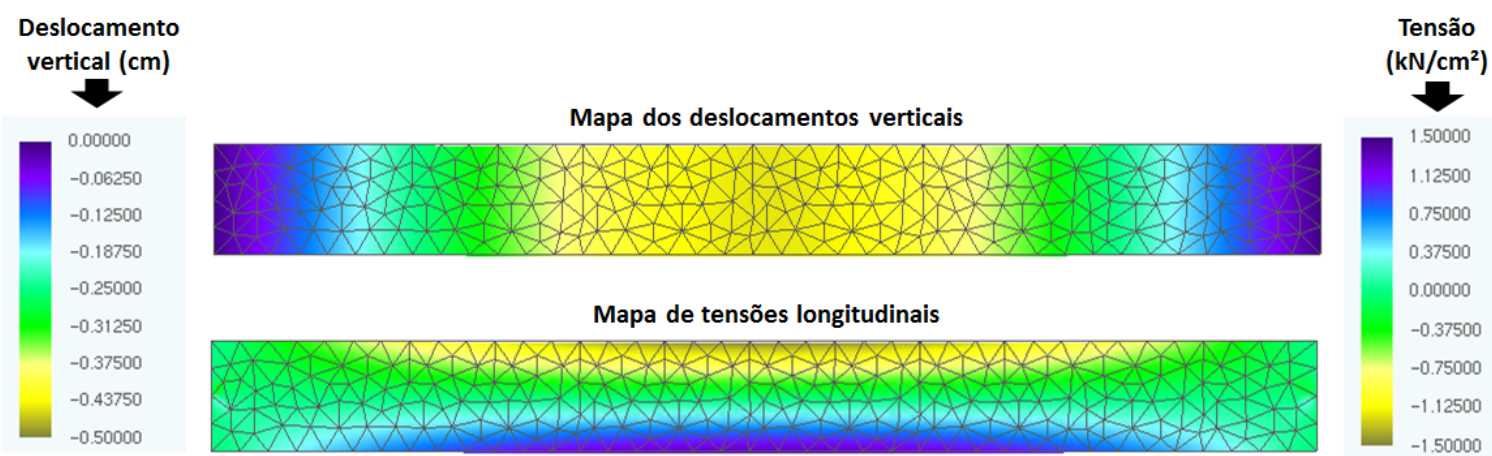

Figura 7.38 - Tensão e deslocamento da viga com cobrimento de $30 \mathrm{~mm}$. 
Já na Figura 7.39, são apresentadas as curvas de deslocamento vertical das três vigas modeladas, para um ponto de análise situado no centro da viga.

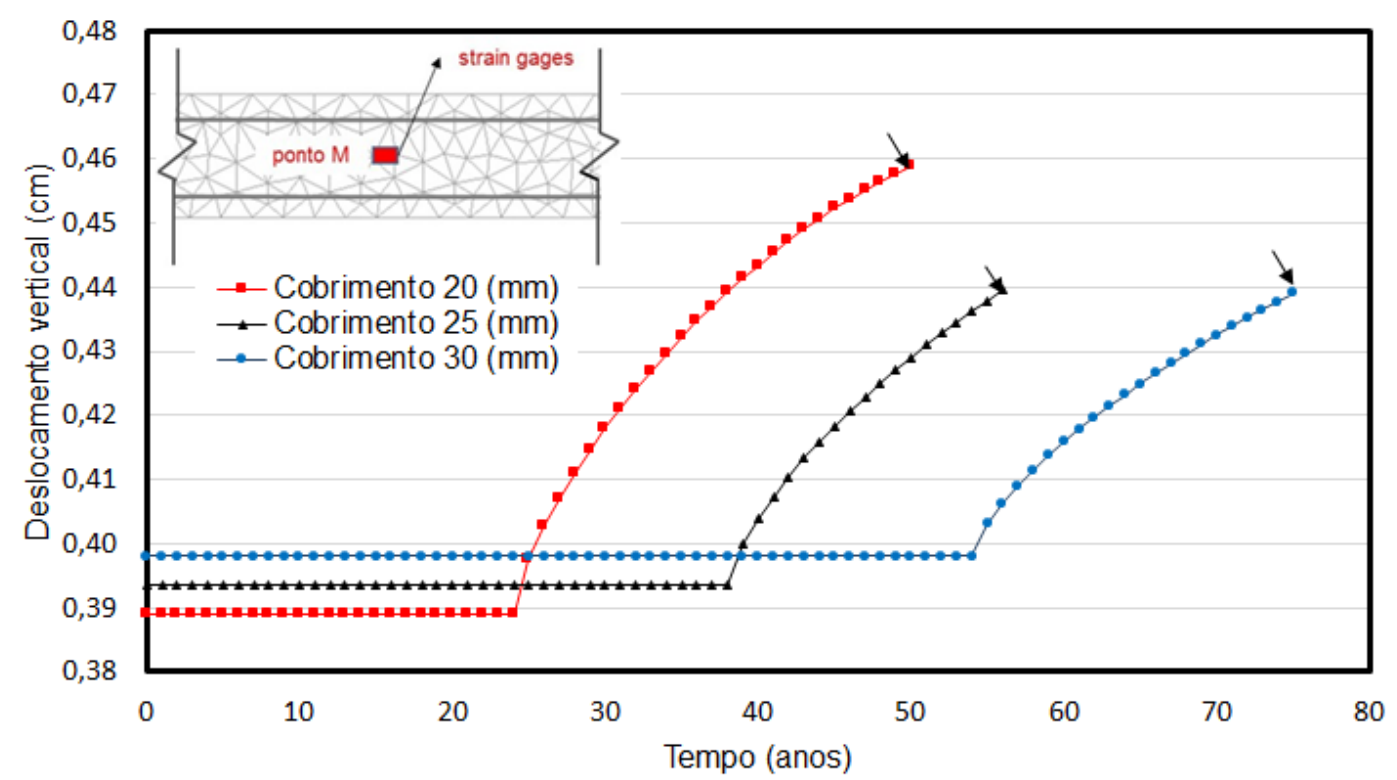

Figura 7.39 - Deslocamento vertical das vigas ao longo da vida útil.

Por meio dos mapas de cores apresentados nas Figuras 7.36, 7.37 e 7.38 é possível ver que os deslocamentos da viga diminuem com o aumento do cobrimento da armadura (considerando o período de propagação da corrosão), sendo comprovado pela Figura 7.39. Isso ocorre devido ao fato de que existe uma camada maior de concreto para a difusão do $\mathrm{CO}_{2}$, retardando o início da corrosão e, consequentemente, a degradação das armaduras.

Diante do exposto, observou-se que embora todas as vigas ao término de sua vida útil estejam com o concreto no mesmo estado de fissuração (mesma abertura máxima de fissura), a capacidade mecânica da viga com $30 \mathrm{~mm}$ de cobrimento é maior, uma vez que as armaduras se encontram com menor grau de corrosão e, consequentemente, maior área útil de aço, demonstrando que um cobrimento coerente com a agressividade do ambiente proporciona além da durabilidade, a segurança de seus usuários.

Por fim, diante das análises realizadas é possível verificar a aplicabilidade do modelo desenvolvido, além da sua eficiência quanto à representação da corrosão e de seus efeitos no comportamento mecânico do concreto armado. 
CAPÍTULO
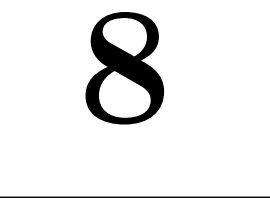

\section{CONCLUSÕES}

Diante das atuais necessidades do setor da construção civil, no que se refere à durabilidade de estruturas de concreto armado, torna-se imprescindível que engenheiros e pesquisadores da área consigam determinar e garantir que as estruturas projetadas tenham no mínimo a vida útil definida em projeto. Nesse contexto, no presente trabalho foram implementados modelos que possibilitaram o estudo e a simulação numérica dos efeitos da corrosão, em especial, da formação dos produtos de corrosão, no comportamento mecânico de estruturas de concreto armado.

O modelo mecânico para a análise não-linear geométrica de sólidos compósitos bidimensionais foi implementado por meio do Método dos Elementos Finitos baseado em posições (MEFP), onde os parâmetros nodais considerados são as posições e as deformações são determinadas em função da posição inicial do corpo. Com o código desenvolvido foi possível simular elementos estruturais compósitos por fibras (elementos lineares) e partículas (elementos bilineares), à exemplo de estruturas de concreto armado.

Para a representação de materiais compósitos, tanto os elementos de fibras quanto os de partículas, foram considerados perfeitamente aderidos à matriz ao qual estavam inseridos, por meio da técnica do embutimento. As vantagens quanto a utilização desta técnica referem-se ao fato de que não há a necessidade de coincidência dos nós dos elementos finitos das partículas ou fibras com os nós da chapa ao qual estão inseridos e, que os graus de liberdade destes elementos não aumentam os do problema à ser resolvido.

Quanto à representação da corrosão uniforme, desenvolveu-se um modelo baseado nas formulações de Kiani e Shodja (2011) e Vu e Stewart (2000), e no MEFP. O modelo implementado permitiu simular e analisar tanto a perda de seção de aço quanto a expansão causada no concreto devido à formação dos produtos de corrosão.

De forma geral, com os modelos implementados neste trabalho pode-se fazer as seguintes conclusões:

i O modelo mecânico para a análise não linear-geométrica de sólidos bidimensionais se 
mostrou eficiente, demonstrando que é capaz de representar coerentemente o campo de deslocamento de um elemento estrutural mesmo sob grandes deslocamentos;

ii Quanto a representação de sólidos compósitos com fibras, o modelo implementado apresentou resultados coerentes quando comparados a outros trabalhos. Com o código foi possível também mostrar a eficiência da utilização de fibras quanto ao enrijecimento de um sólido;

iii O modelo mecânico para a representação de sólidos particulados demonstrou-se eficiente para a modelagem de diferentes problemas, à exemplo, sólidos com grandes oclusões, corpos com macro-fissuras e elementos de concreto armado. O modelo apresentou-se ainda como uma potencial ferramenta para a predição do módulo de elasticidade do concreto;

iv Os modelos para representação da expansão do concreto armado devido à formação dos produtos de corrosão se mostraram coerentes ao comparar os resultados obtidos neste trabalho com os observados experimentalmente em Nguyen et al. (2007), quando considerado o regime elástico linear do concreto, e que possibilitam a correta modelagem da corrosão mesmo quando o elemento estrutural é solicitado externamento por um carregamento;

v Por meio das simulações realizadas, verificou-se que a corrosão tende a alterar o campo de tensão de um elemento estrutural, fazendo com que algumas regiões do concreto passem do estado de compressão para o de tração, à medida que se tem a progressão da corrosão das armaduras;

vi Perante a análise de vida útil realizada por meio do modelo desenvolvido, verificou-se a potencialidade do mesmo no que se refere aos estudos de durabilidade do concreto armado, além de demonstrar a sua desenvoltura quanto à representação dos efeitos da corrosão no comportamento mecânico do material;

vii Por fim, verificou-se que o modelo desenvolvido apresenta uma alternativa viável e confiável para a simulação da corrosão de armaduras, corroborando com a área de patologia de estruturas de concreto.

\subsection{Sugestões para trabalhos futuros}

Diante dos resultados obtidos neste trabalho e da potencialidade dos programas desenvolvidos, na sequência são propostas algumas sugestões para trabalhos futuros.

i Implementar e acoplar um modelo para a consideração da não linearidade física do material, considerando as diferentes fases constituintes de sólido compósito; 
ii Implementar e acoplar ao código, um modelo que descreva o escorregamento da fibra ou partícula, possibilitando assim, a modelagem da perda de aderência da armadura ao concreto concreto, devido à corrosão;

iii Acoplar ao código desenvolvido um modelo não-linear para a formação e distribuição dos produtos de corrosão, de forma a gerar resultados mais realísticos;

iv Acoplar ao código um modelo que descreva o efeito da fluência, uma vez que as deformações residuais devido a este fenômeno contribuem para a perda da capacidade mecânica do concreto sob corrosão;

v Inserir no modelo, as leis de difusão do $\mathrm{CO}_{2}$ no concreto, de forma a representar todo o processo de corrosão, considerando tanto o período de iniciação quanto o de propagação;

vi Implementar formulações para a representação da corrosão por cloretos, considerando a não linearidade da formação dos produtos de corrosão e da perda não uniforme de massa de aço;

vii Desenvolver modelos para a análise em nível mesoscópico do comportamento mecânico de estruturas de concreto armado, considerando as diferentes fases (matriz cimentícia, agregados e macroporos) e materiais (pasta de cimento, agregado graúdo e armaduraaço) do material compósito;

viii Acoplar ao código aqui desenvolvido, modelos mecânico-probabilísticos, a fim de estimar a vida útil de estruturas de concreto armado sob corrosão;

ix Considerar a aleatoriedade dos parâmetros de entrada dos modelos de corrosão, de forma a simular com maior realismo o processo de degradação das armaduras devido à corrosão. 


\section{REFERÊNCIAS}

AÏTCIN, P. C. Concreto de alto desempenho. São Paulo: Pini, p. 667, 2000.

ALMUSALLAM, A. A. Effect of degree of corrosion on the properties of reinforcing steel bars. Construction and Building Materials, Elsevier, v. 15, n. 8, p. 361-368, 2001.

ALMUSALlAM, A. A.; AL-GAHTANI, A. S.; AZIZ, A. R.; RASHEEDUZZAFAR. Effect of reinforcement corrosion on bond strength. Construction and building materials, Elsevier, v. 10, n. 2, p. 123-129, 1996.

ANDRADE, M. C. Manual para diagnóstico de obras deterioradas por corrosão de armaduras. São Paulo: Pini, 1992. 104 p.

ARANHA, P. M. S. Contribuição ao estudo das manifestações patológicas em estruturas de concreto armado na região amazônica. Dissertação (Mestrado) - Programa de Pós Graduação em Engenharia Civil, Universidade Federal do Rio Grande do Sul, Porto Alegre, 1994.

ASSAN, A. E. Método dos elementos finitos: primeiros passos. São Paulo: Ed. da UNICAMP, 2003.

ASSOCIAÇÃO BRASILEIRA DE NORMAS TÉCNICAS. NBR 5735: Cimento portland de alto forno. Rio de Janeiro, 1991.

ASSOCIAÇÃO BRASILEIRA DE NORMAS TÉCNICAS. NBR 5736: Cimento portland pozolânico. Rio de Janeiro, 1991.

ASSOCIAÇÃO BRASILEIRA DE NORMAS TÉCNICAS. NBR 6118: Projeto de estruturas de concreto. Rio de Janeiro, 2014.

BAKKER, R. F. M. Initiation period. Corrosion of steel in concrete, Rilem, p. 22-54, 1988.

BALAFAS, I.; BURGOYNE, C. J. Modeling the structural effects of rust in concrete cover. Journal of Engineering Mechanics, American Society of Civil Engineers, v. 137, n. 3, p. 175-185, 2010.

BATHE, K. J.; DVORKIN, E. N. A formulation of general shell elements - the use of mixed interpolation of tensorial components. International Journal for Numerical Methods in Engineering, Wiley Online Library, v. 22, n. 3, p. 697-722, 1986.

BAUER, L. A. F. Materiais de construção: 2. [S.1.]: Livros Técnicos e Científicos, 2005.

BHARGAVA, K.; GHOSH, A.; MORI, Y.; RAMANUJAM, S. Modeling of time to corrosion-induced cover cracking in reinforced concrete structures. Cement and Concrete Research, Elsevier, v. 35, n. 11, p. 2203-2218, 2005. 
BHARGAVA, K.; GHOSH, A. K.; MORI, Y.; RAMANUJAM, S. Analytical model for time to cover cracking in rc structures due to rebar corrosion. Nuclear engineering and Design, Elsevier, v. 236, n. 11, p. 1123-1139, 2006.

BONET, J.; WOOD, R.; MAHANEY, J.; HEYWOOD, P. Finite element analysis of air supported membrane structures. Computer methods in applied mechanics and engineering, v. 190, n. 5, p. 579-595, 2000.

BÜCHTER, N.; RAMM, E.; ROEHL, D. Three-dimensional extension of non-linear shell formulation based on the enhanced assumed strain concept. International journal for numerical methods in engineering, Wiley Online Library, v. 37, n. 15, p. 2551-2568, 1994.

CABRERA, J. G. Deterioration of concrete due to reinforcement steel corrosion. Cement and concrete composites, Elsevier, v. 18, n. 1, p. 47-59, 1996.

CÁNOVAS, M. F. Patologia e terapia do concreto armado. [S.l.: s.n.], 1988.

CARÉ, S.; NGUYEN, Q. T.; L'HOSTIS, V.; BERTHAUD, Y. Mechanical properties of the rust layer induced by impressed current method in reinforced mortar. Cement and Concrete Research, v. 38, n. 8, p. 1079-1091, 2008.

CARMONA, A.; MAREGA, A. Retrospectiva da patología no brasil; estudo estatístico. In: JORNADAS EN ESPAÑOL Y PORTUGUÊS SOBRE ESTRUCTURAS Y

MATERIALES, Colloquia 88., 1988, Madrid. Anais... Madrid: CEDEX, IETcc, 1988. p. $325-348$.

CASCUDO, O. O controle da corrosão de armaduras em concreto: inspeção e técnicas eletroquímicas. [S.1.]: Pini, 1997.

CHUNG, L.; CHO, S.; KIM, J. J.; YI, S. Correction factor suggestion for aci development length provisions based on flexural testing of rc slabs with various levels of corroded reinforcing bars. Engineering structures, v. 26, n. 8, p. 1013-1026, 2004.

CODA, H. Análise não linear geométrica de sólidos e estruturas: Uma formulação posicional baseada no MEF. 168 p. Tese (Doutorado) — Tese (Tese para concurso de professor titular) - Escola de Engenharia de Estruturas de São Carlos-USP, São Carlos, São Paulo, Brasil, 2003.

CODA, H. B. A solid-like fem for geometrically non-linear 3d frames. Computational Methods in Applied Mechanics and Engineering, n. 198, p. 3712-3722, 2009.

CODA, H. B.; GRECO, M. A simple fem formulation for large deflection 2d frame analysis based on position description. Computer methods in applied mechanics and engineering, Elsevier, v. 193, n. 33, p. 3541-3557, 2004.

CODA, H. B.; GRECO, M. Positional fem formulation for geometrically non-linear shells. Latin American Journal of Solids and Structures, v. 5, n. 3, p. 205-223, 2008.

CODA, H. B.; PACCOLA, R. R. Improved finite element for 3d laminate frame analysis including warping for any cross-section. Applied Mathematical Modelling, n. 34, p. 1107-1137, 2010. 
CODA, H. B.; PACCOLA, R. R. A fem procedure based on positions and unsconstrained vectors applied to non-linear dynamic of 3d frames. Finite Elements in Analisys and Design, n. 67, p. 319-333, 2011.

COIMBRA, A. L. Lições de mecanica do continuo. [S.l.]: E. Blucher, 1978.

CORONELLI, D.; GAMBAROVA, P. Structural assessment of corroded reinforced concrete beams: modeling guidelines. Journal of Structural Engineering, American Society of Civil Engineers, v. 130, n. 8, p. 1214-1224, 2004.

CRIESFIELD, M. A. Non linear finite element analysis of solids and structures, Vol. 1. [S.l.]: Wiley, New York, 1991.

DAL MOLIN, D. C. C. Fissuras em estruturas de concreto armado: análise das manifestações típicas e levantamento de casos ocorridos no estado do Rio Grande do Sul. Dissertação (Mestrado) — Programa de Pós Graduação em Engenharia Civil, Universidade Federal do Rio Grande do Sul, Porto Alegre, 1988.

DU, X.; JIN, L. Meso-scale numerical investigation on cracking of cover concrete induced by corrosion of reinforcing steel. Engineering Failure Analysis, Elsevier, v. 39, p. 21-33, 2014.

DU, Y. G.; CLARK, L. A.; CHAN, A. H. C. Residual capacity of corroded reinforcing bars. Magazine of Concrete Research, [London]: Cement and Concrete Association, 1949-, v. 57, n. 3, p. 135-148, 2005.

DYER, T. A durabilidade do concreto. [S.l.]: Editora Ciência Moderna Ltda., Rio de Janeiro, 2015.

ENRIGHT, M. P.; FRANGOPOL, D. M. Probabilistic analysis of resistance degradation of reinforced concrete bridge beams under corrosion. Engineering structures, Elsevier, v. 20, n. 11, p. 960-971, 1998.

FELIX, E. F. Desenvolvimento de software para a estimativa da profundidade de carbonatação, vida útil e captura de $\mathrm{CO}_{2}$ de estruturas de concreto empregando RNA's. 2015. Monografia (Bacharel em Engenharia Civil de Infraestrutura).

FELIX, E. F.; CARRAZEDO, R.; POSSAN, E. Análise paramétrica da carbonatação em estruturas de concreto armado via redes neurais artificiais. Revista ALCONPAT, v. 7, n. 3, p. 302-316, 2017.

FRIDEL, L. F. O. Análise de estruturas planas reforçadas com fibras ativas viscoelásticas e matriz com modelo constitutivo hiperelástico: aplicações gerais em engenharia e biomecânica. Dissertação (Mestrado) - Escola de Engenharia de São Carlos, Universidade de São Paulo, São Carlos, 2016.

GENTIL, V. Corrosão. Rio de janeiro: Editora LCT, 6º edição, 2011. 376 p. ISBN 9788521618041 .

GERE, J. M.; TIMOSHENKO, S. P. Mechanics of materials. [S.l.]: PWS-KENT Publishing Company, 1997.

GHALI, A.; NEVILLE, A.; BROWN, T. Structural analysis: a unified classical and matrix approach. [S.1.]: Crc Press, 2003. 
GRAEFF, A. G. Avaliação experimental e modelagem dos efeitos estruturais da propagação da corrosão em elementos de concreto armado. Dissertação (Mestrado) Programa de Pós Graduação em Engenharia Civil, Universidade Federal do Rio Grande do Sul, Porto Alegre, 2007.

HAMADA, M. Neutralization (carbonation) of concrete and corrosion of reinforcing steel. In: Proc. of 5 th International Symposium on Cement Chemistry. Tokyo: [s.n.], 1968. p. 343-369.

HAN, J.; LIU, W.; WANG, S.; DU, D.; XU, F.; LI, W.; SCHUTTER, G. D. Effects of crack and itz and aggregate on carbonation penetration based on $3 \mathrm{~d}$ micro x-ray ct microstructure evolution. Construction and Building Materials, v. 128, p. 256-271, 2016.

HANSEN, E. J.; SAOUMA, V. E. Numerical simulation of reinforced concrete deterioration: Part 2-steel corrosion and concrete cracking. ACI Materials Journal, AMERICAN CONCRETE INSTITUTE, v. 96, p. 331-338, 1999.

HELENE, P. Corrosão em armaduras para concreto armado. São Paulo: PINI, 1986. 46 p. ISBN 8509000042.

HELENE, P. R. L. Contribuição ao estudo da corrosão em armaduras de concreto armado. Tese (Doutorado) - (Livre docência em estruturas) - Escola Politécnica, Universidade de São Paulo. São Paulo, 1993.

HO, D. W. S.; LEWIS, R. K. The specification of concrete for reinforcement protection-performance criteria and compliance by strength. Cement and Concrete Research, v. 18, n. 4, p. 584-594, 1988.

HOLZAPFEL, G. A. Nonlinear Solid Mechanics: A Continuum Approach for Engineering. [S.l.]: West Sussex, England: John Wiley \& Sons, Ltd, 2000.

HOUST, Y. F.; WITTMANN, F. H. Influence of porosity and water content on the diffusivity of co2 and o2 through hydrated cement paste. Cement and Concrete Research, v. 24, n. 6, p. 1165-1176, 1994.

HOUST, Y. F.; WITTMANN, F. H. Depth profiles of carbonates formed during natural carbonation. Cement and concrete research, v. 32, n. 12, p. 1923-1930, 2002.

HYVERT, N. Application de l'approche probabiliste à la durabilité des produits préfabriqués en béton. Tese (Doutorado) — Université de Toulouse, Université Toulouse III-Paul Sabatier, 2009.

INGLIS, C. E. Stresses in a plate due to the presence of cracks and sharp corners. Transaction of the Royal Institution of Naval Architects, n. 221, p. 163-198, 1913.

ISAIA, G. C. Carbonatação do concreto: uma revisão. Departamento de Estruturas e Construção Civil, Universidade Federal de Santa Maria, Santa Maria, 1999.

ISGOR, O. B.; RAZAQPUR, A. G. Modelling steel corrosion in concrete structures. Materials and Structures, Springer, v. 39, n. 3, p. 291-302, 2006.

JEPSEN, M. T. Predicting concrete durability by using artificial neural network. Published in a special NCR-publication, Hirtshals, 2002. 
JIANG, L.; LIN, B.; CAI, Y. A model for predicting carbonation of high-volume fly ash concrete. Cement and Concrete Research, v. 30, n. 5, p. 699-702, 2000.

KARI, O. P.; PUTTONEN, J.; SKANTZ, E. Reactive transport modelling of long-term carbonation. Cement and Concrete Composites, v. 42, p. 42-53, 2014.

KAZMIERCZAK, C. S. Contribuição para a Análise da Eficiência de Películas Aplicadas Sobre Estruturas de Concreto Armado com o Objetivo de Proteção Contra a Carbonatação. Tese (Doutorado) — Escola Politécnica, Universidade de São Paulo, São Paulo, 1995.

KHAN, I.; FRANÇOIS, R.; CASTEL, A. Mechanical behavior of long-term corroded reinforced concrete beam. Modelling of Corroding Concrete Structures, p. 243-258, 2011.

KIANI, K.; SHODJA, H. M. Prediction of the penetrated rust into the microcracks of concrete caused by reinforcement corrosion. Applied Mathematical Modelling, Elsevier, v. 35, n. 5, p. 2529-2543, 2011.

KZAM, A. K. L. Análise da instabilidade estrutural global e local pelo MEF posicional com determinação de pontos críticos na trajetória de equilíbrio. 2016.

LARRARD, T. D.; BARY, B.; ADAM, E.; KLOSS, F. Influence of aggregate shapes on drying and carbonation phenomena in $3 \mathrm{~d}$ concrete numerical samples. Computational Materials Science, v. 72, p. 1-14, 2013.

LIMA, J. M. F.; GARCIA, L. F. T. Método das diferenças finitas energéticas na flexão de barras com forte não linearidade geométrica. Revista Sitientibus, n. 28, p. 121-144, 2003.

LIU, L.; HA, J.; HASHIDA, T.; TERAMURA, S. Development of a co2 solidification method for recycling autoclaved lightweight concrete waste. Journal of materials science letters, v. 20, n. 19, p. 1791-1794, 2001.

LIU, Y.; WEYERS, R. E. Modeling the time-to-corrosion cracking in chloride contaminated reinforced concrete structures. Materials Journal, v. 95, n. 6, p. 675-680, 1998.

LUO, D.; NIU, D.; DONG, Z. Application of neural network for concrete carbonation depth prediction. In: . West Lafayette: [s.n.], 2014.

MAGALHÃES, C.; FOLLONI, R.; FURMAN, H. Análise da patologia das obras de arte do município de são paulo. In: Simposium Nacional de Reforç s, Reparos e Proteçâo das Estructuras de Concreto. São Paulo: [s.n.], 1989. p. 3-17.

MARQUES, G. C. S. C. Estudo e desenvolvimento de código computacional baseado no método dos elementos finitos para análise dinâmica nãão linear geométrica de sólidos bidimensionais. Tese (Doutorado) — Escola de Engenharia de São Carlos, Universidade de São Paulo, São Carlos, 2006.

MARTIN-PÉREZ, B.; PANTAZOPOUlOU, S. J.; THOMAS, M. D. A. Numerical solution of mass transport equations in concrete structures. Computers \& Structures, Elsevier, v. 79, n. 13, p. 1251-1264, 2001.

MARTINS, C. A. C. Estimativa da Profundidade de Carbonatação do Concreto com Uso de Redes Neurais. Dissertação (Mestrado) - Escola de Engenharia, Programa de Pós-Graduação em Engenharia Civil, UNICAP, Recife, 2011. 
MARTYS, N. S.; FERRARIS, C. F. Capillary transport in mortars and concrete. Cement and Concrete Research, v. 27, n. 5, p. 747-760, 1997.

MARUYA, T.; HSU, K.; TAKEDA, H.; TANGTERMSIRIKUL, S. Numerical modeling of steel corrosion in concrete structures due to chloride ion, oxygen and water movement. Journal of Advanced Concrete Technology, Japan Concrete Institute, v. 1, n. 2, p. 147-160, 2003.

MASSET, G. E. Para evitar acidentes. Rio de Janeiro: [s.n.], 2006. 10-11 p. Coluna ABADI.

MEHTA, P. K. Durability of concrete-fifty years of progress? Revista ALCONPAT, v. 126, p. 1-32, 1991.

MEHTA, P. K.; MONTEIRO, P. J. M. Concreto: microestrutura, propriedades e materiais. São Paulo: Ibracon, 2014. 751 p. ISBN 9788598576213.

MEIRA, G. R.; PADARATZ, L. J.; ALONSO, M. C.; ANDRADE, M. C. Effect of distance from sea and chloride aggressiveness in concrete structures brazilian coastal site. Materiales de Construcción, v. 53, p. 179-188, 2003.

MIN, Y.; HAO, B.; JIANQIAO, Y.; YIN, C. The effect of random porosity field on supercritical carbonation of cement-based materials. Construction and Building Materials, v. 146, n. Supplement C, p. $144-155,2017$.

MOLINA, F. J.; ALONSO, C.; ANDRADE, C. Cover cracking as a function of rebar corrosion: Part 2-numerical model. Materials and Structures, v. 26, p. 532-548, 1993.

MOURA, C. A. Aplicação de formulação baseada no Método dos Elementos Finitos Posicional na análise bidimensional elástica de compósitos particulados. Dissertação (Mestrado) - Escola de Engenharia de São Carlos, Universidade de São Paulo, São Carlos, 2015.

MUTHULINGAM, S.; RAO, B. N. Non-uniform time-to-corrosion initiation in steel reinforced concrete under chloride environment. Corrosion Science, Elsevier, v. 82, p. 304-315, 2014.

NEVILLE, A. M. Propriedades do concreto. [S.l.]: São Paulo: PINI, 1997.

NGUYEN, Q. T.; CARÉ, S.; MILLARD, A.; BERTHAUD, Y. Analyse de la fissuration du béton armé en corrosion accélérée. Comptes Rendus Mecanique, v. 335, n. 2, p. 99-104, 2007.

NGUYEN, T. T. H.; BARY, B.; DE LARRARD, T. Coupled carbonation-rust formation-damage modeling and simulation of steel corrosion in $3 \mathrm{~d}$ mesoscale reinforced concrete. Cement and Concrete Research, Elsevier, v. 74, p. 95-107, 2015.

NOGUEIRA, C. G.; LEONEL, E. D. Probabilistic models applied to safety assessment of reinforced concrete structures subjected to chloride ingress. Engineering Failure Analysis, Elsevier, v. 31, p. 76-89, 2013.

NOGUEIRA, G. V.; SAMPAIO, M. S. M.; PACCOLA, R. R.; CODA, H. B. Consideração do deslizamento na análise de sólidos elásticos bidimensionais reforçados por fibras através do método dos elementos finitos posicional. In: XXXV Ibero-Latin American Congress on Computational Methods in Engineering, CILAMCE. Fortaleza: [s.n.], 2014. 
OGDEN, R. W. Non-linear elastic deformations. [S.l.]: Courier Corporation, 1997.

OliVER, J.; HUESPE, A. E.; PUliDO, M. D. G.; CHAVES, E. From continuum mechanics to fracture mechanics: the strong discontinuity approach. Engineering fracture mechanics, Elsevier, v. 69, n. 2, p. 113-136, 2002.

OŽBOLT, J.; ORŠANIĆ, F.; BALABANIĆ, G. Modeling pull-out resistance of corroded reinforcement in concrete: Coupled three-dimensional finite element model. Cement and Concrete Composites, Elsevier, v. 46, p. 41-55, 2014.

PACCOLA, R. R.; CODA, H. B. A direct fem approach for particulate reinforced elastic solids. Composite Structures, Elsevier, v. 141, p. 282-291, 2016.

PANTAZOPOULOU, S. J.; PAPOULIA, K. D. Modeling cover-cracking due to reinforcement corrosion in rc structures. Journal of Engineering Mechanics, American Society of Civil Engineers, v. 127, n. 4, p. 342-351, 2001.

PAPADAKIS, V. G.; VAYENAS, C. G.; FARDIS, M. N. Fundamental modeling and experimental investigation of concrete carbonation. Materials Journal, v. 88, n. 4, p. 363-373, 1991.

PARROTT, L. J. A review of carbonation in reinforced concrete. [S.l.: s.n.], 1987.

PASCON, J. P. Modelos constitutivos para materiais hiperelásticos: estudo e implementação computacional. Dissertação (Mestrado) — Universidade de São Paulo, 2008.

PAUL, S. C.; ZIJL, G. P. A. G. V. Chloride-induced corrosion modelling of cracked reinforced shcc. Archives of Civil and Mechanical Engineering, Elsevier, v. 16, n. 4, p. 734-742, 2016.

PENGWEI, X.; NING, Y.; LINWANG, S.; GUOBAO, L.; LEBIN, W. Finite element analysis of expansive behaviour due to reinforcement corrosion in rc structure. Procedia Engineering, Elsevier, v. 12, p. 117-126, 2011.

PLUCIŃSKI, P. Numerical analysis of stress distribution in concrete around corroding rebar. Procedia Engineering, Elsevier, v. 108, p. 598-607, 2015.

POSSAN, E. Modelagem da carbonatação e previsão de vida útil de estruturas de concreto em ambiente urbano. 2010. 265 f. Tese (Doutorado) - Programa de Pós-graduação em Engenharia Civil, Escola de Engenharia, Universidade Federal do Rio Grande do Sul, Porto Alegre, 2010.

POSSAN, E.; THOMAZ, W. A.; ALEANDRI, G. A.; FELIX, E. F.; SANTOS, A. C. P. dos. Co2 uptake potential due to concrete carbonation: A case study. Case studies in construction materials, Elsevier, v. 6, p. 147-161, 2017.

POSTERLLI, M. C. Modelagem da expansão devido à reação álcali-agregado de concreto armado e reforçado com fibras. Dissertação (Mestrado) — Escola de Engenharia de São Carlos, Universidade de São Paulo, São Carlos, 2017.

RAO, A. S.; LEPECH, M. D.; KIREMIDJIAN, A. S.; SUN, X. Y. Simplified structural deterioration model for reinforced concrete bridge piers under cyclic loading. Structure and Infrastructure Engineering, v. 13, p. 55-66, 2017. 
RIBEIRO, D.; CUNHA, M.; HELENE, P. Corrosão em Estruturas de Concreto Armado: Teoria, Controle e Métodos de Análise. São Paulo: Elsevier Brasil, 2015. 272 p. ISBN 9788535275483. Disponível em: < https://books.google.com.br/books?id= W9NeAwAAQBAJ>.

RIGOBELlO, R. Desenvolvimento e aplicação de código computacional para análise de estruturas de aço aporticadas em situação de incêndio. 2011.

RODRIGUEZ, J.; ANDRADE, C. Load-bearing capacity loss in corroding structures. In: Proceedings of ACI convention, Toronto. [S.l.: s.n.], 1990. v. 1, p. 359-363.

RODRIGUEZ, J.; ORTEGA, L. M.; CASAL, J. Load carrying capacity of concrete structures with corroded reinforcement. Construction and building materials, Elsevier, v. 11, n. 4, p. 239-248, 1997.

SAETTA, A. V.; VITALIANI, R. V. Experimental investigation and numerical modeling of carbonation process in reinforced concrete structures: Part i: Theoretical formulation. Cement and concrete research, Elsevier, v. 34, n. 4, p. 571-579, 2004.

SAMPAIO, M. S. M. Análise não linear geométrica de cascas laminadas reforçadas com fibras. Tese (Doutorado) — Escola de Engenharia de São Carlos, Universidade de São Paulo, São Carlos, 2014.

SAMPAIO, M. S. M.; CODA, H. B.; PACCOLA, R. R. Análise não linear geométrica de sólidos elásticos bidimensionais reforçados com fibras via mef. Cadernos de Engenharia de Estruturas, v. 13, n. 59, p. 59-62, 2011.

SÁNCHEZ, P. J.; HUESPE, A. E.; OLIVER, J.; TORO, S. Mesoscopic model to simulate the mechanical behavior of reinforced concrete members affected by corrosion. International Journal of Solids and Structures, Elsevier, v. 47, n. 5, p. 559-570, 2010.

SANTOS, L. Avaliação da resistividade elétrica do concreto como parâmetro para a previsão da iniciação da corrosão induzida por cloretos em estruturas de concreto. Dissertação (Mestrado) - Programa de Pós Graduação em Engenharia Civil, Universidade Federal do Rio Grande do Sul, Porto Alegre, 2006.

ŠAVIJA, B.; LUKOVIĆ, M.; PACHECO, J.; SCHLANGEN, E. Cracking of the concrete cover due to reinforcement corrosion: a two-dimensional lattice model study. Construction and Building Materials, Elsevier, v. 44, p. 626-638, 2013.

SCHLANGEN, E.; GARBOCZI, E. J. New method for simulating fracture using an elastically uniform random geometry lattice. International journal of engineering science, Elsevier, v. 34, n. 10, p. 1131-1144, 1996.

SCHLANGEN, E.; GARBOCZI, E. J. Fracture simulations of concrete using lattice models: computational aspects. Engineering fracture mechanics, Elsevier, v. 57, n. 2, p. 319-332, 1997.

SHODJA, H. M.; KIANI, K.; HASHEMIAN, A. A model for the evolution of concrete deterioration due to reinforcement corrosion. Mathematical and Computer Modelling, Elsevier, v. 52, n. 9, p. 1403-1422, 2010. 
SMOLCZYK, H. G. Written discussion on carbonation of concrete by m. hamada. In: Proc. of 5th International Symposium on the Chemistry of Cement. [S.1.: s.n.], 1968. v. 3, p. 369-384.

STANISH, K. D.; HOOTON, D.; THOMAS, M. D. A. Testing the chloride penetration resistance of concrete: a literature review. Cadana: Department of Civil Engineering, University of Toronto Toronto, Ontario, Canada, 2000. 31 p.

STEFFENS, A.; DINKLER, D.; AHRENS, H. Modeling carbonation for corrosion risk prediction of concrete structures. Cement and Concrete Research, Elsevier, v. 32, n. 6, p. 935-941, 2002.

STEWART, M. G.; ROSOWSKY, D. V. Structural safety and serviceability of concrete bridges subject to corrosion. Journal of Infrastructure systems, American Society of Civil Engineers, v. 4, n. 4, p. 146-155, 1998.

STREHBLOW, H. H.; MARCUS, P. Corrosion Mechanism in theory and practice. [S.l.: s.n.], 1995.

SURANA, K. S. Geometrically nonlinear formulation for the curved shell elements. International Journal for Numerical Methods in Engineering, Wiley Online Library, v. 19, n. 4, p. 581-615, 1983.

SYMON, K. R. Mechanics: 3d Ed. [S.l.]: Addison-Wesley Publishing Company, 1971.

TAFFESE, W. Z.; SISTONEN, E. Service life prediction of repaired structures using concrete recasting method: state-of-the-art. Procedia Engineering, v. 45, p. 1138-1144, 2013.

TAPAN, M.; ABOUTAHA, R. S. Effect of steel corrosion and loss of concrete cover on strength of deteriorated rc columns. Construction and Build Materials, v. 25, p. 2596-2603, 2011.

TUUTTI, K. Corrosion of steel in concrete. Swedish Cement and Concrete Research Institute Stockholm, Stockholm, 1982.

UKRAINEZYK, U.; MATUSINOVIÉ, U. Use of neural network to evaluate rebar corrosion. In: Continental Environment, 3th Int. Conf. Construction Materials, Vancouver. [S.l.: s.n.], 2005.

VANALLI, L. O MEC e o MEF aplicados à análise de problemas viscoplásticos em meios anisotrópicos e compostos. Tese (Doutorado) - Escola de Engenharia de São Carlos, Universidade de São Paulo, São Carlos, 2004.

VANALLI, L.; PACCOLA, R. R.; CODA, H. B. A simple way to introduce fibers into fem models. International Journal for Numerical Methods in Biomedical Engineering, v. 24, n. 7, p. 585-603, 2008.

VEnQUiARUTO, S. D.; ISAIA, G. C.; GASTALDINI, A. L. G. A influência do teor e da quantidade de adições minerais na carbonatação do concreto. In: Congresso Brasileiro do Cimento, 43ํㅡ, Foz do Iguaçu. [S.l.: s.n.], 2001.

VERBECK, G. Carbonation of hydrated portland cement. In: Cement and Concrete. [S.l.]: ASTM International, 1958. 
VESIKARI, E. Service life prediction of concrete structures with regard to corrosion of reinforcement. In: Technical Research Centre of Finland, report n. 553. Finland: [s.n.], 1988. p. 53.

VU, K. A. T.; STEWART, M. G. Structural reliability of concrete bridges including improved chloride-induced corrosion models. Structural Safety, v. 22, n. 4, p. 313-333, 2000.

WANG, X.; LIU, X. Bond strength modeling for corroded reinforcements. Construction and Building Materials, Elsevier, v. 20, n. 3, p. 177-186, 2006.

XU, J.; JIANG, L.; WANG, Q. Finite element model of reinforcement corrosion in concrete. Water Science and Engineering, Elsevier, v. 2, n. 2, p. 71-78, 2009.

YUAN, Y.; JI, Y. Modeling corroded section configuration of steel bar in concrete structure. Construction and Building Materials, Elsevier, v. 23, n. 6, p. 2461-2466, 2009.

ZHAO, Y.; DONG, J.; WU, Y.; JIN, W. Corrosion-induced concrete cracking model considering corrosion product-filled paste at the concrete/steel interface. Construction and Building Materials, Elsevier, v. 116, p. 273-280, 2016.

ZHU, W. Effect of corrosion on the mechanical properties of the corroded reinforcement and the residual structural performance of the corroded beams. Tese (Doutorado) Institut National des Sciences Appliquées de Toulouse (INSA de Toulouse). France, 2014. 